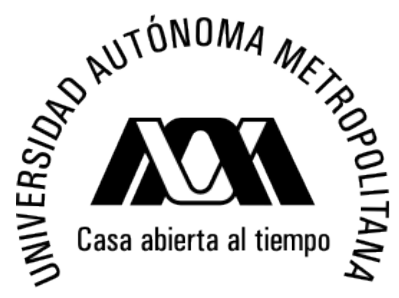
UNIVERSIDAD AUTÓNOMA METROPOLITANA UNIDAD IZTAPALAPA DIVISIÓN DE CIENCIAS BIOLÓGICAS Y DE LA SALUD

\title{
“ATENUACIÓN DE PARÁMETROS METABÓLICOS, INFLAMATORIOS Y DE ESTRÉS OXIDANTE A LO LARGO DE LA VIDA DE RATONES OBESOS GMS "
}

\author{
TES IS \\ Que para obtener el grado de \\ Doctor en Biología Experimental \\ PRESENTA
}

M. en C. René Javier Hernández Bautista

COMITÉ TUTORAL:

Dra. Norma E. López Díaz-Guerrero: Codirectora Dr. Francisco Javier Alarcón Aguilar: Codirector Dra. María del Carmen Escobar Villanueva: Asesora

México, D.F., 20 Febrero de 2015 
El Programa de Doctorado en Biología Experimental de la Universidad Autónoma Metropolitana Unidad Iztapalapa está avalado como Posgrado de Alto Nivel en el Programa Nacional de Posgrados de Calidad (PNPC) del CONACYT, registro 001482; en el Nivel Consolidado, y cuenta con apoyo del mismo Consejo, clave DAFCYT-2003IDPTNNN0020. M. en C. René Javier Hernández Bautista agradece el apoyo recibido por CONACYT (Registro No. 202676). 
El jurado designado por la Comisión Académica del Posgrado en Biología Experimental de la División de Ciencias Biológicas y de la Salud de la Universidad Autónoma Metropolitana aprobó la Tesis titulada: "Atenuación de parámetros metabólicos, inflamatorios y de estrés oxidante a lo largo de la vida de ratones obesos GMS", que presentó

\author{
M. en C. René Javier Hernández Bautista
}

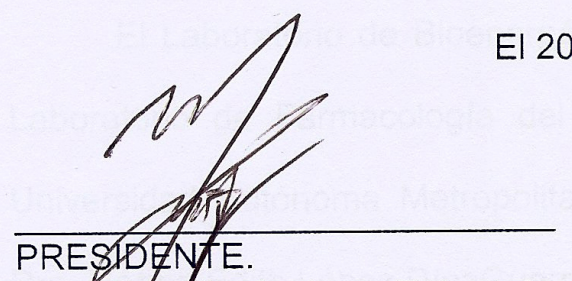

Dra. Mina/Konigsberg Fainstein Departam dento de Ciencias de la Salud Universidad Autónoma MetropolitanaIztapalapa mkf@xanum.uam.nx

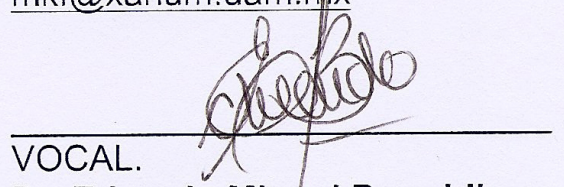

Dr. Eduardo Miguel Brambila Colombres

Facultad de Ciencias Químicas Benemérita Universidad Autónoma de Puebla eduardobrambila1@yahoo.com.mx
SECRETARIO.

\section{Dr. Julio César Almanza Pérez}

Departamento de Ciencias de la Salud Universidad Autónoma MetropolitanaIztapalapa julcesarmac@hotmail.com

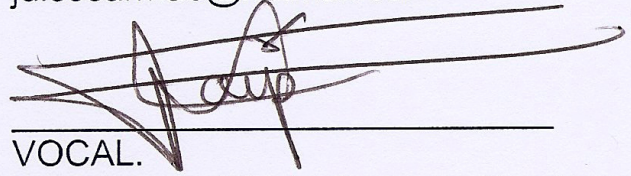

Dr. Alfonso Efraín Campos Sepúlveda Departamento de Farmacología Universidad Nacional Autónoma de México

drefraincampos@gmail.com 
“ATENUACIÓN DE PARÁMETROS METABÓLICOS, INFLAMATORIOS Y DE ESTRÉS OXIDANTE A LO LARGO DE LA VIDA DE RATONES OBESOS GMS" fue realizado por M. en C. René Javier Hernández Bautista en:

El Laboratorio de Bioenergética y Envejecimiento Celular en conjunto con el Laboratorio de Farmacología del Departamento de Ciencias de la Salud de la Universidad Autónoma Metropolitana unidad Iztapalapa, bajo la codirección de la Dra. Norma Edith López DíazGuerrero y del Dr. Francisco Javier Alarcón Aguilar. 


\section{MIEMBROS DEL COMITÉ TUTORAL}

\section{Codirector:}

Dra. Norma Edith López DíazGuerrero

Laboratorio de Bioenergética y Envejecimiento Celular.

Ciencias Biológicas y de la Salud.

Universidad Autónoma Metropolitana Unidad Iztapalapa.

norm@xanum.uam.mx

\section{Codirector:}

Dr. Francisco Javier Alarcón Aguilar

Laboratorio de Farmacología.

Ciencias Biológicas y de la Salud.

Universidad Autónoma Metropolitana Unidad Iztapalapa.

aaaf@xanum.uam.mx

\section{Asesor:}

Dra. María del Carmén Escobar Villanueva

Laboratorio de Farmacología.

Ciencias Biológicas y de la Salud.

Universidad Autónoma Metropolitana Unidad Iztapalapa.

mcev@xanum.uam.mx 


\section{AGRADECIMIENTOS}

En primer lugar, mi más amplio agradecimiento a la Dra. Norma Edith López DíazGuerrero, quien me ha guiado y apoyado para seguir este camino para poder llegar a la conclusión del mismo. Por toda su paciencia y comprensión en cada una de mis inconsistencias en todo momento. Más allá de un director de tesis, se ha convertido en mi amiga y confidente en buenos y malos momentos. Gracias por confiar en mi desde el primer instante.

Al Dr. Francisco Alarcón Aguilar por permitirme conducirme de forma independiente a lo largo de mi formación doctoral. Por cada ocasión donde recurrí a él y me confronto diciéndome: "Es su trabajo, es parte de su formación, es lo que le forjara su carácter científico".

A la Dra. María del Carmen Escobar Villanueva, por ser mi asesora y confiar en cada paso que he dado, por compartir experiencias de vida donde coincidimos con una charla amena que culmino con consejos muy adecuados.

A la Dra. Mina Konigsberg Fainstein, por abrirme las puertas del Laboratorio de Bioenergética y Envejecimiento Celular y por acogerme cuando me sentí desamparado y rescatarme de otros laboratorios. Por cada una de sus observaciones, pero sobre todo por brindarme su confianza en todo momento.

Al Dr. Julio César Almanza Pérez, por cada observación acertada desde que nos vimos por ves primera en la entrevista y en todo momento mostrando su disponibilidad cada que lo requerí. Por alentarme con singular particularidad a lo largo de estos cuatro años.

Al Dr. Eduardo Miguel Brambila Colombres, quien fue el que mostro el camino maravilloso de la ciencia. No olvido su frase que un día me compartió: "Si esta en tu camino de vida, tarde que temprano será para ti, así le des muchas vueltas". Mi mayor admiración, por que ha sido mi ejemplo a seguir desde que nos conocimos. $Y$ por que nunca he dejado de sentirme parte del Laboratorio de Investigaciones Químico-Clínicos de la Benemérita Universidad Autónoma de Puebla. 
Al Dr. Alfonso Efraín Campos Sepúlveda, por formar parte de las evaluaciones importantes de este trabajo que me han permitido llegar a este momento y por aceptar revisar esta tesis que usted ha catalogado como una referencia completa.

A mis compañeros Luis, Gibrán, Pedro, Rafael, Sandra M., Sandra C., Paola, Aglae Trejo, por compartir momentos agradables y hacer más ligera mi estancia en el laboratorio.

A mis amigos Edgar Iván Jasso, Janeth Ventura S., Angélica A. Cruz, Viridiana Yazmín González, Adriana Alarcón, Armando Luna, Violeta Aburto, Anabel Morales por cada momento compartido y por cada consejo recibido.

A Stephanie Rencillas, Diana Romero Z., Marlén Valdez, Ana Susunaga N., y a Héctor Merino A., mis amigos del alma, por apoyarme día a día compartiendo experiencias que nos han unido y nos han hecho compartir dolencias y alegrías. Por cada jalón de orejas en el momento preciso.

A Gabriela Camacho Cortes, por ser parte importante de mi vida, por tu comprensión, paciencia y fuerza, por soportarme en mis momentos de mal humor y por ayudarme en todo momento con una palabra de aliento o con un silencio. Por compartir muchas alegrías y tristezas Te quiero mucho.

A mis hermanos Sandra Luz y Rafael (mi traductor oficial), por confiar en mi aún en la distancia y por apoyarme en todo momento, en cada paso que he dado y confiar en todo lo que hago. Por todos los momentos que hemos compartido.

Principalmente a mis padres, quienes nunca han dejado de preocuparse, que a base de amor, trabajo y sacrificio me han dado todo en todos sentidos, apoyándome en cada instante y por levantarme cuando más lo he necesitado, por toda su confianza depositada en mi, gracias a ustedes he logrado llegar hasta aquí. Las palabras nunca serán suficientes para testimoniar cuanto los quiero y les agradezco.

A todos y cada uno que no menciono pero que de alguna forma han compartido conmigo este camino. Estén donde estén, se merecen buenas palabras.

A todos ustedes, mi mayor reconocimiento y gratitud. 


\section{RESUMEN:}

La obesidad y el sobrepeso se han incrementado de forma alarmante en el mundo durante las tres últimas décadas, lo que ocurre desde la infancia hasta la vejez, debido principalmente a los cambios en el estilo de vida.

La obesidad es un factor crucial en el desarrollo de anormalidades metabólicas, tales como intolerancia a la glucosa, resistencia a la insulina e inflamación con estrés oxidante. Un panorama similar ocurre durante el proceso de envejecimiento, donde se observa alteración de la homeostasis del metabolismo energético y un estado de inflamación crónica sistémica de bajo grado. El estrés oxidante y un pobre funcionamiento físico llevan a un incremento del riesgo para desarrollar enfermedades metabólicas.

A pesar de los diversos estudios que se han realizado sobre los efectos fisiopatológicos de la obesidad, su impacto asociado al género y a lo largo de la vida, en especial durante el envejecimiento, no ha recibido atención.

El propósito de esta investigación fue determinar el estado metabólico general en un modelo de ratones obesos hembra y macho a lo largo de la vida desde los 4 hasta los 20 meses de edad. La obesidad se indujo mediante la administración neonatal de glutamato monosódico (GMS), y posteriormente se cuantificaron parámetros bioquímicos, perfil inflamatorio, tolerancia a la glucosa y sensibilidad a la insulina. Además, se evaluó el daño oxidante y la protección antioxidante en diferentes órganos. 
Los resultados muestran que el Índice Lee (IL), así como los niveles de colesterol y triglicéridos se incrementaron gradualmente en todos los grupos a través del tiempo. En general, los ratones obesos GMS mostraron los niveles más altos de colesterol en comparación de sus controles. Las hembras GMS mostraron niveles más altos en el contenido de triglicéridos que los machos obesos. Se evaluó la función hepática midiendo las actividades de las enzimas AST y ALT, y se encontró que ambas enzimas se incrementaron conforme aumentó la edad en todos los grupos, siendo las hembras quienes mostraron mayores niveles de ALT.

Con relación con el perfil inflamatorio, se encontró que en el grupo de machos, particularmente los ratones obesos GMS, presentaron niveles elevados de TNF- $\alpha$, IL10 e IL-6 a los 12 meses de edad, comparado con el grupo de hembras. Los niveles de adiponectina disminuyeron gradualmente a lo largo de la vida de los ratones obesos y en sus controles; los machos mostraron niveles bajos de adiponectina comparado con las hembras.

También se encontraron alteraciones en la tolerancia a la glucosa y en la sensibilidad a la insulina, tanto en hembras como en machos obesos GMS desde etapas jóvenes, conservándose esta diferencia hasta el envejecimientos. Sin embargo, los ratones obesos machos mostraron los niveles más altos en estas alteraciones. De manera notoria, los aumentos en estos parámetros disminuyeron a los 20 meses de edad sin encontrarse diferencias estadísticas entre los 4 grupos.

Los parámetros oxidantes y antioxidantes, tanto en plasma como en hígado, pulmón, corazón y riñón permitió conocer la influencia del daño oxidante por obesidad durante el proceso de envejecimiento y la respuesta antioxidante. 
Los ratones obesos GMS mostraron alteraciones metabólicas y susceptibilidad asociada al género a lo largo de la vida y durante el proceso de envejecimiento. El entendimiento de las diferencias metabólicas entre los géneros durante la vida, permitirá el descubrimiento de estrategias preventivas específicas para las enfermedades crónicas y contra la pérdida de la funcionalidad por envejecimiento. 


\section{ABSTRACT}

The obesity and overweight have increased at an alarming rate in the world during the last three decades, since childhood to aging ages, mainly due the changes in lifestyles.

The obesity is a crucial factor in the development of metabolic abnormalities, such as intolerance to glucose, resistance to the insulin and inflammation with oxidant stress. A similar panorama occurs during the aging process where is observed alteration of the energetic metabolism homeostasis and a chronic systematic inflammation state of low grade. Oxidant stress and a poor physical performance, lead to a risk to acquire metabolic disease. Despite the diverse studies that have been realized about the pathophysiological effects of obesity, its impact related to gender and through life, in special during aging, hasn't received attention.

The purpose of this investigation is to determinate the general metabolic state in obese mice model through all their lives. The obesity was induced with neonatal monosodium glutamate (MSG) administration and quantified biochemical parameters, cytokines concentration, glucose tolerance and sensitivity to insulin. Also, it was evaluated the oxidant damage since four to twenty months old, including the inflammatory profile.

In relation with the inflammatory profile, it was found that on male mice group, in special obese MSG mice, showed high levels of TNF- $\alpha$, IL-10 and IL-6 at 12 months of age, compared with the group of female mice. The adiponectin levels 
gradually decreased through obese mice life and its controls; male mice showed low levels of adiponectin compared to female mice.

Also it was found alterations in the glucose tolerance and in the insulin sensibility, such as in female as in obese MSG mice and its controls, since young stages to aging; nevertheless, obese mice showed the highest levels that decreased in 20 months age, without finding different statistics between genders and in comparison with its controls.

The oxidant parameters and antioxidants, such as in plasma as in liver, lung, heart and kidney, allowed to know the damage influence due obesity during the aging development and the response to this damage because of oxidant stress.

The results in the metabolic parameters, the low grade inflammation and the oxidant stress between genders, that reflect the effects of obesity associated with aging, allow to conclude that the obesity model induced with MSG can be useful for studying the metabolic changes in obese organisms through life, as well as for the study of therapeutic agents that could prevent or lessen the above alterations.

Obese MSG mice showed metabolic alterations and its susceptibility associated to gender through life and during the aging process. The understanding of the metabolic differences between genders during life will permit the discovering of specific prevent strategies to chronic diseases and against the loss of functionality due aging. 


\section{ABREVIATURAS}

$\begin{array}{ll}\text { 8-epi PGF2 } \alpha & \text { 8-epi-prostaglandina-F2 } \alpha \\ \text { 8OHdG } & \text { 8-hidroxi-2'-deoxiguanosina } \\ \text { AGL } & \text { Ácidos grasos libres } \\ \text { ALT } & \text { Alanina aminotransferasa } \\ \text { AMPK } & \text { Proteína cinasa activada por AMP } \\ \text { ANOVA } & \text { Análisis de varianza } \\ \text { AP1 } & \text { Proteína activadora 1 } \\ \text { AST } & \text { Aspartato-aminotransferasa } \\ \text { BSA } & \text { Albúmina sérica bovina } \\ \text { CAT } & \text { Catalasa } \\ \text { Cd } & \text { Cadmio } \\ \text { cJun/Fos } & \text { Factor de transcripción AP1 } \\ \text { CTE } & \text { Cadena de transporte de electrones } \\ \text { Cu/Zn-SOD } & \text { Superóxido dismutasa Cobre/Zinc } \\ \text { DHA } & \text { Dehidroascorbato } \\ \text { DM2 } & \text { Diabetes mellitus 2 } \\ \text { DNTB } & \text { 5,5'-ditiobis-2-ácido nitrobenzoico } \\ \text { OID } & \text { Obesidad inducida por dieta } \\ \text { DTT } & \text { Ditiotreitol } \\ \text { Ex-SOD } & \text { Superóxido dismutasa extracelular } \\ \text { EDTA } & \text { Ácido etilendiaminotetracético } \\ \text { ELISA } & \text { Ensayo por inmunoabsorción ligado a enzimas } \\ \text { ERN } & \text { Especies reactivas de nitrógeno } \\ \text { ERO } & \text { Especies reactivas de oxígeno } \\ \text { GHRH } & \text { Hormona liberadora de la hormona de crecimiento } \\ \text { GLUT-4 } & \text { Transportador de glucosa 4 } \\ \text { GMS } & \text { Glutamato monosódico } \\ \text { GnRH } & \text { Hormona liberadora de gonadotropina } \\ \text { GPx } & \text { Glutatión peroxidasa } \\ \text { GR } & \text { Glutatión reductasa } \\ \text { GSH } & \text { Glutatión reducido } \\ \text { GSH/GSSG } & \text { Glutatión reducido y oxidado } \\ & \end{array}$




$\begin{array}{ll}\text { GSSG } & \text { Glutatión disulfuro oxidado } \\ \text { GST } & \text { Glutatión S-transferasa } \\ \mathrm{H}_{2} \mathrm{O}_{2} & \text { Peróxido de hidrogeno } \\ \mathrm{HB}-\mathrm{EGF} & \text { Factor de crecimiento epidérmico de unión a la heparina } \\ \mathrm{HCl} & \text { Ácido clorhídrico } \\ \mathrm{HDL} & \text { Colesterol de alta densidad } \\ \mathrm{Hg} & \text { Mercurio } \\ \mathrm{HGF} & \text { Factor de crecimiento hepatocitario } \\ \mathrm{HNE} & \text { 4-hidroxi-2-nonenal } \\ \mathrm{HTA} & \text { Hipertensión arterial } \\ \text { IGF-1 } & \text { Factor de crecimiento insulínico tipo 1 } \\ \text { IGFBP } & \text { Proteína de unión a IGF } \\ \text { IKK } & \text { Cinasa IKB } \\ \text { IL } & \text { Índice Lee } \\ \text { IL-1 } & \text { Interleucina 1 } \\ \text { IL-6 } & \text { Interleucina 6 } \\ \text { IL-8 } & \text { Interleucina 8 } \\ \text { IL-10 } & \text { Interleucina 10 } \\ \text { IMC } & \text { Índice de masa corporal } \\ \text { INOS } & \text { Óxido nítrico sintasa inducible } \\ \text { IOTF } & \text { Internacional Obesity Task Force } \\ \text { IRS-1 } & \text { Sustrato del receptor de insulina-1 } \\ \text { JAK } & \text { Janus cinasa } \\ \text { JNK } & \text { Cinasas c-Jun N-terminal } \\ \text { KDa } & \text { kiloDalton } \\ \text { LDL } & \text { Lipoproteínas de baja densidad } \\ \text { LPL } & \text { Lipoproteína lipasa } \\ \text { LPx } & \text { Lipoperoxidación } \\ \text { M2VP } & \text { 1-metil-2-vinil-piridio trifluorometano sulfonato } \\ \text { MCP-1 } & \text { Proteína quimioatrayente de monocitos-1 } \\ \text { MDA } & \text { Malondialdehído } \\ \text { MIF } & \text { Factor inhibidor de migración de macrófagos } \\ \text { MMP } & \text { Metaloproteinasas de la matríz extracelular } \\ \text { Mn-SOD } & \text { Superóxido dismutasa Manganeso } \\ \text { mTOR } & \text { Blanco de rapamicina en células de mamífero } \\ \text { MTs } & \text { Metalone }\end{array}$




$\begin{array}{ll}\text { NADPH } & \text { Nicotinamida adenina dinucleótido fosfato reducido } \\ \text { NAFLD } & \text { Enfermedad de hígado graso no alcohólico } \\ \text { NBT } & \text { Nitro-azul de tetrazolio } \\ \text { NF-kB } & \text { Factor nuclear-kappaB } \\ \text { NGF } & \text { Factor de crecimiento neural } \\ \text { NK } & \text { Células "natural killer" } \\ \text { NO } & \text { Óxido nítrico } \\ \text { NO }_{2} \bullet & \text { Dióxido de nitrógeno } \\ \text { NOM }_{\text {NOS }} & \text { Norma Oficial Mexicana } \\ \mathrm{O}_{2} & \text { Óxido nítrico sintasa } \\ \mathrm{O}_{2} & \text { Anión superóxido } \\ \text { OH・ } & \text { Oxígeno molecular } \\ \text { OMS } & \text { Radical hidroxilo } \\ \text { ONOO- } & \text { Organización Mundial de la Salud } \\ \text { PAI-1 } & \text { Peroxinitrilo } \\ \text { PBS } & \text { Inhibidor del activador del plasminógeno-1 } \\ \text { PCR } & \text { Buffer fosfato salino } \\ \text { PG } & \text { Proteína C reactiva } \\ \text { PGE } & \text { Perigonadales } \\ \text { PGI2 } & \text { Prostaglandina E } \\ \text { PHL-OOH } & \text { Prostaciclina } \\ \text { PI3K } & \text { Fosfolipoperóxidos } \\ \text { PKB o AKT } & \text { Fosfatidilinositol } 3 \text { cinasa } \\ \text { PMSF } & \text { Proteína cinasa B o AKT } \\ \text { PSA } & \text { Fluoruro de fenilmetilsulfonilo } \\ \text { PT } & \text { Persulfato de amonio } \\ \text { PTGO } & \text { Células del túbulo proximal } \\ \text { PTI } & \text { Prueba de tolerancia a la glucosa oral } \\ \text { PUFAs } & \text { Prueba de tolerancia a la insulina } \\ \text { PVDF } & \text { Ácidos grasos poliinsaturados } \\ \text { RAAS } & \text { Polifluoruro de vinilideno } \\ \text { RI } & \text { Sistema renina-angiotensina-aldosterona } \\ \text { RL } & \text { Resistencia a insulina } \\ \text { RPB-4 } & \text { Radicales libres } \\ \text { S.E.M. } & \text { Proteína transportadora del retinol-4 } \\ & \end{array}$




$\begin{array}{ll}\text { SASP } & \text { Fenotipo secretor asociado a la senescencia } \\ \text { SC } & \text { Subcutáneo } \\ \text { SDS } & \text { Dodecilsulfato de sodio } \\ \text { SIRT1 } & \text { Sirtuina-1 } \\ \text { SM } & \text { Síndrome metabólico } \\ \text { SNC } & \text { Sistema nervioso central } \\ \text { SNS } & \text { Sistema nervioso simpático } \\ \text { SOCS } & \text { Supresor de la señalización de citocinas } \\ \text { SOD } & \text { Superóxido dismutasa } \\ \text { SSI } & \text { Solución salina isotónica } \\ \text { STAT } & \text { Signal transducers and activators of transcription } \\ \text { T } & \text { Timina } \\ \text { TA } & \text { Tejido adiposo } \\ \text { TBA } & \text { Ácido tiobarbitúrico } \\ \text { TBARS } & \text { Sustancias reactivas al ácido tiobarbitúrico } \\ \text { TCA } & \text { Ácido tricloroacético } \\ \text { TEMED } & \text { N,N,N',N'-tetrametiletilendiamina } \\ \text { TG } & \text { Triglicéridos } \\ \text { TGF- } \beta & \text { Factor de crecimiento transformante beta 1 } \\ \text { Th1 } & \text { Células T cooperadora tipo 1 } \\ \text { Th2 } & \text { Células T cooperadoras tipo 2 } \\ \text { TLR4 } & \text { Receptor tipo Toll-4 } \\ \text { TNF- } \alpha & \text { Factor de necrosis tumoral } \\ \text { TP } & \text { Túbulo proximal } \\ \text { UAM-I } & \text { Universidad Autónoma Metropolitana Unidad Iztapalapa } \\ \text { VLDL } & \text { Lipoproteínas de muy baja densidad } \\ \text { XO } & \text { Xantina oxidasa } \\ \text { Zn } & \text { Zinc } \\ & \end{array}$


ABSTRACT

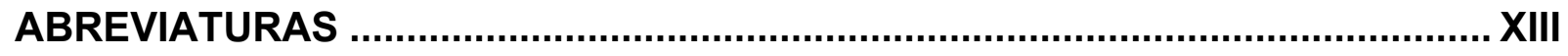

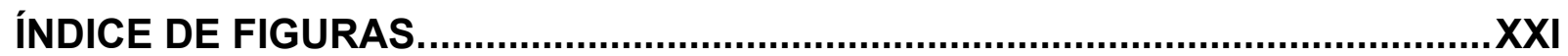

ÍNDICE DE GRÁFICAS .............................................................................XII

ÍNDICE DE TABLAS …..............................................................................

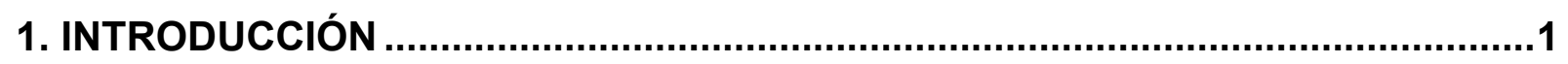

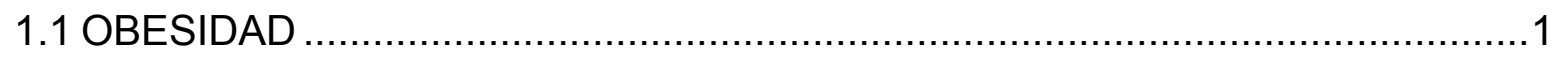

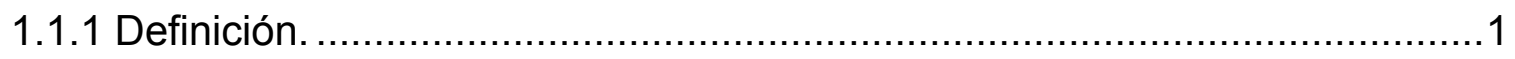

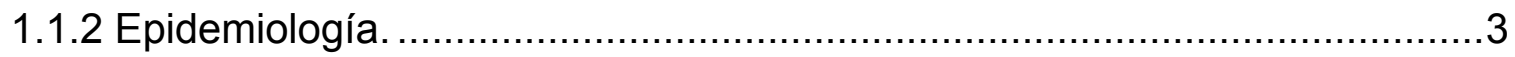

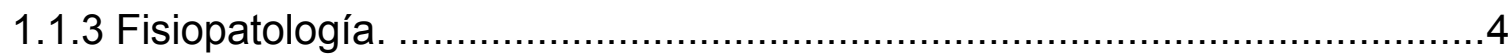

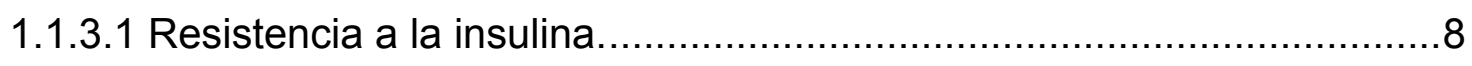

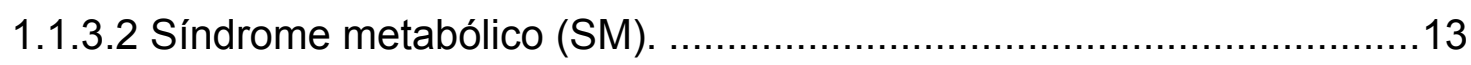

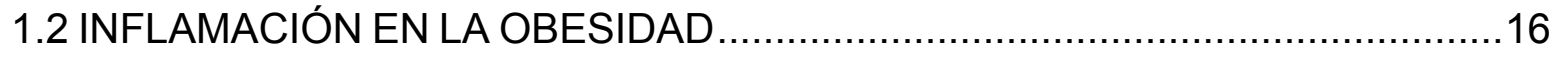

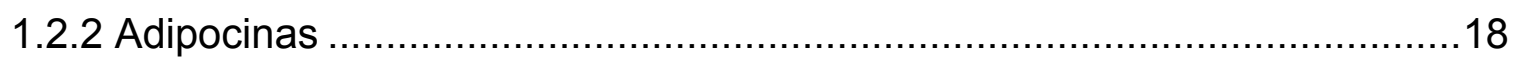

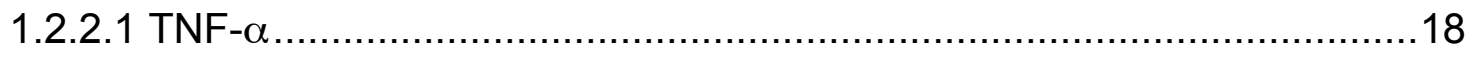

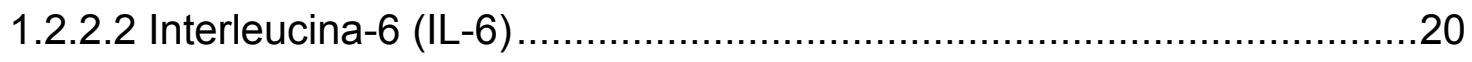

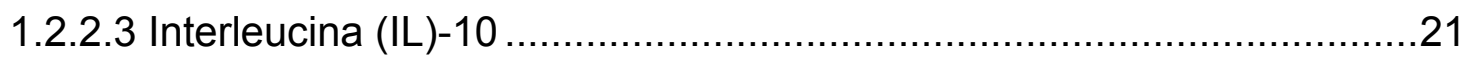

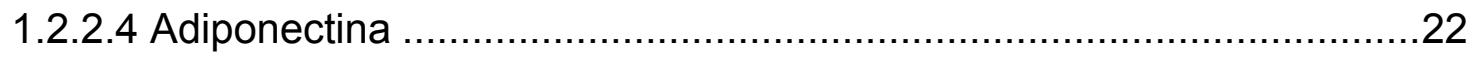

1.2.2.5 Adipocinas, inflamación y resistencia a insulina. ..............................25

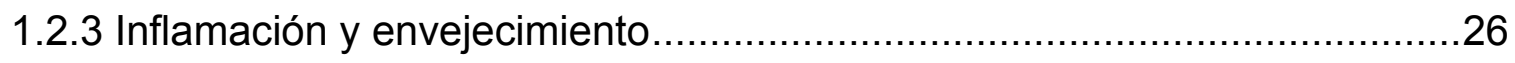

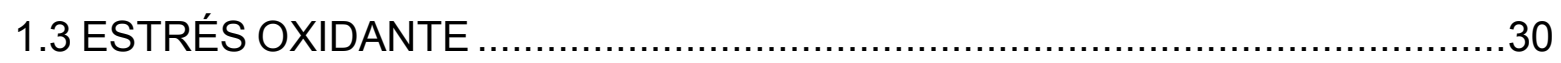

1.3.1 Especies reactivas de oxígeno y nitrógeno (ERO/ERN) ..........................32

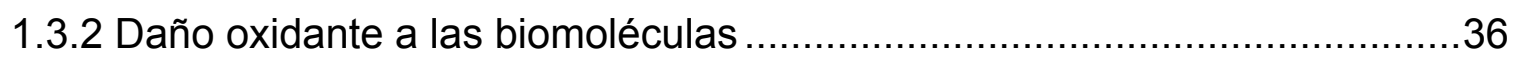

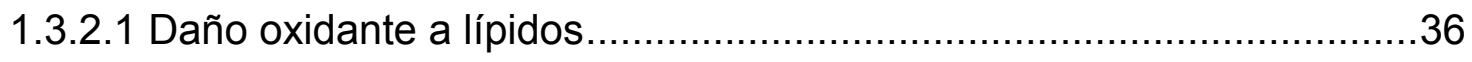

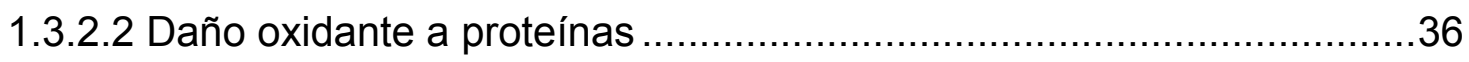




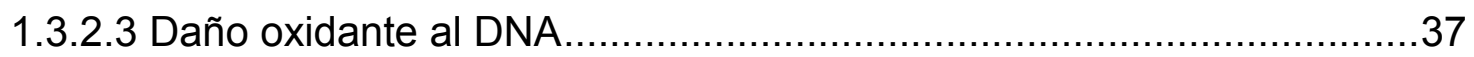

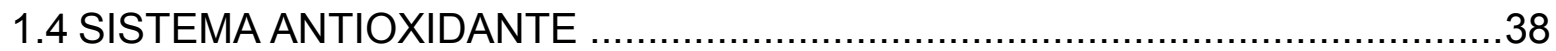

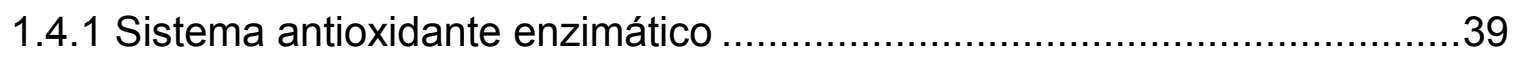

1.4.1.1 Superóxido dismutasa (SOD) …...............................................

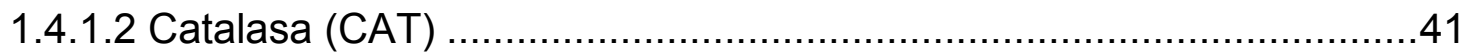

1.4.1.3 Glutatión Peroxidasa (GPx) ….................................................

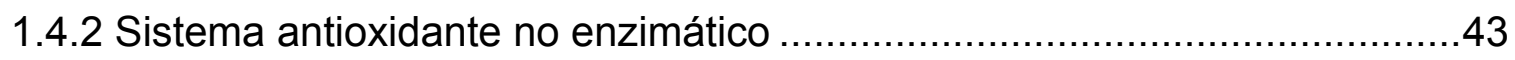

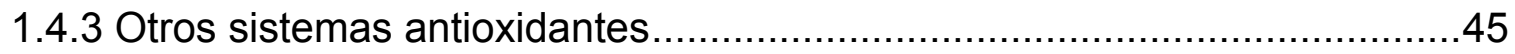

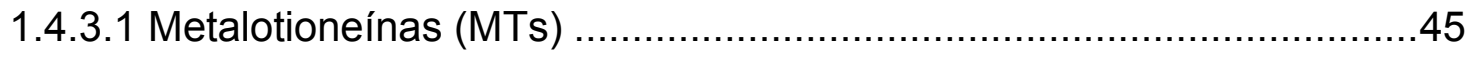

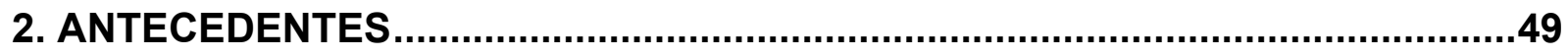

2.1 RELACIÓN INFLAMACIÓN-ESTRÉS OXIDANTE - OBESIDAD ........................49

2.2 HORMESIS Y RESISTENCIA AL ESTRÉS ...............................................52

2.3 RESISTENCIA AL ESTRÉS Y LONGEVIDAD .........................................5

2.4 MODELO DE OBESIDAD: RATÓN NEUROINTOXICADO POR GLUTAMATO

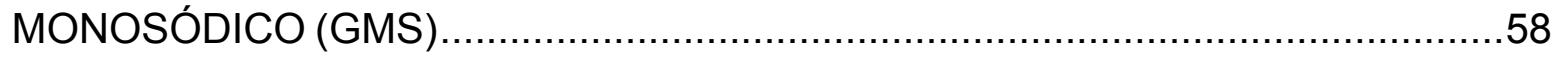

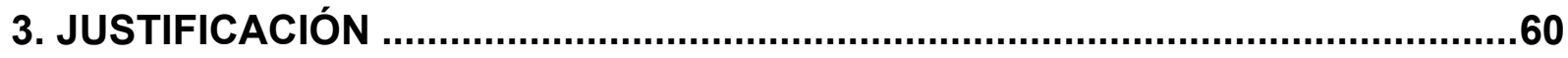

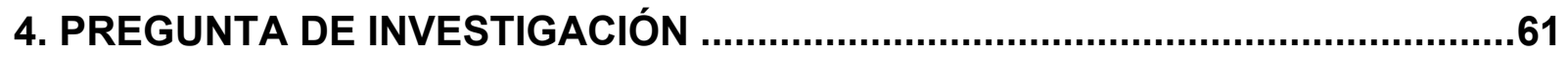

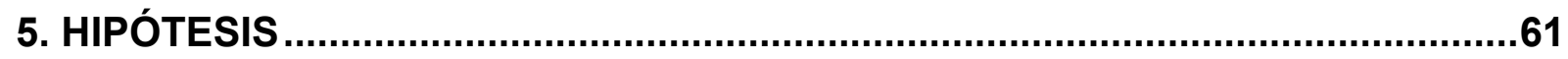

6. OBJETIVOS

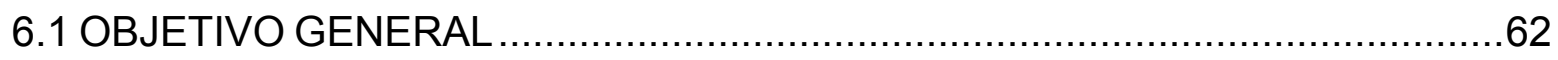

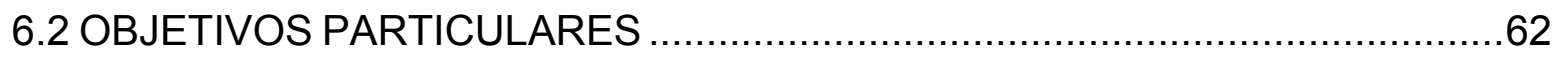

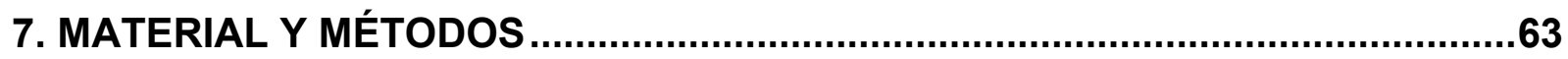

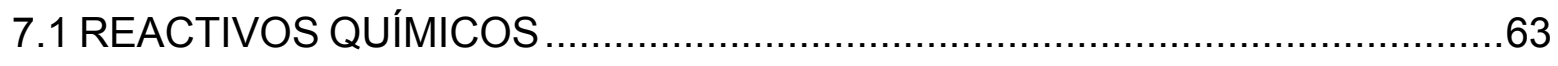

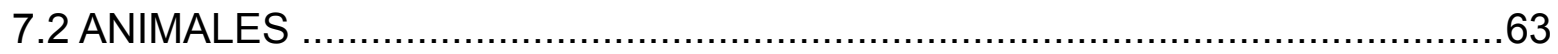

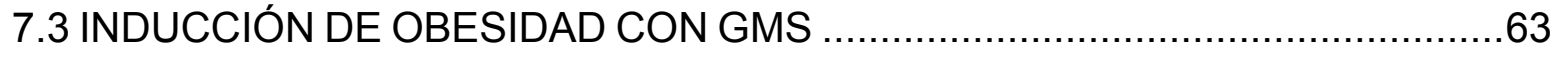

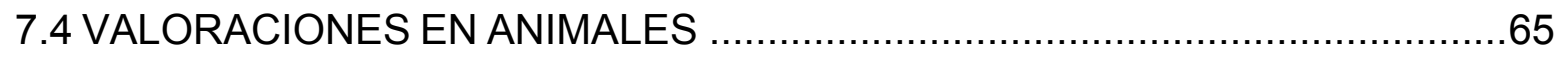

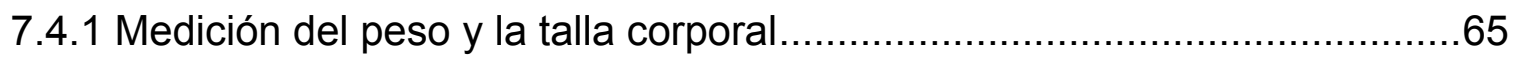

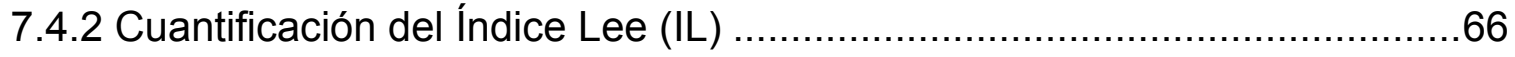


7.5 PRUEBA DE TOLERANCIA A LA GLUCOSA ORAL (PTGO) .........................66

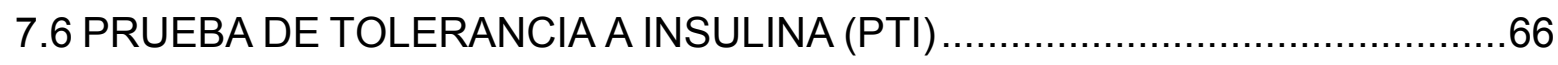

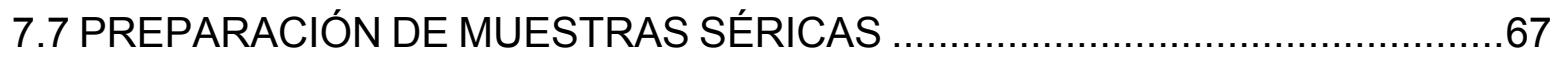

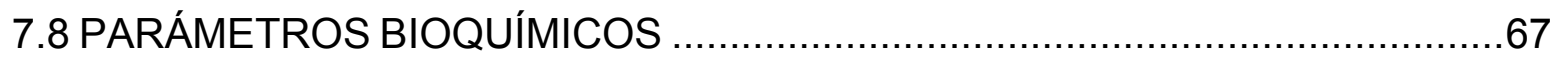

7.9 ENSAYO POR INMUNOABSORCIÓN LIGADO A ENZIMAS (ELISA) …...........67

7.10 OBTENCIÓN Y CONSERVACIÓN DE ÓRGANOS ...................................68

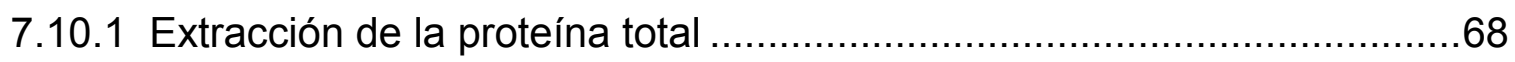

7.10.2 Contenido de proteína por el método de Bradford .................................68

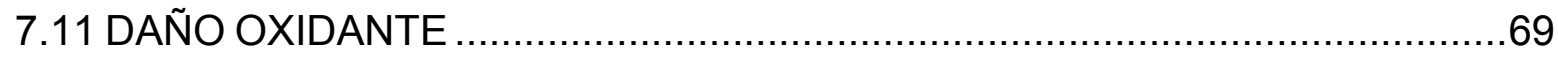

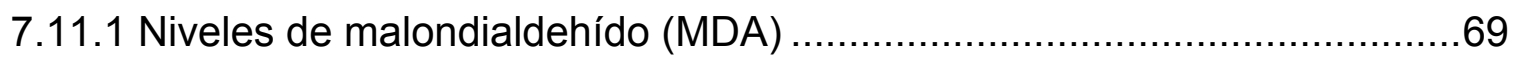

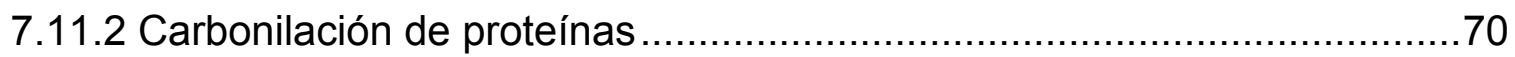

7.12 PARÁMETROS DE ESTADO REDOX, CAPACIDAD ANTIOXIDANTE Y DE

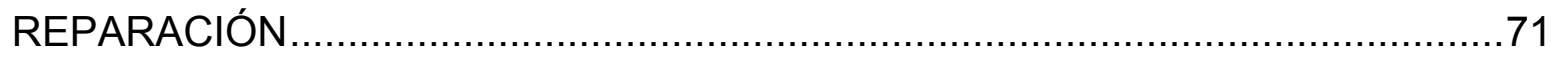

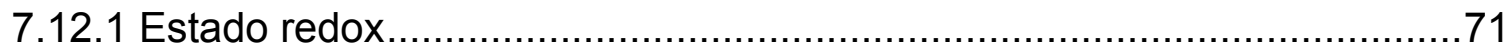

7.12.2 Ensayo de actividad de superóxido dismutasa Cu/Zn (Cu/Zn-SOD)........72

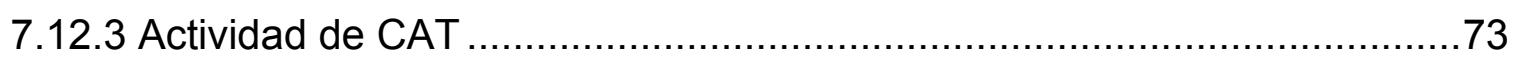

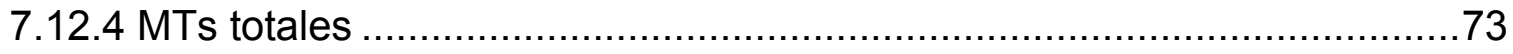

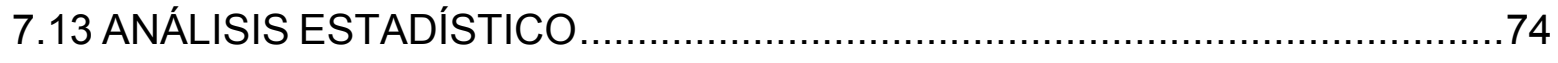

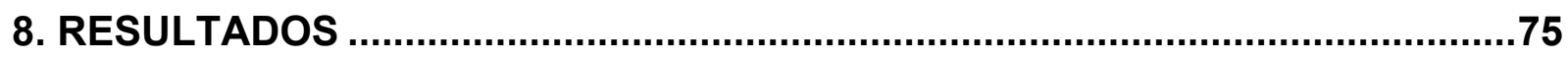

8.1 CURSO TEMPORAL DE PESO, TALLA E ÍNDICE LEE .................................75

8.2 PRUEBA DE TOLERANCIA A LA GLUCOSA ORAL (PTGO) .........................77

8.3 PRUEBA DE TOLERANCIA A LA INSULINA (PTI) .....................................

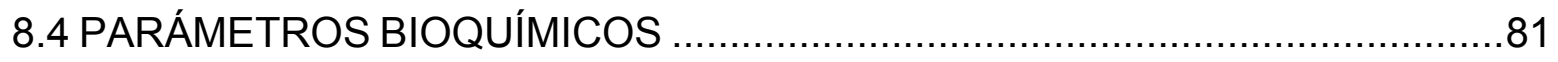

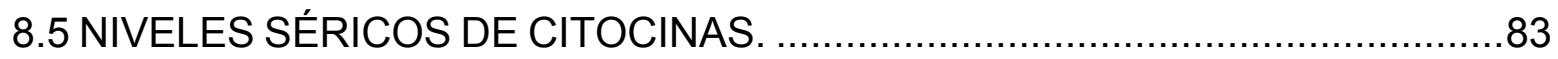

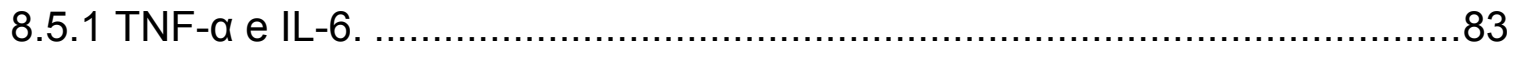

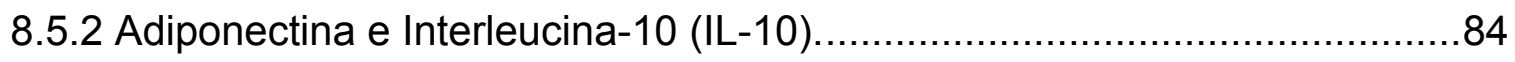

8.6 EVALUACÍON DE DAÑO OXIDANTE Y RESPUESTA ANTIOXIDANTE ..........86

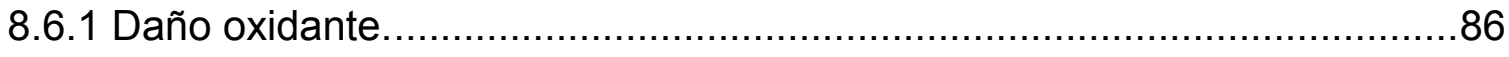

8.6.1.1 Cuantificación de niveles de MDA como índice de lipoperoxidación ...86 8.6.1.2 Carbonilación de proteínas. 


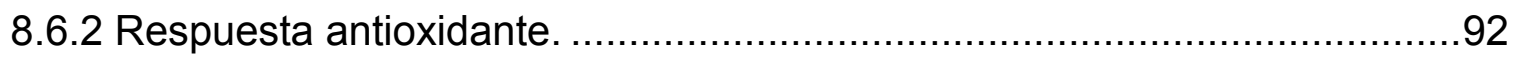

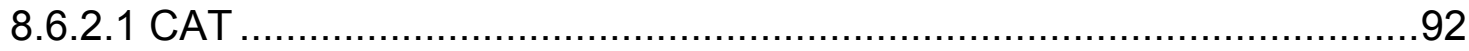

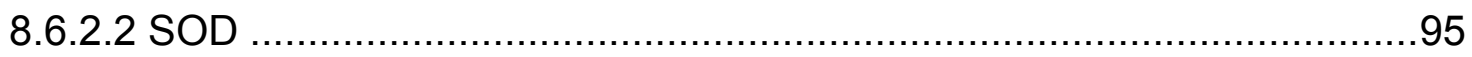

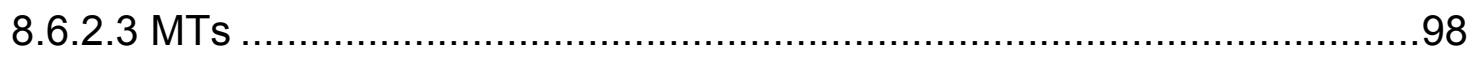

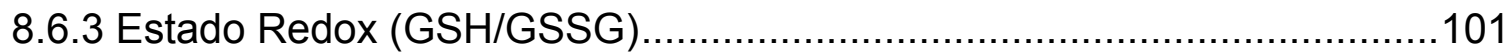

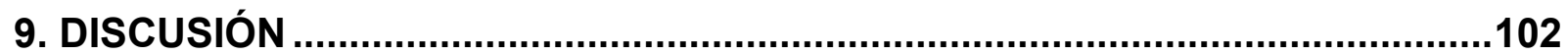

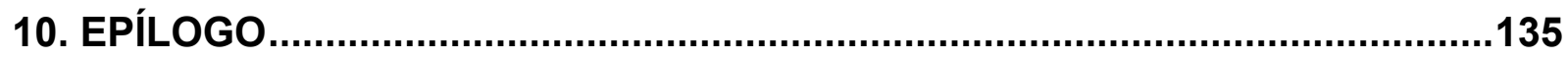

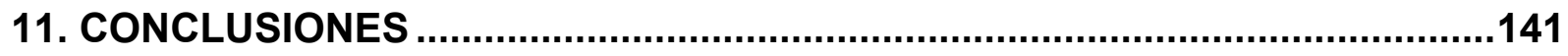

12. PERSPECTIVAS

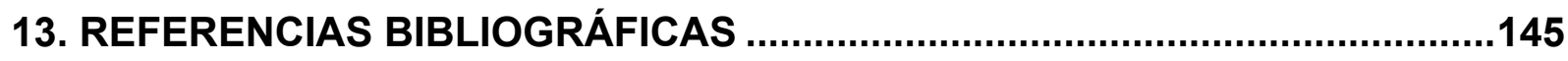


Figura 1. Vías metabólicas del tejido adiposo. .................................................. 4

Figura 2. Mecanismos moleculares de la resistencia a la insulina. ..................... 9

Figura 3. Patogénesis de la resistencia a la insulina asociada con la obesidad. . 11

Figura 4. Desórdenes proaterogénicos asociados al síndrome metabólico. ........ 14

Figura 5. Resistencia a la insulina en el desarrollo del síndrome metabólico. ..... 15

Figura 6. Acciones principales de adiponectina............................................... 24

Figura 7. Obesidad, adipocinas y resistencia a la insulina. ................................ 26

Figura 8. Instauración y desarrollo de daño oxidante........................................ 31

Figura 9. Progresión del estrés oxidante y la obesidad................................... 32

Figura 10. Reducción univalente del oxígeno.................................................... 34

Figura 11. Formación de Radicales Libres. ………........................................ 34

Figura 12. Formacion del radical hidroxilo.................................................. 35

Figura 13. Oxidación enzimática de GSH....................................................... 44

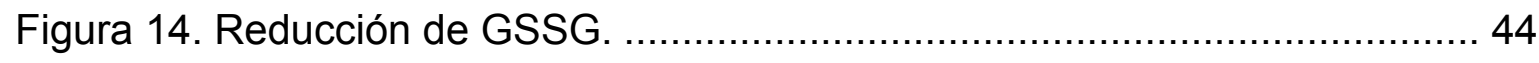

Figura 15. El tejido adiposo en el proceso inflamatorio. ................................... 50

Figura 16. Mediadores de inflamación y su efecto sobre hígado. ....................... 51

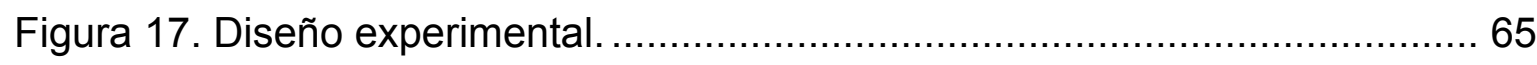

Figura 18. Obesidad-inflamación-estrés oxidante. ........................................ 139

Figura 19. Obesidad y metabolismo de ratones GMS a través de la vida........ 140 
Gráfica 1. Determinación del grado de obesidad................................................ 76

Gráfica 2. Prueba de tolerancia a la glucosa oral (PTGO). ................................ 78

Gráfica 3. Prueba de tolerancia a la insulina (PTI) ....................................... 80

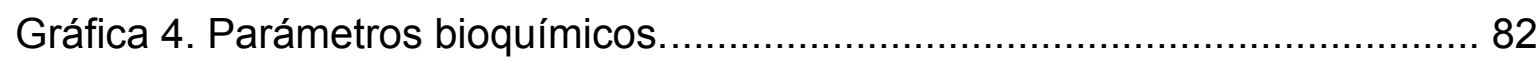

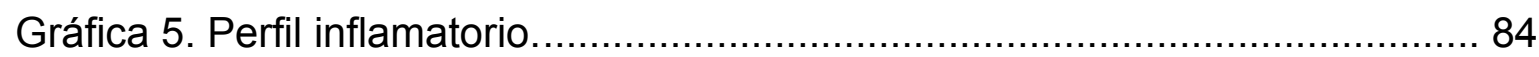

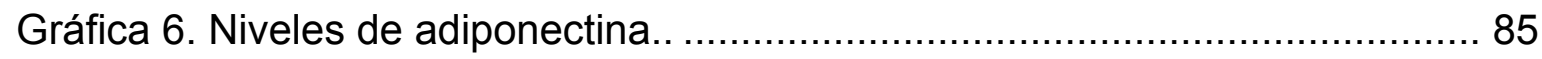

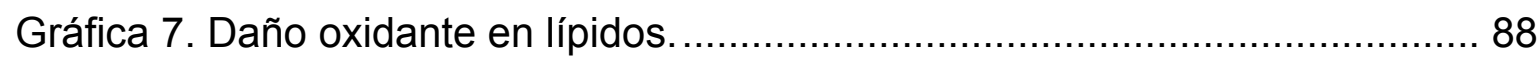

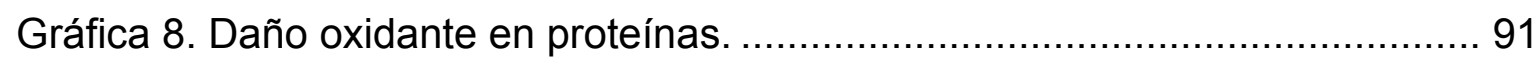

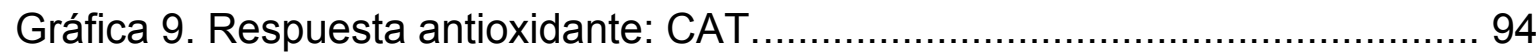

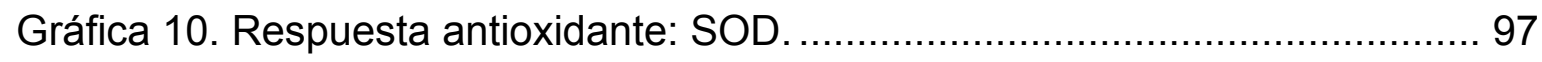

Gráfica 11. Metalotioneínas (MTs).......................................................... 100

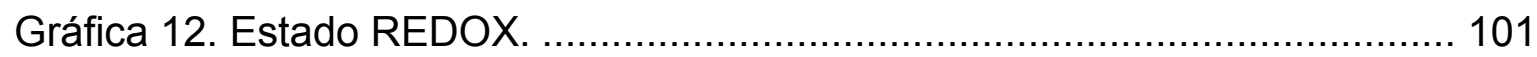




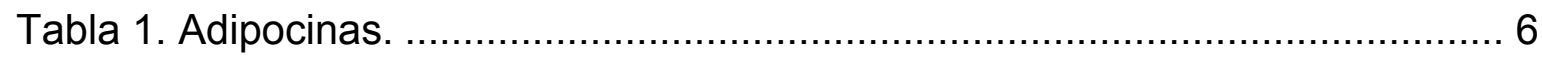

Tabla 2. Especies reactivas de oxígeno (ERO) y de nitrógeno (ERN) ................. 33

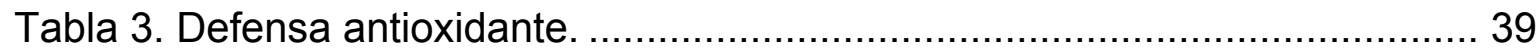

Tabla 4. Carácterísticas de la molécula de MT ................................................ 46

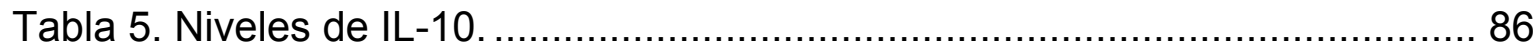




\section{INTRODUCCIÓN}

\subsection{OBESIDAD}

\subsubsection{Definición.}

La obesidad es un problema de salud y es considerada como la patología nutricional más prevalente de los países desarrollados (Fussenegger et al., 2008). La obesidad se define como el exceso de grasa corporal o de tejido adiposo, siendo el resultado de una excesiva ingesta de nutrientes y/o de gasto energético disminuido, mantenido de forma crónica (Aitlhadj et al., 2011). Así mismo la obesidad se caracteriza por el resultado combinado de disfunción del centro de saciedad a nivel cerebral, desbalance de ingesta y empleo de energía, y variaciones genéticas (Cheung et al., 2012; Zelezná et al., 2009), manifestándose en un incremento o acumulación anormal o excesiva de energía en forma de grasa en el tejido adiposo (TA) (Blancas et al., 2010). Algunos autores resaltan la importancia del entorno en su desarrollo, debido a que en este trastorno nutricional influyen arraigadas y profundas normas sociales, difícilmente modificables (Oda, 2008).

Hoy se sabe que en el 95 por ciento de los casos de obesidad, su causa es nutricional, exógena o primaria, y sólo el 5 por ciento es endógena, monogénica o secundaria, debido a otras enfermedades o por la ingesta de fármacos. Según la distribución de grasa corporal, la obesidad se clasifica en central o androide, tipo manzana, con predominio de tejido graso en la región intra-abdominal; o periférica, ginecoide o tipo pera, con acúmulo graso fundamentalmente en la región fémoro- 
glútea. Esta distribución varía según el género y la raza, siendo en la infancia predominantemente mixta.

La diferencia en la distribución de la masa grasa corporal por géneros fue descrita en 1940 y explicada parcialmente por las diferencias hormonales. Los andrógenos se relacionan con un incremento del tejido adiposo visceral, asociándose con factores de riesgo cardiovascular, mientras que los estrógenos se relacionan con el tejido adiposo periférico o subcutáneo (Sweeting, 2007). Durante la pubertad, acontecen cambios en la distribución de grasa corporal influenciadas por la leptina, que induce la secreción de la hormona liberadora de gonadotropina ( $\mathrm{GnRH})$.

La obesidad es un factor de riesgo para un amplio rango de enfermedades que incluyen resistencia a insulina, diabetes tipo 2, dislipidemia y enfermedad cardiovascular, entre otras (Andreazzi et al., 2009; Zelezná et al., 2009; Nickelson et al., 2012). La obesidad tambien ha sido considerada como un proceso de inflamación crónica sistémica de bajo grado, con una importante relación en la inducción de la resistencia a insulina (RI) (Furuya et al., 2010). La expansión del tejido adiposo intraabdominal está asociado con un incremento en la infiltración y activación de la expresión de varias citocinas proinflamatorias, tales como el factor de necrosis tumoral (TNF- $\alpha$ ) e interleucina 6 (IL-6) (Alarcón et al., 2008).

Es notorio que en la obesidad hay diferencias significativas asociadas con el género, tal como lo es la distribución del tejido adiposo y la inflamación. Se sabe que el género femenino tiende a presentar un alto contenido de grasa localizada subcutáneamente, mientras que los hombres tienen menos grasa corporal total con predominancia en la región visceral principalmente (Nickelson et al., 2012). Las 
concentraciones plasmáticas de IL-6 y TNF- $\alpha$ se han encontrado más bajas en mujeres que en hombres, posiblemente debido el efecto inhibitorio de los estrógenos sobre la expresión de genes marcadores de inflamación (Cartier et al., 2009).

Además, la leptina se correlaciona positivamente con el índice de masa corporal (IMC), trasmitiendo información al cerebro sobre la energía almacenada disponible. La concentración sérica de leptina se incrementa en las mujeres durante la pubertad, pero disminuye en los varones después de iniciarse la misma, en el estadio 2 de maduración gonadal, originando el característico patrón androide y ginecoide de distribución de grasa característico del adolescente y del adulto (Muñoz, 2007).

\subsubsection{Epidemiología.}

Actualmente la obesidad es considerada por la Organización Mundial de la Salud (OMS) como "una epidemia mundial creciente" y "uno de los problemas de salud pública más visibles, aunque más desatendidos". Además, es la segunda causa de mortalidad prematura evitable, después del tabaco (WHO, 2014). La Internacional Obesity Task Force (IOTF) la considera como la "enfermedad del milenio" (IOTF, 2008). Globalmente hay más de 300 millones de adultos obesos y 42 millones de niños que cursan con sobrepeso (WHO, 2014). En años recientes, la epidemia de la obesidad no sólo ha llegado a ser un problema que ocurre en la población joven y adulta, sino que también se ha incrementado de forma dramática en el grupo de adultos mayores. 


\subsubsection{Fisiopatología.}

El tejido adiposo (TA), está considerado como el principal órgano de reserva de grasa. Actualmente se le reconoce como un órgano endócrino participante en la respuesta inmune. La masa grasa corporal está distribuida en un $20 \%$ de grasa visceral y un $80 \%$ en el tejido adiposo subcutáneo. Por otra parte, el $80 \%$ del peso de la masa magra son lípidos, de los cuales, el 90\% son triglicéridos (TG) (AntunaPuente et al., 2008; Rabe et al., 2008; Galic et al., 2010).

En función del balance energético, el tejido adiposo puede realizar la lipólisis de los TG mediante la lipoproteína lipasa (LPL), que genera ácidos grasos libres (AGL) y glicerol o tenderá a la esterificación de ambos compuestos a través de la formación de Acil-CoA o de Glicerol-3-P (procesos conocidos como Lipogénesis y Glicerogénesis respectivamente) formando TG nuevamente (Figura 1) (Aguilera et al., 2006).

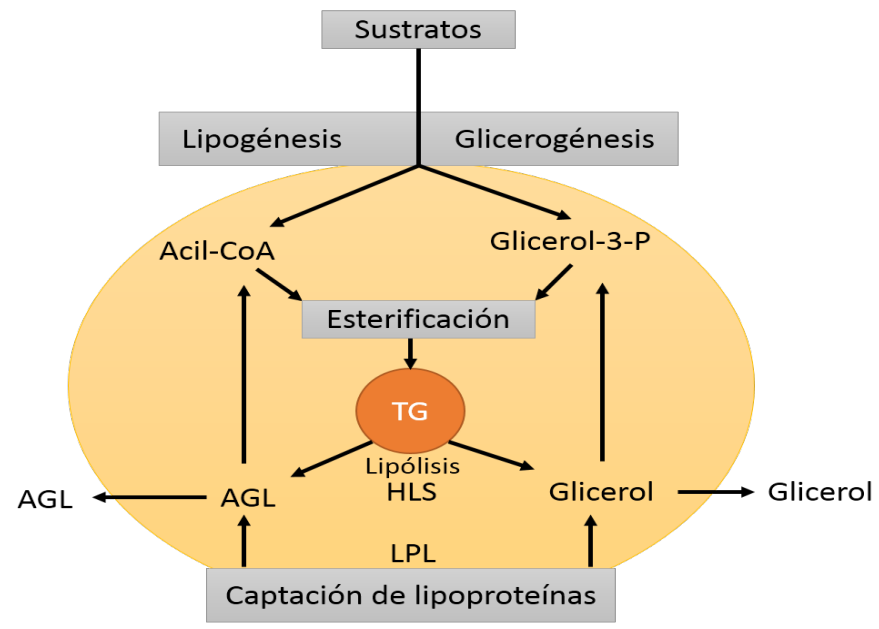

Figura 1. Vías metabólicas del tejido adiposo 
Así, en épocas prolongadas de balance energético positivo (cuando la ingesta de energía es mayor que su gasto), el TA responde reclutando preadipocitos (células sin capacidad de reserva grasa aún) que proliferan (hiperplasia), lo que hipertrofia a los adipocitos maduros con el consiguiente crecimiento estromal y vascular ante la hipoxia adipocitaria. Las alteraciones en cualquiera de estos tres niveles, modulados por factores adipocitarios o no adipocitarios, conllevan consecuencias metabólicas e inmunes. De igual modo, el balance energético positivo incrementa la concentración de AGL en la circulación sistémica, acumulándose en músculo esquelético y en hígado, generando una lipotoxicidad que aumenta la RI (Aguilera et al., 2006), así como dislipidemia, enfermedad hepática no alcohólica (NAFLD) e hipertensión arterial (HTA). A esta RI se le suma la insulinopenia (disminución de niveles de insulina en el torrente sanguíneo) generada por el acúmulo lipídico pancreático y al efecto tóxico que conduce a la apoptosis celular. El estado crónico de estas alteraciones promoverá el desarrollo de diabetes mellitus 2 (DM2) (Trayhurn et al., 2004; Murphy et al., 2006; Aguilera et al., 2006; Rabe et al., 2008).

Se sabe que el tejido adiposo, como órgano endócrino, secreta biomarcadores activos, principalmente por las células estromales presentes en el mismo (células endoteliales, fibroblastos, leucocitos y macrófagos), y en menor medida por los mismos adipocitos. Cuando estos biomarcadores son producidos por los adipocitos, éstos son conocidos como adipocitocinas o adipocinas. Una lista completa de tales adipocinas se muestra en la Tabla 1. Destacan leptina, adiponectina, resistina y visfatina, así como otras que están actualmente en investigación, como la vaspina (Wada et al., 2008) y la proteína transportadora del retinol-4 (RBP-4). Las 
biomoléculas inflamatorias como TNF- $\alpha$, IL-6, IL-8, MCP-1, PAI-1, HGF y NGF (Chudek et al, 2006), actuán sobre diferentes órganos como cerebro, hígado, músculo esquelético y sistema inmune, modulando el balance energético, la sensibilidad a la insulina, el metabolismo hidrocarbonado y lipídico, la inflamación, aterogénesis, hemostasia y la tensión arterial.

\begin{tabular}{|l|}
\hline Tabla 1. Adipocinas. Lista de las adipocinas secretadas por los \\
adipocitos y las células de la matriz tisular \\
\hline Proteína estimulante de acilación \\
Adiponectina \\
Proteína de señalización agouti \\
Angiotensina II \\
Apelina \\
Adipsina (Complemento D) \\
Factor de crecimiento epidérmico de unión a la heparina (HB-EGF) \\
Factor de crecimiento hepatocitario (HGF) \\
Factor de crecimiento insulínico tipo 1 (IGF-1) \\
Interleucina-1 (IL-1) \\
Interleucina-6 (IL-6) \\
Interleucina-8 (IL-8) \\
Interleucina-10 (IL-10) \\
Leptina \\
Factor inhibidor de la migración de macrófagos (MIF) \\
Proteína quimioatrayente de monocitos-1 (MCP-1) \\
Factor de crecimiento neural (NGF) \\
Óxido Nítrico (NO) \\
Inhibidor del activador del plasminógeno-1 (PAI-1) \\
Prostaciclina (PGI2) \\
Prostaglandina E (PGE ) \\
Renina \\
Resistina \\
Factor Tisular \\
Factor de Necrosis Tumoral- $\alpha$ (TNF- $\alpha$ ) \\
Factor de crecimiento endotelial vascular (VEGF) \\
Visfatina
\end{tabular}


En la obesidad ocurre un desequilibrio en estas adipocinas que puede dar lugar a un proceso inflamatorio, así como a alteraciones metabólicas y cardiovasculares (Trayhurn et al, 2004; Rabe et al, 2008). Asimismo, el TA secreta sustancias quimioatractivas para los macrófagos que incrementan y perpetúan el proceso inflamatorio (Fain, 2006). Recientemente, por la íntima relación existente entre la patología del TA y las enfermedades metabólicas se han creado términos como "adiposopatía" (Bays et al., 2008) y "diabesidad", que denotan la íntima relación que existe entre estas dos patologías, obesidad y DM2 (Golay et al, 2005).

Para la homeostasis lipídica y glucémica se requiere un tejido adiposo normofuncional, el cual se ve alterado en estados patológicos como la obesidad por la secreción de adipocinas que favorecen la RI, por el incremento de la lipólisis y la alteración en el almacenamiento de TG. Todo ello conduce al incremento de AGL en la sangre, que aumenta la reserva lipídica muscular y hepática, perjudicando la señal insulínica (Aguilera et al., 2006).

Así, el incremento en la prevalencia de sobrepeso y obesidad en la población está asociado con complicaciones que aumentan el riesgo de muerte del 20 al $40 \%$ en personas con sobrepeso y de 2 a 3 veces en individuos obesos (Cheung et al., 2012).

Además, la inflamación crónica de bajo grado, estrictamente ligada al sobrepeso u obesidad, genera RI que interactúa con otros mecanismos complejos, tales como hipercolesterolemia, tabaquismo, hipertensión, hiperglucemia, factores hemostáticos, diferencias hereditarias asociadas con la estructura de lipoproteínas y a su receptor, metabolismo de la homocisteina, y altos niveles de lipoproteína que 
incrementa el riesgo de enfermedad coronaria (Tilg et al., 2008; Tarantino et al., 2011).

De esta manera, la obesidad participa en la patogénesis de la RI. El dogma central sugiere que la RI por sí misma explica la hipertensión, la hiperglucemia, la hiperinsulinemia, los triglicéridos elevados y la disminución de lipoproteínas de alta densidad (Brock et al., 2007; Tilg et al., 2008; Tarantino et al., 2011). En músculo, hígado, tejido adiposo y riñón son los sitios principales en donde se manifiesta la RI (Brock et al., 2007).

\subsubsection{Resistencia a la insulina.}

La insulina es una hormona pleiotrópica que juega un papel importante en el desarrollo de patologías asociadas con la obesidad, como son hipertensión, diabetes y síndrome metabólico (Liu et al., 2009; Cheung et al., 2012; Connell et al., 2012).

La insulina actúa en los tejidos insulinodependientes cuando se une de manera específica a su receptor, el factor de crecimiento insulinico-1 (IGF-1), y como resultado se activa una cascada de señalización intracelular. Esto estimula la fosforilación de las tirosinas en el sustrato del receptor de insulina-1 (IRS-1), lo que activa al fosfoinositol 3-cinasa ( $\mathrm{PI} 3 \mathrm{~K}$ ) y a su vez a la proteína cinasa $\mathrm{B}$ o AKT (PKB o AKT) permitiendo la traslocación de Glut-4 a la membrana celular y favoreciendo la entrada de glucosa a la célula (Brock et al., 2007; Tilg et al., 2008). La fosforilación de serinas en IRS-1 por varias señales inflamatorias, como por ejemplo IL-6 que activa proteína supresora de la señalización por citocinas-3 (SOCS3), la TNF- $\alpha$ activa a la cinasa c-Jun N-terminal (JNK), así como IL-1 e IL-18 que activan a la cinasa IkB 
(IKK), muestran ser uno de los aspectos clave que perturban la adecuada señalización insulina-receptor induciendo RI (Tilg et al., 2008) (Figura 2).

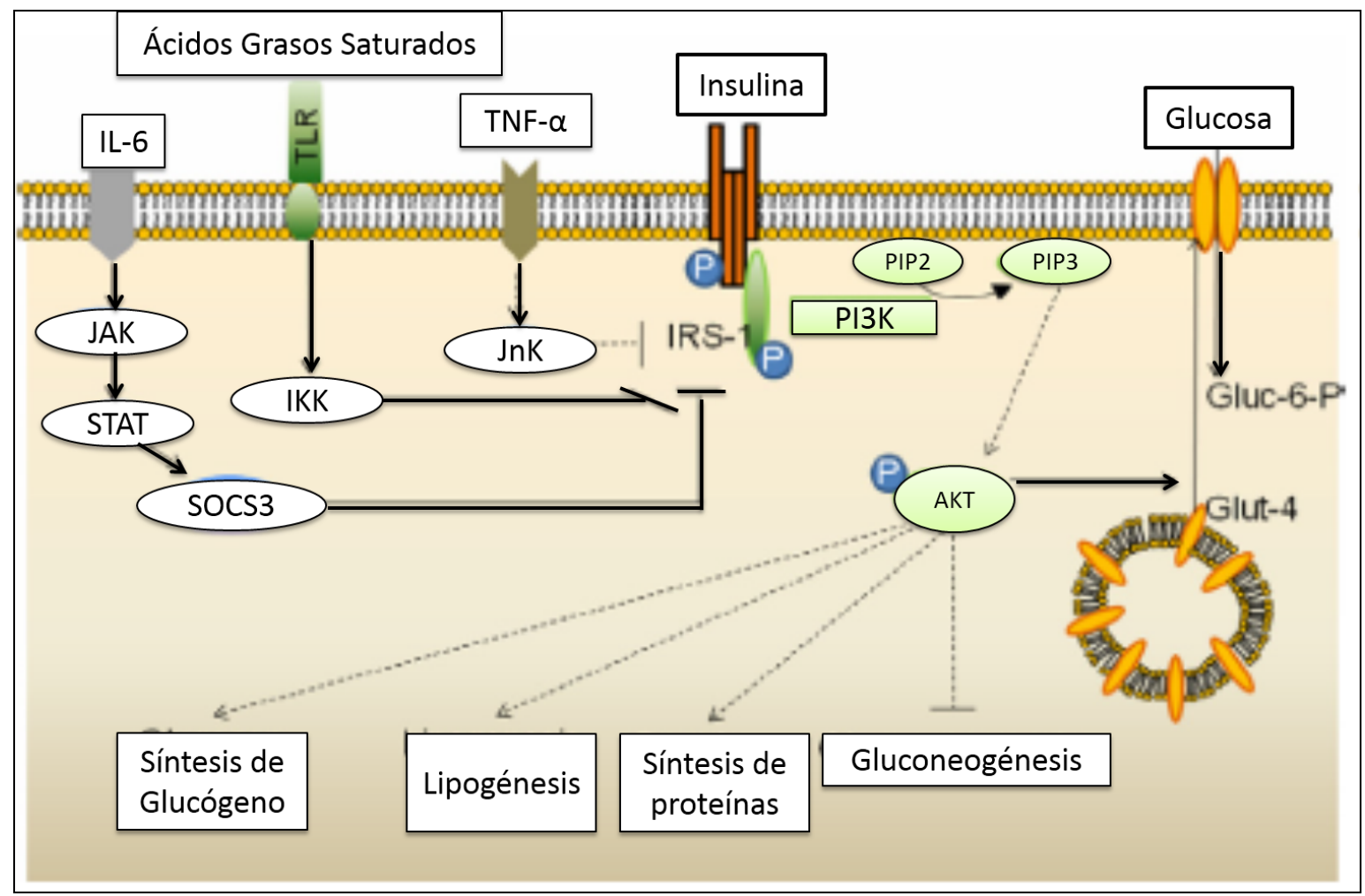

Figura 2. Mecanismos moleculares de la resistencia a la insulina.

Las acciones metabólicas principales de la insulina van dirigidas a estimular la captación de glucosa en el músculo esquelético y corazón, así como para suprimir la producción de glucosa y lipoproteínas de muy baja densidad (VLDL) en el hígado. Bajo condiciones de ayuno, la falta de secreción de insulina conduce a un incremento en la síntesis de glucosa en hígado y riñones (aumentando la glucogenólisis y la gluconeogénesis). Después de la alimentación, la insulina que es liberada desde las células $\beta$-pancreáticas inhibe estos dos proceso. La insulina estimula el sistema nervioso simpático (SNS) para incrementar el gasto cardíaco y la liberación y 
utilización de glucosa en los tejidos periféricos (Cheung et al., 2012). Otros efectos metabólicos de la insulina incluyen la inhibición de liberación de glucosa del hígado, inhibición de la liberación de AGL del TA y la estimulación del proceso por el cual los aminoácidos son incorporados dentro de las proteínas (Cheung et al., 2012).

La RI (Figura 3) es una condición en donde las cantidades normales de insulina son inadecuadas para producir una respuesta normal por parte de las células adiposas, músculo e hígado. Por lo tanto, la insulina no produce los efectos deseados cuando la densidad del receptor y/o su afinidad están disminuidas (Brock et al., 2007; Tilg et al., 2008; Tarantino et al., 2011; Cheung et al., 2012; Connell et al., 2012).

Se ha observado que la RI se incrementa debido a variaciones genéticas, adquiridas y factores ambientales, entre los cuales se incluye la obesidad donde hay un incremento del tejido adiposo (Cheung et al., 2012). Además, frecuentemente este estado se asocia con inflamación de bajo grado, por ello se asume que la inflamación contribuye en una mayor parte a su desarrollo (Tilg et al., 2008).

A pesar de que la $\mathrm{RI}$ se caracteriza por interacciones complejas entre determinantes antigénicos, factores nutricionales y estilo de vida, se ha reconocido que los mediadores sintetizados por las células del sistema inmune, así como del TA están críticamente involucrados en la regulación de la acción de la insulina (Tilg et al., 2008). De hecho, la lipólisis, la cual se inhibe por la insulina, está sobreestimulada en estados de RI, conduciendo a un incremento en el flujo de AGL. La RI en músculo reduce la captación de glucosa, mientras que en hígado reduce su almacenamiento. Ambos efectos propician un incremento de glucosa a nivel 
circulante y la liberación de insulina del páncreas (Tarantino et al., 2011; Gallagher et al., 2010; Cheung et al., 2012). Todas estas alteraciones, como altos niveles de insulina en plasma y glucosa debido a la RI, conducen al síndrome metabólico (SM) y DT2 (Gallagher et al., 2010).

También se ha hecho mención que la Rl puede ser el resultado de una sobreproducción de citocinas proinflamatorias por el tejido adiposo (ej. IL-6, TNF- $\alpha$ y proteína $\mathrm{C}$ reactiva) y la deficiencia relativa de citocinas antiinflamatorias (por ejemplo adiponectina) debido a la obesidad (Cheung et al., 2012).

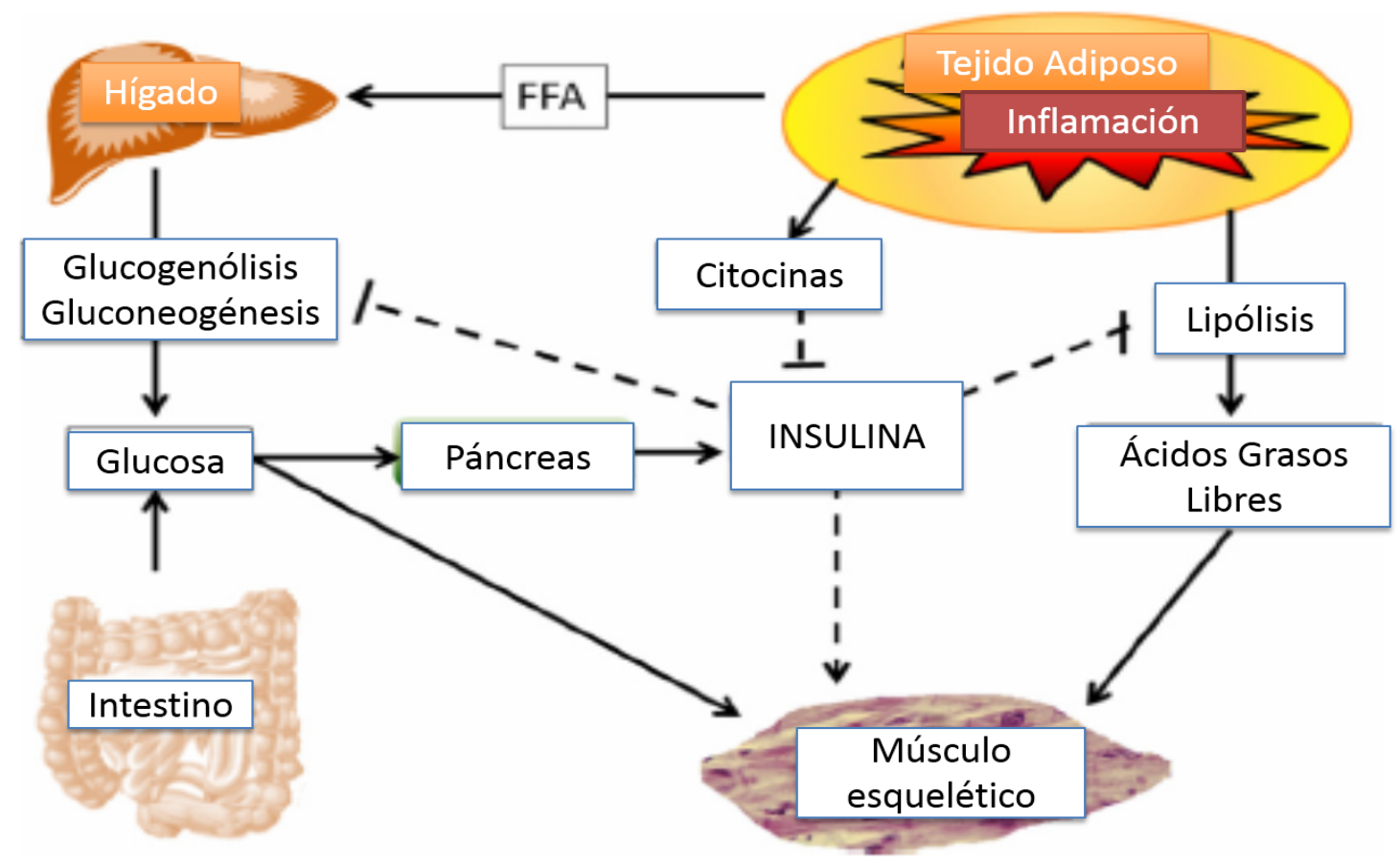

Figura 3. Patogénesis de la resistencia a la insulina asociada con la obesidad. Durante el aumento del TA, la acumulacón de AGL en hígado y músculo esquelético la cantidad de insulina secretada por el páncreas es inadecuada para producir una respuesta normal, favoreciendo la lípólisis, la glucogenólisis y gluconeogénesis que incrementan la concentración de glucosa. 
Se sabe por estudios in vitro e in vivo que varias citocinas proinflamatorias, adipocinas y factores de transcripción están involucrados en la patogénesis de la RI. Este concepto integrador es apoyado por múltiples observaciones en pacientes con DM2, donde la RI se correlaciona con un estado de inflamación crónica de bajo grado (Tilg et al., 2008; Gallagher et al., 2010). Con base en ésto se están proponiendo nuevas estrategias antiinflamatorias en humanos que buscan revertir la RI, lo cual demostraría que la inflamación conduce a la RI (Tilg et al., 2008).

Por otra parte, un hecho muy importante es que la actividad incrementada del sistema renina-angiotensina-aldosterona (RAAS) puede causar RI por vía de la estimulación de receptores Ang II tipo 1, los cuales fomentan la producción de especies reactivas de oxígeno $(\mathrm{ERO})$ en adipocitos, músculo esquelético y tejido cardiovascular de individuos obesos. De esta manera se cree que los AGL inducen RI e incrementan el nivel de estrés oxidante, resultando en disfunción endotelial y aterogénesis (Cheung et al., 2012; Connell et al., 2012).

Así mismo, existe evidencia que sugiere que la $\mathrm{RI}$ puede resultar de anormalidades en moléculas clave de la vía de señalización de insulina, incluyendo la sobreexpresión y desregulación de fosfatasas y/o activación de cascadas de proteína cinasas, conduciendo a anormalidades en la expresión y acción de varias citocinas, factores de crecimiento y péptidos, así como sobreproducción de VLDL, como se mencionó anteriormente (Gallagher et al., 2010; Cheung et al., 2012).

Un importante mecanismo por el cual la señalización de insulina puede estar regulada negativamente es a través de la vía de fosforilación de ciertos residuos de 
serina en IRS-1, lo cual fue descrito en estudios donde se buscaba la relación entre TNF- $\alpha$ y la acción de la insulina (Tarantino et al., 2011).

\subsubsection{Síndrome metabólico (SM).}

El término "síndrome metabólico" establecido por Haller en 1977 describe varios factores de riesgo, entre los que destacan: diabetes, hiperlipidemias, hiperuricemia, obesidad, hipertensión y esteatosis hepática (Bonora, 2007; Gallagher et al., 2010; Brietzke, 2010), que predisponen al desarrollo de DM2 y enfermedad cardiovascular, principalmente, siendo una condición común en la población general (Bonora, 2007; Kotani et al., 2012).

En 1988 Reaven acuño el término "síndrome X" que conceptualmente unía hipertensión, DM2 y propensión incrementada para eventos ateroescleróticos a causa de la RI. Posteriormente Reaven retomó el nombre de SM, el cual tiene como sinónimos "síndrome de resistencia a insulina" y "síndrome cardiometabólico" (Bonora, 2007; Brietzke, 2010).

La International Diabetes Federation, American Heart Asssociation, World Heart Federation International Atheroesclerosis Society, International Association for the Study of Obesity y el National Heart, Lung and Blood Institute en 2009 definieron a un paciente con SM como aquel que presentara al menos tres de los siguientes elementos: obesidad abdominal, presión sanguínea elevada, TG elevados, colesterol de alta densidad bajo o hiperglucemia. Asimismo, se estableció que entre los factores que contribuyen al establecimiento de este síndrome se encuentran: disminución de la actividad física, predisposición genética, inflamación crónica, AGL 
elevados y disfunción mitocondrial (Bonora, 2007; Gallagher et al., 2010; Brietzke, 2010). Así, la RI parece ser un punto en común entre estos elementos, obesidad y SM (Figura 4).

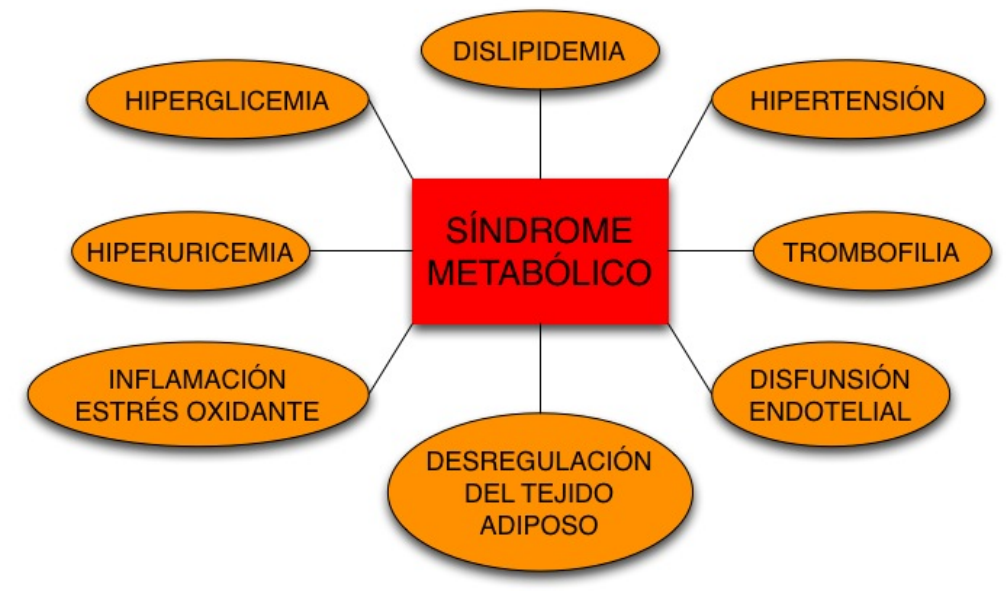

Figura 4. El amplio espectro de los desórdenes proaterogénicos asociados al síndrome metabólico.

La alteración en la señalización de la insulina a nivel cerebral aumenta el apetito y la producción de glucosa por el hígado a través de señales neuronales del hipotálamo (Gallagher et al., 2010) y conduce a la liberación de ácidos grasos libres del tejido adiposo, incrementa la producción a nivel hepático de VLDL y disminuye la producción de colesterol de alta densidad (HDL). La producción incrementada de AGL, citocinas inflamatorias y disfunción mitocondrial contribuyen a dañar la señalización de insulina, disminuyendo la captación de glucosa a nivel de músculo esquelético, gluconeogénesis hepática incrementada y disfunción de la célula $\beta$, conduciendo a la hiperglucemia (Bonora, 2007; Gallagher et al., 2010).

Sin embargo, el fenotipo del SM no está limitado a lo anterior; existen evidencias donde está relacionado con anormalidades en la coagulación, fibrinólisis, 
estrés oxidante, respuesta inmune innata, metabolismo del adipocito y sus actividades endocrinas y función endotelial (Bonora, 2007; Kotani et al., 2012).

En tejido adiposo la producción de leptina se incrementa debido a la resistencia a la leptina; se incrementa la producción de citocinas, diacilglicerol y AGL. Los niveles de adiponectina disminuyen con el incremento en la obesidad. La producción de citocinas por el tejido adiposo, acyl-CoA, diacilglicerol, y AGL conduce a la RI, disfunción mitocondrial, dislipidemia, disminución de la captación de glucosa en el músculo esquelético, aumento en la producción de glucosa en el hígado y toxicidad en la célula $\beta$. De esta forma se instaura la hiperglucemia, y esta a su vez puede causar toxicidad en la célula $\beta$. La RI conduce a la hipertensión a través de su acción sobre el óxido nítrico y endotelina-1 en el endotelio (Gallagher et al., 2010) (Figura 5).

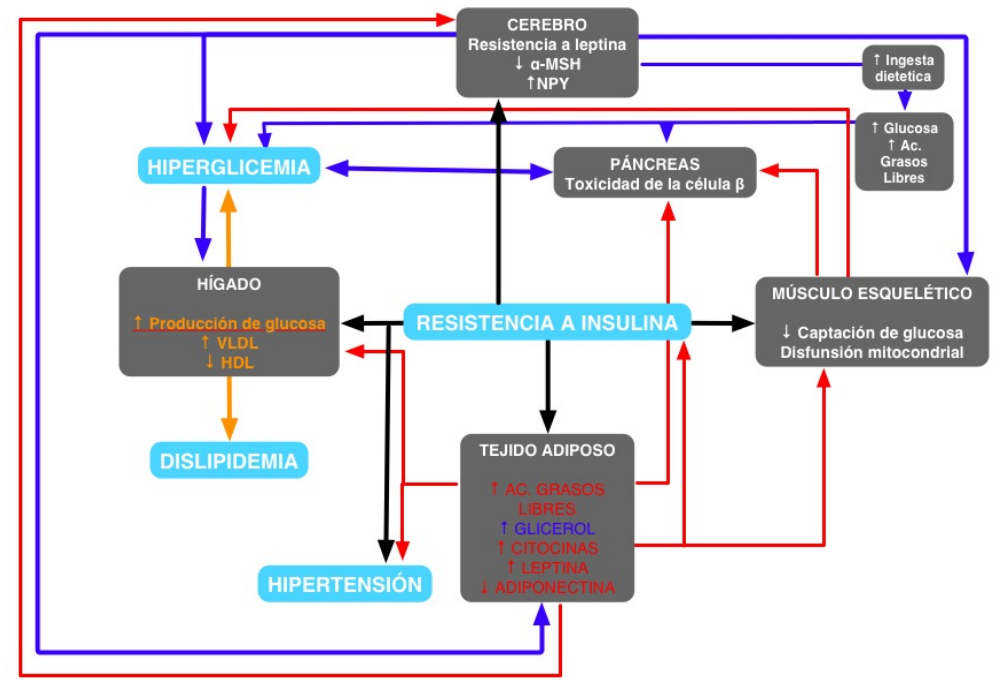

Figura 5. Resistencia a la insulina en el desarrollo del síndrome metabólico. 
Cabe subrayar finalmente que al SM se le reconoce también como una condición oxidante, causado principalmente por la sobreproducción de ERO y/o inactivación de antioxidantes (Brown et al., 2009; Kotani et al., 2012).

\subsection{INFLAMACIÓN EN LA OBESIDAD}

Durante la obesidad se presenta inflamación de bajo grado en la cual participan una red de células y moléculas del sistema inmune innato, el más antiguo y conservado filogenéticamente. La respuesta inflamatoria comienza con el reconocimiento de las señales y la sintesis de proteínas que modifican la respuesta efectora de las células inmunitarias (Blancas et al., 2010).

El descubrimiento de hace ya casi dos décadas de que TNF- $\alpha$ tenía una elevada expresión en el tejido adiposo de ratones obesos, fue la primera indicación de que los mediadores inflamatorios estaban asociados con la obesidad (Hotamisligil et al., 1993; Hotamisligil et al., 1995). Hoy se acepta que los cambios en la señalización inflamatoria de los adipocitos y la infiltración de las células inmunes en TA son las características primordiales de la RI y la enfermedad metabólica asociada con la obesidad, tanto en modelos animales como en humanos.

En el año 2003 se descubrió que en el ratón y en el humano, el TA está infiltrado por macrófagos, hecho que supuso un gran avance en la comprensión de cómo la obesidad propaga la inflamación (Weisberg et al., 2003; Xu et al., 2003). En estos estudios se observó que el TA contenía macrófagos derivados de médula ósea y que el contenido en macrófagos correlacionaba con el grado de obesidad. Se encontró que más del $40 \%$ del total de células del TA en roedores y humanos obesos 
eran macrófagos, lo que contrastaba con el $10 \%$ en animales y sujetos delgados. Además, los macrófagos eran los responsables de la mayor parte de la expresión de TNF- $\alpha$ en el TA y contribuía significativamente a la producción de interleucinas proinflamatorias, como la IL-6 (Weisberg et al., 2003; Xu et al., 2003).

Además de los macrófagos, otras células inmunes tales como los neutrófilos, los mastocitos, las células "natural killer" (NK) y los linfocitos infiltran el TA durante la obesidad o en respuesta a dietas altas en grasas. La razón exacta del porqué estas infiltraciones ocurren, y si son consecuencia o causa del proceso inflamatorio durante la progresión de la enfermedad, está aún por determinarse. Por ejemplo, hay resultados contradictorios en torno a si las células T son reclutadas inicialmente al TA tras someter ratones a dietas altas en grasa, o si es un proceso que ocurre después, una vez de que la infiltración ya ha comenzado (Glass et al., 2006; Nakamura et al., 2010). Sin embargo, resultados recientes han demostrado que otros tipos celulares inmunes tienen un papel activo en la desregulación metabólica, independientemente de que sean reclutados al tejido adiposo o no. Este es el caso de los mastocitos y las células NK ya que su eliminación reduce la inflamación del TA, mejora la respuesta a la insulina y la homeostasis de la glucosa en ratones (Kruth, 2011; Hotamisligil, 2010).

El incremento en la exposición a ácidos grasos, bien por un aumento en el contenido de grasa de las dietas modernas o por una lipólisis aberrante de los adipocitos, se ha propuesto como un factor importante, tanto en la desregulación del metabolismo, como en la señalización inmune durante la inflamación (Suganami et 
al., 2007). Algunos autores definen con el término de "metainflamación" a la respuesta inmunológica modulada por nutrientes y metabolitos (Hotamisligil, 2006).

\subsubsection{Adipocinas}

El TA esta compuesto por adipocitos embebidos en una malla de tejido conectivo laxo que contiene precursores de adipocitos, fibroblastos, células inmunes y otros tipos celulares. Inicialmente se consideraba sólo un órgano de almacenamiento de energía, pero actualmente es reconocido como un órgano endócrino activo en la homeostasis energética (Antuna-Puente et al., 2008; Galic et al., 2010). Participa en diversas funciones fisiológicas, como regulación de la masa grasa y la homeostasis de nutrientes, liberando gran cantidad de mediadores bioactivos (adipocinas) que modulan la homeostasis, la presion sanguínea, el metabolismo de lipidos y carbohidratos, la inflamación y la inmunidad (Rabe et al., 2008; Galic et al., 2010).

Varios estudios han demostrado que la producción de adipocinas se altera en la obesidad, la DM2 y el SM. Esto se observa para la leptina, TNF- $\alpha$, IL-6, la adiponectina y la resistina (Bastard et al., 2006; Tilg et al., 2008; Rabe et al., 2008).

\subsubsection{TNF- $\alpha$}

TNF- $\alpha$ es una citocina proinflamatoria producida por una variedad de tipos celulares, pero principalmente por macrófagos y linfocitos. Puede ser producido por el tejido adiposo, aunque esta producción es escasa en los seres humanos. Sin 
embargo, se cree que desempeña un papel importante en la fisiopatología de la RI en roedores a través de la fosforilación del receptor del sustrato de insulina 1 (IRS-1) evitando su interacción con la subunidad beta del receptor de insulina e impidiendo la señal de la insulina (Bastard et al., 2006).

El primer antecedente donde se pone de manifiesto el vínculo entre el aumento de la expresión de una citocina proinflamatoria (TNF- $\alpha$ ) y la acción de la insulina, proviene de un estudio que llevó al concepto de la inflamación en la obesidad y en donde se demostró que los adipocitos expresan TNF- $\alpha$ (Hotamisligil et al., 1993).

En estos estudios, pacientes y animales obesos mostraron un incremento en la expresión de esta citocina regulando la acción de insulina. En otros estudios publicados por Uysal y colaboradores (1997), se demostró que los ratones que carecian de TNF- $\alpha$ o de receptores a TNF- $\alpha$ mejoraban la sensibilidad a la insulina en el modelo de obesidad, tanto inducida por dieta como por manipulación genética. Estas observaciones fueron corroboradas por estudios realizados en seres humanos, en donde los pacientes presentaban un aumento de tejido adiposo tisular y un aumento en la expresión de TNF- $\alpha$. A nivel molecular, la exposición de las células a TNF- $\alpha$ o a niveles elevados de AGL estimuló la fosforilación inhibitoria de los residuos de serina de IRS-1. El TNF- $\alpha$ ha sido sin duda el mediador proinflamatorio que establece la relación entre la inflamación, la obesidad y la RI (Tilg et al., 2008). 


\subsubsection{Interleucina-6 (IL-6)}

La II-6 es producida por muchos tipos celulares (fibroblastos, células endoteliales y monocitos), incluyendo adipocitos. Se ha descrito que la producción de IL-6 en el tejido adiposo es mayor en la obesidad. Entre un 15 y $30 \%$ de la IL-6 circulante deriva de los niveles de producción del TA en ausencia de una inflamación aguda (Fontana et al., 2007; Klover et al., 2005; Wallenius et al., 2002).

Por otra parte, la secreción de IL-6 es mayor en el tejido adiposo visceral que en el tejido adiposo subcutáneo. Sin embargo, la mayor producción de IL-6 no es producida por los adipocitos maduros, sino más bien por una fracción de células del estroma vascular, incluyendo preadipocitos, células endoteliales, los monocitos y macrófagos (Fontana et al., 2007).

La IL-6 es una citocina multifuncional o pleiotrópica que actúa sobre muchas células y tejidos. Dentro de los principales efectos de la IL-6 está la inducción de la producción hepática de la proteína $\mathrm{C}$ reactiva $(\mathrm{PCR})$, la cual es un marcador independiente de riesgo cardiovascular. Curiosamente hay una relación muy estrecha entre el contenido proteínico en el tejido adiposo y los niveles circulantes de IL-6 y PCR. Ademas, se ha postulado recientemente que la IL-6 desempeña un papel central en la relación entre obesidad, inflamación y las enfermedades coronarias (Kang, 2013).

Por otra parte, la producción del IL-6 en el TA podría directamente afectar el metabolismo del hígado por la inducción de la secreción de VLDL e hipertrigliceridemia, debido a que el tejido adiposo visceral está estrechamente relacionado al hígado por el sistema venoso portal (Kaur, 2014). 
Estudios recientes han sugerido que la IL-6 podría estar involucrada en la RI y sus complicaciones. El receptor de IL-6 pertenece a la clase de la familia de receptores que emplean la vía de señalización JAK/STAT. Janus cinasa (JAK), induce la activación de STAT (signal transducers and activators of transcription) a través de la fosforilación, dimerización y translocación al núcleo para regular la transcripción de genes blanco (Galic et al., 2010).

Actualmente se establece de manera clara una fuerte interacción entre las citocinas y las vías de señalización de la insulina por lo que puede conducir a un deterioro en el efecto biológico de la insulina. Aunque los mecanismos exactos no han sido completamente dilucidados, podrían implicar la activación de la tirosin fosfatasa o la interacción entre el supresor de la señalización de citocinas (SOCS), las proteínas y el receptor de insulina (Bastard et al., 2006; Tilg et al., 2008).

\subsubsection{Interleucina (IL)-10}

IL-10 fue identificada inicialmente como un producto de celulas T cooperadoras tipo 2 (Th2) y es conocida como una citocina antiinflamatoria, inhibiendo la actividad de la celula T cooperadora tipo 1 (Th1). Se deriva de una variedad de celulas que incluyen monocitos, celulas dendríticas, linfocitos, macrófagos y células T. Existe evidencia que apoya que la IL-10 se correlaciona negativamente con el IMC, la obesidad, la RI y la DM2; además, la sobreexpresión de IL-10 o administración de IL-10 reduce el peso corporal, mejora la sensibilidad a la insulina y aumenta el control glucémico, aun cuando el mecanismo de acción no está esclarecido (Nishida et al., 2007; Wang, 2014a). 
IL-10 polariza los macrófagos del fenotipo activado M1 al fenotipo activado M2 y TH1/17 a Th2/Treg, sobreregula el receptor de IL-1 y al factor de crecimiento transformante beta 1 (TGF- $\beta$ ), inhibe la fagocitosis y las citocinas proinflamatorias y quimiocinas. Además bloquea al receptor tipo Toll-4 (TLR4), al factor nuclear-kappaB (NF-kB) y otras vías de señalización; activa la vía de señalización de JAK/STAT. Esto resulta en una atenuacion del proceso inflamatorio inducido por TNF- $\alpha$, IL-6, IL-1, IL12 y otras citocinas proinflamatorias (Choi et al., 2007; Wang, 2014a).

En estudios recientes, la producción disminuida de IL-10 fue asociada con un incremento en el riesgo de daño y diabetes tipo 2. En un estudio realizado en mujeres obesas, Esposito y cols. en 2003, reportaron que los niveles de IL-10 son más bajos en personas con SM.

\subsubsection{Adiponectina}

La adiponectina (Acrp30 o adi-POQ, GBP28 o APM1) está altamente expresada en el tejido adiposo. Los niveles plasmáticos de adiponectina (lo que constituye el $0.01 \%$ de proteínas circulantes) están entre 5 y $30 \mathrm{mg} / \mathrm{L}$ en sujetos sanos (Tilg et al., 2008). La expresión del RNAm de adiponectina depende de la localización del tejido adiposo. Es más baja en el tejido adiposo visceral que en el tejido adiposo subcutáneo. La adiponectina tiene varias particularidades que la distinguen de otras adipocinas (Bastard et al., 2006; Tilg et al., 2008): 
- Los niveles circulantes están disminuidos en pacientes obesos y/o pacientes diabéticos tipo 2, así como en pacientes con enfermedades coronarias.

- Existe una fuerte correlación positiva entra la adiponectina y la sensibilidad a la insulina.

- Existe una correlación inversa entre la adiponectinemia (niveles disminuidos de adiponectina en sangre) y la obesidad, particularmente con la obesidad abdominal.

- La adiponectinemia puede desempeñar un papel protector contra la aterosclerosis y la RI.

- La sensibilidad a la insulina por la adiponectina puede implicar la activación de la proteína cinasa activada por AMP (AMPK), que participa en la disminución de la lipogénesis asociada con aumento de ß-oxidación mitocondrial.

- La adiponectina es también capaz de regular la producción hepática de glucosa mediante la reducción de la expresión del RNAm de fosfoenolpiruvato carboxicinasa y la glucosa-6-fosfatasa, dos enzimas claves de la gluconeogénesis.

Por otra parte, la adiponectina puede modular la respuesta inflamatoria inducida por TNF- $\alpha$, debido a que se ha demostrado que la adiponectina reduce la secreción de TNF- $\alpha$ por parte de los macrófagos. Este efecto anti-TNF- $\alpha$ puede explicarse en parte por el efecto antiinflamatorio y antiaterogénico que presenta. Por 
el contrario, tanto TNF- $\alpha$ e IL-6 reducen la expresión del RNAm de adiponectina, siendo éste un mecanismo adicional por el cual estas dos citocinas inducen RI (Bastard et al., 2006).

Se han identificado dos receptores para adiponectina (AdipoR1 y Adipo R2) AdipoR1 es expresado ampliamente en todos los organos de ratones y AdipoR2 se expresa principalmente en hígado. La importancia en la alteración en los receptores se ha demostrado recientemente, donde la disrupción de ambos receptores abate las funciones de la adiponectina con incremento en el contenido de TG, inflamación y estrés oxidante (EO), lo cual conduce a un estado de RI y una marcada intolerancia a la glucosa [Bastard et al., 2006; Metha et al., 2007; Tilg et al., 2008]. Todos estos descubrimientos apoyan firmemente el papel de la adiponectina en la regulación de la sensibilidad a la insulina (Tilg et al., 2008; Metha et al., 2007) (Figura 6).

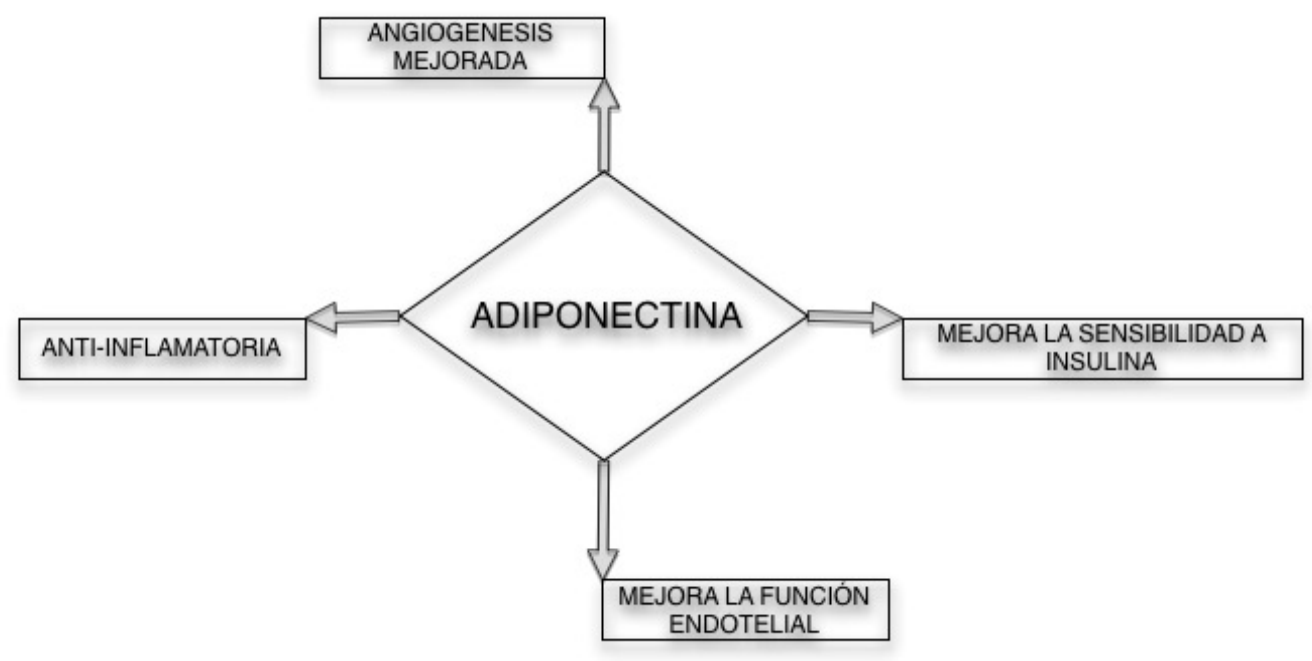

Figura 6. Acciones principales de adiponectina. 


\subsubsection{Adipocinas, inflamación y resistencia a insulina.}

La RI puede y debe ser conceptualizada ampliamente tomando en cuenta la interaccion entre la nutrición, la glucosa, la insulina y las adipocinas en diversos tejidos de importancia metabólica. Las interacciones entre las adipocinas secretadas por el TA, añade una complejidad adicional al panorama que se presenta durante la obesidad (Rabe et al., 2008).

Adiponectina y TNF- $\alpha$ controlan la sintesis y actividad de otras adipocinas, creando una situación fisiológica balanceada. En la sobrealimentación se activan las vias inflamatorias, causando un desbalance crítico que conduce a la disminución en la expresión de adiponectina (Rabe et al., 2008). TNF- $\alpha$ e IL-6 tienen un papel importante en la regulación de muchas adipocinas por ejemplo, se ha reportado que TNF- $\alpha$, desregula la producción de RPB4 en adipocitos humanos. Por otra parte, la expresión de leptina, resistina y visfatina sobreregulan la producción de TNF- $\alpha$ e IL-6, sugiriendo que estas adipocinas podrían dirigir o participar en el proceso inflamatorio a través de acciones paracrinas y/o autocrinas (Rabe et al., 2008). Leptina, sin embargo, ha sido reportada por suprimir la expresión de resistina y RPB4. Vaspina posee propiedades anti-inflamatorias, suprime la expresión de leptina, resistina y TNF- $\alpha$ en el tejido adiposo blanco e incrementa la expresión de adiponectina (Rabe et al., 2008) (Figura 7). 


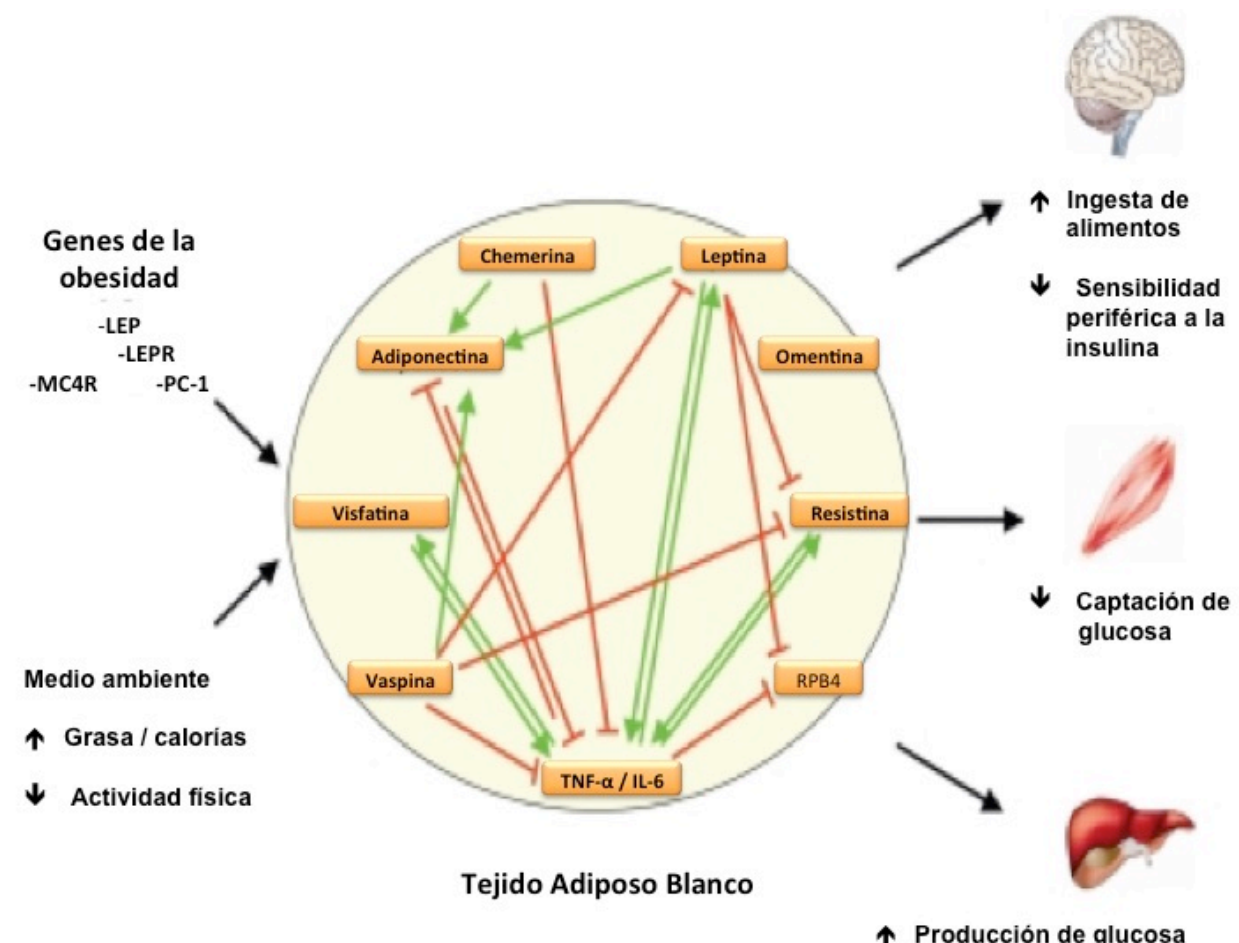

Figura 7. Obesidad, adipocinas y resistencia a la insulina. Expresión de adipocinas y secreción por el tejido adiposo. Las lineas verdes indican estimulación y las lineas rojas, indican supresión de expresion de genes

\subsubsection{Inflamación y envejecimiento}

El envejecimiento sigue siendo uno de los fenómenos biológicos no comprendidos totalmente, debido en gran parte a su inherente y compleja naturaleza integradora, así como por la dificultad para disociar los efectos del envejecimiento normal y los que se manifiestan como consecuencia de condiciones de enfermedad asociadas con la edad (Kregel et al., 2007).

Según la definición de Harman, el envejecimiento es un fenómeno biológico complejo e inevitable relacionado con el deterioro irreversible de las capacidades fisiológicas, bioquímicas y estructurales a lo largo de la vida, que finalmente conduce 
a la muerte (Harman, 1956).

Muchos estudios han demostrado que el estrés oxidante y la disfunción mitocondrial son dos factores importantes que contribuyen al proceso de envejecimiento (Cui et al., 2011). A lo largo de la vida, las células continuamente se encuentran expuestas a una gran variedad de factores externos de daño como radiación ionizante, así como por factores endógenos propios del metabolismo, como las citocinas proinflamatorias, eventos en los cuales las ERO tienen un papel importante. Las respuestas celulares ante el estrés oxidante pueden ir desde la recuperación hasta la muerte celular (López-Díazguerrero et al., 2005).

La senescencia celular es un tipo de respuesta ante el daño oxidante que se ha observado en las células que tienen capacidad proliferativa. La senescencia celular funciona como supresor de tumores al detenerse irreversiblemente la proliferación celular por activación de inhibidores del ciclo celular como p16 y p21, y a su vez estimula la reparación celular ante el daño. Sin embargo, la senescencia celular también es un contribuyente fundamental del envejecimiento y las enfermedades asociadas, como diabetes, enfermedades neurodegenerativas, artritis, obesidad y SM (Rodier et al., 2011).

Las células senescentes presentan un fenotipo secretor (SASP) que comprende componentes como factores proinflamatorios y otros que dañan los tejidos, provocando disfunción a nivel local y de todo el organismo. Se ha encontrado que el SASP es el principal contribuyente de la inflamación asociada al envejecimiento, al menos en el TA. La secreción de moléculas del SASP, tales como TNF- $\alpha$, IL-6, metaloproteinasas de la matríz extracelular (MMP), MCP-1, y la proteína 
de unión a IGF (IGFBPs), entre otras, se incrementan en múltiples tejidos durante el envejecimiento (Freund et al., 2010). Por ejemplo, en el tejido adiposo la expresión de los componentes de SASP como IL-6, la proteína de unión a IGF/IGFBP-2, y el inhibidor del activador de plasminógeno 1 (PAl-1) es mayor en las células senescentes positivas a p16 en comparación con células no senescentes (Baker et al., 2011).

Como en la inflamación aguda, el SASP podría ser apagado para evitar consecuencias. En algunos contextos, las células senescentes son eliminadas por células fagocíticas, sin embargo, esos mecanismos fallan en el envejecimiento (Xue et al., 2007).

Los efectos locales del SASP en los tejidos o los componentes específicos del SASP están implicados en una amplia variedad de patologías relacionadas con la edad in vivo. Por ejemplo, en el caso de la diabetes, la pérdida de la capacidad regenerativa de las células $\beta$ está presente en el envejecimiento de roedores y humanos debido a la disminución de células funcionales y la presencia de células senescentes. Los adipocitos senescentes que aumentan en el envejecimiento generan aumento de la RI, lo que conduce al aumento de la prevalencia del SM en la vejez (Slawik et al., 2006).

A pesar de los efectos dañinos del SASP, que contribuyen a las patologías en el envejecimiento, los nuevos hallazgos sugieren que el envejecimiento es un factor de riesgo modificable y que es viable retrasar las enfermedades relacionadas con la edad mediante la modulación de los mecanismos fundamentales del envejecimiento. Hasta ahora, se han generado modelos de ratones modificados genéticamente que 
permiten diseccionar la relación causal entre la senescencia cellular, el SASP y las enfermedades relacionadas con la edad, como el SM (Tchkonia et al., 2013).

Por ejemplo, en un estudio con ratones modificados genéticamente se diseñó una estrategia para eliminar de manera inducible las células senescentes positivas a p16. Con este estudio se encontró que la eliminación de células senescentes del tejido adiposo retrasó la aparición de patologías relacionadas con la edad como la DM2 y el SM (Baker et al., 2011).

La inflamación crónica que se asocia con el envejecimiento se conoce como "inflammaging" que es un proceso sistémico y multifactorial que juega un papel causal en varias enfermedades asociadas de la vejez (Chung et al., 2009). Entre los principales marcadores de inflamación encontrados en el envejecimiento, están los elevados niveles de IL- 6 , TNF- $\alpha$ y otras citocinas, que se sabe interfieren con la acción de la insulina. Esas citocinas son derivadas tanto de la grasa visceral como por el fenotipo secretor de las células senescentes SASP (Sepe et al., 2011).

Todas las alteraciones en el metabolismo y en la distribución de grasa en el cuerpo durante el envejecimiento son participantes activos en un círculo vicioso que a su vez aceleran el proceso de envejecimiento y establecen las enfermedades asociadas como las neurodegenerativas, la depresión, la ateroesclerosis, el cáncer, la artritis y la osteoporosis, la falla renal, la obesidad, y el SM (Michaud et al., 2013; Pennix et al., 2003; Wang et al., 2010; Campisi, 2013; Manolagas, 2010; Vlassara et al., 2009; Figaro et al., 2006; Hildrum et al., 2007).

La condición de inflamación en el envejecimiento también está asociada con una disminución de la capacidad autofágica que perjudica la limpieza celular, y que 
conduce finalmente a la agregación de proteínas y acumulación de las mitocondrias disfuncionales que provocan ERO y por tanto, se genera EO. Estudios recientes han indicado claramente que la producción de ERO inducida por daño mitocondrial puede estimular plataformas multiproteínicas sensoras de daños intracelulares, llamados inflamosomas (Rubinsztein et al., 2011; Rezzani et al., 2012).

En el envejecimiento los niveles de marcadores proinflamatorios y de citocinas circulantes están incrementados. Los cambios en el sistema inmune y la secreción de citocinas por el tejido adiposo representan la mayor causa de inflamación crónica, donde los niveles incrementados de IL-6, IL-1 y TNF- $\alpha$ conllevan un alto riesgo de morbilidad y mortalidad. Diversos estudios han propuesto que la sobreexpresión de TNF- $\alpha$ e IL-6 podría servir como marcador de fragilidad (Michaud et al., 2013).

\subsection{ESTRÉS OXIDANTE}

El estrés oxidante es causado por un desequilibrio entre la producción de radicales libres $(R L)$ como ERO y de especies reactivas de nitrógeno $(E R N)$ y las defensas antioxidantes responsables de la detoxificación de dichos radicales en el organismo (Vincent et al., 2006; Vincent et al., 2007; Brock et al., 2007; Barbosa et al., 2008; Valdecantos et al., 2009; Sood et al., 2009; Brown et al., 2009).

La superación de los sistemas prooxidantes en proporción a los antioxidantes favorece la instauración del estrés oxidante, caracterizado por la producción exacerbada de RL ERO o/y ERN. Lo cual conlleva al desarrollo de daños oxidantes, por medio de oxidación a las biomoléculas y/o por la alteración de la homeostasis. A 
su vez, los daños oxidantes, están involucrados en la etiología de enfermedades crónicas no transmisibles (Barbosa et al., 2008) (Figura 8).

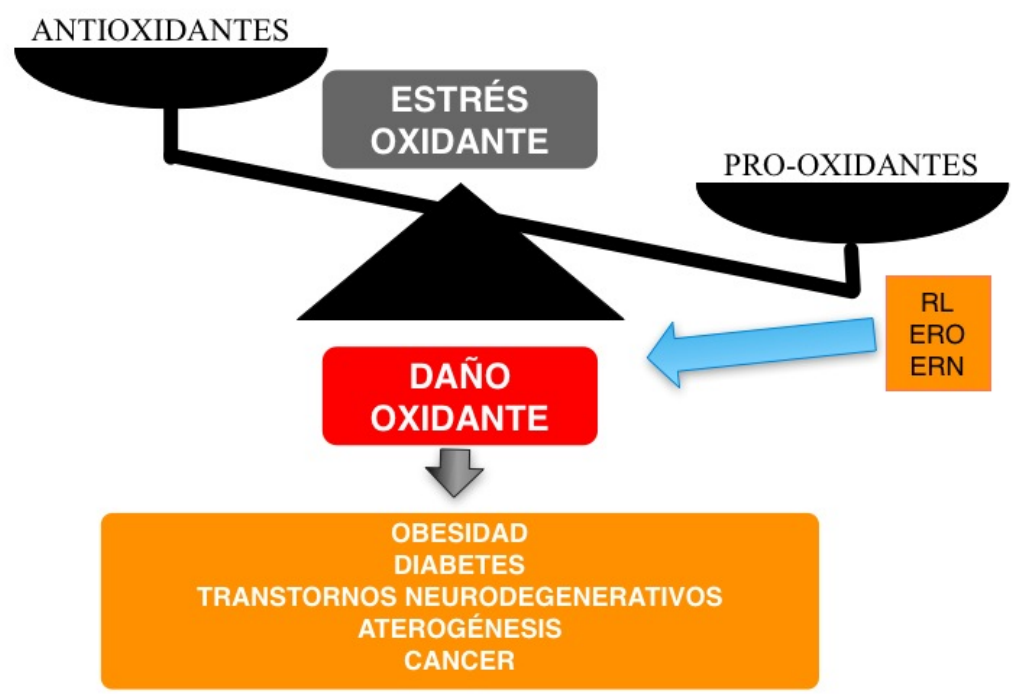

Figura 8. Instauración y desarrollo de daño oxidante. Participación del estrés oxidante en la etiología de enfermedades crónicas.

El estrés oxidante está involucrado en la patogénesis de múltiples enfermedades a lo largo de la vida (Figura 9) (Mohanti et al., 2014; Birch-Machin et al., 2013; Poljšak et al., 2014). Según la "Hipótesis de los Radicales Libres y el Envejecimiento" (Harman, 1956), el incremento de los radicales libres produce la acumulacion de daño oxidante en las biomoléculas a lo largo de la vida que es lo que causa el deterioro celular asociado con el envejecimiento (Ristow et al., 2014).

Dada la dificultad que existe para detectar directamente los RL, se puede conocer el estado de estrés oxidante mediante la medición de las biomoléculas oxidadas (lípidos, DNA, proteínas, carbohidratos), o mediante el conocimiento de la depleción de moléculas antioxidantes. Un aumento del estrés oxidante puede estar producido 
por tres condicionantes; por un aumento mantenido de ERO y/o ERN que superan los mecanismos de defensa, por una disminución de la defensa antioxidante o por la acción conjunta de ambos mecanismos, lo que provocaría un daño oxidante crónico.

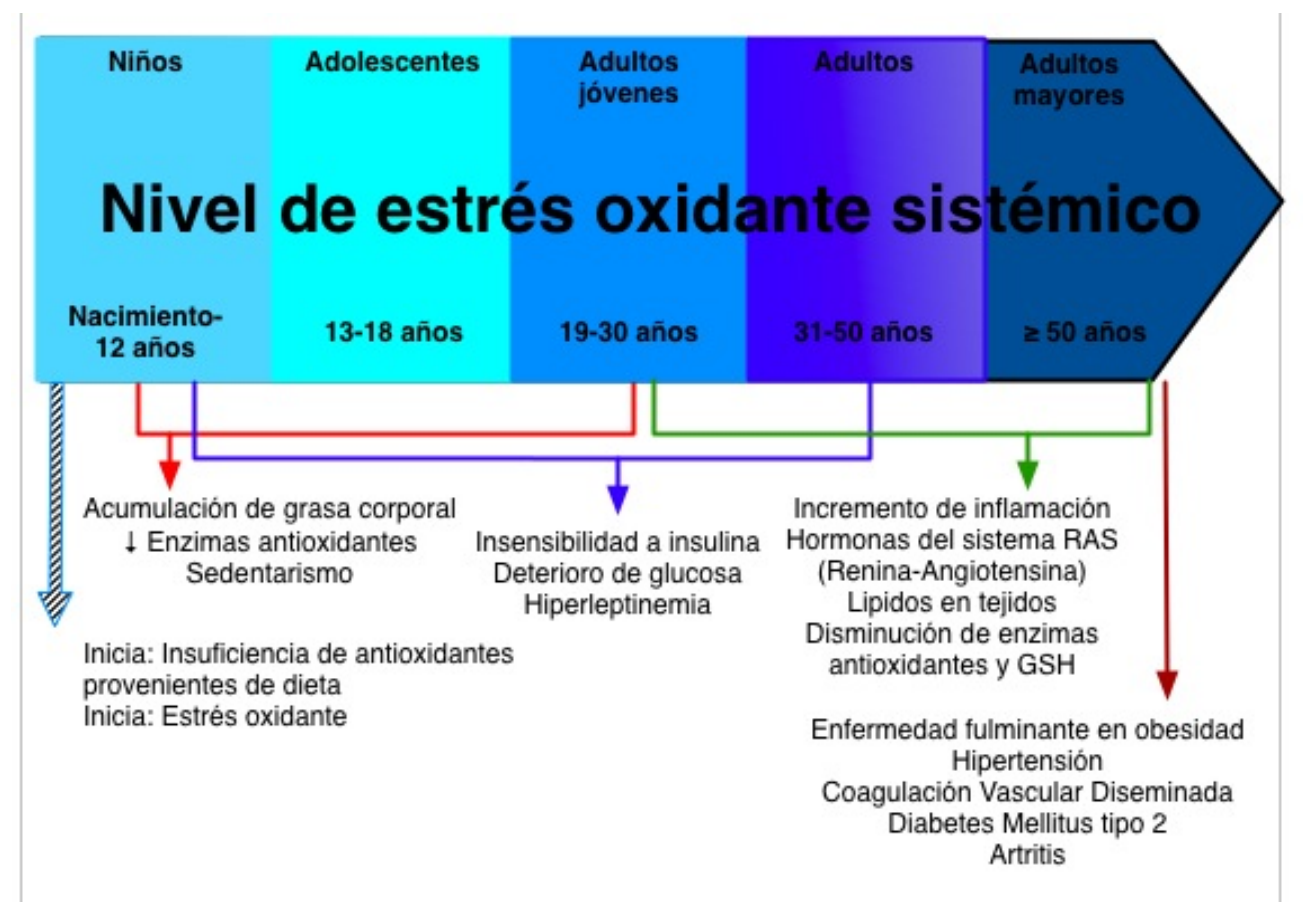

Figura 9. Progresión del estrés oxidante y la obesidad. Enfermedades asociadas con la obesidad a lo largo de la vida.

\subsubsection{Especies reactivas de oxígeno y nitrógeno (ERO/ERN)}

En los organismos vivos, los RL se están formando continuamente, siendo los más abundantes y reactivos los centrados en el oxígeno conocidos como ERO (Halliwell, 2012). Las ERO más estudiadas son el anión superóxido $\left(\mathrm{O}_{2}{ }^{\circ}\right)$, el peróxido de hidrogeno $\left(\mathrm{H}_{2} \mathrm{O}_{2}\right)$, el radical hidroxilo $(\mathrm{OH} \bullet)$, el óxido nítrico $(\mathrm{NO})$ y el peroxinitrilo (ONOO-) (Halliwell et al., 2004; Vincent et al., 2007; Brock et al., 2007; Verrotti et al., 2008; Brown et al., 2009; Halliwell, 2012) (Tabla 2). 


\begin{tabular}{|c|c|c|}
\hline \multicolumn{3}{|c|}{ Tabla 2. Especies reactivas de oxígeno (ERO) y de nitrógeno (ERN) } \\
\hline \multirow[b]{2}{*}{$\begin{array}{l}\text { Especies reactivas } \\
\text { de oxígeno (ERO) }\end{array}$} & Radicales & \multirow{2}{*}{\begin{tabular}{l}
\multicolumn{2}{l}{ No Radicales } \\
Peróxido de hidrógeno \\
$\left(\mathrm{H}_{2} \mathrm{O}_{2}\right)$
\end{tabular}} \\
\hline & Superóxido $\left(\mathrm{O}_{2} \bullet^{-}\right)$ & \\
\hline & Hidroxilo $(\mathrm{OH} \bullet)$ & Ácido hipocloroso (HOCl) \\
\hline & Peroxilo( $\left(\mathrm{RO}_{2} \bullet\right)$ & Ácido hipobromoso (HOBr) \\
\hline & Alcoxilo (RO•) & Ozono $\left(\mathrm{O}_{3}\right)$ \\
\hline & Hidroperoxilo( $\left(\mathrm{HO}_{2} \bullet\right)$ & Oxígeno singulete $\left({ }^{1} \mathrm{O}_{2}\right)$ \\
\hline \multirow{8}{*}{$\begin{array}{ll}\text { Especies } & \text { reactivas } \\
\text { de } & \text { nitrógeno } \\
(E R N) & \end{array}$} & Óxido nítrico (NO•) & Ácido nitroso $\left(\mathrm{HNO}_{2}\right)$ \\
\hline & Dióxido de nitrógeno $\left(\mathrm{NO}_{2}\right)$ & Catión nitrosilo (NO+) \\
\hline & Anión nitroxilo (NO-) & \\
\hline & Peroxinitrito (ONOO-) & \\
\hline & Ácido peroxinitroso & \\
\hline & $(\mathrm{ONOOH})$ & \\
\hline & Alquil peroxinitrito & \\
\hline & (ROONO) & \\
\hline
\end{tabular}

El radical superóxido $\left(\mathrm{O}_{2}{ }^{--}\right)$procede de la reducción univalente del oxígeno molecular $\left(\mathrm{O}_{2}\right)$. No es el radical más reactivo y se forma espontáneamente en medios aerobios; la principal fuente de este radical puede ser la cadena de transporte de electrones (CTE) mitocondrial (Ballester, 1996; Bartsch et al., 1973). También es producido por enzimas como la NADPH oxidasa, xantina oxidasa (XO), óxido nítrico sintasa (NOS), lipooxigenasa y ciclooxigenasa [Jomova et al., 2011]. El daño biológico directo que puede causar este radical es muy selectivo y de el deriva el $\mathrm{H}_{2} \mathrm{O}_{2}$ y los demás $\mathrm{RL}$ (Cheeseman et al., 1993). El superóxido suele producir 
reacciones con otros radicales, como el óxido nítrico o con iones $\mathrm{Fe}$ que contienen determinadas proteínas (Aruoma et al., 2006) y tiene la capacidad de reaccionar con los lípidos de las membranas celulares, alterando con ello su funcionalidad (Figura 10).

$$
\mathrm{O}^{2} \underset{+e^{\bullet}}{\longrightarrow} \mathrm{O}_{2}^{\bullet} \underset{2 \mathrm{H}^{+}}{\stackrel{+e^{\bullet}}{\longrightarrow}} \mathrm{H}_{2} \mathrm{O}_{2} \underset{\mathrm{H}_{2} \mathrm{O}+\mathrm{H}^{+}}{\stackrel{+e^{\bullet}}{\longrightarrow}} \stackrel{\bullet H \rightarrow}{\underset{H^{+}}{\longrightarrow}} \mathrm{H}_{2} \mathrm{O}
$$

Figura 10. Reducción univalente del oxígeno.

El $\mathrm{H}_{2} \mathrm{O}_{2}$, que no es propiamente un $\mathrm{RL}$, se forma por adición de un electrón y dos protones al radical $\mathrm{O}_{2}{ }^{--}$catalizado por la enzima superóxido dismutasa (SOD). La importancia del $\mathrm{H}_{2} \mathrm{O}_{2}$ se debe a su participación en numerosas reacciones que dan lugar a la generación de otros RL, además de su capacidad para atravesar con mucha facilidad las membranas biológicas (Kaludercic et al., 2014). Una vez que ha difundido, puede dar lugar a la formación del radical $\mathrm{OH}^{*}$ vía oxidación de metales de transición en una reacción conocida como reacción de Fenton (Halliwell et al., 1992; Valko et al., 2006; Kumar et al., 2012) (Figura 11).

$$
\text { A) } \begin{aligned}
2 \mathrm{O}_{2}^{\bullet-}+2 \mathrm{H}^{\bullet} \underset{\mathrm{SOD}}{\longrightarrow} \mathrm{O}_{2}+\mathrm{H}_{2} \mathrm{O}_{2} & \text { B) } \mathrm{Fe}^{2+}+\mathrm{H}_{2} \mathrm{O}_{2} \rightarrow \mathrm{Fe}^{3+}+\mathrm{OH}+\mathrm{OH} \bullet \\
\mathrm{O}_{2}+2 e^{-}+2 \mathrm{H}^{+} \rightarrow \mathrm{H}_{2} \mathrm{O}_{2} &
\end{aligned}
$$

Figura 11. Formación de Radicales Libres. A) Dismutación del anión superóxido catalizada por la SOD. (B) Reacción de Fenton: formación de radical hidroxilo a partir de peróxido de hidrógeno 
El radical hidroxilo $\left(\mathrm{OH}^{\circ}\right)$ es la molécula más reactiva capaz de reaccionar con diferentes biomoléculas, lo que causa disfunción celular (Kumar et al., 2012; Ghone et al., 2013). En los organismos vivos la principal fuente de producción al parecer es la descomposición del $\mathrm{H}_{2} \mathrm{O}_{2}$ en presencia de metales de transición, principalmente el hierro y el cobre. La reacción de Haber-Weiss genera radicales $\mathrm{OH}^{*}$ a partir del $\mathrm{H}_{2} \mathrm{O}_{2}$ y aniones superóxido, y es activada en presencia de los cationes Fe (III), generados en la reacción de Fenton (Halliwell et al., 1992; Valko et al., 2006; Kumar et al., 2012) (Figura 12).

$$
\begin{aligned}
& \mathrm{Fe}^{2+}+\mathrm{O}_{2} \longrightarrow \mathrm{Fe}^{3+} \mathrm{O}_{2}^{\bullet-} \\
& \mathrm{O}_{2}^{\bullet-}+\mathrm{H}_{2} \mathrm{O}_{2} \longrightarrow \mathrm{O}_{2}+2 \mathrm{OH}^{\bullet}
\end{aligned}
$$

Figura 12. Formacion del radical hidroxilo. Reacciones de Fenton y de HaberWeiss.

Las ERN incluyen especies derivadas de nitrógeno. Entre las ERN se encuentran los radicales óxido nítrico $(\mathrm{NO} \cdot)$, dióxido de nitrógeno $\left(\mathrm{NO}_{2} \cdot\right)$ y peroxinitrito $\left(\mathrm{ONOO}^{-}\right)$, entre otros. El NO• es capaz de reaccionar con especies como el radical $\mathrm{O}_{2} \bullet$ - para formar $\mathrm{ONOO}^{-}$, de gran importancia debido a su capacidad para modificar biomoléculas como proteínas (Aruoma et al., 2006; Newairy et al., 2007; Evans et al., 2001). 


\subsubsection{Daño oxidante a las biomoléculas}

Los RL tienen una gran capacidad de reacción con moléculas de todo tipo, tanto radicales como no radicales, esto justifica su implicación en una amplia variedad de procesos fisiológicos y patológicos. Los $\mathrm{RL}$ pueden dañar la mayor parte de moléculas biológicas, causando daño oxidativo celular y dando lugar a nuevas especies reactivas capaces de continuar la acción oxidante.

\subsubsection{Daño oxidante a lípidos}

En los lípidos se produce el mayor daño oxidante en un proceso que se conoce como lipoperoxidación (LPx) y representa una forma de daño que puede ser desencadenado por el $\mathrm{O}_{2}$, el $\left({ }^{1} \mathrm{O}_{2}\right)$, el $\mathrm{H}_{2} \mathrm{O}_{2}$ y el $\mathrm{OH} \bullet$, afectando a las estructuras ricas en ácidos grasos poliinsaturados (PUFAs-polyunsaturated fatty acids) de las membranas celulares, lo que indica una mayor susceptibilidad conforme aumenta el número de dobles enlaces (Siddique et al., 2012; Perluigi et al., 2012). La LPx es un proceso considerado como factor importante en el envejecimiento de las células (Perluigi et al., 2012; Morgan et al., 2008).

\subsubsection{Daño oxidante a proteínas}

Todos los aminoácidos presentes en las proteínas tienen residuos susceptibles a ser atacados por los $\mathrm{RL}$, sobre todo por el radical $\mathrm{OH} \cdot$. Se produce el daño oxidante sobre un grupo de aminoácidos como fenilalanina, tirosina, histidina, triptófano y metionina; además se forman entrecruzamientos de cadenas peptídicas, 
hay fragmentación de la proteína por ruptura de enlaces peptídicos y por último, formación de grupos carbonilos que impiden el normal desarrollo de sus funciones. El sistema de oxidación catalizada por metales es el mecanismo más importante en la modificación oxidativa de las proteínas (Wang et al., 2014b). Estas oxidaciones pueden dar lugar a un cambio conformacional de la proteína y como consecuencia a una pérdida o modificación de su actividad biológica, así como a alteraciones en la susceptibilidad a la degradación (Winrow et al., 1993).

Las células por lo general eliminan las proteínas modificadas oxidativamente mediante proteólisis; sin embargo, algunas de las proteínas oxidadas pueden presentar una mayor resistencia a ser eliminadas, que junto con una mayor tasa de formación puede contribuir al acúmulo de proteínas oxidadas y a los efectos dañinos derivados de ellas. Se ha sugerido que esta diferencia en la susceptibilidad a la proteólisis depende del grado de oxidación de las proteínas, de manera que las proteínas parcialmente desnaturalizadas o poco oxidadas presentan una menor resistencia a la proteólisis (Nystrom, 2005) que las que están muy oxidadas (Pickering et al., 2012). En envejecimiento hay acumulación de proteínas oxidadas y disminución de la capacidad de degradar estas proteínas (Wang et al., 2014b).

\subsubsection{Daño oxidante al DNA}

El daño oxidante al DNA puede producir un mayor número de mutaciones, entrecruzamientos, rompimientos espontaneos en las cromátidas y pérdida de fragmentos cromosómicos, llegándose incluso a la pérdida total de determinados cromosomas (Mehdi et al., 2013). Las principales ERO involucradas en el daño 
directo son los radicales $\mathrm{OH} \bullet$ y el $\mathrm{H}_{2} \mathrm{O}_{2}$. Dentro de las alteraciones más frecuentes en las bases púricas, destaca la formación de 8-hidroxi-2'-deoxiguanosina $(8 \mathrm{OHdG})$ con un alto efecto mutagénico. Respecto a las bases pirimídicas, se encuentra la formación de glicoles de timina ( $\mathrm{T}$ ) y citocina (C), además de los hidratos de pirimidina, los cuales dan lugar a fragmentación (Alizadeh et al., 2013; Jia et al., 2008).

\subsection{SISTEMA ANTIOXIDANTE}

Para sobrevivir a la oxidación o daño nitrosante, el organismo ha desarrollado una serie de mecanismos de defensa antioxidante enzimática y no enzimática, diseñados para protegerse de la acción de las ERO/ERN (Chen et al., 2012). Halliwell y colaboradores (1995) definen a un antioxidante como "cualquier sustancia que, en bajas concentraciones respecto al sustrato oxidable, disminuye significativamente o inhibe la oxidación de este sustrato" (Halliwell et al., 1995; Aruoma et al., 2006) (Tabla 3). 


\begin{tabular}{|c|c|c|}
\hline $\begin{array}{l}\text { 1.- Antioxidantes enzimáticos } \\
\text { (captadores): }\end{array}$ & \multicolumn{2}{|c|}{ Reacción enzimática } \\
\hline $\begin{array}{l}\text { Superóxido dismutasa (SOD) } \\
\text { Glutatión peroxidasa (GPx) } \\
\text { Catalasa (CAT) }\end{array}$ & \multicolumn{2}{|c|}{$\begin{array}{c}2 \mathrm{O}_{2^{-}}+2 \mathrm{H}^{+} \rightarrow \mathrm{H}_{2} \mathrm{O}_{2}+\mathrm{O}_{2} \\
2 \mathrm{GSH}+\mathrm{H}_{2} \mathrm{O}_{2} \rightarrow \mathrm{GSSG}+\mathrm{H}_{2} \mathrm{O} \\
2 \mathrm{GSH}+\mathrm{ROOH} \rightarrow \mathrm{GSSG}+\mathrm{ROH}+\mathrm{H}_{2} \mathrm{O} \\
2 \mathrm{H}_{2} \mathrm{O}_{2} \rightarrow \mathrm{O}_{2}+2 \mathrm{H}_{2} \mathrm{O}\end{array}$} \\
\hline $\begin{array}{lll}\text { 2.- } & \text { Antioxidantes } & \text { no } \\
\text { enzimáticos (captadores): } & \end{array}$ & $\begin{array}{c}\text { Glutatión } \\
\text { Vitamina E } \\
\text { Vitamina C } \\
\text { Vitamina Q } \\
\text { Carotenoides } \\
\text { Flavonoides } \\
\text { Fitoestrógenos }\end{array}$ & $\begin{array}{c}\text { Cofactores } \\
\text { Cobre } \\
\text { Zinc } \\
\text { Manganeso } \\
\text { Hierro } \\
\text { Selenio }\end{array}$ \\
\hline 3.- Preventivos & $\begin{array}{r}\text { Transf } \\
\text { Ferri } \\
\text { Cerulopl } \\
\text { Albúr } \\
\text { Bilirru } \\
\text { Metaloti } \\
\text { Ácido }\end{array}$ & \\
\hline
\end{tabular}

\subsubsection{Sistema antioxidante enzimático}

Los sistemas antioxidantes enzimáticos están formados por complejos proteínicos que a través de diferentes reacciones transforman las especies reactivas más dañinas en formas menos perjudiciales (Barbosa et al., 2008; Bashan et al., 2009). 


\subsubsection{Superóxido dismutasa (SOD)}

La SOD (EC 1.15.1.1) pertenece a una familia de metaloenzimas, conocida por acelerar la dismutación espontánea del radical anión superóxido $\left(\mathrm{O}_{2}{ }^{-{ }^{-}}\right)$hacia oxígeno y $\mathrm{H}_{2} \mathrm{O}_{2}$ (Valko et al., 2006). La SOD también puede actuar como una peroxidasa capaz de emplear el $\mathrm{H}_{2} \mathrm{O}_{2}$ como reductor para formar el radical $\mathrm{O}_{2}{ }^{--}$ (Demicheli et al., 2007; Strange et al., 2012; Liochev et al., 2010). Las SOD se encuentran ampliamente distribuidas en los organismos aeróbicos, jugando un papel importante en el control de los niveles del radical $\mathrm{O}_{2}{ }^{--}$, siendo la primera defensa contra estos radicales (Buettner, 2011; Valko et al., 2006; Main et al., 2012).

En mamíferos existen tres grandes familias de SOD indetificadas con base en los metales que contienen y/o por su localización celular. Dos son intracelulares, la superóxido dismutasa cobre/zinc (Cu/Zn-SOD) y la manganeso (Mn-SOD); la otra es extracelular (Ec-SOD) (Buettner et al., 2011; Valko et al., 2006). La CU/Zn-SOD (SOD1), presenta un peso molecular de $32 \mathrm{KDa}$, estando constituida por dos subunidades idénticas, con un átomo de Cu y otro de Zn cada una (Miller, 2012). El cobre es el que presenta mayor actividad catalítica, localizándose en el sitio activo de la enzima, mientras que el $\mathrm{Zn}$ desempeña una función básicamente estructural (Jomova et al., 2011). Esta familia se localiza principalmente a nivel citosólico. La Mn-SOD (SOD2) está constituida por cuatro subunidades idénticas, con un átomo de $\mathrm{N}$ por unidad y un peso molecular de $80 \mathrm{kDa}$; su localización es mitocondrial primordialmente (Miller, 2012). La Ec-SOD (SOD3) fue descubierta en 1982 por Stefan Marklund en tejido pulmonar, tratándose de un tetrámero de $135 \mathrm{KDa}$, que 
contiene un átomo de Cu por subunidad y se presenta con menos actividad que las intracelulares.

\subsubsection{Catalasa (CAT)}

La CAT (EC 1.11.1.6) es una enzima antioxidante que se encuentra prácticamente en todas las células de animales y plantas (Nazıroğlu, 2012). Se trata de una enzima intracelular ferriporfirínica, constituida por 4 subunidades, cada una con un grupo hemo enlazado en su centro activo y localizada principalmente en peroxisomas, mientras que en las mitocondrias y citosol la actividad es muy baja. Dentro de los peróxidos eliminados se encuentra el $\mathrm{H}_{2} \mathrm{O}_{2}$ y los hidroperóxidos de alquilo (metanol, etanol, ácido fórmico y fenoles) (Kodydková et al., 2014). La CAT presenta afinidad por el $\mathrm{H}_{2} \mathrm{O}_{2}$ baja y necesita altas concentraciones del mismo $\left(\mathrm{H}_{2} \mathrm{O}_{2}\right)$ para poder trabajar rápidamente (Hebert-Schuster et al., 2012), aunque se ha observado una rápida inactivación de la actividad de la catalasa a concentraciones de $\mathrm{H}_{2} \mathrm{O}_{2}$ superiores a $0.1 \mathrm{M}$ (Kodydková et al., 2014), igualmente se ha observado la inactivación de CAT por el radical $\mathrm{O}_{2}{ }^{--}$(Díaz et al., 2005).

\subsubsection{Glutatión Peroxidasa (GPx)}

La GPx (EC 1.11.1.9) está formada por cuatro subunidades idénticas y cada una de ellas contiene un residuo de selenio-cisteína que es esencial para su actividad enzimática. Comparte sustrato con la CAT, catalizando la reducción de diferentes hidroperóxidos $\left(\mathrm{ROOH}\right.$ y $\mathrm{H}_{2} \mathrm{O}_{2}$ ), usando glutatión reducido $(\mathrm{GSH})$ y dando lugar a la formación de glutatión disulfuro oxidado (GSSG) y un producto de 
reducción. EI GSSG, a su vez, es reducido a GSH por la glutatión reductasa (GR) en presencia de $\mathrm{NADPH}+\mathrm{H}^{+}$formando un ciclo redox, impidiendo que se agoten las reservas de GSH. En los organismos se encuentran dos grandes grupos, la glutatión peroxidasa-selenio dependiente y la selenio independiente (Brigelius-Flohé et al., 2013). La selenio dependiente es tetramérica, con contenido de selenio en enlaces covalentes selenio-cisteina en su centro activo. Son activas frente a hidroperóxidos orgánicos y $\mathrm{H}_{2} \mathrm{O}_{2}$, localizándose primordialmente en el citosol (70\%) y en menor cantidad en las mitocondrias $(30 \%)$, en la matriz mitocondrial y en lugares de contacto entre la membrana externa e interna mitocondrial (Brigelius-Flohé et al., 2013; Ribas et al., 2014). En mamíferos existen 4 formas de GPx:

- GPx-C o forma celular que es ubicua, tiene mayor afinidad por el $\mathrm{H}_{2} \mathrm{O}_{2}$ que por el lipoperóxido.

- GPx-P o forma extracelular, presenta afinidad semejante por ambos sustratos.

- GPx-Gl o gastrointestinal.

- GPx-PH o asociada a la membrana, tiene afinidad específica por lipoperoxidos.

Las formas GPx-C y GPx-P utilizan como sustratos los $\mathrm{H}_{2} \mathrm{O}_{2}$ y los L-OOH; $\sin$ embargo, no son capaces de utilizar los fosfolipoperóxidos (PHL-OOH) que son sustratos principales para la GPx-PH (Brigelius-Flohé et al., 2013; Ribas et al., 2014; Marí et al., 2009; Marí et al., 2013).

El segundo grupo lo forma la glutatión S-transferasa (GST), que no requiere selenio para su actividad catalítica, presentando en general una menor afinidad por el 
$\mathrm{H}_{2} \mathrm{O}_{2}$. La GST se localiza en citosol, mitocondrias y fracciones celulares que contengan membranas (Brigelius-Flohé et al., 2012; Aniya et al., 2011).

\subsubsection{Sistema antioxidante no enzimático}

Por otra parte, los antioxidantes de naturaleza no enzimática son considerados en dos grupos principales. Las sustancias de naturaleza endógena las cuales están constituidas principalmente por los compuestos con grupos tioles en su composición entre los que destaca el GSH, que al mantener su equilibrio con la forma oxidada (GSSG) mantiene el balance redox celular (Bashan et al., 2009).

EI GSH es una tiol tripéptido de bajo peso molecular con la fórmula Y-glu-cysgly. Esta molécula multifuncional es una parte importante de la defensa antioxidante contra el estrés oxidante y contribuye a la defensa y protección celular (Fotopoulos et al., 2010). La función como antioxidante deriva del hecho de que GSH participa en el ciclo ascorbato-glutatión como un agente reductor de dehidroascorbato (DHA) mientras que también posee la capacidad para proteger la integridad de la membrana plasmática por mantener el alfa-tocoferol y zeaxantina en un estado reducido. Asimismo, protege a las proteínas de la desnaturalizacion causada por la oxidación de los grupos tioles en las proteínas. Adicionalmente, el glutatión ejerce esta capacidad antioxidante a través de sensar y de actuar como el sustrato para la GPx y GST (Fotopoulos et al., 2010).

La oxidación enzimática de GSH se produce como un producto de la actividad de la GPx como se describe a continuación (Figura 13): 


$$
\mathrm{H}_{2} \mathrm{O}_{2}+\mathrm{GSH} \underset{\mathrm{GPx}}{\longrightarrow} 2 \mathrm{H}_{2} \mathrm{O}+\underset{\begin{array}{l}
\text { Glutatión } \\
\text { oxidado }
\end{array}}{G S S G}
$$

Figura 13. Oxidación enzimática de GSH.

El glutatión oxidado (GSSG) es posteriormente reducido por la glutatión reducatsa (GRd), que emplea la coenzima nicotinamida adenina dinucleótido fosfato reducido (NADPH), proveniente de la vía pentosa fosfato como dador de electrones, manteniendo así la proporción GSH/GSSG (Figura 14).

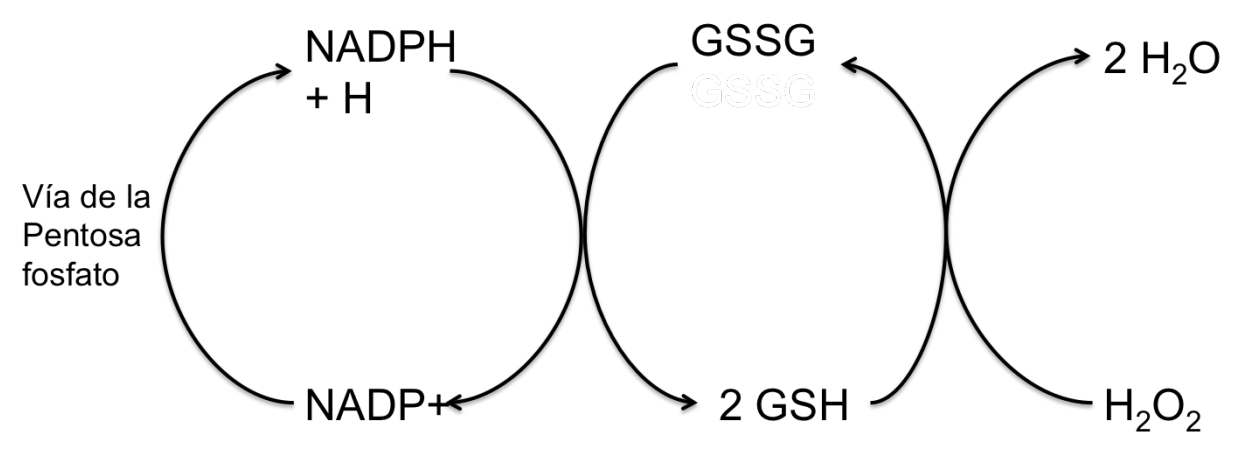

Figura 14. Reducción de GSSG.

La concentracion de GSH está incrementada bajo condiciones estresantes, y este incremento le permite a la célula contrarrestar la oxidación de glutatión, provocando alteraciones en la expresión de genes, directamente o a través de su interrelación con proteínas regulatorias y/o factores de transcripción (Fotopoulos et al., 2010). Esta elevación en la concentracion de GSH es de vital importancia porque induce la transducción de señales y la defensa contra ERO, las cuales son alcanzadas a traves de la vía con varios puntos de control, incluyendo la activación controlada de genes que codifican enzimas relacionadas con el metabolismo de glutatión (Fotopoulos et al., 2010). 
Las sustancias antioxidantes exógenas se pueden dividir en tres grandes grupos: las vitaminas antioxidantes (E, C y A), los minerales con capacidad antioxidante (selenio, zinc, cobre y manganeso) y los fitoquímicos (el ácido lipoico, el resveratrol, catequinas y otros compuestos fenólicos (Bashan et al., 2009).

Los antioxidantes no enzimáticos al interaccionar con un RL le ceden un electrón oxidándose a su vez y transformándose luego en un $R L$ débil no tóxico, debido a que interactúan más rápido con los $R L$ que con el resto de las moléculas presentes. La acción de los antioxidantes la ejercen en la membrana plasmática, el citosol, el núcleo o líquido extracelular, es decir, tanto en medios hidrofílicos como hidrofóbicos, alterando su propia integridad molecular. Los antioxidantes exógenos actúan como moléculas suicidas, por lo que su reposición debe ser continua a través de la ingesta de nutrientes que los contengan (Aruoma et al., 2006; Peng et al., 2014; Le-Lay et al., 2014; Fridovich, 2013).

\subsubsection{Otros sistemas antioxidantes}

\subsubsection{Metalotioneínas (MTs)}

Las metalotioneínas (MTs) son una familia de proteínas de bajo peso molecular (6-7 $\mathrm{kDa}$ ), ricas en cisteínas con alta afinidad por metales, las cuales tienen diversas funciones, dentro de las cuales destaca su papel fisiológico como regulador de la homeostasis de metales esenciales, tales como Cu y Zn. Las MTs tambien participan en la detoxificación de niveles excesivos de metales esenciales y no esenciales; y posiblemente realizan otras funciones, las cuales incluyen señalizaciones 
dependientes de zinc y del estado redox (Tabla 4) (Margoshes y Valle, 1957; Kang, 2006; Sato et al., 2010; Byun et al., 2011; Ogawa et al., 2011; Figueira et al., 2012; Haynes et al., 2012).

\begin{tabular}{l} 
Tabla 4. Carácterísticas de la molécula de MT \\
\hline 1.- Alto contenido de metales ( 7 átomos de Zn o Cd/molécula o 12 \\
átomos de Cu/molécula de proteína. \\
2.- Peso molecular bajo (aproximadamente 6800 Da en MT-I) \\
3.- Alto contenido de cisteínas ( 20 cisteínas sobre un total de 61 \\
aminoácidos), inexistencia de aminoácidos aromáticos, enlaces \\
disulfuro e histidina. \\
4.- Presencia de isoformas. \\
5.- Agrupaciones metalo-tíolatos (agrupación A y agrupación B). \\
6.- Afinidad por los metales. \\
7.-. Termoestable
\end{tabular}

Diversos investigadores han demostrado que frente a la toxicidad por metales pesados como cadmio $(\mathrm{Cd})$ y mercurio $(\mathrm{Hg})$, hay un incremento de la expresión de MTs ligado al incremento en la concentración de estos metales en los tejidos (Figueira et al., 2012).

Las MTs se localizan en diferentes compartimientos celulares y están involucradas en la translocación de zinc del citoplasma al núcleo durante la proliferación, o del espacio intermembranal de la mitocondria, donde podría modular la función de la respiración mitocondrial (Maret, 2008; Gonzalez et al., 2014). Estas proteínas también han sido localizadas en el espacio extracelular y son captadas por las células a través de una vía endocítica, en la que los metales pero no las 
proteínas, se traslocan al citoplasma (Maret, 2008). Existen cuatro isoformas de MTs (Mt1-4) en ratón. Mt1 y Mt2 se expresan de forma ubicua en la mayoría de los tejidos, mientras que Mt3 se expresa principalmente en el sistema nervioso central (SNC) y la Mt4 se expresa en el epitelio estratificado escamoso (Kang, 2006; Byun et al., 2011; Haynes et al., 2012; Chen et al., 2012).

Por otra parte, a través de las cisteínas presentes en su estructura, se ha demostrado la capacidad de las MTs como represores de un amplio rango de ERO y ERN con alta eficiencia, tal como lo hacen los antioxidantes antes descritos (Kang, 2006; Chen et al., 2012; Qu et al., 2013).

El papel de las MTs en la protección frente al estrés oxidante puede ser de varias formas (Figueira et al., 2012; Haynes et al., 2012; Chen et al., 2012)., distribuyendo el zinc (metal que participa en la modulación protectora frente a la peroxidación lipídica), manteniendo los niveles adecuados de MTs, como componente esencial de la SOD, previniendo la formación de RL causado por la interacción entre los grupos químicos con el hierro (reacciones de Fenton), estabilizando el DNA y reaccionando directamente con las ERO producidas por la mitocondria cuando la tasa metabólica y el empleo de los depósitos de grasa se incrementan (Figueira et al., 2012; Sato et al., 2010).

Diversos estudios reportan la capacidad de las MTs para secuestrar ERO tanto en organismos vertebrados como invertebrados, lo cual sugiere que podrían emplearse como sensores proteínicos frente al estrés oxidante, mecanismo que aún permanece sin dilucidarse. Adicionalmente también actúan como defensa frente a la inflamación (González et al., 2014). 
La participación del estrés oxidante en el desarrollo de la diabetes tipo 1 y 2 ha sido documentado. Se han descrito que las enzimas antioxidantes y nutrientes antioxidantes tienen un efecto protector contra la diabetes. Por ejemplo, las MTs son capaces de prevenir el estrés oxidante a través de su actividad como sensor de ERO. Se ha demostrado que polimorfismos de las isoformas MT1 y MT2 están asociados con la progresión de patologías tales como diabetes tipo 2, ateroesclerosis, inflamación y complicaciones cardiovasculares en pacientes obesos (Haynes et al., 2012). 


\section{ANTECEDENTES}

\subsection{RELACIÓN INFLAMACIÓN-ESTRÉS OXIDANTE - OBESIDAD}

Recientemente se está tratando de asociar la obesidad con el proceso de inflamación de bajo grado en el TA, sin embargo, los mecanismos fisiopatológicos aun no están esclarecidos. Otro de los aspectos fisiológicos y patológicos que ha sido motivo de estudio es referente a los adipocitos.

Como hemos mencionado, muchas líneas de investigación han demostrado que la activación crónica de las vías proinflamatorias en las células diana de insulina puede conducir a la obesidad relacionada con la resistencia a la insulina. De acuerdo con esto, se han observado niveles elevados de algunas citocinas proinflamatorias como TNF- $\alpha$, IL-6 y la PCR en individuos con RI y diabetes. Por otra parte, los niveles de TNF- $\alpha$ están elevados en el tejido adiposo y en sangre de roedores obesos (Cheung et al., 2012).

Los ácidos grasos, la microhipoxia en el TA, el estrés oxidante y ciertas citocinas pueden iniciar todas las respuestas proinflamatorias mediante activación de vías de señalización de JNK/proteína activadora 1 (AP1) e IKK /NFkB. La señalización de JNK e IKK está activada durante la RI humana y en el músculo esquelético de roedores. Esto es algo muy importante debido a que las serin-cinasas fosforilan al factor de transcripción AP1 (cJun/Fos) y NF-kB, el cual después se activa transcripcionalmente y modula una serie de genes inflamatorios, lo cual conduce al decremento en la sensibilidad a la insulina. Como consecuencia, la inhibición de JNK1 o IKKB previene la RI en cultivos celulares y en modelos de ratón, así como en modelos humanos (Schenk et al., 2008). 
Un iniciador importante de la respuesta inflamatoria es el TA, que secreta ácidos grasos y una gran variedad de polipéptidos, dentro de los que destacan hormonas, citocinas y quimiocinas que pueden funcionar tanto a nivel endócrino como parácrino. El TA consiste de una variedad de tipos celulares que incluyen a los adipocitos, las células inmunes (macrófagos y linfocitos), preadipocitos y células endoteliales, que producen citocinas y quimiocinas como MCP-1, IL-6, IL-1B, factor inhibidor de migración de macrófagos (MIF) y TNF-a. Los adipocitos son la única fuente de secreción de adipocinas tales como leptina y adiponectina, los cuales pueden promover la sensibilidad a insulina, tanto como la resistina y la proteína de unión a retinol 4 (RPB4), el cual puede afectar la sensibilidad a la insulina (Figura 15) (Schenk et al., 2008).

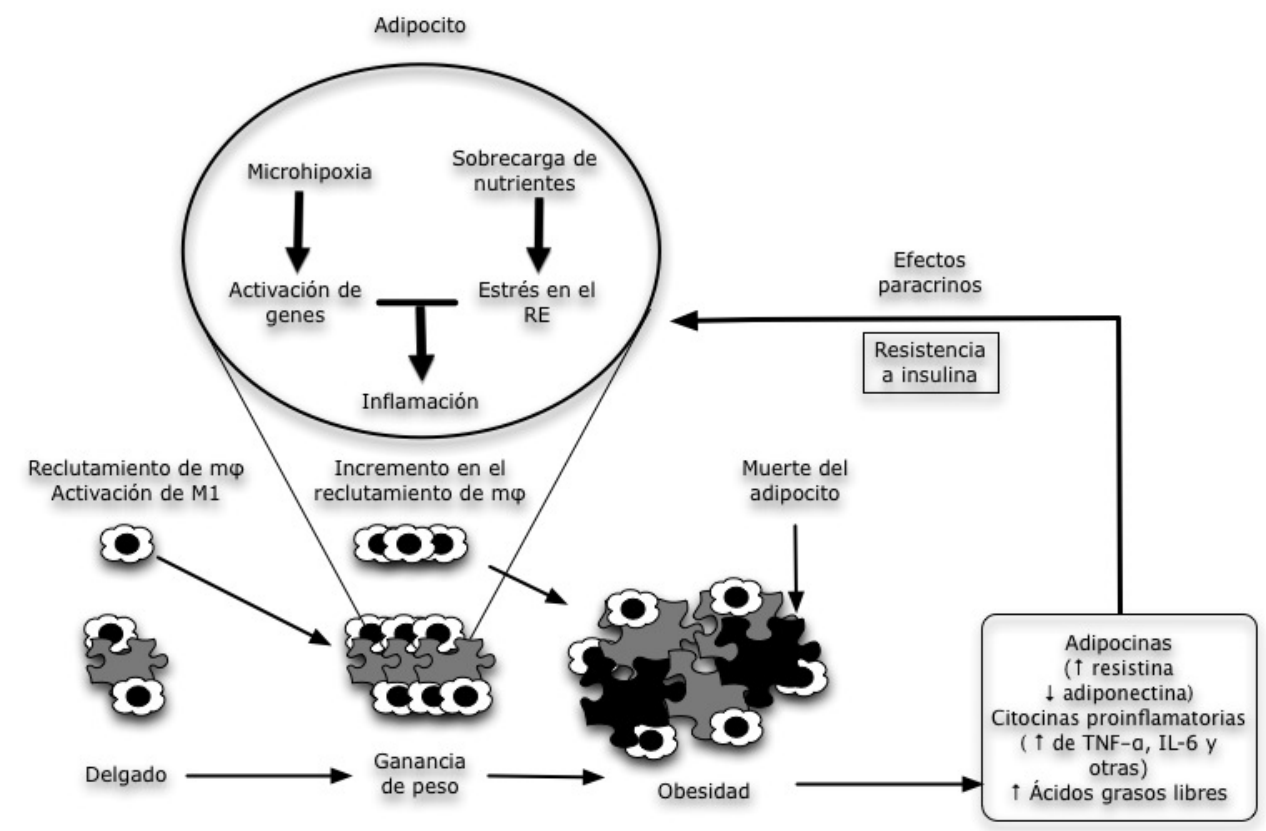

Figura 15. El tejido adiposo en el proceso inflamatorio. 
La mezcla de adipocinas secretada por el TA en un estado fisiopatológico puede tener efectos importantes sobre la sensibilidad a la insulina de manera sistémica y de forma particular sobre tejidos como el hepático (Figura 16) (Schenk et al., 2008).

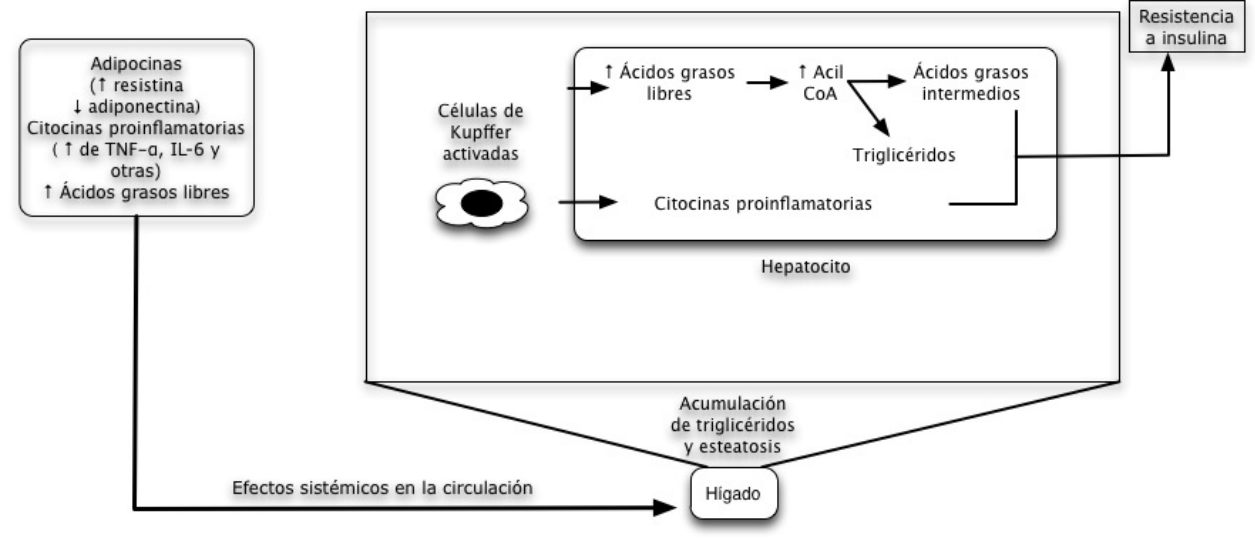

Figura 16. Mediadores de inflamación y su efecto sobre hígado.

Por otra parte, la obesidad en el humano se ha considerado como un estado de estrés oxidante crónico (Vincent et al., 2007; Barbosa et al., 2008; Verrotti et al., 2008). Diversas investigaciones reportan correlaciones positivas entre la baja ingesta de antioxidantes naturales y la obesidad (Valdecantos et al., 2009). Por ejemplo, se ha relacionado a la obesidad y el sobrepeso con bajos niveles plasmáticos de antioxidantes (Valdecantos et al., 2009). Asimismo se ha relacionado con una modificación en la actividad de las principales enzimas antioxidantes. Algunas investigaciones proponen que en el inicio del desarrollo de la obesidad tiene lugar un incremento en la actividad de la SOD, como un intento para combatir la formación de RL (Valdecantos et al., 2009; Halliwell, 2012). 
Existe evidencia que una vez establecida la obesidad se produce una disminución tanto de la actividad como de la expresión de ambas isoformas de SOD (Valdecantos et al., 2009; Brown et al., 2009). Referente a la actividad de CAT, Lazarevic demostró una disminución en la actividad de la CAT en una población con obesidad y diabetes tipo 2 (Lazarevic et al., 2006). Furukawa en 2004 estudió la actividad de SOD, GPx y CAT en modelos animales con obesidad (ratón KKAy), ratificando la disminución tanto de la actividad como de la expresión de estas enzimas en el tejido adiposo blanco.

\subsection{HORMESIS Y RESISTENCIA AL ESTRÉS}

La continua exposición al estrés ambiental y al estrés intrínseco resulta en la acumulación de daño en las macromoléculas (Brown et al., 2009). Un pequeño pero creciente grupo de estudios menciona el papel de la hormesis en el aumento de la longevidad. La hormesis es el fenómeno por el cual la respuesta adaptativa a bajas dosis de agentes tales como calor, radiación o sustancias químicas, entendidos como pequeños estresores, permite en los organismos que se manifieste la capacidad de sobrellevarlo (Calabrese, 2008; Calabrese et al., 2010), pudiendo llegar a la adaptación y sobrevivencia. La habilidad para lidiar con esos estresores incrementa la resistencia a la enfermedad con aumento en la longevidad, lo que es entonces una respuesta benéfica. Agentes con efectos horméticos favorecen la expresión de genes que promueven mecanismos de defensa para proteger a las células del daño; lo anterior se puede entender cómo resistencia al estrés. Hay muchos ejemplos de este fenómeno, incluida la restricción calórica, que puede 
reflejar una respuesta fisiológica de sobrevivencia que se ha conservado entre las especies a lo largo de la evolución (Pickering et al., 2012).

Los efectos benéficos de un estrés no severo $u$ hormético sobre el envejecimiento y la longevidad se han estudiado por algunos años. Ese estrés parece que incrementa ligeramente la longevidad, y retrasa el envejecimiento, aunque hay que mencionar que no todos los estresores tienen tales efectos benéficos (Le Bourg, 2009).

Por más de un siglo, los estudios toxicológicos han demostrado que bajas dosis de sustancias tóxicas pueden tener efectos estimulantes sobre el crecimiento de plantas, bacterias y hongos. Esos efectos estimulantes pueden ser explicados como una respuesta directa al estímulo, o a una respuesta de sobrecompensación después de la exposición a un agente tóxico que altera la homeostasis. Sin embargo, esos estímulos de bajas dosis, o de efectos horméticos, no están restringidos solamente a los estudios toxicológicos. Por lo tanto, la hormesis podría verse como un proceso reparativo que se ha adaptado en la naturaleza y que está altamente conservada vía selección natural.

La inducción de dosis bajas y la subsecuente respuesta de adaptación típicamente condicionan el sistema biológico adaptado, lo que le lleva a tener una mayor resistencia cuando posteriormente es sometido a un mayor estrés. Muchos experimentos sobre envejecimiento y longevidad se han realizado con especies de invertebrados, principalmente con D. Melanogaster, C. elegans (Murakami, 2006), en roedores y humanos (Le Bourg, 2009). La teoría de la resistencia al estrés que también abarca las fuentes de estrés intrínseco y extrínseco (ambiental), se basa en 
la hipótesis de que el incremento a la resistencia al estrés en los organismos lleva a la sobrevivencia del organismo (Brown et al., 2009; Le Bourg, 2009).

El envejecimiento podría ser considerado un proceso dinámico que lleva a la adaptación continua del cuerpo tras la exposición a estresores ambientales dañinos a lo largo de la vida. Esos estresores incluyen agentes de daño producidos por el organismo como consecuencia del metabolismo como las ERO, aquellos derivados de agentes físicos (radiación, etc.) y biológicos (bacterias, virus, etc.). El organismo tiene que neutralizar los efectos negativos de tales estresores con un panel de mecanismos antiestrés. Los estresores actúan a diferentes niveles: molecular, celular, sistémico, orgánico. Todas esas respuestas integradas dependerán del tipo de estresor y el tiempo de exposición.

Durante la evolución, un proceso de selección positiva tuvo que haber ocurrido para maximizar la eficiencia de esos mecanismos de defensa debido a que eran críticos para mantener un estado saludable que maximizara la capacidad reproductiva. Esta es la razón principal de por qué desde un punto de vista evolutivo se puede asumir que los mecanismos biológicos fundamentales juegan un papel principal en el proceso del envejecimiento y que son altamente conservados a través de la evolución.

Podemos especular que la plasticidad y maleabilidad inesperada del proceso del envejecimiento y longevidad tienen una fuerte base evolutiva, que es un prerrequisito para la adaptación a los cambios ecológicos, para finalmente tener también un equilibrio ecológico entre las especies. Los mecanismos homeostásicos que disminuyen los efectos del estrés progresivamente se deterioran con la edad. El 
deterioro ocurre sobre una amplia variedad de funciones como la disminución de la capacidad celular a expresar proteínas de choque térmico, presentándose de esta manera una capacidad reducida para reaccionar a nuevos estresores internos y externos, sin poderse adaptar a los nuevos ambientes (Minois, 2000).

Sin embargo, un importante componente de la resistencia al estrés es elevar la homeostasis fisiológica. Sobrevivir en el envejecimiento está asociado con una homeostasis elevada y vitalidad por genes de resistencia al estrés (Parsons, 2007). En algunos estudios que han utilizado dosis moderadas de estrés se ha visto que ha aumentado la longevidad, sin embargo aún no han podido explicarse por qué también se retrasa el envejecimiento (Le Bourg, 2009).

Basado en esa hipótesis del envejecimiento, las capacidades de defensa antioxidante han sido los primeros candidatos a ser evaluados para el estudio en la adaptación y sobrevivencia de algunos animales. Se han estudiado en células y tejidos los procesos de enzimas como CAT, SOD y GPx; así como los mecanismos no enzimáticos como glutatión GSH, ácido ascórbico y sistemas de MTs. Se han realizado estudios in vivo e in vitro para examinar la resistencia tanto a los estresores oxidantes como a los no oxidantes (Brown-Borg, 2006).

\subsection{RESISTENCIA AL ESTRÉS Y LONGEVIDAD}

Se ha reportado recientemente una relación positiva entre la resistencia al estrés y el aumento en el tiempo de vida de un organismo (Avogaro et al., 2010). El envejecimiento es un proceso regulado por mecanismos de señalización altamente conservados que incluyen insulina/IGF-1, TOR, vía de AMPK (proteín cinasa 
activada por AMP) y sirtuinas. Es importante el estudio de la regulación coordinada de esas vías de señalización de respuesta al estrés que intervienen en sensar nutrientes (Sengupta et al., 2010), en la función mitocondrial, el metabolismo redox (Wellen et al, 2010), la respuesta al daño al ADN (Ciccia et al., 2010), la proteostasis (Buchberger et al., 2010) y la autofagia (Kroemer et al., 2010).

Existe evidencia de una relación directa y del potencial que existe entre las vías de señalización GH/IGF-1/insulina y la resistencia al estrés. La señalización reducida en la vía GH/IGF-1/insulina en ratón (y otras especies) lleva a un aumento significativo en la longevidad. Se cree que disminuir este sistema hormonal pudiera entonces actuar como mediador hormético que lleve al aumento de la resistencia al estrés con un aumento en la longevidad (Brown-Borg, 2006).

Descubrimientos recientes sugieren que la señalización de la respuesta al estrés puede ser manipulada para extender la vida y retardar la patología asociada al envejecimiento, sugiriendo un nuevo acercamiento para tratar desórdenes degenerativos en el envejecimiento de humanos (Haigis et al., 2010). Mutaciones en las vías de señalización incluida insulina/IGF-1, el blanco de rapamicina (mTOR), AMP cinasa y las sirtuinas parecen mandar instrucciones para disminuir el metabolismo lo que pudiera reducir daños en las proteínas, lípidos y ácidos nucleicos.

En este sentido la señalización reducida de insulina/IGF-1 tiene un efecto similar a la restricción calórica. La secreción reducida de insulina/IGF-1 o la RI como resultado de la alteración en la vía de señalización lleva a la obesidad y a la diabetes, sin embargo los modelos que existen con esta falla presentan un incremento en la 
esperanza de vida, como lo muestran los ratones que tienen longevidad extendida (Snell y Ames). El aumento en la longevidad de estos modelos puede ser del 20 al $50 \%$, dependiendo de su alimentación y fondo genético.

El nivel más bajo de GH y de IGF-1 es característico de modelos de ratones de larga vida con mutaciones de los componentes del eje regulador $\mathrm{GH} / \mathrm{IGF}-1$, lo que es causa del retraso de la pubertad, alteración en la función reproductiva y cambios en los "ritmos biológicos" con retraso en el envejecimiento. Otros factores de longevidad en estos ratones son: disminución en los niveles de insulina y de sensibilización de los tejidos a la hormona, reducción del metabolismo oxidante, un incremento en la resistencia al estrés, un tamaño del cuerpo más pequeño y relativamente bajo peso (Chistyakova, 2008). Los genes que codifican componentes de esta vía son fuertes candidatos para longevidad en humanos y en otros modelos animales.

En modelos animales como el ratón, la disminución en la expresión de la vía (GH/IGF-1/insulina) se asocia con aumento en la longevidad mientras que niveles elevados de IGF-1 están asociados con una longevidad corta (Dozmorov et al., 2001). La insulina es una molécula clave implicada en el envejecimiento y se conoce que está involucrada en el aumento del tiempo de vida comprobado en modelos mutantes (Kenyon, 2005). La principal función de la insulina es la regulación en la homeostasis de la glucosa, pero también regula indirectamente la homeostasis de los lípidos y proteínas. 


\subsection{MODELO DE OBESIDAD: RATÓN NEUROINTOXICADO POR GLUTAMATO MONOSÓDICO (GMS)}

La neurointoxicación con GMS en el ratón neonato, produce lesiones hipotalámicas que incluyen necrosis del núcleo arcuato, lo cual conduce a varias alteraciones neuroendocrinológicas que incluyen inadecuada señalización de insulina y leptina, entre otros efectos, ya que núcleo arcuato es una estructura del sistema

nervioso central relacionado con la ingesta de alimentos (Takasaki, 1978). Los animales obesos GMS son hipófagicos y tienen características físicas típicas, tales como un retardo en el crecimiento que llega a ser evidente a las 8 semanas de edad (Andreazzi et al., 2009; Yamamoto et al., 1993; Collison et al., 2012).

Cuando existe daño en el núcleo arcuato se observa una secreción disminuida de la hormona liberadora de la hormona de crecimiento (GHRH), lo que pudiera explicar las alteraciones en el desarrollo gonadal y la disminución en la talla. Aunque son hipofágicos, los ratones GMS terminan desarrollando obesidad (Olney, 1969). E ratón GMS es un modelo caracterizado por obesidad central y resistencia a la insulina (Nagata et al., 2006).

De manera interesante el ratón GMS exhibe remarcadamente acumulación de lípidos en el hígado, por lo que es usado para estudios de obesidad y de la enfermedad de hígado graso no alcohólico (NAFLD). El ratón neonato que es neurointoxicado con GMS desarrolla durante la edad adulta obesidad severa, intolerancia a la glucosa y SM (Nagata et al., 2006), el cual posee una etiología compleja y multifactorial. 
Las características que siempre están presentes en el SM son la RI, diabetes, bajos niveles de lipoproteínas de alta densidad, altos niveles de TG, inflamación y estrés oxidante general (Segura et al., 2009). Se sabe que la hiperinsulinemia y las enfermedades metabólicas están asociadas con reducción en el tiempo de vida del organismo, ya que promueve la formación de ERO, favorece el estado proinflamatorio y regula otras señalizaciones como la vía de la fosfatidilinositol 3 cinasa (PI3K), crucial en aspectos de crecimiento y supervivencia celular. La disminución de la sirtuina desacetilasa dependiente de NAD (Sirt) 1 puede mediar el acortamiento de la esperanza de vida en condiciones de RI (Avogaro et al., 2010). 


\section{JUSTIFICACIÓN}

Por observaciones en el laboratorio de Farmacología de la UAM Iztapalapa, y mencionado en la tesis doctoral de Campos Sepúlveda (2003) se observó que los ratones obesos GMS vivían más tiempo a pesar de la serie de alteraciones que presentaban por ser resistentes a la insulina; aparentemente se encontraban en mejores condiciones físicas que los ratones del grupo control; es decir, con un fenotipo menos envejecido. Por los resultados anteriores encontrados en el laboratorio de Farmacología (UAM-I) se ha empezado a hacer colaboración con el laboratorio de Bioenergética y Envejecimiento Celular (UAM-I) para investigar si este aumento en el tiempo de vida de los ratones obesos GMS podría deberse a que el estrés crónico oxidante que presentan por su condición, tuviera un efecto de resistencia al estrés, permitiéndoles vivir más y en mejores condiciones fisiológicas que los ratones control.

Por otro lado, la obesidad se ha convertido en un importante problema de salud que no solamente se ve en la edad adulta, sino también en la niñez. Presentar la condición de obesidad desde edad temprana puede generar alteraciones metabólicas que conduzcan al síndrome metabólico y a diabetes tipo II. A pesar del gran problema que lo anterior representa, no existen estudios que muestren qué cambios existen en el proceso de obesidad-envejecimiento. 


\section{PREGUNTA DE INVESTIGACIÓN}

¿Cuál es el papel de la inflamación crónica de bajo grado en un organismo obeso que le permita adaptarse y sobrevivir durante el envejecimiento?

\section{HIPÓTESIS}

Los ratones obesos GMS con RI e inflamación crónica de bajo grado presentan cambios que les permiten adaptarse y sobrevivir a pesar del deterioro durante el envejecimiento. 


\section{OBJETIVOS}

\subsection{OBJETIVO GENERAL}

Determinar el impacto de la inflamación crónica de bajo grado, en un modelo de obesidad inducido con la administración de GMS, sobre los parámetros metabólicos, el proceso inflamatorio y el estado redox a lo largo de la vida.

\subsection{OBJETIVOS PARTICULARES}

1. Relacionar la aparición de las alteraciones metabólicas debidas a la obesidad con aquellas relacionadas con el envejecimiento de ratones GMS.

2. Determinar el comportamiento de la obesidad y el perfil inflamatorio a lo largo de la vida de los ratones GMS.

3. Determinar la relación entre la obesidad y los parámetros de estrés oxidante en los ratones GMS a lo largo de su vida. 


\section{MATERIAL Y MÉTODOS}

\subsection{REACTIVOS QUÍMICOS}

Todos los químicos y reactivos fueron comprados en Sigma Chemical Co. (St. Louis, MO, USA). Los reactivos obtenidos de otras fuentes están detallados a través del texto.

\subsection{ANIMALES}

Se emplearon ratones adultos hembra y macho de la cepa CD-1 (25-30 g), los cuales fueron apareados en una proporción 2:1 para la obtención de ratones neonatos. Los ratones se mantuvieron bajo ciclos de luz/obscuridad de 12 horas, el acceso al alimento (Harlan Laboratories) y agua fue ad libitum. Los ratones fueron obtenidos del bioterio de la Universidad Autónoma Metropolitana Unidad Iztapalapa (UAM-I) y manipulados de acuerdo a los estándares éticos internacionales y nacionales: la Guía Internacional para el cuidado y manejo de animales de laboratorio NRC 2002, y la Norma Oficial Mexicana (NOM-062-ZOO-1999, revised 2001).

\subsection{INDUCCIÓN DE OBESIDAD CON GMS}

La obesidad fue inducida en los ratones por neurointoxicación neonatal con GMS (Campos et al., 2002; Andreazzi et al., 2009). En el día uno y previo a la neurointoxicación, los ratones neonatos fueron separados al azar en dos grupos: 
1) Grupo GMS.

2) Grupo control.

El grupo 1 (GMS) recibió una inyección subcutánea de 2 mg de GMS (Sigma Chemical) por gramo de peso corporal en los días postnatales 2 y 4 , así como $4 \mathrm{mg} / \mathrm{g}$ en los días postnatales 6,8 y 10. El GMS se disolvió en $0.01 \mathrm{~mL}$ de solución salina. El grupo 2 recibió el mismo patrón de administración con un volumen equivalente de solución salina isotónica (SSI).

Los ratones fueron separados después del destete por sexo y se colocaron cinco ratones por caja, formando los siguientes grupos:

- Grupo I. Ratones control sano (machos).

- Grupo II. Ratones tratados con GMS (machos).

- Grupo III. Ratones Control sano (hembras).

- Grupo IV. Ratones tratados con GMS (hembras).

Cada grupo de ratones fue analizado a los 4, 8, 12, 16 y 20 meses de edad, y fueron alimentados con una dieta comercial (Harlan 2018S, Harlan Teklad, Madison, WI, USA). 


\subsection{VALORACIONES EN ANIMALES}

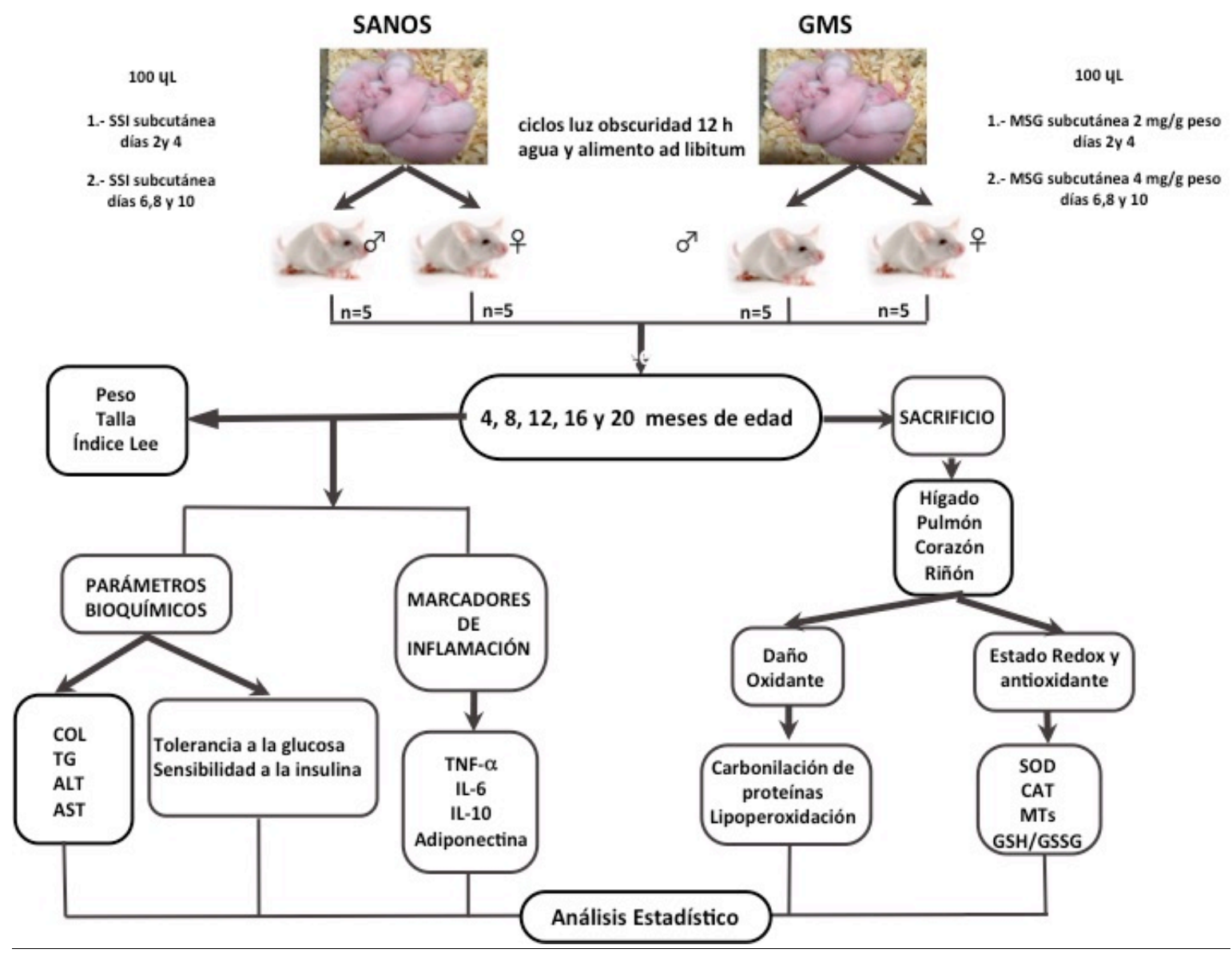

Figura 17. Diseño experimental. Metodología empleada para la evaluación de parámetros bioquímicos, inflamatorios y de estrés oxidante en ratones obesos GMS a lo largo del tiempo.

\subsubsection{Medición del peso y la talla corporal}

Durante los tiempos establecidos para la valoracion en los ratones, se midió la longitud desde la punta de la nariz hasta el ano con ayuda de calipers en ratones anestesiados y el peso corporal fue determinado usando una balanza electrónica sensible, empleando 5 ratones por grupo. 


\subsubsection{Cuantificación del Î́ndice Lee (IL)}

El índice Lee fue empleado como un predictor de obesidad y fue calculado mediante la siguiente fórmula (Campos et al., 2008):

$$
\text { Índice de Lee }=\sqrt[3]{\frac{\text { peso corporal }(\mathrm{g}) \times 10}{\text { longitud naso-anal }(\mathrm{cm})}}
$$

\subsection{PRUEBA DE TOLERANCIA A LA GLUCOSA ORAL (PTGO)}

La PTGO se realizó a los 4, 8, 12, 16 y 20 meses de edad, mediante administración oral de $2 \mathrm{~g} / \mathrm{kg}$ de peso de dextrosa posterior a un ayuno de $8 \mathrm{~h}$. Se tomaron muestras de sangre de la vena de la cola de los ratones anestesiados para determinar los niveles de glucosa al tiempo 0 y posterior a la administración en intervalos de $30 \mathrm{~min}$ por $150 \mathrm{~min}$. Los niveles glucémicos se determinaron con el método de oxidación de glucosa catalizado por la glucosa deshidrogenasa (Roche Diagnostics, Mannheim, Germany), utilizando un sensor de glucosa Accu-Chek Sensor Comfort Glucose (Alarcón et al., 2008).

\subsection{PRUEBA DE TOLERANCIA A INSULINA (PTI)}

La PTI fue realizada a los 4, 8, 12, 16 y 20 meses de edad. Los animales se mantuvieron en ayuno durante la noche previa al ensayo; posteriormente se evaluó el nivel basal de glucosa, seguida de una administración intraperitoneal con insulina (0.75 IU/kg peso corporal). Se recolectaron muestras de sangre $(20 \mu \mathrm{L})$ de la vena de 
la cola. Las mediciones de la prueba fueron establecidas a los $0,15,30,45$ y 60 min, y los niveles de glucosa fueron medidos en la misma forma que en la prueba de tolerancia a la glucosa descrita previamente (Alarcón et al., 2008; Mori et al., 2008).

\subsection{PREPARACIÓN DE MUESTRAS SÉRICAS}

Los ratones fueron sacrificados a los $4,8,12,16$ y 20 meses de edad. Se recolectó sangre total y las muestras se colocaron a temperatura ambiente por una hora y posteriormente se centrifugaron a $2000 \times g$ por $15 \mathrm{~min}$. Las muestras obtenidas posteriormente fueron almacenadas a $-70^{\circ} \mathrm{C}$ hasta el día de los ensayos. El suero fue usado para la medición de los parámetros bioquímicos e inflamatorios.

\subsection{PARÁMETROS BIOQUÍMICOS}

Se determinaron niveles séricos de alanin-aminotransferasa (ALT) y aspartatoaminotransferasa (AST), triglicéridos y colesterol total mediante un método espectrofotométrico empleando el equipo Reflotron System (Roche Diagnostics, Indianápolis, IN, USA) (Alarcón et al., 2008).

\subsection{ENSAYO POR INMUNOABSORCIÓN LIGADO A ENZIMAS (ELISA)}

Las citocinas IL-6, TNF- $\alpha$ (Thermo Fisher Scientific, Rockford, IL, USA), IL-10 (Abcam, Cambridge, UK) y adiponectina (Invitrogen of life technologies Corporation, Frederick, MD, USA) fueron evaluadas en suero, previamente almacenado a $-70^{\circ} \mathrm{C}$, mediante la técnica de ELISA. La densidad óptica se determinó fotométricamente a $450 \mathrm{~nm}$ con un lector de ELISA (Alarcón et al., 2008). 


\subsection{OBTENCIÓN Y CONSERVACIÓN DE ÓRGANOS}

Se obtuvieron los órganos de los ratones sanos control y de los ratones obesos GMS después de eutanasia por dislocación cervical en diferentes tiempos: 4, 8, 12, 16 y 20 meses de edad. De los ratones se obtuvo hígado, pulmón, riñón y corazón. La mitad de cada órgano se colocó en una solución fría de buffer PBS 50 $\mathrm{mM}$ a pH 7.4, y la otra mitad se colocó en solución de RNA later. Se mantuvieron los tejidos a $-70^{\circ} \mathrm{C}$.

\subsubsection{Extracción de la proteína total}

La extracción de la proteína total se realizó de acuerdo con el método descrito por Laemmli (1970), empleando $300 \mu \mathrm{L}$ de solución de lisado $(10 \mathrm{~mL}$ de TissueProtein Extraction Reagent, Pierce, Rockford, IL), una pastilla de inhibidor de proteasas (Complete, Roche, Indianápolis, IN), $100 \mu \mathrm{L} 0.1 \mathrm{M}$ de PMSF y $100 \mu \mathrm{L} 1 \mathrm{M}$ de DTT. Posteriormente, se incubó en hielo durante $15 \mathrm{~min}$. Los homogenados se centrifugaron a $20,000 \times$ g por 15 min a $4^{\circ} \mathrm{C}$. EL sobrenadante conteniendo la proteína total fue almacenado en pequeñas alicuotas y almacenados a $-70^{\circ} \mathrm{C}$ para posteriormente determinar su concentración.

\subsubsection{Contenido de proteína por el método de Bradford}

El contenido de proteína en las muestras se realizó por el método de Bradford (1976). Se realizó una curva patrón con albúmina sérica bovina (BSA) (Sigma) en un rango de $0-25 \mu \mathrm{g} / \mu \mathrm{L}$. Se tomó una alícuota de $1 \mu \mathrm{L}$ de la proteína extraída y se le 
adicionaron $200 \mu \mathrm{L}$ del reactivo de Bradford (BIO RAD). Se mezcló y se incubó durante $5 \mathrm{~min}$ a $25^{\circ} \mathrm{C}$. La absorbancia fue medida a $595 \mathrm{~nm}$ y se determinó la concentración de la proteína con ayuda de la curva patrón.

\subsection{DAÑO OXIDANTE}

\subsubsection{Niveles de malondialdehído (MDA)}

El grado de lipoperoxidación se determinó por el método de Buege y Aust (1978), el cual se basa en la formación de MDA en presencia de ácido tiobarbitúrico (TBA). El tejido se homogenizó en $1 \mathrm{~mL}$ de PBS. De este lisado se tomó $0.1 \mathrm{~mL}$ para determinar la concentración de proteína por el método de Bradford y a los $0.9 \mathrm{ml}$ restantes se les adicionaron $2 \mathrm{~mL}$ de una solución reactiva formada por ácido tricloroacético (TCA) al 15\%, TBA al $0.5 \%$ y ácido clorhídrico $(\mathrm{HCl}) 0.25 \mathrm{~N}$. Las muestras se agitaron vigorosamente y se incubaron en baño maría a $100^{\circ} \mathrm{C}$ durante 40 min. Se dejaron enfriar y se centrifugaron a $1500 x g$ por 10 min. La absorbancia del sobrenadante se leyó a $535 \mathrm{~nm}$. La concentración de MDA se determinó mediante la siguiente relación:

$$
C=A / \varepsilon I
$$

Donde $\mathrm{C}$ es la concentración de MDA, A es la absorbancia, $\varepsilon$ es el coeficiente de extinción molar $(1.56 \times 105 / \mathrm{cmM})$ e I es el grosor de la celda. Los resultados se expresaron en nmol de MDA por mg de proteína. 


\subsubsection{Carbonilación de proteínas}

Se extrajo la proteína total y se determinó el contenido proteínico por Bradford (1976). El ensayo de OxyBlot fue empleado como método para evaluar el daño oxidante de las proteínas totales del tejido. Se realizó de acuerdo con el método descrito por Laemmli (1970), el cual se basa en la identificación de la proteína oxidada citoplásmica por medio de la unión específica con el anticuerpo primario y el reconocimiento de este anticuerpo por un segundo anticuerpo para mostrar que se encuentra presente.

Se tomaron $10 \mu \mathrm{g}$ de la proteína total, la cual fue derivatizada con dinitrofenil hidrazina, siguiendo el protocolo del kit OxyBlot (Chemicon Internacional, Temecula, CA), un kit comercial el cual determina proteínas oxidadas. Las muestras fueron colocadas en un gel de separación al 12\% (3.35 mL de agua destilada, $2.5 \mathrm{~mL}$ de Tris 1-5 $\mathrm{M} \mathrm{pH} 8.8,100 \mathrm{~mL}$ de dodecilsulfato de sodio (SDS) al $10 \%, 4 \mathrm{~mL}$ de acrilamida/bis $30 \%, 50 \mu \mathrm{L}$ de persulfato de amonio (PSA) $10 \%, 5 \mu \mathrm{L}$ de $\mathrm{N}, \mathrm{N}^{\prime} \mathrm{N}^{\prime}, \mathrm{N}^{\prime}$ tetrametiletilendiamina (TEMED) y $10 \mathrm{~mL}$ de gel concentrador al $4 \%(6.1 \mathrm{~mL}$ de agua destilada, $2.5 \mathrm{~mL}$ de Tris $0.5 \mathrm{M} \mathrm{pH} 6.8,100 \mathrm{~mL}$ de SDS $10 \%, 1.3 \mathrm{~mL}$ de bisacrilamida al 30\%, $50 \mu \mathrm{L}$ de persulfato de amonio al 10\% (PSA), $10 \mu \mathrm{L}$ de TEMED). Posteriormente las muestras se dejaron correr en una cámara de electroforesis vertical (mini-Protean II, BIO-RAD) con un amortiguador de corrida $\mathrm{pH}$ 8.3, formado por Tris-Base $0.25 \mathrm{M}$, glicina $1.92 \mathrm{M}$ y SDS $1 \%$ durante 90 minutos a 120 Volts y $25^{\circ} \mathrm{C}$. Las proteínas fueron transferidas a una membrana de polifluoruro de vinilideno (PVDF) (HEALTHCARE, USA), usando un amortiguador de transferencia pH 8.3 frío 
(Tris-Base 25 mM, glicina 192 mM, SDS al 0.05\%, metanol al 20\% y TWEEN 20 1X), durante 120 min a 120 Volts a $4^{\circ} \mathrm{C}$.

Después de la transferencia, la membrana fue bloqueada con una solución de leche descremada al 8\% en amortiguador TBS-Tween 20 pH $7.5(\mathrm{NaCl} 150$ mM, Tris$\mathrm{HCl} 20 \mathrm{mM}$ y Tween 20 al $0.1 \%$ ), por $30 \mathrm{~min}$, dos veces. La membrana fue lavada con TBS-Tween 20 varias veces y se le adicionó el anticuerpo primario que reconoce a la proteína derivatizada 1:500 (Kit OxyBlot) por 90 min y con agitación lenta. La membrana posteriormente y por duplicado se lavó con TBS-Tween 20 durante 10 min. Después de dos lavados con TBS-Tween 20 se agregó el anticuerpo secundario acoplado a la peroxidasa de rábano (kit OxyBlot) 1:10000 por 90 min. La membrana fue lavada con TBS-Tween 20 durante $10 \mathrm{~min}$, por triplicado y $5 \mathrm{~min}$ con TBS. Finalmente la membrana fue tratada con SuperSignal ${ }^{\circledR}$ West Pico Substrate (Pierce, Rockford, IL) durante 2 min. La identificación de las proteínas oxidadas fue visualizado en un fotodocumentador GEL LOGIC 1500, Molecular Imaging System (CARESTREAM HEALTH, INC.) para observar la luminiscencia generada en la reacción de la peroxidasa y fue analizado con ayuda del software KODAK Molecular Imaging.

\subsection{PARÁMETROS DE ESTADO REDOX, CAPACIDAD ANTIOXIDANTE Y DE REPARACIÓN}

\subsubsection{Estado redox}

La relación de glutatión reducido y oxidado (GSH/GSSG) en sangre total fue determinada mediante espectrofotometría con ayuda de un kit comercial 
(Calbiochem, catalogo no. 371757). Las muestras sanguíneas fueron homogenizadas en un buffer Tris- $\mathrm{HCl} 50 \mathrm{mM}$, el cual contenía EDTA $5 \mathrm{mM}$ y DTT 1 $\mathrm{mM}, \mathrm{pH}$ 7.5, mantenidas durante todo el ensayo en hielo, obteniendo los sobrenadantes. El agente atrapador de tioles 1-metil-2-vinil-piridio trifluorometano sulfonato (M2VP) fue agregado a las muestras de GSSG para remover el GSH, previo a la adición del buffer y la producción del sobrenadante final. La relación GSH/GSSH fue medida usando un metodo enzimático desarrollado por Tietze (Tietze, 1969]). El metódo emplea el reactivo de Ellman 5,5'-ditiobis-2-ácido nitrobenzoico (DNTB), el cual reacciona con el GSH para formar un color que es detectado a $412 \mathrm{~nm}$, por tres min a intervalos de $15 \mathrm{seg}$, tanto para GSH como para GSSG y de esta forma calcular el cociente GSH/GSSG.

\subsubsection{Ensayo de actividad de superóxido dismutasa Cu/Zn (Cu/Zn-SOD)}

La actividad de la SOD fue determinada por el método de Winterbourn et al., (1975), el cual se basa en la habilidad de la SOD para inhibir la reducción del nitroazul de tetrazolio (NBT) por superóxido, el cual es generado por la reacción de fotoreducción de la riboflavina y el oxígeno. En una serie de tubos se preparó la mezcla de reacción formada por 0.1 a $10 \mu \mathrm{g}$ de enzima (fracción citosólica), $0.2 \mathrm{~mL}$ de ácido etildiaminotetracético (EDTA) $0.1 \mathrm{M}$, cianuro de sodio $0.3 \mathrm{mM}, 0.1 \mathrm{~mL}$ de NBT $1.5 \mathrm{mM}$ y buffer de fosfatos $0.067 \mathrm{M}$ a pH 7.8 en un volumen final de $3 \mathrm{~mL}$. Los tubos se colocaron en una caja conteniendo una lámpara fluorescente de $40 \mathrm{~W}$ por un período de 5 a $8 \mathrm{~min}$. Pasado ese tiempo se le agregaron $0.05 \mathrm{ml}$ de riboflavina 
$0.12 \mathrm{mM}$ y se incubaron en la misma caja por $12 \mathrm{~min}$; las muestras se leyeron a 560 nm. Se determinó el porcentaje de inhibición de la reducción NBT para determinar los $\mu \mathrm{g}$ de enzima que corresponde a la mitad de la máxima inhibición. La actividad de la enzima fue determinada por la siguiente relación:

Unidades X mg de proteina $=\frac{1000}{\mu g \text { enzima resultado de la } 1 / 2 \text { de la máxima inhibición }}$

\subsubsection{Actividad de CAT}

La actividad de CAT fue determinada por el método de Berrs y Sizer (1952), el cual se basa en la desaparición del $\mathrm{H}_{2} \mathrm{O}_{2}$ utilizado por la CAT. Se tomó $0.1 \mathrm{ml}$ de la fracción citosólica, se le adicionó $1.9 \mathrm{ml}$ de $\mathrm{H}_{2} \mathrm{O}$ desionizada, $1 \mathrm{ml}$ de $\mathrm{H}_{2} \mathrm{O}_{2} 0.059 \mathrm{M}$ en 0.0.05 M de buffer de fosfatos $\mathrm{pH}$ 7. Las muestras fueron leídas a una longitud de $240 \mathrm{~nm}$ a $25^{\circ} \mathrm{C}$ cada minuto durante 5 minutos y la actividad fue medida por la disminución de la absorbancia. La actividad de la CAT fue expresada como UI/mg de proteína/min.

\subsubsection{MTs totales}

La determinación de la concentración de la cantidad total de MTs en los tejidos animales se realizó de acuerdo con el método modificado de saturación con ${ }^{109} \mathrm{Cd}$, descrito por Eaton y Toal (1982) (Eaton et al., 1982; Eaton et al., 1983; Brambila et al., 2002). Esta técnica permitió la evaluación de la concentración de las MTs en tejidos homogeneizados mediante su capacidad de unirse a metales pesados como el Cd. El tejido se homogenizó con Tris- $\mathrm{HCl} 30 \mathrm{mM}$ a un pH de 8.0, posteriormente 
fue centrifugado durante 15 minutos a $30000 x g$ para la obtención de la fracción sobrenadante. Se tomó una alícuota de $0.1 \mathrm{ml}$ de cada sobrenadante y se le agregó $0.1 \mathrm{~mL}$ de ${ }^{109} \mathrm{CdCl}_{2}$ seguido de una incubación de 10 minutos a temperatura ambiente. Posteriormente el ${ }^{109} \mathrm{Cd}$ no ligado a las MTs se eliminó empleando 0.05 $\mathrm{mL}$ de hemoglobina de bovino al $2 \%$. Posteriormente se sometieron las muestras a un tratamiento térmico llevado a ebullición con el uso de baño maría durante un minuto para precipitar el complejo hemoglobina-Cd; este paso fue repetido una vez más. Las muestras se dejaron enfriar a temperatura ambiente y posteriormente se centrifugaron a $30000 \times$ por 5 min para precipitar la hemoglobina. Finalmente la cantidad de ${ }^{109} \mathrm{Cd}$ fijado por las MTs presente en el sobrenadante fue cuantificado con ayuda de un detector de centelleo gamma automático (Wizard 1470, Perkin Elmer, Finland).

\subsection{ANÁLISIS ESTADÍSTICO}

Los datos representan la media \pm el error estándar de la media (S.E.M.) ( $n=5$ en cada grupo). Las comparaciones estadísticas dentro del mismo grupo fueron realizadas con un análisis de varianza (ANOVA). Para las comparaciones entre los grupos se empleó el análisis de varianza (ANOVA) de una vía, seguido de una prueba post hoc de comparación múltiple, Tukey-Kramer. La comparación entre dos grupos fue realizada con la prueba de $t$ de Student. Todos los valores $p \leq 0.05$ fueron considerados estadísticamente significativos. En todo el análisis estadístico se empleó el software NCSS 2001 (NCSS, Kaysville, UT, USA). 


\section{RESULTADOS}

\subsection{CURSO TEMPORAL DE PESO, TALLA E ÍNDICE LEE}

Se evaluó el peso y talla de los ratones tratados con GMS y se observó un incremento gradual a lo largo del tiempo en el peso corporal, tanto en los grupos control como en los obesos, aunque los ratones tratados con GMS mostraron un peso significativamente mayor que los controles. El peso corporal en las hembras incrementó a los 4 meses (20\%), a los 8 meses (42\%), a los 12 meses (36\%) y a los 16 meses de edad (20\%); en machos obesos se incrementó $18 \%, 51 \%, 23 \%$ y un $21 \%$ en las edades respectivas (Gráfica 1a).

A los 8 meses de edad se observó una diferencia significativa entre los géneros, siendo los ratones machos GMS los que presentaron mayor peso corporal (13\%) comparados con las hembras obesas GMS. A los 12 meses de edad, este comportamiento cambió y los ratones hembra GMS mostraron un mayor peso corporal que los ratones macho GMS (Gráfica 1a) $(p<0.05)$. De manera interesante, a los 16 meses de edad y aún más evidentemente a los 20 meses, el peso corporal disminuyó en los cuatro grupos. En el caso de las hembras GMS, el peso corporal disminuyó un $33 \%$ y en el caso de machos tratados un $17 \%$ en relación con su control.

Se evaluó la longitud naso-anal para determinar el tamaño de los ratones y se observó que estos valores disminuyeron, tanto en ratones obesos como en controles a través del tiempo. Sin embargo, los ratones tratados con GMS fueron más 
pequeños que los ratones control: $14 \%$ en ratones hembra obesas y $12 \%$ en ratones obesos macho (Gráfica 1b).

El IL se incrementó en todos los grupos durante la vida. Los grupos tratados con GMS presentaron los valores más altos comparados con sus controles. Los valores de este índice en ratones obesos hembra fueron del $21,32,24,19$, y $26 \%$ más altos comparados con las hembras control a los $4,8,12,16$ y 20 meses de edad, respectivamente; por su parte, los ratones macho obesos mostraron índices de $11,28,27,27$ y $20 \%$ superiores a su control, en los mismos tiempos evaluados. Con respecto al género, las hembras presentaron aproximadamente un IL10\% más alto que los machos en ambos casos (controles y obesos) (Gráfica 1c), y en todos los casos esta diferencia fue significativa $(p<0.05)$.
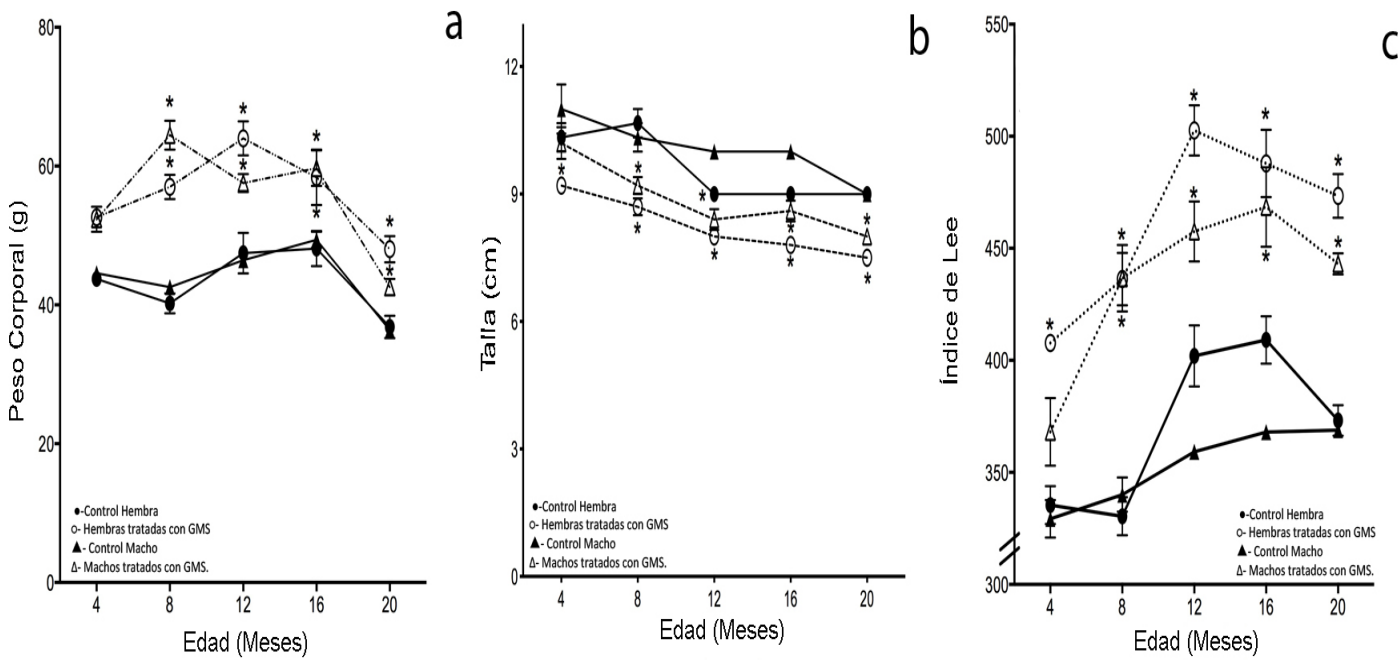

Gráfica 1. Determinación del grado de obesidad. en ratones macho y hembra tratados con GMS. (a) peso corporal; (b) talla e (c) Índice Lee. Las mediciones se determinaron a los $4,8,12,16$ y 20 meses de edad. Los datos se presentan como la media \pm S.E.M., de cinco ratones por grupo. ${ }^{*} p<0.05$ vs. Control. 


\subsection{PRUEBA DE TOLERANCIA A LA GLUCOSA ORAL (PTGO)}

La Gráfica 2 muestra las alteraciones en la PTGO en los ratones control y obesos a los 4, 8, 12, 16 y 20 meses de edad. Ambos grupos de hembras (controles y tratados) mostraron una alteración en la homeostasis de glucosa a través del tiempo.

A los 4 meses, los valores glucémicos más altos se obtuvieron en las hembras tratadas con GMS (35\%), 30 min después de la administración de dextrosa al compararlos con el grupo control. Este valor se incrementó $44 \%$ a los 8 meses de edad (Gráfica 2a); sin embargo, de los 12 a los 20 meses de edad las diferencias entre los grupos se hicieron menos evidentes (Gráfica 2c,e,g,i) $(p<0.05)$.

Con relación a los machos, se observaron diferencias significativas a los 4 y 8 meses de edad entre los ratones control y obesos $(48 \%$ y $61 \%$ más alto en ratones GMS 30 minutos después de la administración de dextrosa). Sorpresivamente, a partir de los 16 meses de edad no se encontraron diferencias significativas. La glucemia en los ratones tratados con GMS disminuyó hasta los valores de los controles, los que tendieron, a su vez, a incrementar sus valores, dando como resultado la compactación de las curvas (Gráfica $2 b, d, f, h, j)(p<0.05)$.

Los machos mostraron valores más altos de intolerancia a glucosa que las hembras. A los cuatro meses de edad, los ratones tratados GMS mostraron niveles altos de intolerancia a la glucosa ( $53 \%$ y $52 \%$, respectivamente a los 30 y $60 \mathrm{~min})$. A los 8 meses de edad, las diferencias se incrementaron a $117 \%$ y $85 \%$, respectivamente. No se encontraron diferencias en otros puntos de la PTGO, ni a los 12,16 y 20 meses de edad. 

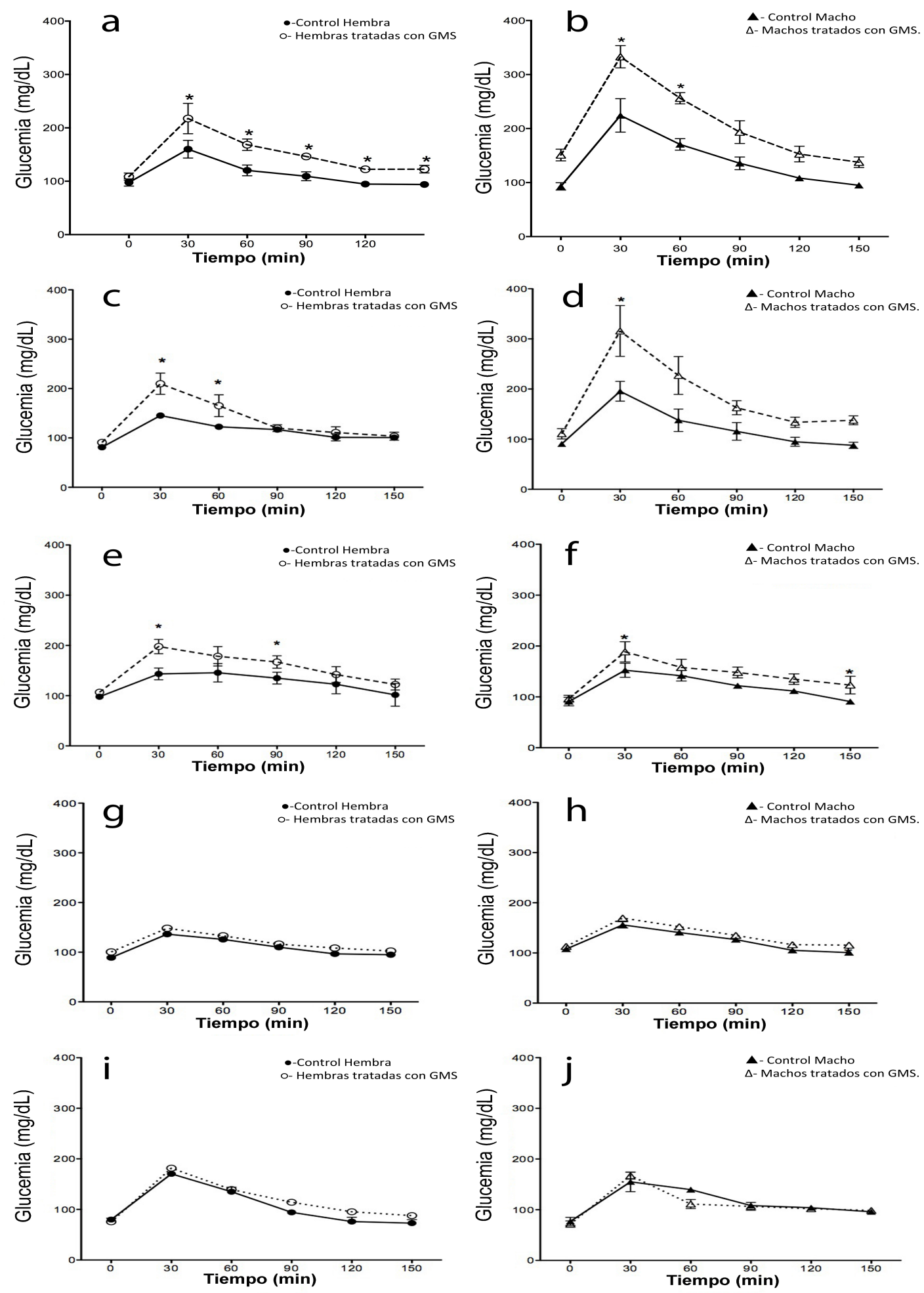

Gráfica 2. Prueba de tolerancia a la glucosa oral (PTGO) en ratones machos y hembras tratados con GMS. Las pruebas se realizaron a los 4 (a, b), 8 (c, d), 12 (e, f), $16(\mathrm{~g}, \mathrm{~h})$ y $20(\mathrm{i}, \mathrm{j})$ meses de edad. Los datos se representan como la Media \pm S.E.M. , de cinco ratones por grupo. ${ }^{*} p<0.05$ vs. Control. 


\subsection{PRUEBA DE TOLERANCIA A LA INSULINA (PTI)}

La sensibilidad a la insulina disminuyó gradualmente en los grupos tratados con GMS durante la vida (Gráfica 3). No se encontraron diferencias significativas en los niveles glucémicos entre los grupos hembra control y tratados con GMS de los 4 a los 12 meses de edad; sin embargo, a los 16 y 20 meses las hembras obesas mostraron un incremento del $25 \%$ en los valores glucémicos con respecto al control normal. Cuando los ratones hembra de 20 meses de edad (obesos y controles) fueron comparados con los ratones hembra jóvenes (4 meses de edad), se observaron aumentos significativos en los niveles glucémicos $(35 \%$ y $15 \%$, respectivamente) (Gráfica 3, c, e, g, i) $(p<0.05)$.

Por el contrario, los machos obesos de 4 meses de edad mostraron valores glucémicos $37 \%$ más altos en los primeros 30 minutos posteriores a la administración de insulina con respecto al grupo control. Es importante señalar que se observó mayor pérdida de la sensibilidad a la insulina en los ratones macho obesos durante toda su vida $(8,12,16$ y 20 meses de edad) (Gráfica 3b, d, f, h, j) $(p<0.05)$.

Cuando la sensibilidad a la insulina se comparó por género, los ratones macho GMS mostraron $30 \%$ menos sensibilidad a la insulina comparada con el grupo de hembras GMS a los 4 meses de edad. Sin embargo, no se observaron diferencias en las demás edades. En los grupos control no se observaron diferencias con respecto al género, excepto a los 20 meses de edad, donde los machos mostraron un $25 \%$ de menos sensibilidad a insulina que las hembras control $(p<0.05)$. 

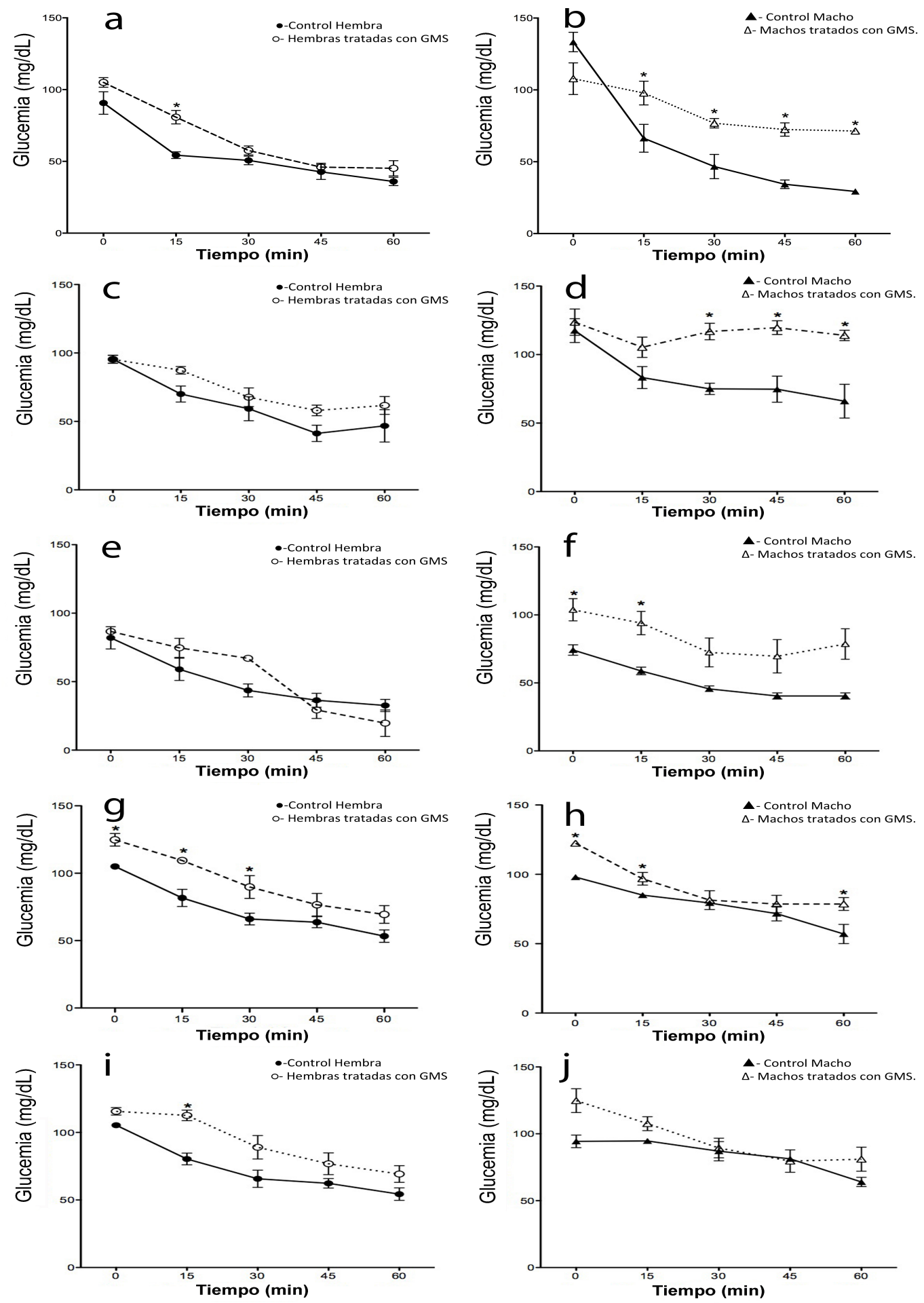

Gráfica 3. Prueba de tolerancia a la insulina (PTI) en ratones macho y hembra tratados con GMS. Las pruebas se realizaron a los 4 (a, b), 8 (c, d), 12 (e, f), 16 (g, h) y 20 (i, j) meses de edad. Los datos se representan como la media \pm S.E.M., de cinco ratones por grupo. ${ }^{*} p<0.05$ vs. Control; •, control hembras; $\circ$, Hembras tratadas con GMS; $\boldsymbol{\Lambda}$, control machos; $\Delta$, Machos tratado con GMS. 


\subsection{PARÁMETROS BIOQUÍMICOS}

La Gráfica 4a muestra los niveles de colesterol total en hembras y machos control y tratados con GMS a lo largo de la vida. Los ratones obesos mostraron altos niveles de colesterol comparados con los grupos control desde los 4 hasta los 20 meses de edad. Ademas, el contenido de colesterol fue más alto en machos que en hembras. Los niveles de colesterol en obesos, machos y hembras, incrementaron en un $41 \%$ y $26 \%$, respectivamente, comparados con sus grupos control a los 16 meses de edad; además, los machos obesos mostraron $50 \%$ más colesterol que las hembra obesas $(p<0.05)$.

En la Gráfica 4b se muestra que las hembras GMS presentaron niveles incrementados de triglicéridos de $36 \%, 40 \%, 100 \%$ y $130 \%$ a los $4,8,12,16$ y 20 meses de edad, respectivamente, comparados con el grupo control $(p<0.05)$.

Se observaron diferencias en el contenido de triglicéridos entre los machos obesos y los controles a los 4 y 20 meses de edad, donde el contenido de triglicéridos incrementó en $50 \%$ y 55\%, respectivamente, en los ratones tratados.

El análisis por género reveló que los niveles de triglicéridos en los ratones hembra tratados GMS fue $47 \%$ y $31 \%$ más elevados al compararse con los ratones macho GMS a los 16 y 20 meses de edad.

Los niveles de AST (Gráfica 4c) se incrementaron gradualmente a lo largo de la vida, y tres de los cuatro grupos mantuvieron similitud a lo largo del estudio; sólo los controles hembra mostraron niveles más bajos en el contenido de AST (180\%) a los 16 y a los 20 meses de edad, en relación con los otros grupos $(p<0.05)$. 
Las determinaciones de ALT (Gráfica 4d) mostraron un comportamiento similar en todos los grupos de 4 a 20 meses de edad. El grupo de los machos presentó un nivel mayor de ALT (30\%) que las hembras entre los 8 y 16 meses de edad. A los 20 meses de edad, en ambos grupos disminuyó en $25 \%$ el contenido de AST, pero las hembras mostraron $15 \%$ más de la enzima con respecto a los machos control.
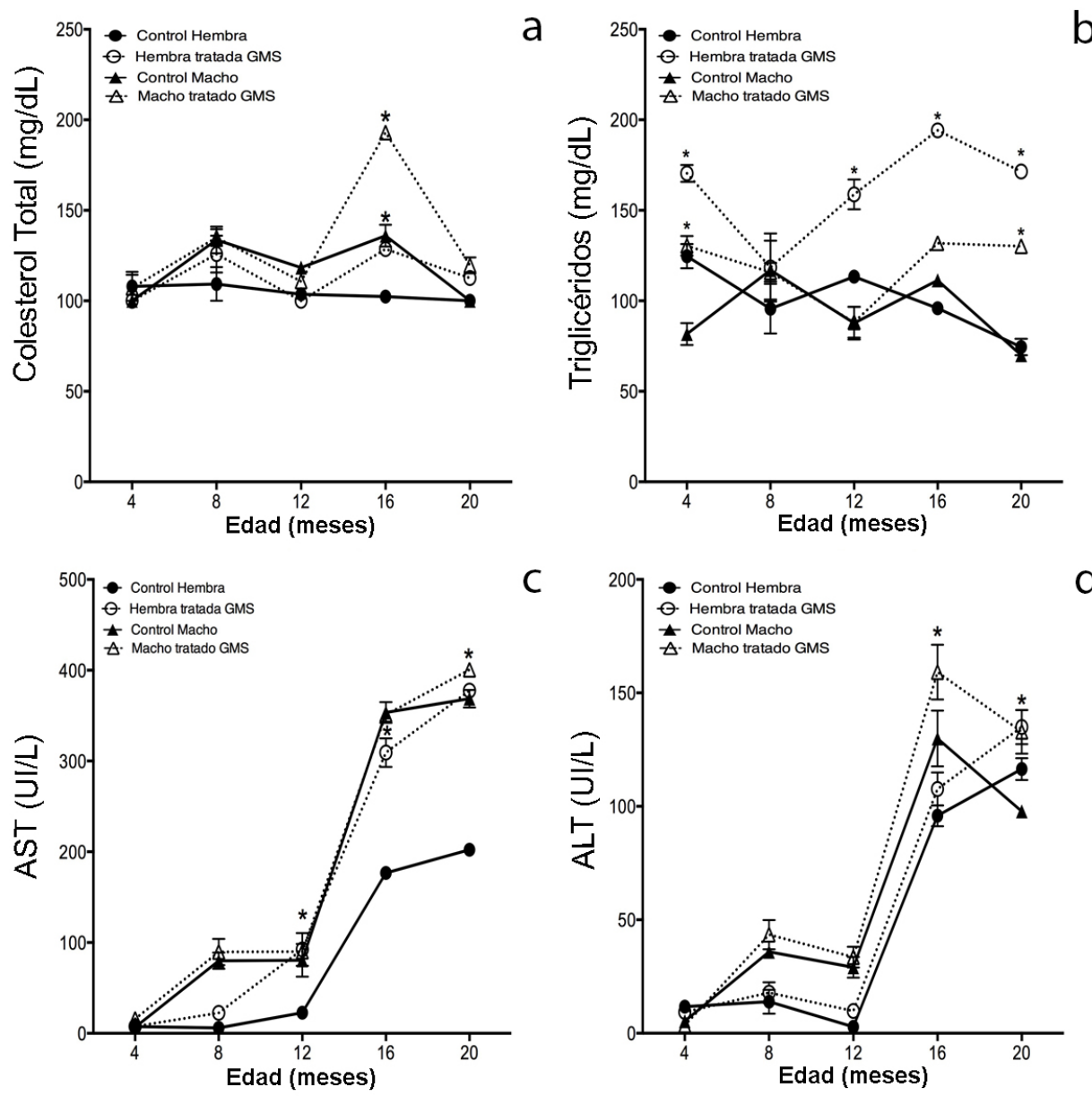

Gráfica 4. Parámetros bioquímicos en ratones macho y hembra tratados con GMS. (a) colesterol total; (b) triglicéridos; (c) aspartato aminotransferasa (AST) y (d) alanina aminotransferasa (ALT), fueron determinados como se describió en la sección de material y métodos a los 4, 8, 12, 16 y 20 meses de edad. Los datos se representan como la media \pm S.E.M., de cinco ratones por grupo. ${ }^{*} p<0.05$ vs. Control; •, control hembras; ○, Hembras tratadas con GMS; $\boldsymbol{\Lambda}$, control machos; $\Delta$, Machos tratados con GMS. 
Cuando se realizó la comparación por género, los machos control tuvieron niveles más altos, no significativos, de ALT que los ratones hembra control a los 8,12 y 16 meses de edad. Los machos tratados mostraron un incremento del $22 \%$ y $35 \%$ de ALT a los 16 y 20 meses de edad respectivamente, comparado con los grupos control. No se observaron diferencias entre el grupo de hembras obesas tratadas y su grupo control a lo largo del tiempo (Gráfica 4d) $(p<0.05)$.

\subsection{NIVELES SÉRICOS DE CITOCINAS.}

\subsubsection{TNF- $\alpha$ e IL-6.}

Se realizó el estudio del perfil inflamatorio, donde se evaluaron los niveles de TNF- $\alpha$, IL-6 y adiponectina (Gráfica 5). Los niveles de TNF- $\alpha$ gradualmente incrementaron en los cuatro grupos desde los 4 meses de edad, alcanzando valores máximos a los 12 meses; estos niveles disminuyeron durante los siguientes meses. No se encontraron diferencias entre los ratones obesos hembra y su control. Sin embargo, los ratones macho tratados con GMS mostraron un aumento del $43 \%$ y $114 \%$ respecto al grupo control a los 8 y 12 meses de edad, respectivamente (Gráfica 5a).

A los 12 meses de edad, tanto el grupo control como el grupo GMS en machos mostraron incrementos del 197 y $140 \%$ en los niveles de TNF- $\alpha$ comparado con los grupos de ratones control y obeso en hembras. A los 16 meses de edad, los niveles de TNF- $\alpha$ disminuyeron en todos los grupos y permanecieron constantes hasta los 20 meses de edad. 
La Gráfica 5b muestra las mediciones de IL-6. A los 12 meses de edad, la concentración de IL-6 en los grupos de machos mostraron un pico de 163\% comparado con los ratones hembra tratados con GMS $(p<0.05)$. Cuatro meses después, los niveles de IL-6 disminuyeron y no se observaron diferencias significativas entre géneros.
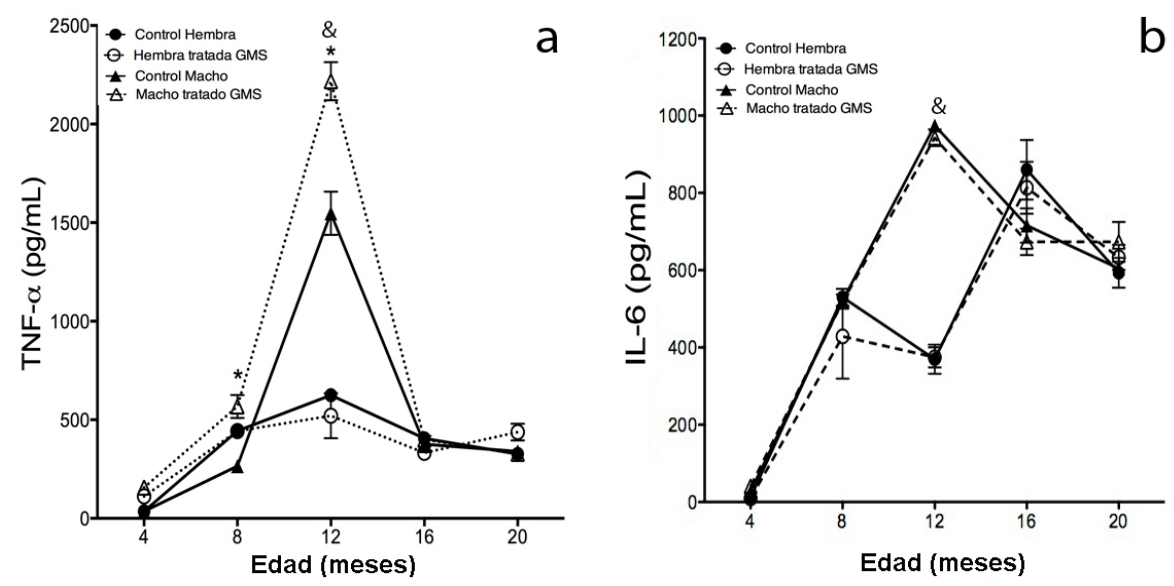

Gráfica 5. Perfil inflamatorio en ratones macho y hembra tratados con GMS. Los niveles séricos de (a) TNF- $\alpha$ e (b) IL-6 fueron cuantificados a los 4, 8, 12, 16 y 20 meses de edad. Los datos se presentan como la media \pm S.E.M., de cinco ratones por grupo. ${ }^{*} p<0.05$ vs. Control.

\subsubsection{Adiponectina e Interleucina-10 (IL-10).}

En la Gráfica 6 se observa que la concentración de adiponectina mostró un comportamiento diferente a los observados con TNF- $\alpha$ e IL-6. La concentración de adiponectina disminuyó a lo largo del estudio tanto en los grupos de hembras como en los grupos de machos. A los 4 meses de edad, las hembras y los machos obesos presentaron una disminución del $33 \%$ y $49 \%$, respectivamente, comparado con sus grupos control. A los 8 y 12 meses de edad, la hormona se encontró disminuida en 
todos los grupos, pero a los 16 meses de edad los niveles de adiponectina presentaron una importante elevación en los grupos de ratones obesos (machos y hembras), así como en el grupo control de hembras. El análisis realizado no reveló diferencias significativas entre los grupos de hembras al final del estudio, pero en los machos control se presentó $185 \%$ menos concentración de adiponectina comparado con el grupo de ratones macho obesos a los 20 meses de edad.

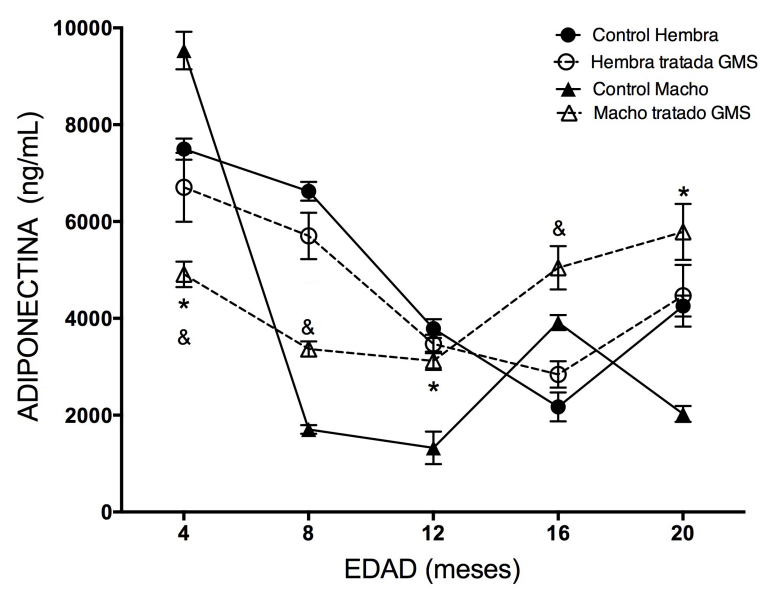

Gráfica 6. Niveles de adiponectina $(\mathrm{ng} / \mathrm{mL})$ en ratones macho y hembra tratados con GMS. Los niveles séricos de adiponectina se cuantificaron por el método de ELISA a los 4, 8, 12, 16 y 20 meses de edad. Los datos se representan como la media \pm S.E.M., de cinco ratones por grupo. ${ }^{*} p<0.05$ vs. Control.

De acuerdo con la Tabla 5, los niveles de IL-10 disminuyeron $14 \%$ en el grupo de machos tratados a los 12 meses de edad comparados con su control $(p<0.05)$. Por otra parte, el análisis por género reveló que los machos tratados presentaron un incremento de 17 veces en los niveles de IL-10 a los 12 meses de edad, comparados con las hembras tratadas $(p<0.05)$. 
Tabla 5. Niveles de IL-10 en ratones control y tratados con GMS a lo largo de su vida.

\begin{tabular}{c|ccccc}
\hline Citocina & $\begin{array}{c}\text { Edad } \\
\text { (mes) }\end{array}$ & C-H & H-GMS & C-M & M-GMS \\
\hline $\begin{array}{c}\text { IL-10 } \\
\text { (ng/mL) }\end{array}$ & $\mathbf{4}$ & $0.34 \pm 0.01$ & $0.31 \pm 0.01$ & $0.31 \pm 0.01$ & $0.28 \pm 0.008$ \\
& $\mathbf{8}$ & $0.34 \pm 0.01$ & $0.29 \pm 0.01$ & $0.37 \pm 0.03$ & $0.30 \pm 0.01$ \\
& $\mathbf{1 2}$ & $0.29 \pm 0.01$ & $0.27 \pm 0.01$ & $5.53 \pm 0.33$ & $4.80 \pm 0.23 * \&$ \\
& $\mathbf{1 6}$ & $0.30 \pm 0.01$ & $0.28 \pm 0.02$ & $0.38 \pm 0.05$ & $0.28 \pm 0.01$ \\
& $\mathbf{2 0}$ & $0.33 \pm 0.05$ & $0.31 \pm 0.05$ & $0.44 \pm 0.06$ & $0.32 \pm 0.02$ \\
\hline
\end{tabular}

C-H: Control hembra; H-GMS: Hembra GMS; C-M: Control Macho; M-GMS: Macho GMS. ${ }^{*} p<0.05$ vs. Control. \& $p<0.05$ M-GMS vs H-GMS.

\subsection{EVALUACÍON DE DAÑO OXIDANTE Y RESPUESTA ANTIOXIDANTE}

\subsubsection{Daño oxidante.}

\subsubsection{Cuantificación de niveles de MDA como índice de lipoperoxidación}

Se determinó el nivel de MDA en varios tejidos provenientes de los ratones control y obesos GMS de 4, 8, 12, 16 y 20 meses de edad (Gráfica 7a-h).

Hígado. La evaluación de lipoperoxidación reveló que en hígado existe un incremento en la concentración de MDA a los 12 meses de edad en los machos tratados con GMS (138\%) comparados con su control; en las hembras no se observaron cambios significativos (Gráfica 7a-b) $(p<0.05)$.

Pulmón. En el pulmón de las hembras GMS a partir de los 16 meses de edad se observó un incremento en los niveles de MDA (72\%) comparado con su control; en machos GMS se presentaron incrementos a los 12 meses (193\%), 16 meses (117\%) y a los 20 meses de edad (118\%) comparados con su control (Gráfica 7c-d) $(p<0.05)$. 
Corazón. En el corazón de ratones hembra tratados con GMS (Gráfica 7e-f) se presentaron incrementos a los 16 meses (93\%) y a los 20 meses de edad (115\%) comparados con su control respectivo; en el caso de los machos GMS, se incrementó la concentración de MDA a partir de los 12 meses (184\%), 16 meses $(117 \%)$ y a los 20 meses de edad (135\%) comparados con su control $(p<0.05)$.

Riñón. La concentración de MDA en el riñón de las hembras GMS se incrementó a los 16 meses (264\%) y a los 20 meses de edad (110\%) cuando se compararon con su control (Gráfica 7g-h). En el riñón de machos tratados con GMS a los 12 meses se incrementó el MDA 5 veces comparado con su control (542\%) y a los 20 meses aunque disminuyó el porcentaje comparado con los 12 meses, se mantuvo un $54 \%$ mayor que el control $(p<0.05)$.

Comparación por género. El análisis por género reveló que los machos presentaron mayor concentración de MDA a los 12 meses de edad $(75 \%)$ en el hígado. En pulmón presentaron mayor concentración de MDA a los 12 meses (899\%), a los 16 meses $(50 \%)$ y a los 20 meses de edad $(32 \%)(p<0.05)$ en comparación con las hembras GMS. Este mismo comportamiento fue observado en el corazón de los machos GMS a los 12 meses (1075\%) y a los 16 meses (20\%), donde se incrementaron los niveles de MDA comparado con los niveles evaluados en las hembras obesas $(p<0.05)$. En el caso del riñón, a los 16 meses de edad las hembras obesas son las que presentarón mayores niveles de MDA (26\%) comparado con los machos GMS y a los 20 meses de edad los machos GMS presentaron mayores niveles de MDA (24\%) que las hembras GMS $(p<0.05)$. 

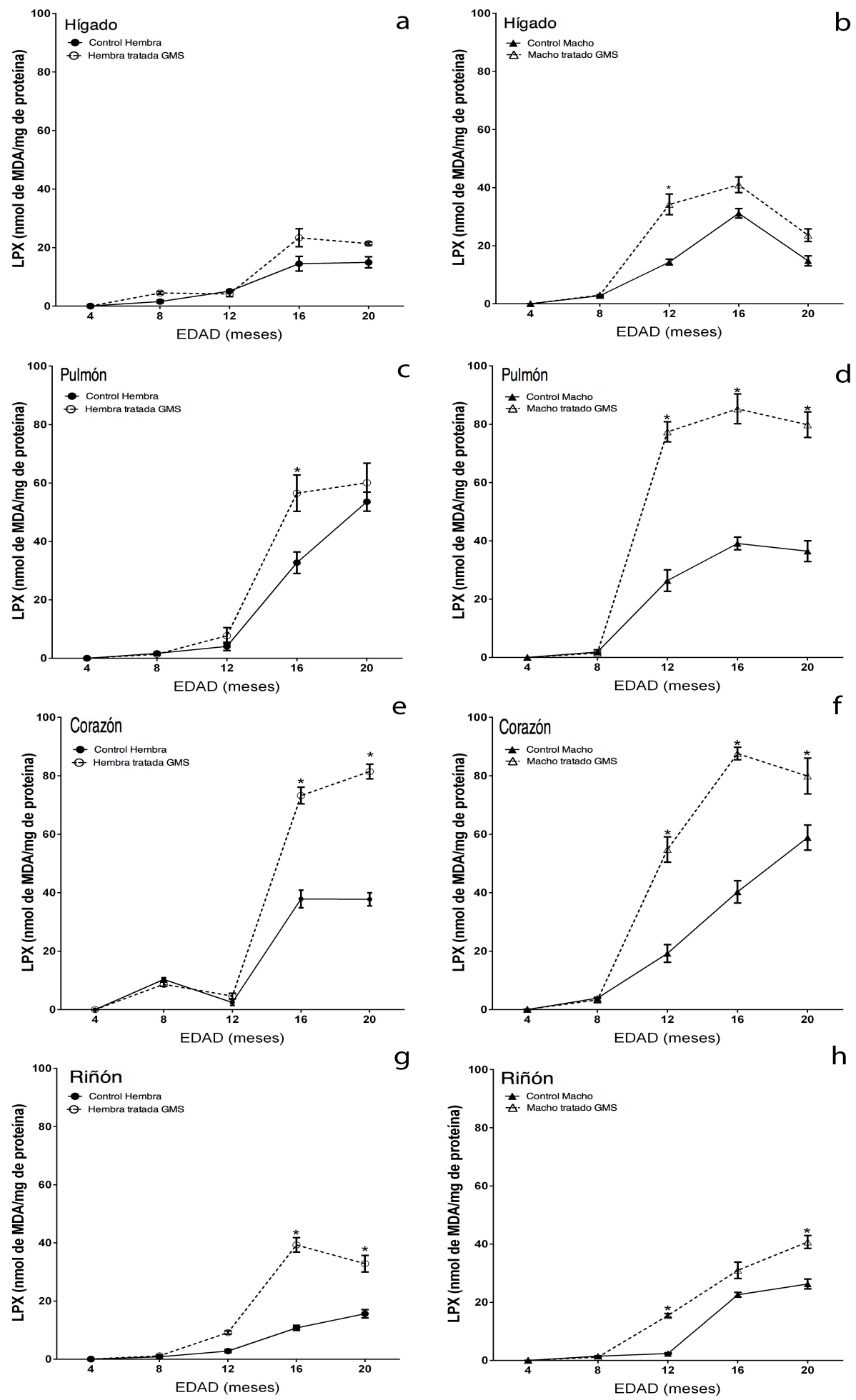

Gráfica 7. Daño oxidante en lípidos. Cuantificación de lipoperoxidación en ratones control y GMS (machos y hembras) a diferentes edades, cuantificados en a, b) hígado, c, d) pulmón, e, f) corazón y g, h) riñón. $\pm S$.E.M., de cinco ratones por grupo. ${ }^{*} p<0.05$ vs Control. 
En el caso del riñón, a los 16 meses de edad las hembras son las que presentaron mayores niveles de MDA (26\%) comparados con los machos GMS y a los 20 meses de edad los machos GMS presentaron mayores niveles de MDA (24\%) que las hembras GMS $(p<0.05)$.

\subsubsection{Carbonilación de proteínas.}

Los tejidos homogenizados fueron analizados para determinar la oxidación de proteínas. Se emplearon muestras provenientes de ratones control y obsesos GMS de $4,8,12,16$ y 20 meses de edad y se realizó la técnica para la detección de proteínas carboniladas (Gráfica 8). Se observó mayor proporción de proteínas oxidadas en los tejidos de machos y hembras GMS, en relación con sus controles.

Hígado. La determinación de proteínas carboniladas en los grupos control y tratados con GMS, tanto en hembras como en machos, indicó que en hígado (Gráfica $8 a$ y $8 b)$ se encuentran incrementadas las proteínas carboniladas de manera estadísticamente significativa principalmente en hembras al compararlas con su control a los 4 meses de edad; posteriormente a los 8 meses y 12 meses los niveles descendieron comportándose como los niveles detectados en el grupo de machos.

Pulmón. En pulmón (Gráfica 8c y 8d) se observó una tendencia al incremento de proteínas carboniladas en el grupo de hembras GMS, siendo esta diferencia respecto a su control estadísticamente significativa a los 8 y 12 meses de edad. Sin embargo, en machos control y GMS se observó una menor tendencia al incremento a través del tiempo. 
Riñón. La determinación de carbonilación en riñón (Gráfica 8e y 8f) denotó un incremento estadísticamente significativo a los 8 meses de edad en el grupo de hembras GMS respecto a su control, en el grupo de machos GMS se apreció una tendencia al incremento a los 8 meses de edad. Posteriormente, a los 12 meses de edad los niveles de carbonilación disminuyeron prácticamente a los niveles presentados a los 4 meses de edad en ambos grupos.

Corazón. La carbonilación de proteínas en corazón (Gráfica 8g y 8h) mostraró diferencias estadísticamente significativas en los grupos de hembras GMS a los 4 y 12 meses de edad y en machos GMS a los 8 meses de edad, comparados con su control respectivo.

Comparación por género. El análisis por género sugiere que el hígado a los 4 meses de edad presentó mayor carbonilación de proteínas; el pulmón a partir de los 8 y 12 meses de edad, en el grupo de hembras GMS principalmente. 

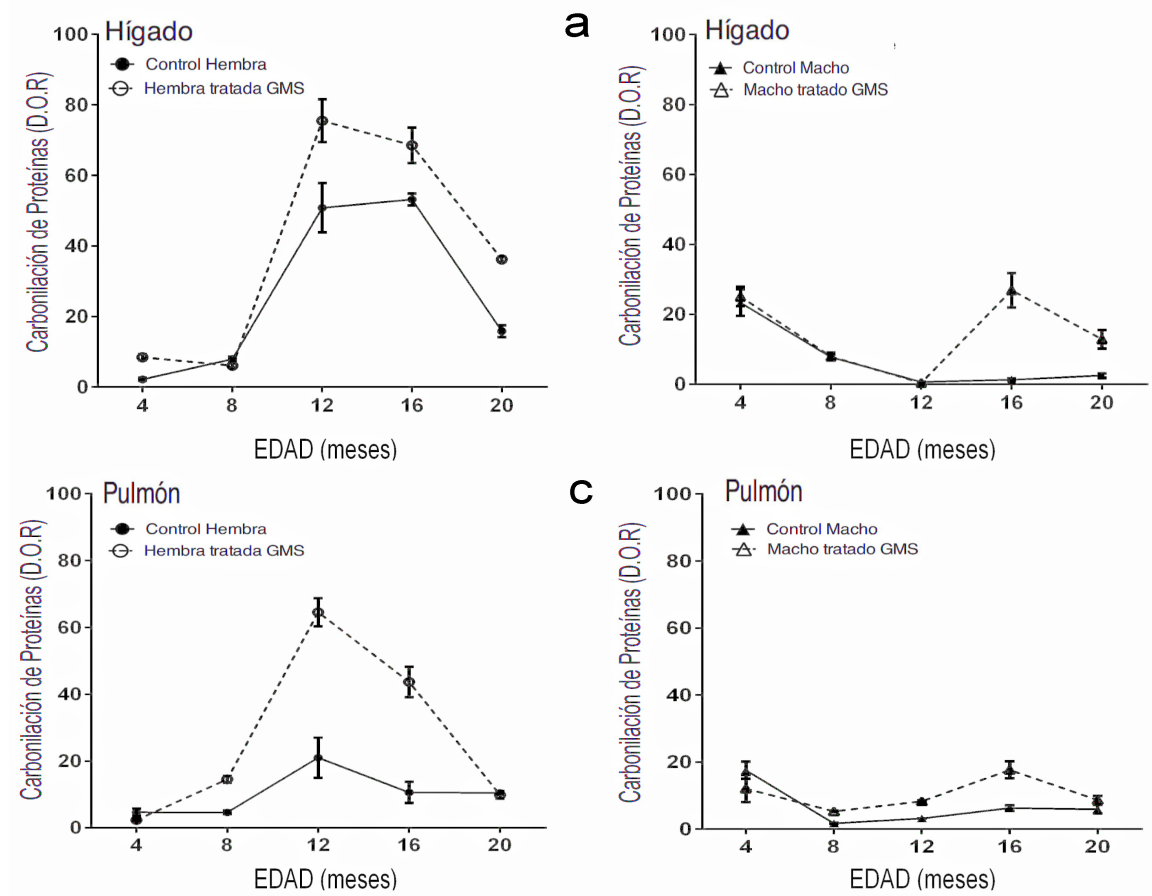

C
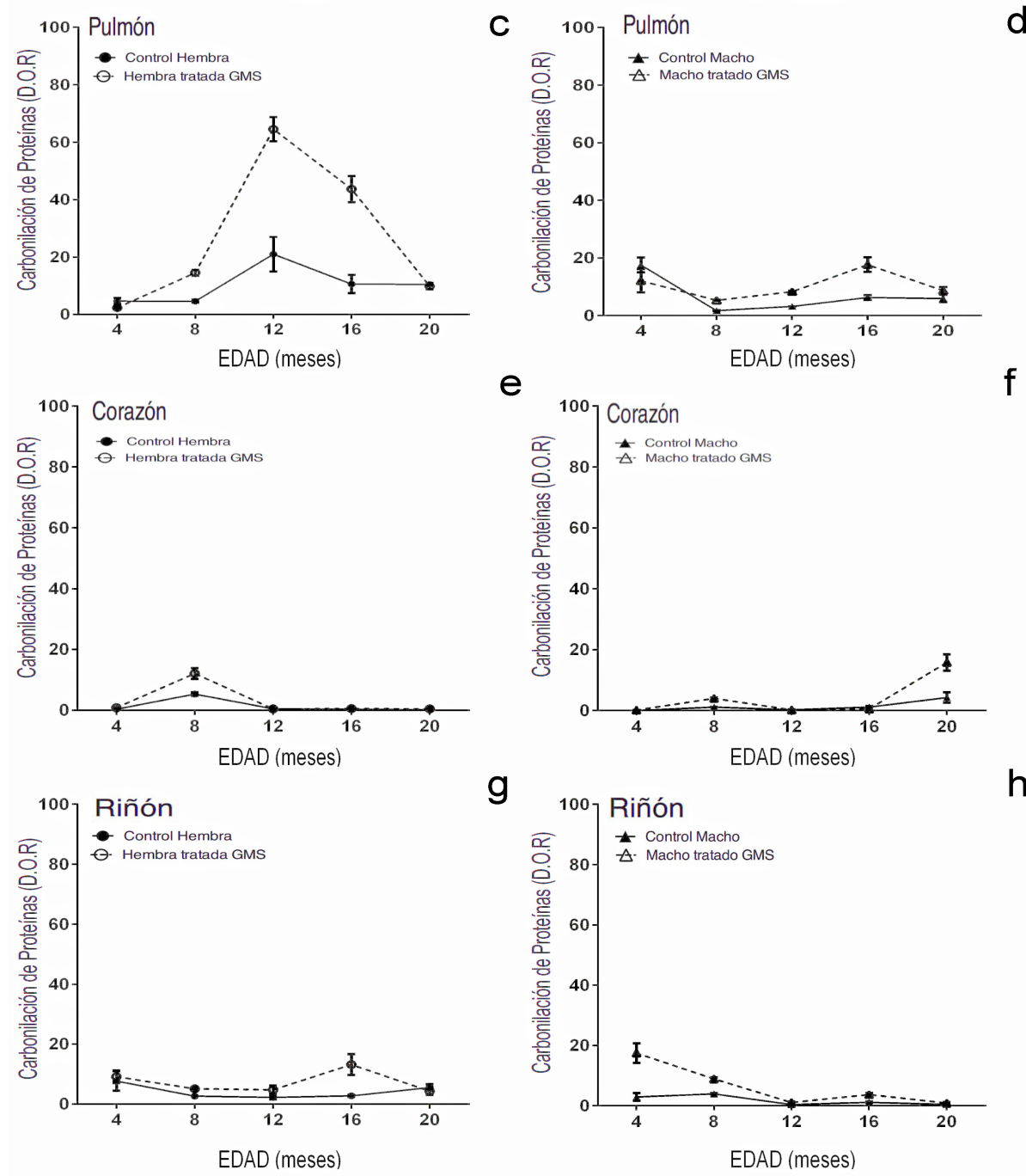

Gráfica 8. Daño oxidante en proteínas. Presencia de proteínas carboniladas en ratones control y GMS (hembra y macho) a diferentes edades, cuantificado en $a, b$ ) Hígado, c, d) Pulmón, e, f) riñón y g, h) corazón. \pm S.E.M., de cinco ratones por grupo. ${ }^{*} p<0.05$ vs Control. Densidad Óptica Relativa (D.O.R). 


\subsubsection{Respuesta antioxidante.}

\subsubsection{CAT}

En el modelo de obesidad inducida por GMS se determinó la actividad de la enzima, dado que en la condición de obesidad se generan radicales libres y peróxido de hidrógeno que deben ser detenidos (Gráfica 9a-h).

Hígado. La actividad de CAT en hígado (Gráfica 9a y 9b) de ratones control y GMS (hembras y machos) en diferentes intervalos de tiempo mostró un incremento gradual a partir de los 8 meses de edad en ambos grupos GMS, siendo estadísticamente significativo a los 12 meses de edad en hembras obesas (79\%). Este incremento continuó a los 16 meses (400\%) y a los 20 meses de edad (50\%), comparados con su control respectivo. En el caso de machos sólo a los 16 meses de edad se presentó un incremento (172\%) comparado con su control $(p<0.05)$.

Pulmón. En pulmón (Gráfica 9c y 9d) la actividad de CAT se incrementó gradualmente conforme avanzó el tiempo; sin embargo, sólo a los 20 meses de edad se reflejó un incremento significativo (22\%) en hembras GMS comparado con su control. En machos GMS a esa edad presentaron una disminución en la actividad de la enzima $(69 \%)$ en comparación con su control $(p<0.05)$.

Corazón. La actividad de la enzima en corazón (Gráfica 9e y 9f) se encontró disminuida en machos GMS a los 12 meses (72\%), a los 16 meses (79\%) y a los 20 meses de edad $(26 \%)$ comparados con su control $(p<0.05)$. Sin embargo, en las hembras GMS hubo un incremento a los 16 meses de edad (158\%) continuando a los 20 meses de edad $(90 \%)$ al compararse con su control $(p<0.05)$. 
Riñón. En riñón (Gráfica 9g y 9h) la actividad de CAT se encontró incrementada en hembras GMS a los 16 meses (38\%) y a los 20 meses de edad (57\%) comparado con su control; en machos GMS a los 20 meses de edad se presentó un incremento (22\%) en la actividad de esta enzima comparado con su control $(p<0.05)$.

Comparación por género. El análisis por género reveló que en hígado las hembras GMS a los 12 meses de edad presentaron mayor actividad de la enzima (94\%), el cual continuó a los 16 meses de edad (32\%) cuando fueron comparados con los machos GMS $(p<0.05)$. Este comportamiento se observó más acentuado en pulmón de hembras GMS a partir de los 12 meses (1284\%), a los 16 meses (2107\%) y a los 20 meses de edad (404\%), comparado con los machos GMS $(p<0.05)$. En corazón, se repite este comportamiento en las hembras GMS a los 12 meses de edad (dos veces más) y a los 16 meses de edad fue seis veces mayor comparadas con machos GMS. Finalmente en riñón de hembras GMS se presentó mayor actividad de la enzima a los 12 meses (75\%), a los 16 meses de edad (137\%) y a los 20 meses de edad (62\%) en comparación con los machos tratados con GMS. Con base en este análisis la mayor actividad de la catalasa se presentó en hembras GMS a partir de los 12 meses de edad en los órganos analizados (hígado, pulmón y riñón). 

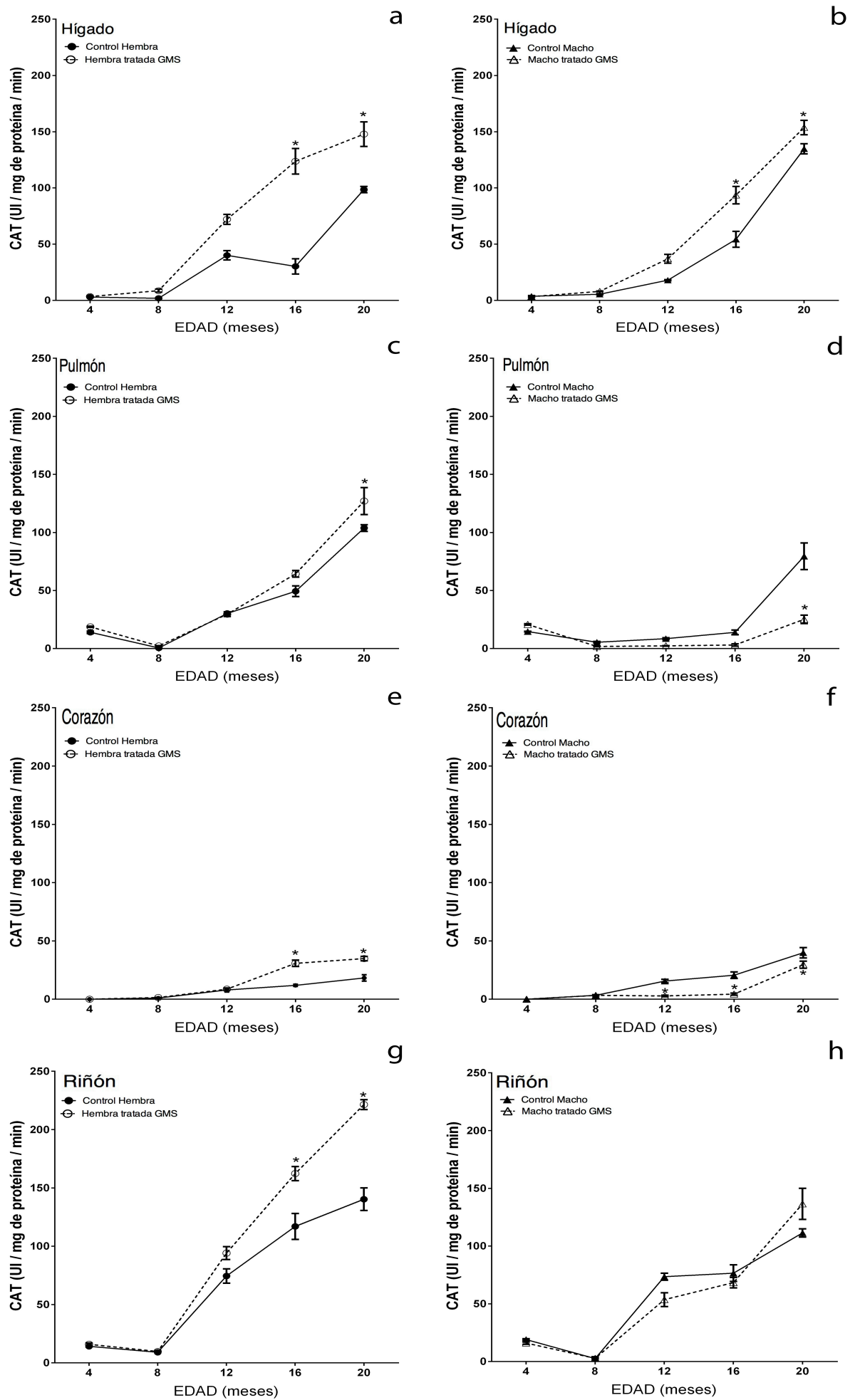

Gráfica 9. Respuesta antioxidante: CAT. Cuantificación de la actividad de la enzima Catalasa en ratones control y GMS (hembra y macho) a diferentes edades, determinado en $a, b$ ) hígado, c, d) pulmón, e, f) corazón y g,h ) riñón. \pm S.E.M., de cinco ratones por grupo, ${ }^{*} p<0.05$ vs Control. 


\subsubsection{SOD}

La actividad de la enzima SOD fue determinada en diferentes órganos (hígado, pulmón, corazón y riñón) de ratones control y ratones tratados con GMS a diferentes edades (4, 8, 12, 16 y 20 meses de edad) (Gráfica 10a-h).

Hígado. No se observaron diferencias significativas en la actividad de SOD en hígado de ratones hembra, tanto control como obesos a lo largo del tiempo (Gráfica 10a); en el hígado de ratones macho no se encontraron cambios en la actividad de SOD desde los 4 hasta los 16 meses de edad; sin embargo, a los 20 meses de edad se presentó un incremento en la actividad de la enzima en ratones obesos GMS $(22 \%)$ comparado con su grupo control $(p<0.05)$. Es de notar que los niveles en ambos grupos fueron superiores a los evaluados en el resto de las edades (Gráfica 10b).

Pulmón. En pulmón de ratones hembra control y tratados con GMS no hubo diferencias significativas (Gráfica 10c), en machos se incrementó la actividad de la enzima SOD a los 8 meses (casi 4 veces, 398\%) y a los 12 meses de edad (154\%) comparado con su control respectivo; posteriormente disminuyó la actividad a los 16 y 20 meses de edad (Gráfica 10d) $(p<0.05)$.

Corazón. En corazón de hembras y machos, tanto control como tratados con GMS (Gráfica 10e y f), no se observaron diferencias significativas en las edades evaluadas. Sin embargo se observó una tendencia a disminuir la actividad de SOD conforme envejece el organismo. 
Riñón. Se observó un comportamiento similar al determinado en corazón, ya que el riñón de ratones macho y hembra tanto control como en ratones tratados con GMS presentó una tendencia a disminuir la actividad de SOD a través de la vida del ratón (Gráfica 10g y h).

Comparación por género. El análisis por género reveló que la actividad de SOD en hígado a los 20 meses de edad en machos tratados con GMS fue mayor que las hembras (174\%); asimismo, en el control macho se presentó mayor actividad de la enzima comparada con el control de hembras $(105 \%)(p<0.05)$. En las otras edades evaluadas no se observaron diferencias por género. En pulmón los machos presentaron mayor actividad de la enzima SOD a los 4 meses (118\%), a los 8 meses (456\%) y a los 12 meses de edad (140\%) comparado con las hembras tratadas con GMS $(p<0.05)$. En corazón y en riñón de ratones tratados con GMS, no se presentaron diferencias en la actividad de la enzima SOD por género a través del tiempo. 

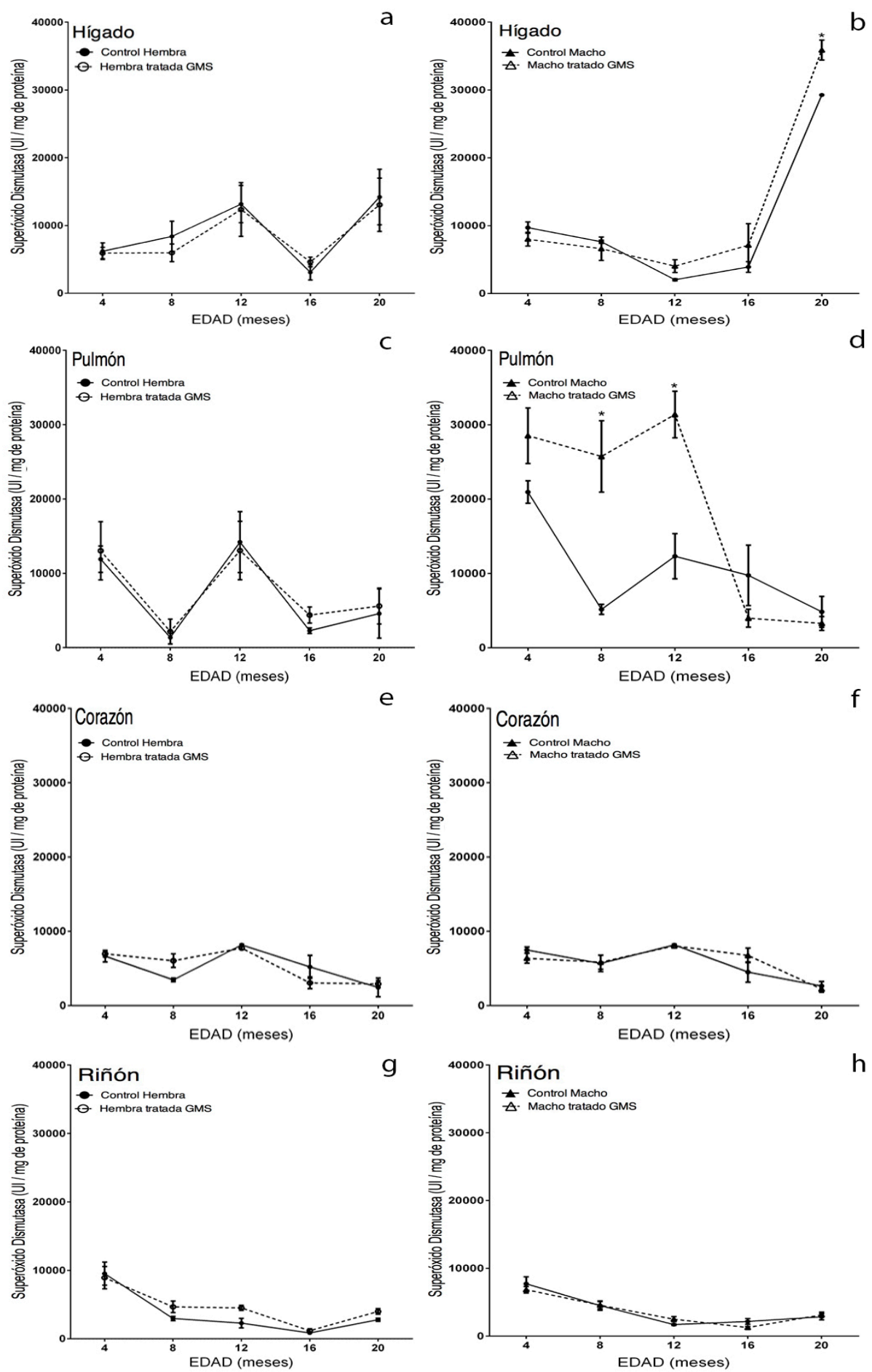

Gráfica 10. Respuesta antioxidante: SOD. Determinación de actividad de Superoxído dismutasa en ratones control y GMS (hembra y macho) a diferentes edades, determinado en $a, b)$ hígado, $c$, d) pulmón, e, f) corazón y $g, h$ ) riñón. \pm S.E.M., de cinco ratones por grupo * $p<0.05$ vs Control. 


\subsubsection{MTs}

Los niveles de MTs a lo largo del tiempo en los tejidos estudiados no mostraron diferencias significativas entre los ratones macho y hembra tratados con MSG comparado con su control respectivo (Gráfica 11a-g), excepto en riñón de machos tratados con MSG, donde hubo un incremento de los niveles de MTs (34\%) comparado con su control a los 4 meses de edad (Gráfica 11h) $(p<0.05)$. Sin embargo, se observó una tendencia en púlmón, corazón y riñón a disminuir los niveles de MTs a través del tiempo, contrario a lo observado en hígado donde se observo un aumento gradual.

Hígado. La comparación de los niveles de MTs evaluadas en las distintas edades reveló diferencias significativas; en hígado de hembras tratadas con MSG (Gráfica 11a) se observó un incremento de 31 veces en los niveles de MTs a los 16 meses respecto a los 4 meses $(p<0.05)$. Por otra parte, los niveles de MTs en el hígado de los ratones macho tratados con MSG (Gráfica 11b), a los 12 meses de edad aumentó 10 veces y a los 16 meses este aumento fue de 15 veces, comparado con los niveles detectados a los 4 meses de edad $(p<0.05)$.

Pulmón. Las MTs evaluadas en hembras tratadas con MSG (Gráfica 11c), disminuyeron a los 8 meses (75\%), continuando a los 12 meses de edad (85\%). A los 16 meses de edad esta disminución en los niveles se mantuvo (75\%), comparado con los niveles determinados a los 4 meses de edad $(p<0.05)$. En el caso del pulmón de los machos tratados con MSG (Gráfica 11d), el comportamiento en los niveles de MTs fue muy parecido al de las hembras, donde se observaron decrementos a los 8 
(78\%), a los $12(78 \%)$ y a los 16 meses de edad (82\%), cuando se compararon con los niveles evaluados inicialmente a los 4 meses de edad $(p<0.05)$.

Corazón. El comportamiento de las MTs en corazón de hembras tratadas con GMS (Gráfica 11e), disminuyó a los 8 meses (75\%), a los 12 meses (84\%) y se mantuvo a los 16 meses de edad (85\%), comparado con los niveles de MTs a los 4 meses de edad. En el grupo de machos tratados con GMS (Gráfica 11f), los niveles detectados de MTs, disminuyeron a los 8 meses (87\%), a los 12 meses de edad se observó una disminución más acentuada (98\%) y posteriormente a los 16 meses la disminución fue similar a la observada a los 8 meses de edad (85\%) al comparalos con los niveles evaluados a los 4 meses $(p<0.05)$.

Riñón. En este caso se presentó un comportamiento similar al observado tanto en pulmón como en corazón. En el grupo de hembras tratadas con GMS (Gráfica 11g) se observó una disminución en el contenido de MTs a los 8 meses de edad (72\%), acentuándose a los 12 meses de edad (84\%) y finalmente a los 16 meses de edad $(86 \%)$, comparado con los niveles detectados a los 4 meses de edad $(p<0.05)$. Por otra parte, los niveles evaluados en riñón del grupo de machos tratados con GMS (Gráfica 11h), a los 8 meses de edad se observó una disminución (86\%), continuando a los 12 meses (99\%). A los 16 meses de edad esa disminución fue muy parecida a la observada a los 8 meses de edad (85\%), cuando se comparó con los determinados a los 4 meses de edad $(p<0.05)$. 

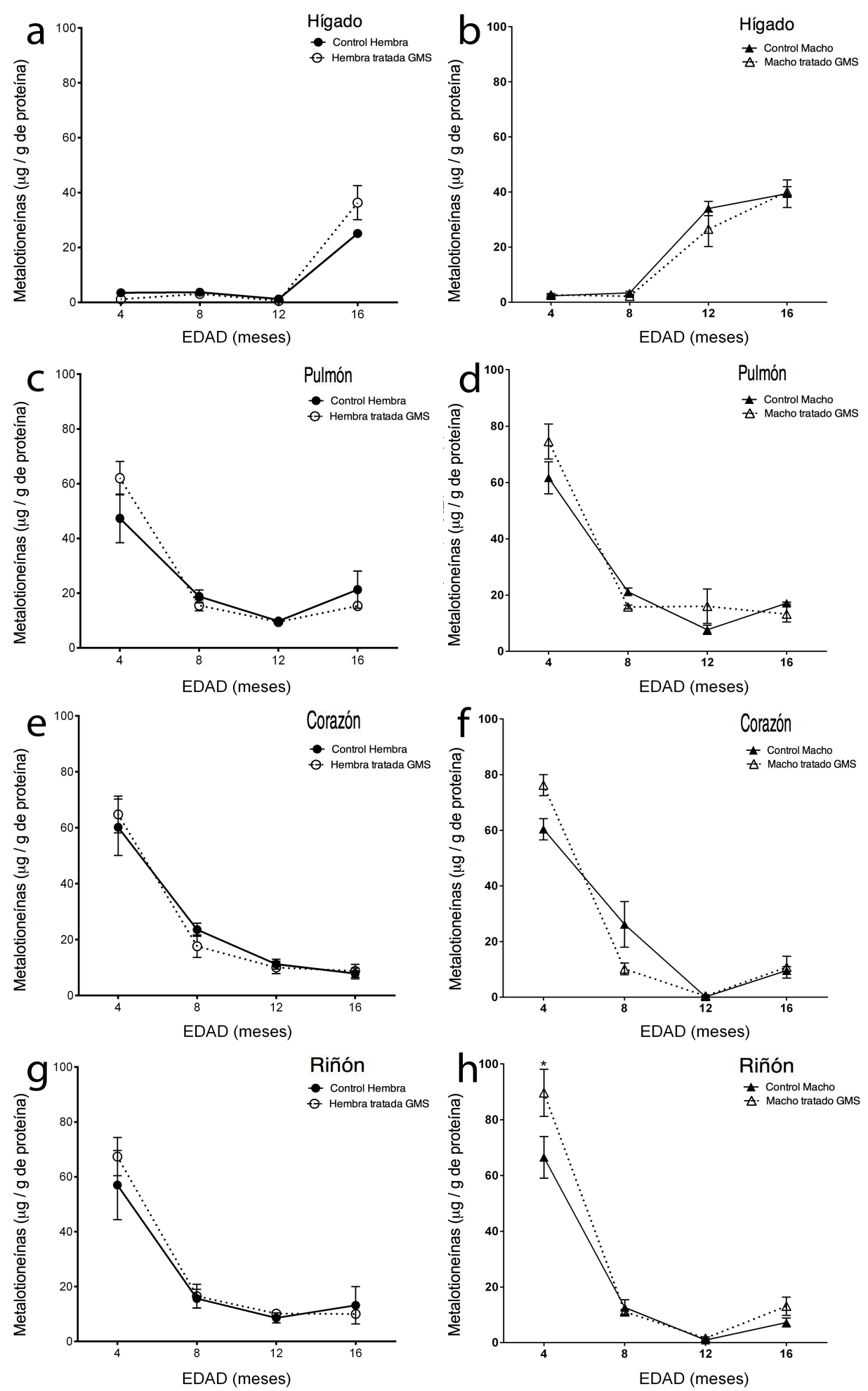

Gráfica 11. Metalotioneínas (MTs) como sistema antioxidante. Cuantificación de MTs en ratones control y GMS (hembra y macho) a diferentes edades, determinado en a, b) hígado, c, d) pulmón, e, f) riñón y g, h) corazón. \pm S.E.M., de cinco ratones por grupo. * $p<0.05$ vs Control. 


\subsubsection{Estado Redox (GSH/GSSG)}

La evaluación del estado redox a nivel sistemico indica que no se presentaron diferencias significativas a traves del tiempo en hembras GMS cuando se compararon con su control, pero se aprecia que las hembras tratadas presentaron una tendencia a un estado más oxidado (Gráfica 12a). Los machos tratados con GMS (Gráfica 12b) no presentaron diferencias significativas excepto a los 16 meses de edad, donde predominó un estado oxidado (64\%) comparado con el control y posteriormente a los 20 meses de edad se encontraron en balance nuevamente $(p<0.05)$.

El análisis de género indicó que sólo a los 4 meses de edad las hembras se encontraban en un estado mayormente oxidado (57\%) comparado con los machos $(p<0.05)$
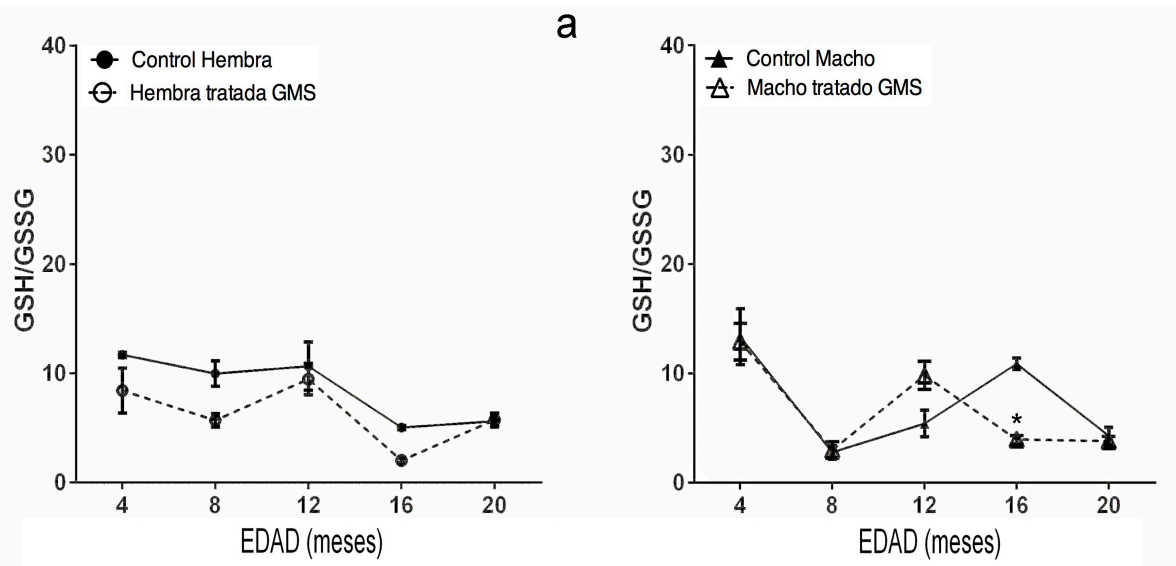

Gráfica 12. Estado REDOX. Determinación del índice GSH/GSSG en sangre total de ratones control y GMS a) hembra y b) macho a diferentes edades. \pm S.E.M., de cinco ratones por grupo. ${ }^{*} p<0.05$ vs Control. 


\section{DISCUSIÓN}

La población de adultos mayores del mundo crece rápidamente; y se ha visto que la prevalencia de la obesidad y el sobrepeso también se han incrementado de manera lineal con la edad. A pesar de que existen varios informes que estudian la relación entre la obesidad y la edad, son pocos los estudios longitudinales que analizan el efecto de la obesidad durante toda la vida, es decir, desde los jóvenes hasta los ancianos. Por lo tanto, nuestro interés fue evaluar las alteraciones en los parámetros bioquímicos e inflamatorios, la homeostasis de glucosa e insulina y los parámetros de daño oxidante durante el proceso de la obesidad-envejecimiento.

El modelo de obesidad inducido con GMS generó ratones hembras y machos obesos en la edad adulta, con pesos corporales claramente mayores a sus compañeros de camada. El aumento de peso comenzó a disminuir a los 16 meses de edad en todos los grupos, manifestándose una correlación inversa con la longitud naso-anal. Los ratones hembra tratados con GMS mostraron el mayor Índice Lee de todos los grupos estudiados, lo cual podría considerarse consistente con los estudios realizados en humanos, donde las mujeres presentan porcentajes más altos de grasa corporal comparado con los hombres (Tchkonia et al., 2010).

Los cambios observados en el peso corporal podrían explicarse debido a un aparente dimorfismo sexual, con diferencias en la distribución abundancia del tejido adiposo. De hecho, tanto las hembras delgadas como obesas presentaron mayor contenido de grasa subcutánea, lo cual puede asociarse con disminución en la 
producción de hormonas ováricas (Meyer et al., 2011). Contrariamente, el TA en los ratones macho predominó en la región visceral (Nickelson et al., 2012).

El peso corporal declinó en ratones control y obesos de los 16 a los 20 meses de edad, lo cual también parece consistente con los estudios realizados en humanos, ratones y ratas, en donde los cambios en la masa del TA y su función a través de la vida se reflejan en la disminución del peso corporal. El incremento en el peso asociado con la edad es comúnmente debido a la acumulación de grasa en diversos depósitos, y se ha reportado que, en humanos, el promedio de edad donde la acumulación de grasa comienza a disminuir es a la edad de 60 años y, aproximadamente a la edad de los 80 años, la prevalencia de la obesidad se reduce en un tercio.

En la vejez principalmente, la pérdida de peso también representa un problema de salud, debido a que está asociado con la sarcopenia, como resultado de cambios endócrinos y disminución en la actividad física (Kennedy et al., 2006). Las razones precisas responsables de la disminución en el peso corporal son complejas y aún se desconocen. Sin embargo, se sabe que la grasa se redistribuye durante el envejecimiento en diversas especies, lo cual se ha asociado con lipotoxicidad y longevidad reducida. Sin embargo, mayor proporción de grasa subcutánea que visceral se ha relacionado con mayor longevidad (Tchkonia et al., 2010; Meyer et al., 2011; Raguso et al., 2006; Kehayias et al., 1997).

El comienzo de la obesidad desde la niñez y durante la vida puede promover alteraciones metabólicas como diabetes (Furuya et al., 2010; Giannini et al., 2009; García et al., 2011; González et al., 2013; Jiang et al., 2013); sin embargo, no es 
claro cómo la obesidad puede alterar el proceso de envejecimiento. En el presente trabajo se encontró alteración en la tolerancia a la glucosa con resistencia a insulina en los ratones obesos GMS hembras y macho comparados con sus grupos control, principalmente de los 4 a los 16 meses de edad, lo cual se correlaciona con el periodo de ganancia de peso corporal.

Estos resultados concuerdan con estudios previos en donde se emplean animales de 54 semanas de edad (Tchkonia et al., 2010; Islam et al., 2009), en los cuales se les asocio mayor adiposidad, estrés oxidante e inflamación (Giannini et al., 2009; Evans et al., 2003). En nuestro estudio, los grupos control machos y hembras mostraron alteración de la tolerancia a la glucosa y resistencia a insulina a lo largo del estudio, pero no excedieron los valores alcanzados por los ratones obesos. Las hembras y los macho GMS mostraron entre los 4 y 16 meses de edad niveles de glucosa e insulina significativamente más altos que los controles pero a los 16 meses de edad los valores disminuyeron en ambas pruebas terminando con valores similares a los observados en los controles. Este comportamiento de los ratones obesos se correlacionó con la pérdida de peso y redistribución de la grasa corporal como parte del proceso de envejecimiento, el cual se presenta posiblemente por los cambios fisiológicos conforme se envejece como un intento para reducir los factores de riesgo, como la inflamación y el estrés oxidante, los cuales se correlacionan con la alteración de la homeostasis de glucosa y la secreción de insulina. Aunque se sabe poco acerca de los mecanismos de adaptación al estrés crónico de bajo grado, como la obesidad durante el envejecimiento, estas respuestas deben estar presentes para permitir que el organismo se adapte a las alteraciones metabólicas. 
Uno de los diversos mecanismos por los cuales la sensibilidad a la insulina está disminuida o ausente en la obesidad se debe al incremento en la producción de NO, particularmente como resultado de la actividad de la sintasa del óxido nítrico inducible (iNOS), la cual se ha sido asociado con la RI (Evans et al., 2013). Durante el envejecimiento, muchos factores están involucrados en el desarrollo de la disminución en la sensibilidad a la insulina, tales como la pérdida de la secreción de insulina estimulada por glucosa y mediada por sirtuina-1 (Sirt1), una disminución en la sensibilidad de la célula $\beta$, disminución de la función mitocondrial, la acumulación de células senescentes en el tejido adiposo y un incremento del estrés oxidante. Sin embargo, el mecanismo molecular fundamental de estos cambios no es totalmente claro y comúnmente se atribuyen a múltiples causas (Jiang et al., 2013; Cai et al., 2012; Gong et al., 2012).

Nuestros resultados demuestran una alteración en la tolerancia a la glucosa y en la sensibilidad a la insulina, lo cual podría estar relacionado con el aumento de TA hasta los 12 meses de edad, ya que se sabe que esta característica tiene un papel importante en la homeostasis de glucosa y en el control de la sensibilidad a la insulina. Por otra parte, Macotela y colaboradores (2009) encontraron un importante papel de los esteroides sexuales en la modulación del TA y la sensibilidad a la insulina. Por ejemplo, los adipocitos femeninos tienen aumentada la síntesis de lípidos comparados con los adipocitos masculinos, tanto en los depósitos perigonadales (PG) como en los subcutáneos (SC) (Macotela et al., 2009).

En mujeres, los adipocitos PG tienen una mayor sensibilidad a la insulina para la lipogénesis y la señalización de la insulina. Esta situación contribuye a la 
sensibilidad a la insulina en todo el cuerpo, permitiendo que los ratones hembra permanezcan sensibles a la insulina, a pesar de su mayor contenido de tejido adiposo. Las diferencias por género en el tejido adiposo visceral disminuyen a edades más avanzadas, ya que en las mujeres postmenopáusicas aumenta la acumulación de grasa visceral (Goodman et al., 1996; Camhi et al., 2011).

Es importante hacer hincapié en el papel de los esteroides gonadales en este fenómeno. A pesar de que el más alto valor del IL fue determinado para los ratones hembra, se sabe que éstas son más sensibles a la insulina que los ratones macho. Así mismo, las mujeres tienen una mejor tolerancia a la glucosa y un aumento en la sensibilidad a la insulina comparado con los hombres (Yki-Jarvinen, 1984). En diferentes modelos murinos de intolerancia a la glucosa, RI y diabetes, los machos muestran un fuerte fenotipo comparado con las hembras (Zierath et al., 1997; Li et al., 2000). Estas diferencias relacionadas con el sexo en la sensibilidad a la insulina y el desarrollo y función del tejido adiposo pueden ser parcialmente atribuidas a los efectos de estrógenos y testosterona. Sin embargo, cómo la insulina afecta de forma distinta a machos y hembras, y cómo estas diferencias ligadas al sexo impactan en el desarrollo del tejido adiposo y en la regulación de su función son preguntas que todavía no se han resuelto. La variabilidad estructural o anatómica del organismo está involucrada probablemente en algunas de las diferencias funcionales entre el TA de machos y hembras. Por ejemplo, el tejido adiposo está inervado por los nervios eferentes simpáticos y estas inervaciones son distintas entre los géneros. Curiosamente las ratas macho tienen más neuronas que se proyectan hacia la grasa abdominal, mientras que las hembras tienen más proyecciones a la grasa 
subcutánea (Adler et al., 2012). En la presente investigación, los niveles de TG en las hembras control fueron más altos que en los machos control durante todos los puntos de este estudio, pero los animales tratados con GMS mostraron niveles más altos de TG que los controles. Este resultado podría ser explicado por la dislipidemia y la inducción de lipogénesis durante el envejecimiento (Gendron et al., 2007; Kuhla et al., 2011), junto con incrementos en los niveles de lípidos totales, AGL, TG y fosfolípidos reportados en otros estudios (Ahluwalia et al., 2005; Barzilai et al., 2012; Malik et al., 1994; Singh et al., 2012). En nuestro estudio encontramos que los triglicéridos pueden ser exacerbados por la obesidad durante el envejecimiento.

Así mismo, los niveles de colesterol fueron más altos en ratones obesos en comparación con los grupos control, sin embargo, cuando los ratones obesos fueron comparados por género, se observó que la única diferencia estadística fue a los 16 meses de edad, con un aumento significativo en los machos comparado con las hembras. Por lo tanto, nuestros resultados concuerdan con estudios previos de dislipidemia severa en ratones machos tratados con GMS, que se caracteriza por la hiperinsulinemia e hipercolesterolemia a los 4 meses (Hata et al., 2012) y 7 meses de edad (Nagata et al., 2006).

No hay estudios en donde se compare el contenido de colesterol total y TG determinados durante la vida de los ratones obesos. Otro hallazgo en el presente estudio fue la disminución de los niveles de colesterol total y de TG a los 16 y 20 meses de edad en ratones obesos, coincidiendo con los cambios en la homeostasis de glucosa e insulina en estas edades. Es importante mencionar que el efecto de la edad sobre la homeostasis de colesterol está pobremente explicado en la literatura. 
Un gran número de estudios epidemiológicos sugieren que los niveles de colesterol tienden a incrementarse en los adultos, pero posteriormente disminuyen en personas ancianas (Bertolotti et al., 2014). Del mismo modo, se ha encontrado que personas obesas, tanto jóvenes como adultos mayores, muestran niveles plasmáticos significativamente más altos de colesterol y TG (Kronmal et al., 1993). De manera interesante, el grupo de Karaouzene (2010) mostró que los hombres obesos jóvenes tenían cambios relativamente más grandes y acentuados en los lipidos plasmáticos y lipoproteínas que los pacientes ancianos (Karaouzene et al., 2011).

Este resultado podría explicar los picos elevados de colesterol encontrados en los ratones macho obesos a los 16 meses de edad y posteriormente la reducción a los 20 meses. A pesar de este valor particularmente alto, el aumento de colesterol en plasma se produce de forma continua durante toda la vida. Hay otros estudios realizados en humanos de edad media, donde el contenido de colesterol total se incrementa en suero durante varios años antes de que éste comience a disminuir en un rango de $0.04 \mathrm{mmol} / \mathrm{L}$ por año (Weijemberg et al., 1996). Por otra parte, Abbot y colaboradores (1997) encontraron que el contenido de colesterol total disminuye en un rango de $1.6-1.8 \mathrm{mg} / \mathrm{dL}$ por año por un periodo de 20 años en hombres de edad avanzada (Abbott et al., 1997).

Otros estudios encontraron que los decrementos en el contenido de colesterol observado en hombres y mujeres jóvenes sanos se debieron a la pérdida de peso, siendo el factor más importante asociado con los cambios en los lipidos (Ferrara et al., 1997). El aumento en la concentración de colesterol total y posteriormente su 
disminución en los ancianos se asoció con una reducción en el IMC (Wilson et al., 1994), lo que sugiere que el descenso en el nivel de colesterol total con la edad avanzada puede ser parte del proceso natural de envejecimiento. Otra condición en la redistribución de la grasa durante el envejecimiento, que promueve anormalidades, es la enfermedad del hígado graso no alcohólico (NAFLD) ampliamente asociada con el síndrome metabólico de resistencia a la insulina (NAFLD primario) (Giannini et al., 2009).

El alto IMC y la gran circunferencia de la cintura observados durante la obesidad se han asociado con niveles elevados de transaminasas: AST y ALT (Rodríguez et al., 2013). Ambas enzimas son empleadas como marcadores de daño hepatocelular (Inuwa et al., 2011). Aunque ALT y AST son detectadas en el hígado, éstas se encuentran presentes en el suero y en varios tejidos. En particular los niveles séricos de ALT llegan a elevarse durante enfermedades del hígado, y por lo tanto, son considerados como mejor marcador de daño hepático que AST (Kunutsor et al., 2013).

Cuando se evaluó la función hepática, encontramos un incremento gradual de los niveles de ALT y AST a lo largo de la vida, tanto en los grupos control como en los obesos, con elevado índice de AST/ALT, el cual fue empleado como una referencia para el daño hepático. De manera interesante, los grupos de ratones macho tuvieron valores de ALT superiores comparados con los grupos de hembras a través del tiempo. Esta diferencia disminuyó a los 20 meses de edad. Ademas, los niveles de AST en los grupos de hembras control fueron más bajos comparados con los otros tres grupos evaluados. 
Actualmente, no hay estudios de evaluación de los marcadores hepáticos en ratones obesos durante el envejecimiento; sin embargo, estudios puntuales en humanos han demostrado que la AST se encuentra ligeramente incrementada en los hombres obesos; mientras que en las mujeres obesas, los niveles de ALT y AST no cambian, y los niveles de estas enzimas están muy por debajo de los niveles reportados en los grupos de hombres control (Gong et al., 2012; Qureshi et al., 2006). De manera similar, Choi y colaboradores en 2003, estudiaron la obesidad en humanos y encontraron que los varones mostraron valores más altos de AST y ALT que las mujeres obesas.

En nuestro modelo, los niveles de ALT disminuyeron en machos de los 16 a los 20 meses de edad, sin embargo, los valores de ALT en ratones obesos permanecieron elevados comparados con su control. En ratones hembras durante el mismo periodo, los niveles de ALT también aumentaron, pero no con la misma intensidad comparado con meses previos. Estos resultados concuerdan con los encontrados por Dong y colaboradores en 2010, quienes encontraron que los niveles de ALT disminuyen con la edad tanto en hombres como en mujeres, independiente de los componentes del síndrome metabólico, biomarcadores de la señalización de la adiposidad y otras pruebas comúnmente empleadas para la evaluación de la función hepática. No obstante, se requiere realizar otros estudios para entender los mecanismos responsables de la disminución de los niveles de ALT con la edad, sin embargo, es importante sugerir que se deben generar límites de referencia dependiente del género para AST y ALT para personas de la tercera edad. 
Por otro lado, la inflamación crónica de bajo grado se caracteriza por un aumento en las concentraciones de marcadores inflamatorios en la circulación sistémica y es considerada como un factor de riesgo para el SM y para la diabetes tipo 2 (Calder et al., 2011; Van-Beek et al., 2014). La inflamación crónica de bajo grado cursa con un aumento en los indicadores sistémicos de inflamación, como leucocitos, concentraciones de proteínas de fase aguda en suero y plasma, citocinas proinflamatorias, quimiocinas, moléculas de adhesión y mediadores protrombóticos.

En pacientes obesos se han observado altas concentraciones sistémicas de mediadores proinflamatorios (TNF- $\alpha$, IL-6, MCP-1, IL-18) y disminución de los niveles de adiponectina (Calder et al., 2011; Van-Beek et al., 2014). Una conexión mecanistica entre la obesidad y la inflamación de bajo grado, fue propuesta inicialmente por Hotamisligil y colaboradores, quienes mostraron que el tejido adiposo blanco sintetiza y libera la citocina proinflamatoria TNF- $\alpha$ (Calder et al., 2011).

Con respecto al perfil inflamatorio evaluado en nuestro estudio,, los marcadores séricos proinflamatorios como TNF- $\alpha$ e IL-6 aumentaron en los ratones tratados con GMS y en los ratones control, a lo largo del tiempo. El aumento de dichas citocinas se correlacionó con la obesidad, con el IL y con la homeostasis de glucosa e insulina. Esta correlación es consistente con el hecho de que TNF-a es un factor clave en la patogénesis de la pérdida de la sensibilidad a la insulina (Uchida et al., 2012; Tweedell et al., 2011; Yoneda et al., 2011; Zhang et al., 2010).

Los ratones macho mostraron una mayor expresión de TNF- $\alpha$ comparado con los ratones hembras a lo largo del estudio, pero los ratones macho obesos GMS 
presentaron mayores niveles de TNF- $\alpha$ comparados con las hembras obesas y los grupos control. Los niveles séricos de IL-6 se incrementaron gradualmente a través del tiempo en los cuatro grupos y a los 12 meses de edad se observó un incremento significativo en los ratones macho comparado con las hembras. No se encontraron diferencias entre los ratones tratados con GMS y sus controles. Es importante mencionar que los niveles de las citocinas proinflamatorias disminuyeron en todos los grupos a partir de los 12 meses de edad, sin diferencias entre ellos.

Para explicar el efecto de TNF- $\alpha$ sobre la sensibilidad a la insulina se han propuesto tres posibles mecanismos: (1) a través de una fosforilación anormal del sustrato del receptor de insulina (IRS)1; (2) por pérdida en el adipocito del transportador de glucosa 4 (GLUT-4) y (3) por la supresión de adiponectina (García et al., 2010; Antuna et al., 2008; Ye et al., 2012).

Es muy importante mencionar que el papel preciso de la adiponectina en la progresión de la diabetes no está bien caracterizado, a pesar que es considerada como una adipocina benéfica, mostrando correlaciones negativas con muchas enfermedades relacionadas con la obesidad y la edad y una correlación positiva con la longevidad y la sensibilidad a la insulina (Arai et al., 2011). Resultados previos de nuestro grupo de trabajo han mostrado que bajas concentraciones de adiponectina en animales obesos están asociadas con la inflamación crónica, RI y DM2 (Almanza et al., 2010).

En nuestro estudio, los niveles de adiponectina disminuyeron gradualmente desde los 4 hasta los 12 meses de edad, tanto en hembras como en machos tratados con GMS, pero principalmente en estos últimos. En este periodo de tiempo 
los ratones mostraron una ganancia de peso y niveles elevados de TNF- $\alpha$, así como una homeostasis de glucosa e insulina alterada. Sin embargo, a los 16 meses de edad, los niveles de adiponectina incrementaron en los ratones control y obesos, mientras que el peso corporal y los niveles de TNF- $\alpha$ disminuyeron.

Estos resultados concuerdan con estudios previos en los que se han reportado que las concentraciones de adiponectina se incrementan con la edad en humanos (Cnop et al., 2003). Los niveles circulantes de adiponectina correlacionan positivamente con la sensibilidad a la insulina inducida por la actividad del receptor nuclear PPAR-y en humanos y roedores (Hocking et al., 2013; Izadi et al., 2013; Takashi et al., 2006). Una comparación por género mostró que los ratones macho presentan una menor concentración de adiponectina comparado con los ratones hembra. Un dimorfismo sexual repercute en los niveles circulantes de adiponectina, siendo las hembras quienes presentan mayores niveles comparados con los machos (Combs et al., 2003; Xu et al., 2005).

Esto fue corroborado en nuestro estudio, sin embargo, la influencia directa de los andrógenos sobre las concentraciones de adiponectina no es clara aún y se ha sugerido que las hormonas sexuales podrían regular la producción de adiponectina, aunque aún es controversial. Lo anterior podría explicar parcialmente por qué las hembras son más susceptibles a la insulina que los machos (Kadowaki et al., 2011) y por que las concentraciones de adiponectina correlacionan de forma negativa con el tejido adiposo visceral, (predominante en hembras) pero de forma positiva con el tejido adiposo subcutáneo (Hanley et al., 2008). 
Por otra parte, la propiedad antiinflamatoria de adiponectina podría estar mediada por la liberación de IL-10 de macrófagos. La adiponectina promueve la polarización de macrófagos a través del fenotipo M2 y reduce la generación de ERO (Nakatsuji et al., 2014). Se han propuesto dos mecanismos adicionales para la hipoadiponectinemia en la obesidad, un mecanismo indica que la adiponectina podría ser secretada por adipocitos y después permanecer en el intersticio del tejido adiposo. Los ratones obesos obviamente poseen mayor cantidad de TA que los ratones delgados, por lo tanto, estos mecanismos pueden explicar en parte la hipoadiponectinemia de la obesidad. El segundo mecanismo indica que T-cadherina (molécula de adhesión celular) también podría desempeñar un papel en la hipoadiponectinemia de la obesidad. T-cadherina secuestra la adiponectina en el corazón. Ratones KO para T-cadherina muestran hiperadiponectinemia comparado con ratones WT. Además, el gen $\mathrm{CDH} 13$ que codifica para T-cadherina tiene un papel importante en las variaciones de las concentraciones de adiponectina en humanos. T-cadherina puede capturar adiponectina libre del torrente sanguíneo y unirla en diversos tejidos, afectando los niveles circulantes de adiponectina en la obesidad (Nakatsuji et al., 2014).

El envejecimiento está asociado con cambios complejos en la desregulación del sistema inmune, el cual incluye componentes inflamatorios. Por lo que la inmunosenescencia ha sido propuesta como una consecuencia continua del desgaste causado por la sobrecarga antigénica crónica. El envejecimiento está acompañado por un estado de inflamación crónica de bajo grado, donde se 
encuentran de 2 a 4 veces incrementados los niveles séricos de diversos mediadores inflamatorios tales como TNF-a, PCR e IL-1 (Calder et al., 2011).

En el modelo de ratones obesos GMS se observa un estado inflamatorio crónico de bajo grado caracterizado por incremento de citocinas proinflamatorias (TNF-a e IL-6), reducción en la expresión de adiponectina (Shore, 2010) y una elevación plasmática de esta adipocina. En estudios futuros es necesario establecer la asociación entre adiponectina, género, envejecimiento y los factores de riesgo metabólicos.

En cuanto al daño oxidante generado en la obesidad, se sabe que la expansión de la masa del TA se ha asociado con varios factores, incluyendo hipoxia del tejido de manera localizada, infiltración de células inflamatorias (macrófagos) y alteración del perfil de citocinas. Esta hipoxia genera inhibición de la señalización del receptor de insulina, lipólisis incrementada y una sobreproducción de ERO (Roguee, 2009; Brigitte et al., 2011; Nakatsuji et al., 2014). En ratones obesos, los niveles de estrés oxidante están incrementados, y pueden ser disminuídos con el uso de antioxidantes para evitar el desarrollo de diabetes. De esta forma, el tejido adiposo representa una fuente importante de ERO, lo cual podría contribuir al desarrollo de resistencia a la insulina debida a obesidad (Matsuda et al., 2013).

Con la finalidad de estudiar el estrés oxidante y el posible desarrollo de enfermedades asociadas por la falta de un correcto o adecuado funcionamiento del sistema antioxidante, se evaluó primeramente el impacto de la obesidad sobre las biomoleculas (proteinas y lípidos) mediante la detección de proteinas carboniladas y la cuantificacion de MDA, como se comenta a continuación. 
Los resultados obtenidos muestran que la obesidad incrementa la peroxidación lipídica en el tejido hepático, pulmonar, renal y cardiaco, principalmente en ratones obesos adultos y envejecidos, expresado por el incremento en los niveles de MDA.

Nuestros resultados concuerdan con estudios previos en los que se muestra que la obesidad es un factor de riesgo independiente para el incremento en la peroxidacion lipídica y reducción en la actividad citoprotectiva de enzimas (Amirkhizi et al., 2007; Noeman et al., 2011). Por ejemplo, en un estudio observacional de 140 hombres y mujeres no diabéticos (con un promedio de edad de 59 años) el IMC y la circunferencia abdominal estuvieron directamente asociados con las sustancias reactivas al ácido tiobarbitúrico en plasma (TBARS) para la formación de productos de peroxidación de lípidos como la 8-epi PGF2a urinaria. El análisis de 2828 sujetos (con un promedio de edad de 61 años) de la cohorte Framingham, reveló una correlación lineal entre la obesidad y la peroxidación de lípidos. De forma similar, el 8-epi PGF2 $\alpha$ ha sido asociado en estudios con hombres de la misma edad con adiposidad, resistencia a la insulina y moléculas de adhesión endotelial (Bagchi et al., 2012).

Existen mecanismos potenciales que tratan de explicar el incremento de la peroxidación de lípidos en tejido hepático, cardiaco y renal. Por un lado, las ERO y los productos de LPx impiden el correcto funcionamiento de la cadena respiratoria en los hepatocitos ya sea de forma directa o indirectamente a través del daño oxidante en el genoma mitocondrial (Amirkhizi et al., 2007; Rogge, 2009; Noeman et al., 2011). Estas características conducen a la generación de más ERO y se establece 
un círculo vicioso. La disfunción mitocondrial puede conducir a la apoptosis o necrosis dependiendo del estado energético de la célula. Por ejemplo en hígado, las ERO y los productos de peroxidación lipídica activan a las células estelares hepáticas, generando enfermedad por fibrosis (Noeman et al., 2011).

La peroxidación de lípidos en el corazón induce a la pérdida de la integridad de la membrana celular debido a una modificación oxidativa de los lípidos y proteínas que pueden conducir a la presencia de arritmias cardiacas, contractilidad pobre, infartos, falla cardiaca y finalmente la muerte (Amirkhizi et al., 2007; Rogge, 2009; Noeman et al., 2011). La obesidad incrementa la carga metabólica y mecánica sobre el miocardio, incrementando así el consumo de oxigeno miocárdico (Amirkhizi et al., 2007). Esta sobrecarga mecánica induce el aumento en el consumo de oxígeno por parte del músculo cardiaco y acelera el flujo de electrones a través de las mitocondrias en proporción a la necesidad de ATP, lo cual resulta en una fuga de electrones de la cadena de transporte aumentando así la producción del radical superóxido $\left(\mathrm{O}_{2}^{-} \bullet\right.$ ), peroxinitrito $\left(\mathrm{ONOO}^{-}\right)$, radical hidroxilo $\left(\mathrm{OH}^{-} \bullet\right)$ y peróxido de hidrogeno $\left(\mathrm{H}_{2} \mathrm{O}_{2}\right)$ (Rogge, 2009; Noeman et al., 2011).

La interrupción de la función mitocondrial resulta en un daño celular como la peroxidacion de lípidos de membranas, oxidación de ácidos nucleicos mitocondriales, y proteínas, especialmente las enzimas esenciales de la cadena respiratoria (Amirkhizi et al., 2007; Rogge, 2009; Noeman et al., 2011). Lo anterior está de acuerdo con nuestro estudio en el que observamos que a partir de los 12 meses de edad, es decir, la etapa en donde los ratones tratados con GMS presentan un grado 
máximo de obesidad, también presentan diferencias significativas en el incremento de lípidos oxidados en corazón.

También la peroxidación de lípidos y el estrés oxidante participan en los mecanismos que contribuyen al establecimiento y progresión de la disfunción renal en la obesidad. Por ejemplo una dieta alta en grasa, induce la alteración del metabolismo de lípidos a nivel renal por un desbalance entre la lipogénesis y la lipólisis en riñón, asi como anormalidades metabólicas sistémicas con la subsecuente peroxidacion de lípidos que conduce finalmente al daño en el riñón (Amirkhizi et al., 2007; Noeman et al., 2011).

La acumulación del TA alrededor de los riñones de ratas obesas penetra en los sinusoides medulares incrementando la presión intrarenal el cual produce daño del tejido renal, y de esta forma el tejido renal dañado se convierte en una fuente de ERO que finalmente llevan a peroxidación lipídica (Noeman et al., 2011). El incremento en la peroxidacion de lípidos en el tejido renal, asi como la modificación de la fracción LDL/VLDL (low-density lipoprotein I very low-density lipoprotein) circulante, participan en el establecimiento de las lesiones renales en un modelo normoglucémico de roedores obesos (Noeman et al., 2011).

Otro mecanismo propuesto establece que la obesidad puede causar un incremento en la peroxidación de lípidos por una progresiva acumulación de daño celular en el TA (Amirkhizi et al., 2007). Este daño celular causa la liberación de citocinas, especialmente del TNF- $\alpha$, el cual genera ERO en el TA y a su vez causa peroxidación de lípidos (Noeman et al., 2011; Bikkad et al., 2013). La hipertrigliceridemia observada en ratas obesas podría contribuir a la alteración en el 
balance oxidante/antioxidante, sugiriendo que un incremento en la biodisponibilidad de AGL puede incrementar la peroxidación de lípidos (Rogge, 2009; Noeman et al., 2011).

Como se ha visto, la obesidad promueve la peroxidación lipídica y puede potenciar el estrés oxidante en algunos tejidos del cuerpo, lo cual podría asociarse con una disminución en la capacidad protectora de los antioxidantes, concordando con otros estudios en donde se ha concluido que la obesidad en machos está asociada con un estado antioxidante deficiente e hipozinquemia (disminución de los niveles plasmáticos de zinc), con implicaciones en el desarrollo de la obesidad relacionado con problemas de salud (Bikkad et al., 2013).

Por otra parte, se ha reportado que la carbonilación de proteínas puede ser un mecanismo favorable para la regulación de la homeostasis de proteínas en condiciones naturales, por ejemplo, de la degradación de proteínas que no son empleadas, o en la degradación de enzimas para bloquear algunas vías metabólicas que no son requeridas en una situación fisiológica determinada (Grimsrud et al., 2008). Además, en los últimos años se ha propuesto que la carbonilación de proteínas puede intervenir en la transducción de señales celulares (Wong et al., 2010), teniendo varias repercusiones a nivel biológico (Nystrom, 2005). Sin embargo, cuando las proteínas están dañadas pierden su función biológica (Brigitte et al., 2011). Por tanto el conocer el grado de daño causado por estrés oxidante inducido por la obesidad en las proteínas nos puede proporcionar información acerca de las alteraciones de las vías metabólicas y la función de los órganos a través del tiempo. 
En este estudio se determinaron proteínas carboniladas mediante el uso del oxyblot en diferentes órganos a diferentes edades en la vida del ratón obeso. Al parecer los productos carbonilados son más estables que los productos de LPx como el MDA (Pradeep et al., 2013). El incremento y acumulación de las proteínas carboniladas debido a productos de LPx como el MDA y el HNE están asociados a enfermedades neurodegenerativas, diabetes y síndrome de Down, entre otras (Baraibar et al., 2012).

Los resultados mostraron que las hembras obesas fueron principalmente las que tuvieron aumento significativo en el daño de proteínas a partir de los 8 meses de edad, tanto en hígado como en pulmón debido al estrés oxidante generado por un exceso de $\mathrm{H}_{2} \mathrm{O}_{2}$ (Bansode et al., 2013).. Las proteínas carboniladas disminuyeron posteriormente a los 20 meses, tanto en controles como en ratones obesos, lo cual podría indicarnos algún mecanismo de reparación y/o adaptación al estrés oxidante a través de la vida.

Nuestros resultados concuerdan con reportes realizados por Noeman, quien empleó un modelo de obesidad inducido por una dieta alta en grasa, el cual se relacionó con un incremento de estrés oxidante en hígado, corazón y riñón y por reducción en las actividades enzimaticas antioxidantes y los niveles de glutatión con incremento de peroxidación de lípidos y proteínas carboniladas (Noeman et al., 2011). Existen reportes en otros estudios donde el incremento significativo de cobre, que forma parte de la enzima antioxidante Cu/Zn-SOD puede intervenir como agente catalítico y producir radicales $\mathrm{OH} \bullet$ muy reactivos, originando niveles elevados de proteínas carboniladas (Zitnanova et al., 2006). 
En nuestro estudio encontramos estrés oxidante que se manifiestó desde edades previas a la etapa adulta en los ratones obesos GMS, principalmente en hígado y pulmón. Este daño oxidante podria ser un mecanismo regulador de la patogénesis de la obesidad o influir en la aparición de algunas de las características que la engloba.

Existen evidencias del deterioro del proteosoma en enfermedades crónico degenerativas como la diabetes y la obesidad (Ciechanover et al., 2000; WallerEvans et al., 2013). Las proteínas oxidadas pueden a su vez actuar como agentes prooxidantes, produciendo daño adicional a otras biomoleculas (Stadman et al., 1992; Andersson et al., 2013) y al mismo tiempo al proteosoma (Koga et al., 2011), que es el responsable de la degradación de las proteínas oxidadas (Sitte et al., 2000; Shang et al., 2011).

En nuestro estudio encontramos una mayor señal de las proteínas oxidadas en el control con respecto a las detectadas en el ratón obeso que podría ser explicado mediante un fenómeno de degradación de proteínas, en donde al mantenerse en un estado de estrés el órgano en cuestión, son rápidamente degradadas de manera específica. Otra posible explicación está basada en que estas proteínas podrían ser más propensas a formar cúmulos citotóxicos (Nystrom, 2005) y, por lo tanto, debido a esta degradación o por la formación de cúmulos, podríamos estar observando disminuida la señal de estas proteínas oxidadas en el ratón obeso.

Se sabe que el recambio proteínico que se lleva acabo principalmente en el proteosoma y en los lisosomas durante el envejecimiento está disminuido (Szweda et 
al., 2002). Así, la pérdida de la función proteolítica contribuye a la fragilidad de las células desde etapas jóvenes hasta la etapa adulta (Szweda et al., 2002; Proctor et al., 2011). En algunos estudios previos, por ejemplo en fibroblastos embrionarios humanos, se han detectado 180 proteínas modificadas oxidativamente, de las cuales el $35 \%$ se encuentran en fibroblastos senescentes. Entre ellas se encuentran la SOD1 y la SOD2, lo que propiciar un incremento de proteinas dañadas (Ahmed et al., 2010; Ahmed et al., 2007).

Estos resultados indican la susceptibilidad particular de ciertas proteínas a modificaciones oxidantes, lo cual sugiere que la modificación proteínica no es un proceso que ocurre de forma aleatoria y probablemente está implicada en enfermedades relacionadas con la edad y con el envejecimiento (Baraibar et al., 2012). También se han identificado proteínas modificadas oxidativamente asociadas con el envejecimiento en humanos y en modelos animales mamíferos. En estos estudios se ha demostrado un incremento de proteínas carboniladas, localizadas principalmente en el citosol y en las mitocondrias.

La disfunción mitocondrial es uno de los procesos principales por los cuales se origina el mayor número de proteínas carboniladas (Baraibar et al., 2012). En nuestro modelo encontramos que estas modificaciones oxidantes de las proteínas en el ratón obeso GMS posiblemente contribuyeron al envejecimiento prematuro al compararlo con los controles. Sin embargo, encontramos una disminución de la oxidación de las proteínas tanto en obesos como en los controles a partir de los 16 meses, lo que puede correlacionarse con el aumento de la catalas a lo largo de la vida. También 
pueden existir otros mecanismos de protección que le permiten al organismo hacer frente a este daño.

Se ha encontrado que un incremento en el TA está asociado con un incremento en los niveles de proteínas carboniladas. Así mismo, la resistencia a la insulina en humanos está relacionado con la acumulación de lípidos intracelulares y con el incremento de proteínas carboniladas en células musculares (Grimsrud et al., 2007; Frohnert et al., 2013).

Además, en el tejido adiposo subcutáneo de humanos se observó de forma similar niveles incrementados de proteínas carboniladas asociadas con el incremento del peso corporal (Frohnert et al., 2013). Lo anterior está de acuerdo con nuestros resultados, en donde durante etapas adultas de la vida del raton obeso, tanto hembras como machos, encontramos mayores alteraciones en la mayoría de las mediciones. En el caso de las hembras, específicamente se presentó mayor grado de proteínas carboniladas en hígado a los 12 meses de edad, lo cual se relaciona con el mayor grado de obesidad observado en este modelo a esa edad.

También se relaciona que la disminución de peso a partir de los 16 meses de edad en todos los grupos se asocia con la disminución de las proteínas carboniladas.

De esta forma se podría hipotetizar que la carbonilación incrementada se debe a la inflamación por aumento de peso, como lo han demostrado estudios en donde se ha observado que el tratamiento de adipocitos 3T3-L1 con TNF- $\alpha$ conduce al incremento de peroxidación de lípidos, incremento en las proteínas carboniladas y disfunción mitocondrial (Frohnert et al., 2013), lo cual estaría de acuerdo con 
nuestros resultados en donde también se observan niveles incrementados de TNF- $\alpha$ a partir de los 12 meses de edad.

Se ha descrito que la carbonilación de proteínas en el TA se relaciona directamente con el IMC y con los niveles séricos de AGL (Brigitte et al., 2011), así como con la carbonilación de proteínas asociada con la disfunción mitocondrial y la RI. Es necesario realizar más estudios para esclarecer la relación entre la carbonilación y la sensibilidad a la insulina. Adicionalmente, la identificación de blancos de carbonilación y su regulación por estrés oxidante podría darnos información acerca del papel de este proceso en la obesidad y su relación con la disfunción del TA en el envejecimiento.

Como se ha visto en adultos, los mecanismos de defensa celular podrían estar relacionadas con la obesidad y sus complicaciones (Sfar et al., 2013). En el presente estudio, la respuesta antioxidante manifestada por la actividad de enzimas como CAT, SOD, así como algunas otras moléculas como GSH y MTs que tienen un papel protector frente al daño oxidante generado por obesidad a través del tiempo fue evaluado en hígado, pulmón, corazón y riñón.

Con respecto a la actividad de CAT, se encontró más elevada en los ratones obesos comparados con sus controles respectivos tomando en cuenta el género y las variaciones relacionadas con la edad. En hígado, se observó un incremento en la actividad de la enzima a partir de los 8 meses de edad, patrón que se repite en las determinaciones en pulmón, corazón y riñón, siendo mayor en las hembras obesas comparadas con los machos obesos a través del tiempo. 
En machos obesos se observó una disminución en la actividad de CAT comparado con su control respectivo en pulmón, corazón y riñon, lo cual concuerda con estudios realizados por Noeman en 2011, quien determinó que la actividad de CAT permanece sin cambios significativos o incluso disminuida en riñón de ratas obesas. Esto podría estar relacionado con la inactivación de enzimas antioxidantes y proteínas por un alto nivel de peroxidación de lípidos, como se ha descrito en la obesidad (Noeman et al., 2011). Estos resultados, confirman que la obesidad está asociada con el incremento de estrés oxidante iniciado en etapas adultas en la vida de los ratones obesos, lo cual concuerda con el incremento en el peso corporal, con el incremento del grado de obesidad, y con la alteraciones bioquímicas y metabólicas, que se establecen en la etapa adulta de estos ratones como lo vimos en nuestro estudio.

La adaptación celular para este incremento en la producción de radicales, como consecuencia de la obesidad, se reflejó con el incremento en la actividad de CAT, como se observó en hembras obesas en nuestro estudio, las que presentaron el mayor incremento en el TA y el mayor grado de obesidad demostrado mediante el IL. Es importante mencionar que el incremento en la actividad de CAT se acentuó durante el envejecimiento, tanto en los ratones obesos como en los controles.

Existen reportes que mencionan que la actividad de CAT está asociada con biomarcadores de obesidad, tales como el peso corporal y el IMC, que correlacionan con una tendencia significativa con la Rl. Además se ha visto que la actividad de CAT es significativamente más baja en niños obesos y, a su vez, se correlaciona con biomarcadores de obesidad y RI (Rupérez et al., 2013). Sin embargo, son necesarios 
más estudios tanto in vitro como in vivo que nos permitan entender el papel de la actividad de CAT en el desarrollo de la RI durante el desarrollo de la obesidad. Nosotros hipotetizamos que la CAT posee un papel en las complicaciones tempranas de la obesidad, debido a que es una etapa donde el organismo sufre cambios metabólicos importantes.

Por otra parte, se han identificado proteínas con un alto grado de contenido de carbonilos que se acumulan con la edad, entre las que destaca, la SOD Cu/Zn (Chaudhuri et al., 2006), lo cual podría explicar el por qué los niveles detectados en la actividad de esta enzima en los ratones obesos GMS no presentan diferencias significativas con respecto a sus controles, en los órganos analizados. Esto concuerda con estudios realizados por Brown y colaboradores, quienes no encontraron diferencias significativas en el estado antioxidante total, SOD y GSH entre adultos normales, con sobrepeso y obesos (Brown et al., 2009).

Otros estudios demuestran que la actividad de SOD (Cu/Zn-SOD) en eritrocitos fue significativamente más baja en sujetos obesos comparados con sujetos sanos (Sfar et al., 2013). Esto podría estar relacionado directamente con la duración de la obesidad, por ejemplo, en las etapas iniciales del desarrollo de la obesidad, las enzimas antioxidantes pueden ser estimuladas, mientras que en la obesidad crónica y a largo plazo, las fuentes de enzimas antioxidantes llegan a estar depletadas, conduciendo a un bajo nivel de actividad (Sfar et al., 2013). Por otra parte, una disminución en las enzimas antioxidantes podría ser debido a un rápido consumo y agotamiento en el almacen de estas enzimas en la lucha contra los 
radicales libres generados durante el desarrollo de la obesidad (Noeman et al., 2011).

Los efectos de la obesidad crónica sobre la respuesta antioxidante, especificamente en la actividad de SOD, no han sido completamente estudiadas. En nuestro estudio mostramos estos efectos sobre el la expresión de la SOD en la obesidad y su impacto de forma cronológica.

Para conocer el estado redox sistémico, se evaluó la relación GSH/GSSG que posee multiples funciones a nivel celular y es un sensor de radicales libres, además de actuar como un antioxidante primario de defensa, confiriendo protección intracelular y extracelular, asi como participante en la detoxificación de ciertos xenobióticos y metales pesados. A nivel celular, el GSH total existe libre o unido a proteínas (Zitka et al., 2012). La disminución significativa del contenido de GSH de eritrocitos en el sobrepeso y la obesidad infantil puede deberse a un incremento en la forma oxidada (GSSG) a través de la detoxificacion de ERO y otros peróxidos para cambiar el estrés oxidante predominante generado por ERO. Esto es consistente con la función de GSH para sensar los oxidantes por unión a ellos de forma covalente. Ademas, la reducción en el contenido de GSH de eritrocitos puede ser atribuido a su uso en el reciclaje de la vitamina $\mathrm{E}$ y reducir las moléculas oxidadas tales como hidroperóxidos lipídicos. Adicionalmente, la disminución de GSH en las células rojas puede resultar de un disminución en la actividad de la GRd (Albuali, 2014).

Los cambios de concentración de GSH en sangre podrían dar una medida del estrés oxidante in vivo. La importancia de sus funciones dentro de los sistemas biológicos ha dado lugar a la existencia de un sistema GSH que incluye además 
enzimas relacionadas con su metabolismo, responsables del mantenimiento de su estado redox en condiciones fisiológicas (Cisneros et al., 2011), y está sujeto a un constante recambio en el organismo; hígado, riñones, pulmones, corazón, intestinos y músculos son los principales órganos responsables de su homeostasis (Cisneros et al., 2011).

La relación GSH/GSSG dentro de las células es a menudo, empleado como un marcador de citotoxicidad y salud celular (Owen et al., 2010); adicionalmente, esta relación se ha empleado para evaluar el estado de estrés oxidante en sistemas biológicos y la alteración de esta relación se ha demostrado en cáncer, HIV y enfermedades cardiovasculares (Serru et al., 2001). La relación del par redox GSH/GSSG en condiciones fisiológicas es mayor a 100:1, y en varios modelos donde las células están expuestas a niveles incrementados de estrés oxidante se acumula GSSG, disminuyendo la relación GSH a GSSG a valores de 10:1 e incluso 1:1 (Cisneros et al., 2011; Zitka et al., 2012), lo que indica cambios en el estado redox que afectan el balance de la proliferación, la diferenciación y la muerte celular (Cisneros et al., 2011).

En nuestro estudio, la relación GSH/GSSG plasmática en los ratones obesos mostró valores menores a 100:1, lo cual nos indica que existió mayor proporción de la forma oxidada (GSSG), probablemente producto de la actividad de GSH peroxidasa o por un deficiente sistema de recuperación de la forma reducida (Cisneros et al., 2011). Este comportamiento fue observado mayormente en hembras tratadas con GMS, donde la relación GSH/GSSG fue mucho más bajo comparado 
con su control, indicando un estado predominantemente oxidado, aun cuando no se encontraron diferencias significativas.

En el caso de los ratones machos obesos, fue a los 16 meses de edad cuando se observó un estado más oxidado comparado con su control. La determinación de la relación GSH/GSSG refleja los cambios que, al parecer, se producen en tejidos extrahépaticos (Cisneros et al., 2011). Al ser el GSSG un metabolito capaz de atravesar fácilmente las membranas biológicas y acceder al torrente circulatorio, ocasiona un aumento del cociente GSSG/GSH o una disminución de este cociente GHS/GSSG, lo que explica el aspecto más interesante del glutatión como índice de estrés oxidante, puesto que a nivel sanguíneo refleja el daño que se ha producido en otros tejidos (Ríspoli et al., 2013). Un incremento en la concentración de GSH, en ratas obesas en respuesta a la formación de radicales libres es un esfuerzo para proteger las células contra el estrés oxidante (Noeman et al., 2011).

Adicionalmente, en este trabajo evaluamos los efectos de la obesidad sobre la inducción de las MTs en diferentes órganos, proteína que ha sido considerada como parte de la defensa antioxidante, siendo principalmente en hígado donde observamos un incremento a partir de los 12 meses de edad en el caso de hembras y en el caso de machos a partir de los 8 meses de edad. Esto correlaciona con el incremento del tejido adiposo, un incremento de citocinas proinflamatorias y la disminución de citocinas antiinflamatorias.

Aun cuando la presencia de las MTs esta asociada en todos los tipos celulares de mamífero, se ha sugerido que estas metaloproteínas podrían tener un papel importante en las funciones intracelulares (Sabolic' et al., 2010). Las MTs han sido 
detectadas en varios órganos en humanos y animales experimentales con altas concentraciones en hígado, riñón páncreas y testículos. Sin embargo, el papel de las MTs en la edad y sexo han sido pobremente estudiados (Sabolic' et al., 2010). De esta manera, los resultados obtenidos en nuestro estudio, donde se observa incremento de MTs en hígado y un descenso gradual conforme avanza el tiempo en pulmón, corazón y riñón, puede estar relacionado con la localización de las MTs en diversas etapas de la vida.

Se ha reportado, que altas concentraciones de MTs, especialmente en núcleo, fueron encontrados en hígado, riñones y otros órganos durante periodos embrionarios, fetales y posnatalmente, tanto en animales de experimentación como en humanos. Posterior al nacimiento, los niveles de MTs en la mayoría de órganos de roedores fueron encontrados elevados y gradualmente decrecen, alcanzando los niveles detectados en adultos a las 2-3 semanas (Sabolic' et al., 2010). En órganos adultos, cantidades variables de MTs fueron detectadas en citoplasma. En riñón se detectó MTs exclusivamente en el núcleo y citoplasma de las células del túbulo proximal (TP), con una intensidad variable, pero no se observó correlación con el grado de desarrollo.

Contrario a lo que se ha estudiado con respecto a la expresión de MTs en hígado y riñones de animales y humanos adultos perinatales y jóvenes, la expresión en los animales y humanos que envejecen ha sido poco investigada. La capacidad del tejido renal para producir MTs puede ir disminuyendo conforme avanza la edad debido a que la síntesis de proteínas es menos eficiente (Sabolic' et al., 2010). En un reporte realizado por Yoshida en 1998, tanto el hígado como los riñones de personas 
japonesas mostraron niveles disminuidos de MTs durante la infancia, con una tendencia a incrementar el contenido en el tejido de MTs en la vejez. Estos datos apoyan fuertemente los resultados obtenidos en nuestro estudio, donde las concentraciones de MTs determinadas en riñón de ratones obesos disminuyeron con respecto al tiempo, sin embargo, conforme el ratón envejece se observa una tendencia a incrementar los niveles, lo cual estaría también asociado con la disminución del grado de obesidad durante el envejecimiento. Nuestro estudio indica que la abundancia de MTs en los riñones, corazón y pulmón de ratones obesos es independiente del sexo; las MTs estan aumentadas en etapas tempranas y declinan en el envejecimiento (Sabolic' et al., 2010).

Por otro lado, un componente fundamental en la función de las MTs es el zinc (Zn) (Vasto et al., 2006; Wong et al., 2012), el cual participa en el metabolismo de las hormonas involucradas en la fisiopatología de la obesidad, tales como insulina y hormonas tiroideas. Diversos estudios han demostrado bajas concentraciones de $\mathrm{Zn}$ en el plasma, eritrocitos y suero de individuos obesos, asociado con alteraciones en el metabolismo del TA de estos pacientes (Dos Santos et al., 2010; Wong et al., 2012). El Zn es el principal regulador del gen de MTs y la expresión de la proteína. Los niveles de MTs decrecen con el envejecimiento y enfermedades crónico degenerativas, lo cual puede resultar en la liberación de Zn, que es potencialmente citotóxico. Este estado observado con el incremento del estrés oxidante y la inflamación sugiere que la función antioxidante de las MTs está dañado.

Las MTs como antioxidantes pueden mitigar la destrucción celular inducida por estrés oxidante por captura y neutralización de RL a través de ligandos formados por 
azufre en las cisteínas. Esta propiedad de las MTs está comúnmente ligada a su capacidad de unir $\mathrm{Zn}$ y sirve como un donador de iones $\mathrm{Zn}$ en un modo redox dependiente en los procesos celulares (González et al., 2014). A pesar del incremento de las MTs-Zn con la edad en hígado y cerebro, el daño oxidante a nivel celular es un evento común durante el envejecimiento, como se ha enfatizado con la teoría de los $\mathrm{RL}$ en el envejecimiento. Debido a que la biodisponibilidad de los iones libres de $Z n$ es baja en el envejecimiento, las MTs-Zn podrían no tener un papel protector como un donante de $\mathrm{Zn}$ en el envejecimiento, más bien ellas secuestran Zn (Vasto et al., 2006), lo cual puede inducir la baja biodisponibilidad de iones libres de Zn para las funciones inmunológicas, endocrinas y cerebrales (Vasto et al., 2006; Mocchegiani et al., 2001; Fairweather-Tait et al., 2008; Wong et al., 2012).

Por otra parte, durante el envejecimiento la respuesta de fase aguda asociada con las condiciones inflamatorias e infecciones, precipita los cambios en el metabolismo de Zn (Fairweather-Tait et al., 2008; Wong et al., 2012; Wong et al., 2013). Las personas, especialmente después de los 70 años, aumentan el riesgo de una ingesta inadecuada de $\mathrm{Zn}$, lo cual se traduce en una deficiencia de $\mathrm{Zn}$, que afecta la inmunidad celular, oxidación y daño del DNA, así como disfunción mitocondrial, todos estos eventos asociados al envejecimiento (Maret, 2008; Wong et al., 2012; Wong et al., 2013). Los mecanismos precisos que ligan el Zn, edad e inflamación no son completamente claros, sin embargo, se ha propuesto un mecanismo para la disminución en la concentración plasmática de $\mathrm{Zn}$ inducido por IL-6. Se trata de la sobrerregulación en la expresión del transportador de Zn, Zip14, en el hígado. La redistribución de Zn en el cuerpo, está asociada a las MTs, las 
cuales preferentemente se unen a $\mathrm{Zn}$ y son expresadas en respuesta a citocinas inflamatorias.

Una inflamación crónica, como hemos mencionado, es una característica asociada a la obesidad, al envejecimiento y se asume que también con un continuo secuestro de $\mathrm{Zn}$ intracelular, por lo tanto las funciones dependientes de Zn se verían afectadas, por ejemplo el sistema inmune (Fairweather-Tait et al., 2008). El proceso de inflamación provoca una pérdida constante de $\mathrm{Zn}$ a través de la orina y heces, pero al mismo tiempo, la producción de citocinas proinflamatorias, en turno, inducen la expresión de MT-RNA. Como resultado, el balance es negativo, la biodisponibilidad de iones $\mathrm{Zn}$ es baja y se incrementa el secuestro de iones remanentes por las MTs durante la inflamación transitoria. Este fenómeno es más acentuado en la inflamación crónica, tal como en el envejecimiento (Vasto et al., 2006; Wong et al., 2013) lo cual, hipotetizamos, está sucediendo durante la obesidad en nuestro modelo de estudio.

Los cambios en el metabolismo de $\mathrm{Zn}$ con la edad son específicos para cada tejido. Se ha observado una reducción en la liberación de este metal de los glóbulos rojos, un incremento en hígado, reducción en tejido muscular y en la secreción intestinal; así mismo un incremento en la compartamentalización en células rojas de hombres pero no de mujeres. Los efectos de la carga de $\mathrm{Zn}$ incluyen un incremento en la concentración plasmática de Zn, siendo ésta mayor en pacientes envejecidos que en jóvenes. Se ha observado también un incremento en la secreción de Zn a nivel urinario en personas envejecidas comparadas con personas jóvenes y una disminución en la captación por parte de los eritrocitos (Fairweather-Tait et al., 2008). 
El papel potencial de las MTs durante la vida es fundamentalmente protector en la edad joven-adulta; sin embargo, durante el envejecimiento podría ser peligrosa. Este cambio en la función es estrictamente dependiente de una condición de estrés, que es transitoria durante la etapa joven-adulta y constante durante el envejecimiento (Mocchegiani et al., 2001). 


\section{EPÍLOGO}

Uno de los principales hallazgos del presente trabajo fue la atenuación del daño o un efecto de adaptación asociado con el incremento en la edad, tanto en controles como en ratones tratados con GMS en cuanto a los parámetros evaluados, como lo es la homeostasis de glucosa e insulina, marcadores inflamatorios y de estrés oxidante. Al inicio del estudio, los ratones obesos hembra y macho mostraron alteraciones metabólicas incrementadas. Sin embargo, a edades medias y mayores, cuando todos los grupos comienzan a perder peso, mejoran la tolerancia a la glucosa y la acción de la insulina. Este efecto fue más intenso en ratones tratados con GMS, y conforme pasó el tiempo o envejecieron disminuyeron las diferencias encontradas con respecto a los grupos control.

Otro factor que posiblemente contribuyó a esta atenuación fue el incremento en los niveles de adiponectina durante el envejecimiento, el cual se correlacionó positivamente con la pérdida de peso y el mejoramiento en la sensibilidad a la insulina. Se sabe que la reducción en el peso en personas obesas ancianas mejora el perfil de riesgo cardiovascular, reduce la inflamación crónica y correlaciona con una mejor calidad de vida.

Nuestros resultados mostraron que los efectos de la obesidad fueron atenuados durante el envejecimiento, a pesar que las alteraciones primero fueron observadas en edades jóvenes. Evidencia creciente sugiere que la asociación entre la obesidad y la mortalidad declina con el avance de la edad en ambos géneros (Corrada et al., 2006). Sería importante discutir el paradigma de que la obesidad está siempre asociada con un alto riesgo de mortalidad, porque no se sabe si la 
asociación obesidad-mortalidad se mantiene en la vejez. Wang informó recientemente en un meta-análisis sistemático sobre la asociación obesidadmortalidad en hombres y mujeres, el debilitamiento de la asociación obesidadmortalidad al aumentar la edad (Wang, 2014b). Por lo tanto, la obesidad puede desempeñar un papel más importante en el riesgo de mortalidad elevada en las personas más jóvenes que en las personas mayores.

Nuestros datos concuerdan con reportes previos en los que se han encontrado alteraciones en el control metabólico e inflamación incrementada en ratones hembra y macho obesos. Adicionalmente, nuestros datos sugieren la existencia de una atenuación o un efecto de adaptación en el envejecimiento, lo cual podría debilitar la asociación entre la obesidad y la mortalidad con el avance en la edad en ambos géneros.

Hay factores asociados con la disminución en la sensibilidad a la insulina y la tolerancia a la glucosa, los cuales predisponen al desarrollo de la obesidad en edades tempranas, el cual se continua incrementando en a edades intermedias y disminuye en el envejecimiento; es decir, la edad tiene una influencia significativa en la disminución en la sensibilidad a la insulina. Pero esta asociación hace difícil discernir en qué medida la disminución de la sensibilidad a la insulina es una consecuencia del envejecimiento como tal, o por el contrario es causado por un aumento de la adiposidad.

Los datos obtenidos en el presente estudio muestran que hay alteraciones en la tolerancia a la glucosa y la sensibilidad a la insulina en los ratones tratados con GMS, las cuales están presentes en edades tempranas de la vida del ratón, que 
continua en la edad adulta y parecen disminuir, sin diferencias significativas en el grupo control. Esto suguiere que la obesidad es un factor que contribuye de manera significativa en estos cambios; sin embargo, los animales control mostraron estas anormalidades metabólicas cuando envejecen, lo cual nos indica que la edad también contribuye de manera significativa en la reducción de las capacidades metabólicas.

Los ratones tratados con GMS mostraron altos niveles de TG y una disminución durante el envejecimiento, lo cual se vió asociado con una disminución de la adiposidad en el envejecimiento. Por su parte, la función hepática, estuvo asociada directamente con el grado de obesidad, en especial en machos, pero de forma natural con el paso del tiempo.

Un proceso que está ampliamente asociado con la obesidad es la produccion de componentes inflamatorios y, por supuesto, un mecanismo opuesto que tiene el organismo para tratar de compensar esta inflamacion es la producción de componentes antiinflamatorios. Se mostró que durante el proceso de obesidad se incrementan los niveles de citocinas proinflamatorias y disminuye el contenido de citocinas inflamatorias circulantes en etapas jóvenes.

Nosotros sugerimos que la etapa adulta es un punto crucial donde el organismo trata de compensar esta inflamación, sin embargo, un mecanismo exacto por el cual este evento ocurre no se conoce completamente. Además, el establecimiento de esta inflamación está relacionado con disminución en la tolerancia a la glucosa, disminución en la sensibilidad a la insulina, la función hepática y la 
presencia de dislipidemia a través de la vida de un organismo y como un factor adicional, la disminución de las capacidades fisiológicas atribuidas al envejecimiento.

Por otra parte, la generación de estrés oxidante, la hiperglucemia que observamos, la dislipidemia, una defensa antioxidante inadecuada y la inflamación crónica están presentes en la obesidad en forma conjunta lo cual nos sugiere que la obesidad afecta muchos órganos en el cuerpo, tales como el hígado, corazón y riñón, y conforme avanza el tiempo favorece la aparición de las complicaciones comunes en la obesidad. Tratar de entender estos mecanismos en el inicio de la obesidad podría permitirnos centrar la búsqueda de blancos terapéuticos adecuados para prevenir estas complicaciones en etapas adultas e incluso durante el envejecimiento.

Asimismo, este estudio nos da la pauta para poder continuar investigando de forma especifica sobre la elucidación de los mecanismos involucrados en las alteraciones asociadas con la obesidad y su influencia con la función metabolica a través del tiempo, así como de la comprensión de los mecanismos de daño oxidante, los sistemas de respuesta antioxidante y de adaptación que tiene el organismo.

A manera de resumen, en la Figura 18 se ilustra la relación entre la progresión de la obesidad, su participación como un proceso inflamatorio de bajo grado (metainflamación), la relación existente con las alteraciones metabólicas encontradas a lo largo del estudio y el efecto directo en la generación de estrés oxidante y, a su vez, como un componente crucial en el agravamiento de las alteraciones y el establecimiento del circulo vicioso obesidad-inflamacion-estrés oxidante. 


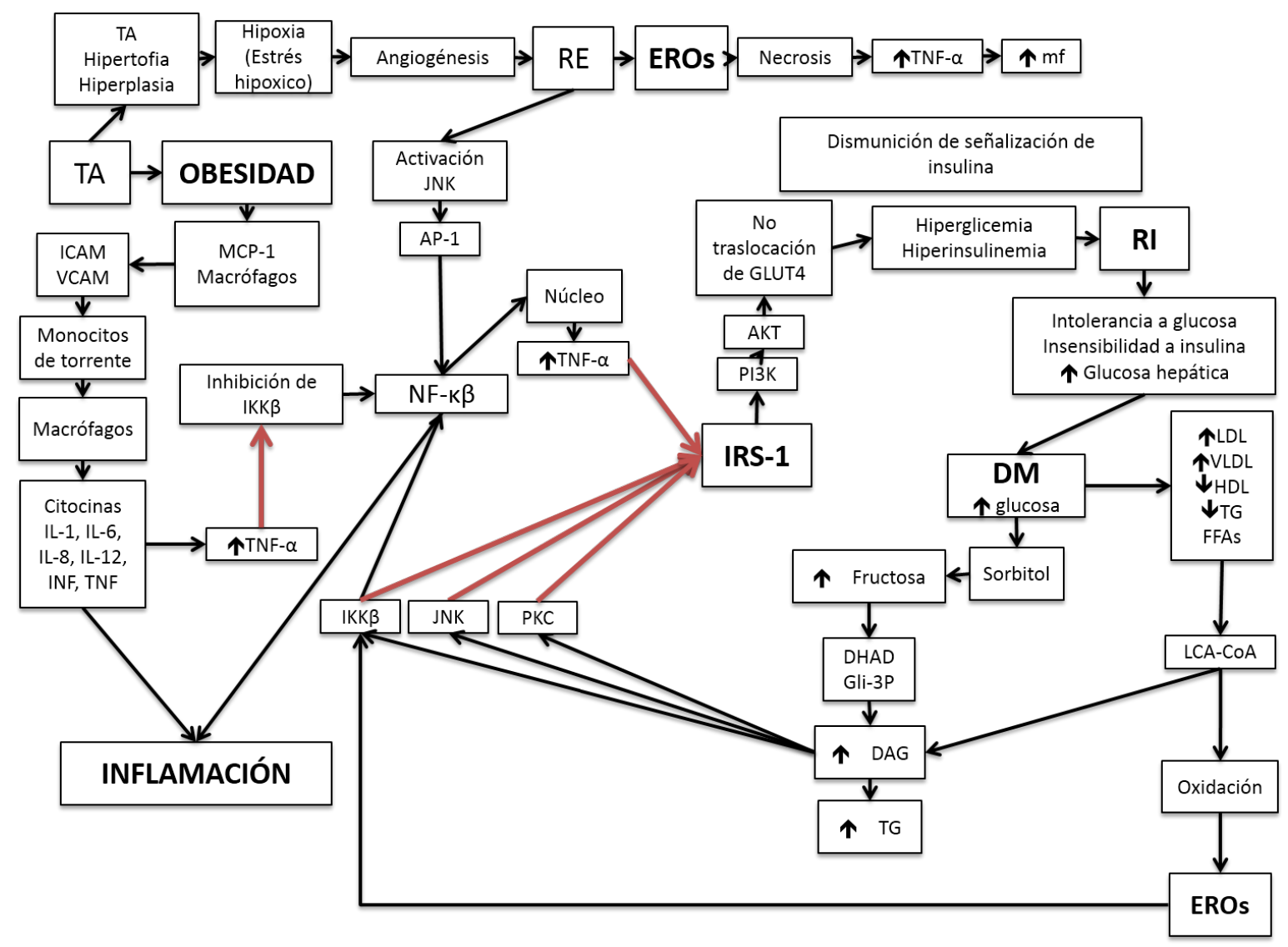

Figura 18. Obesidad-inflamación-estrés oxidante. Relación de la obesidad como un proceso inflamatorio de bajo grado con la aparición de alteraciones metabólicas y estrés oxidante.

Por último, las principales alteraciones en el metabolismo halladas en nuestro estudio a través del tiempo en ratones obesos tratamos de resumirla en la Figura 19. 


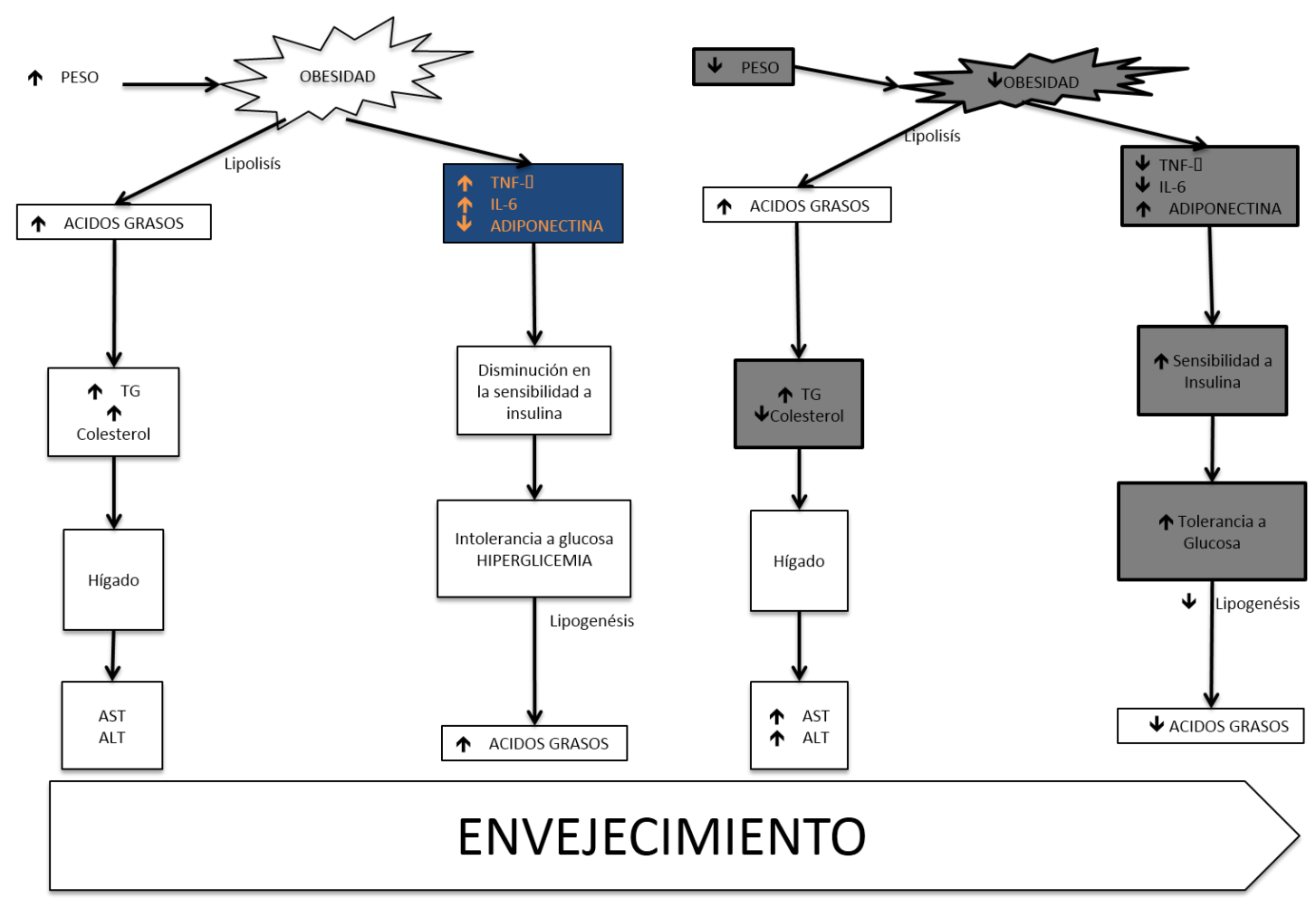

Figura 19. Participación de la obesidad en el metabolismo de ratones GMS a través de la vida. 


\section{CONCLUSIONES}

- La obesidad desde edades tempranas se relaciona con la intolerancia a la glucosa y disminución en la susceptibilidad a la insulina así como la alteración de parametros bioquímicos.

- Un organismo no obeso presenta deterioro en la tolerancia a la glucosa y en la susceptibilidad a la insulina y los parámetros bioquimícos, acentuándose durante el envejecimiento.

- Los ratones obesos a los 20 meses recuperan la tolerancia a la glucosa y la sensibilidad a la insulina y mejoran los parámetros bioquímicos, lo cual esta asociado también a una redistribución del tejido adiposo.

- De acuerdo al análisis por género, los machos obesos presentan una mayor intolerancia a la glucosa y una marcada disminución en la susceptibilidad a la insulina que las hembras obesas.

- Los machos obesos presentan mayor contenido de colesterol, ALT y TNF- $\alpha$, así como una menor concentración de TG y adiponectina con respecto a las hembras obesas.

- La obesidad promueve el estrés oxidante y puede potenciar la peroxidación lípidica en algunos tejidos del cuerpo por ejemplo en hígado, pulmón y corazón de ratones machos obesos, lo cual podría asociarse con disminución en la capacidad protectora de los antioxidantes a través del tiempo.

- El daño a las proteínas por estrés oxidante asociado a la obesidad fue mayor en hígado y pulmón de los ratones hembras obesas. 
- La respuesta antioxidante determinada por CAT reveló que en ambos grupos tratados se incrementa con respecto al tiempo.

- La actividad de MTs, incrementa con la edad en el hígado de ratones obesos (hembras y machos) y disminuye en pulmón, corazón y riñón.

- La inflamación de bajo grado asociado a la obesidad a la cual estan sometidos los ratones desde etapas iniciales de su vida, favorecen el desarrollo de alteraciones metábolicas, aparición de estrés oxidante y un desbalance entre este y los sistemas antioxidantes, lo cual genera daño en las biomoleculas, sin embargo, el organismo a través del tiempo, presenta mecanismos aún no comprendidos completamente, que permiten establecer una resistencia al estrés, lo cual permite al organismo obeso adaptarse y prolongar la expectativa de vida durante el envejecimiento.

- La obesidad es una condición donde el organismo sufre una serie de alteraciones, que de forma natural se presentan durante el envejecimiento, lo cual permite, asociar la obesidad como un proceso de envejecimiento prematuro. 


\section{PERSPECTIVAS}

Nuestra hipótesis fue confirmada debido a que los ratones obesos GMS con RI e inflamación crónica de bajo grado presentaron cambios que les permitieron adaptarse y sobrevivir a pesar del deterioro durante el envejecimiento, por lo tanto, se plantean como perspectivas:

- Estudiar los mecanismos moleculares involucrados en la disminución en la sensibilidad a la insulina asociado a la pérdida de la secreción de insulina estimulada por glucosa y mediada por Sirt1.

- Evaluar el mecanismo en la perdida de la susceptibilidad a la insulina asociado a la susceptibilidad de la célula $\beta$, disminución de la función mitocondrial, la acumulación de células senescentes en el tejido adiposo y un incremento del estrés oxidante.

- Conocer el efecto de estrógenos y andrógenos sobre la susceptibilidad a la insulina y sobre el desarrollo, función y regulación del tejido adiposo.

- Estudiar el papel de la edad sobre la homeostasis del colesterol ligada al género.

- Entender los mecanismos responsables de la disminución de los niveles de ALT con la edad.

- Generar un límites de referencia dependiente de género para AST y ALT para personas de la tercera edad, que permitan dar un tratamiento adecuado. 
- Conocer el papel preciso de la adiponectina en la progresión de la diabetes, que no ha sido caracterizado completamente a pesar que es considerada como una adipocina benéfica.

- Estudiar la influencia de los andrógenos sobre las concentraciones de adiponectina.

- Establecer la asociación entre adiponectina, género, envejecimiento y los factores de riesgo metabólicos.

- Estudiar el impacto de las proteínas oxidadas sobre el proteosoma en el modelo de obesidad inducido con GMS.

- Identificar blancos de carbonilación de proteínas y conocer su regulación para entender su influencia en la respiración celular que junto con el estrés oxidante intervienen en la aparición de envejecimiento prematuro en el raton obeso GMS.

- Entender el papel de la actividad de CAT en el desarrollo de la RI durante etapas iniciales de la obesidad. 


\section{REFERENCIAS BIBLIOGRÁFICAS}

1. Abbott, R.D., Sharp, D.S., Burchfiel, C.M., Curb, J.D., Rodriguez, B.L., Hakim, A.A., et al. (1997). Cross-sectional and longitudinal changes in total and highdensity-lipoprotein cholesterol levels over a 20 -year period in elderly men: The Honolulu Heart Program. Annals of Epidemiology, 7, 417-424.

2. Adler, E.S., Hollis, J.H., Clarke, I.J., Grattan, D.R., \& Oldfield, B.J. (2012). Neurochemical characterization and sexual dimorphism of projections from the brain to abdominal and subcutaneous white adipose tissue in the rat. The Journal of Neuroscience, 32, 15913-15921.

3. Aguilera, C.M., Gil-Campos, M., Cañete, R., \& Gil, A. (2006). Alteraciones del metabolismo lipídico en la obesidad. Revista Espanola de Obesidad, 4, 261-74.

4. Ahluwalia, P., Sharma, J., Sharma, U., Singh, K., \& Mahmood, A. (2005). Effect of oral ingestion of monosodium glutamate (MSG) on certain lipid fractions and carbohydrate metabolizing enzymes in the intestinal tissue of male mice. Toxicology International, 12, 93- 96.

5. Ahmed, E.K., Picot, C.R., Bulteau, A.L., \& Friguet, B. (2007). Protein oxidative modifications and replicative senescence of WI-38 human embryonic fibroblasts. Annals of the New York Academy of Sciences, 1119, 88-96.

6. Ahmed, E.K., Rogowska-Wrzesinska, A., Roepstorff, P., Bulteau, A.L., \& Friguet, B. (2010). Protein modification and replicative senescence of WI-38 human embryonic fibroblasts. Aging Cell, 9, 252-272.

7. Aithadj, L., Avila, D.S., Benedetto, A., Aschner, M., \& Stürzenbaum, S.R. (2011). Environmental exposure, obesity, and Parkinson's disease: Lessons from fat and old worms. Environmental Health Perspectives, 119, 20-28.

8. Alarcón, A.F.J., Almanza, P.J.C., Blancas, F.G., Angeles, S., Garcia, R., Roman, R.R., et al. (2008). Glycine regulates the production of pro-inflammatory cytokines in lean and monosodium glutamate-obese mice. European Journal of Pharmacology, 599, 152-158.

9. Albuali, W.H. (2014). Evaluation of oxidant-antioxidant status in overweight and 
morbidly obese Saudi children. World Journal of Clinical Pediatrics, 3(1), 6-13.

10. Alizadeh, E., \& Sanche, L. (2013). The Role of Humidity and Oxygen Level on Damage to DNA Induced by Soft X-rays and Low-Energy Electrons. Journal of Physical Chemistry C: Nanomaterials and interfaces, 117, 22445-22453.

11. Almanza, P.J.C., Alarcón, A.F.J., Blancas, F.G., Campos, S.A.E., Roman, R.R., Garcia, M.R., et al. (2010). Glycine regulates inflammatory markers modifying the energetic balance through PPAR and UCP-2. Biomedicine \& Pharmacotherapy, $64,534-540$.

12. Amirkhizi, F., Siassi, F., Minaie, S., Djalali, M., Rahimi, A., \& Chamari, M. (2007). Is obesity associated with increased plasma lipid peroxidation and oxidative strees in women? ARYA Atherosclerosis, 2, 189-192.

13. Andersson, V., Hanzén, S., Liu, B., Molin, M., \& Nyström, T. (2013). Enhancing protein disaggregation restores proteasome activity in aged cells. Aging, 5, 80212.

14. Andreazzi, A.E., Scomparin, D.X., Mesquita, F.P., Balbo, S.L., Gravena, C., de Oliveira, J.C., et al. (2009). Swimming exercise at weaning improves glycemic control and inhibits the onset of monosodium L-glutamate-obesity in mice. Journal of Endocrinology, 201, 351-359.

15. Aniya, Y., \& Imaizumi N. (2014). Mitochondrial glutathione transferases involving a new function for membrane permeability transition pore regulation. Drug Metabolism Reviews, 43, 292-299.

16. Antuna-Puente B., Feve, B., Fellahi, S., \& Bastard, J.P. (2008). Adipokines: the missing link between insulin resistance and obesity. Diabetes Metab, 34, 2-11.

17. Arai, Y., Takayama, M., Abe, Y., \& Hirose, N. (2011). Adipokines and aging. Journal of Atherosclerosis and Thrombosis, 18, 545-550.

18. Aruoma O.I., Grootveld, M., \& Bahorun, T. (2006). Free radicals in biology and medicine: from inflammation to biotechnology. Biofactors, 27, 1-3.

19. Avogaro, A., de Kreutzzenberg, S.V., \& Fadini, G.P. (2010). Insulin signaling and life span. Pflügers Archiv European Journal of Physiology, 459, 301-314.

20. Bagchi, D., \& Preuss, H.G. (2012). Oxidative Stress Status in Humans With 
Metabolic Syndrome. In Obesity: Epidemiology, pathophysiology and prevention. CRC Press. 2012. Second Edition. USA. P195.

21. Baker. D.J., Wijshake, T., Tchkonia, T., LeBrasseur, N.K., Childs, B.G., van de Sluis, B., et al. (2011). Clearance of p16Ink4a-positive senescent cells delays ageing associated disorders. Nature, 479, 232-236.

22. Ballester, M. (1996). Anti-oxidants, free radicals, and health. A chemical, organic, and physical approach. Medicina Clínica, 107, 509-515.

23. Bansode, S.B., Chougale, A.D., Joshi, R.S., Giri, A.P., Bodhankar, S.L., Harsulkar, A.M., et al. (2013). Proteomic analysis of protease resistant proteins in the diabetic rat kidney. Molecular \& Cellular Proteomics, 12, 1, 228-236.

24. Baraibar, M.A., Liu, L., Ahmed, E.K., \& Friguet, B. (2012). Protein oxidative damage at the crossroads of cellular snescence, aging, and age-related diseases. Oxidative Medicine and Cellular Longevity, 2012, 919832.

25. Barbosa, K.B., Bressan, J., Zulet, M.Z., \& Martínez, J.A. (2008). Influencia de la dieta sobre marcadores plasmáticos de estrés oxidante en humanos. Anales del sistema sanitario de Navarra, 31(3), 259-280.

26. Bartsch, M., Gobbato, E., Bednarek, P., Debey, S., Schultze, J.L., et al. (1973). The mitocondrial generation of hydrogen peroxide, General properties and effect of hyperbaric oxygen. Biochemical Journal, 134(3), 707-16.

27. Barzilai, N., \& Ferrucci, L. (2012). Insulin resistance and aging: A cause or a protective response? The Journals of Gerontology Series A: Biological Sciences and Medical Sciences, 67, 1329-1331.

28. Bashan, N., Kovsan, J., Kachko, I., Ovadia, H., \& Rudich, A. (2009). Positive and negative regulation of insulin signaling by reactive oxygen and nitrogen species. Physiological reviews, 89, 27-71.

29. Bastard, J.P., Maachi, M., Lagathu, C., Kim, M.J., Caron, M., Vidal, H., et al. (2006). Recent advances in the relationship between obesity, inflammation, and insuline resistance. European Cytokine Network, 17 (1), 4-12.

30. Bays, H., González-Campoy, J.M., Bray, G.A., Kitabchi, A.E., Bergman, D.A., Schorr, A.B., et al. (2008). Pathogenic potential of adipose tissue and metabolic 
consequences of adipocyte hypertrophy and increased visceral adiposity. Expert Review of Cardiovascular Therapy, 6, 343-68.

31. Beers, R.F. \& Sizer, I. W. (1952). A spectrophotometric method for measuring the breakdown of hydrogen peroxide by catalase. Journal of Biological Chemistry, 195, 133-140.

32. Bertolotti, M., Mussi, C., Pellegrini, E., Magni, A., del Puppo, M., Ognibene, S., et al. (2014). Age-associated alterations in cholesterol homeostasis: evidence from a cross-sectional study in a Northern Italy population. Clinical Interventions in Aging, 17, 425-432.

33. Bikkad, M.D., Ghuge, S.H., Somwanshi, S.D., \& Madole, M.B. (2013). Oxidative stress in obesity. Journal of Medical Education and Research, 3(1), 31-36.

34. Birch-Machin, M.A., Rusell, E.V., Latimer, J.A. (2013). Mitochondrial DNA damage as a biomarker for ultraviolet radiation exposure and oxidative stress. British Journal of Dermatology, 169(S2), 9-14.

35. Blancas, F.G., Almanza, P.J.C., López, R.R.I, Alarcón, A.F.J., García, M.R., \& Cruz M. (2010). La obesidad como un proceso inflamatorio. Boletin Médico del Hospital Infantil de México, 67, 88-97.

36. Bonora, E. (2007). The metabolic syndrome: Is it still alive. International Congress Series, 1302, 3-9.

37. Bradford, M.M. (1976). A rapid sensitive method for quantitation of protein utilizing the principle of dye-protein binding. Analytical Biochemistry, 72, 248-254.

38. Brambila, E., Jie, L., Morgan, D.L., Beliles, R.P., \& Waalkes, M.P. (2002). Effect of mercury vapor exposure on metallothionein and glutathione $s$-transferase gene expression in the kidney of nonpregnant, pregnant, and neonatal rats. Journal of Toxicology and Environmental Health, Part A, 65, 1273-1288.

39. Brietzke, S.A. (2010). A personalized approach to Metabolic Aspects of Obesity. Mount Sinai Journal of Medicine, 77, 499-510.

40. Brigelius-Flohé R., \& Maiorino, M. (2013). Glutatione peroxidases. Biochimica et Biophysica Acta, 1830(5), 3289-3303.

41. Brock, R.W., \& Dorman, R.B. (2007). Obesity, insulin resistance and hepatic 
perfusion. Microcirculation, 14, 339-347.

42. Brown, L.A., Kerr, C.J, Whiting, P., Finer, N., McEnemy, J., \& Ashton, T. (2009). Oxidant Stress in Healthy Normal-weight, Overweight and Obese individuals. Obesity Journals, 17, 460-466.

43. Brown-Borg, H. M. (2006). Longeviity im mice: is stress resistance aq common factor? Age, 28(2), 145-62.

44. Buchberger, A., Bukau, B., \& Sommer, T. (2010). Protein quality control in the cytosol and the Endoplasmic Reticulum: Brothers in Arms. Molecular Cell, 40(2), 238-252.

45. Buege, J.A. \& Aust, S.D. (1978). Microsomal lipid peroxidation. Methods in Enzymology, 52, 302-310.

46. Buettner, G.R. (2011). Superoxide dismutase in redox biology: the roles of superoxide and hydrogen peroxide. Anti-Cancer Agents in Medicinal Chemistry, 11(4), 341-6.

47. Byun, H.R., Kim, D.K., \& Koh, J.Y. (2011). Obesity and down regulated hypothalamic leptin receptors in male metallothionein-3-null mice. Neurobiology of Disease, 44, (1) 125-132.

48. Cai, D., \& Liu, T. (2012). Inflammatory cause of metabolic syndrome via brain stress and NF-kB. Aging, 4(2), 1-18.

49. Calabrese, E.J. (2008). Hormesis and medicine. British Journal of Clinical Pharmacology, 66(5), 594-617.

50. Calabrese, C.C., Trovato, A., Cavallaro, M., Mancuso, C., Di Rienzo, L., Condorelli, D., et al. (2010). The hormetic role of dietary antioxidants in free radicals related diseases. Current Pharmaceutical Design, 16(7), 877-83.

51. Calder, P.C., Ahluwalia, N., Brouns, F., Buetler, T., Clement, K., Cunningham, K., et al. (2011). Dietary factors and low-grade inflammation in relation to overweight and obesity. British Journal of Nutrition, 106(S3), S1-S78.

52. Camhi, S.M., Bray, G.A., Bouchard, C., Greenway, F.L., Johnson, W.D., Newton, R.L., et al. (2011). The relationship of waist circumference and BMI to visceral, subcutaneous, and total body fat: Sex and race differences. Obesity, 19, 402- 
408.

53. Campisi, J. (2013). Aging, cellular senescence, and cancer. Annual Review of Physiology, 75, 685-705.

54. Campos, K.E., Volpato, G.T., Calderon, I.M.P., Rudge, M.V.C., \& Damasceno, D.C. (2008). Effect of obesity on rat reproduction and on the development of their adult offspring. Brazilian Journal of Medical and Biological Research, 41, 122-125.

55. Campos, S.A.E., Ayala, G.F., Rubio, P.C., \& Roman, R.R. (2002). Neonatal monosodium glutamate increases ethanol susceptibility effect in adult mice. Proceedings of the Western Pharmacology Society, 45(1), 44-46.

56. Cartier, A., Coté, M., Lemieux, I., Pérusse, L., Tremblay, A., Bouchard, C., et al. (2009). Sex differences in inflammatory markers: what is the contribution of visceral adiposity? The American Journal of Clinical Nutrition, 89(5), 1307-1314.

57. Chaudhuri, A.R., De Waal, E.M., Pierce, A., Van Remmen, H., Ward, W.F., \& Richardson, A. (2006). Detection of protein carbonyls in aging liver tissue. A florescence-based proteomic approach. Mechanisms of Ageing and Development, 127(11), 849-861.

58. Cheeseman, K.H., \& Slater, T.F. (1993). An introduction to free radical biochemistry. British Medical Bulletin, 49(3), 481-93.

59. Chen, Z., Li, J., Zhao, T.J., Li, X.H., Meng, F.G.; Mu, H., et al. (2012). Metallothioneins protect cytosolic creatine kinases against stress induced by nitrogen-based oxidants. Biochemical Journal, 441, 623-632.

60. Cheung, B.M.Y., \& Li, C. (2012). Diabetes and hypertension: Is there a common metabolic pathway. Current Atherosclerosis Reports, 14(2), 160-166.

61. Chistyakova, O.V. (2008). Signaling pathway of insulina-like growth factor 1 (IGF1) as a potencial regulador of lifespan. Journal of Evolutionary Biochemistry and Physiology, 44(1), 3-11.

62. Choi, J.W. (2003). Association between elevated serum hepatic enzyme activity and total body fat in obese humans. Annals of Clinical \& Laboratory Science, 33, 257-264.

63. Choi, K.M., Ryu, O.H., Lee, K.W., Kim, H.Y., Seo, J.A., Kim, S.G., et al. (2007). 
Serum adiponectin, interleukin-10 levels and inflammatory markers in the metabolic syndrome. Diabetes Research and Clinical Practice, 75(2), 235-240.

64. Chudek, J. \& Wiecek, A. (2006). Adipose tissue, inflammation and endotelial dysfunction. Pharmacological Reports, 58, 81-8.

65. Chung, H.Y., Cesari, M., Anton, S., Marzetti, E., Giovannini, S., Seo, A.Y., et al. (2009). Molecular inflammation: underpinnings of aging and age-related diseases. Ageing Research Reviews, 8(1), 18-30.

66. Ciccia, A., \& Elledge, S.J. (2010). The DNA Damage Response: Making it safe to play with knives. Molecular Cell 40(2), 179-204.

67. Ciechanover, A., Orian, A., \& Schwartz, A.L. (2000). The ubiquitin-mediated proteolytic pathway: mode of action and clinical implications. Journal of cellular biochemistry. Supplement, 34, 40-51.

68. Cisneros, R., Oré, R., Arnao, I., \& Suaréz. S. (2011). Relación de glutatión reducido/oxidado (GSH/GSSG) en ratas diabéticas tratadas con maca (Lepidimium meyenii walp). Anales de la Facultad de Medicina, 72(2), 107-111.

69. Cnop, M., Havel, P.J., Utzschneider, K.M., Carr, D.B., Sinha, M.K., Boyko, E.J., et al. (2003). Relationship of adiponectin to body fat distribution, insulin sensitivity and plasma lipoproteins: Evidence for independent roles of age and sex. Diabetologia, 46, 459-469.

70. Collison, K.S., Makhoul, N.J., Zaidi, M.Z., Al-Rabiah, R., Inglis, A., Andres, B.L., et al. (2012). Interactive effects of neonatal exposure to monosodium glutamate and aspartame on glucose homeostasis. Nutrition \& Metabolism, 9, 58-71.

71. Combs, T.P., Berg, A.H., Rajala, M.W., Klebanov, S., lyengar, P., JimenezChillaron, J.C., et al. (2003). Sexual differentiation, pregnancy, calorie restriction, and aging affect the adipocyte-specific secretory protein adiponectin. Diabetes, 52, 268-276.

72. Connell, A.W., \& Sowers, J.R. (2012). Oxidative stress in the cardiorenal metabolic syndrome. Current Hypertension Report, 14, 360-365.

73. Corrada, M.M., Kawas, C.H., Mozaffar, F., \& Paganini-Hill, A. (2006). Association of body mass index and weight change with all cause mortality in the elderly. 
American Journal of Epidemiology, 163, 938-949.

74. Cui, H., Kong, Y., \& Zhang H. (2011). Oxidative stress, mitochondrial dysfunction, and aging. Journal of Signal Transduction, 2012, 646354.

75. Demicheli, V., Quijano, C., Alvarez, B., \& Radi, R. (2007). Inactivation and nitration of human superoxide dismutase (SOD) by fluxes of nitric oxide and superoxide. Free Radical Biology and Medicine, 42(9),1359-1368.

76. Díaz, A., Muñoz-Clares, R.A., Rangel, P., Valdés, V.J., \& Hansberg, W. (2005). Functional and structural analysis of catalase oxidized by singlet oxygen. Biochimie, 87(2), 205-14.

77. Dong, M.H., Bettencourt, R., Barrett-Connor, E., Loomba, R. (2010). Alanine aminotransferase decreases with age: The Rancho Bernardo Study. PLoS One, 5(12), 1-7.

78. Dos Santos, R.P.B.K., de Castro, A.A., de Sousa, A.F., do Monte, S.J.H., da Mata-Sousa, L.C.D., Nogueira, N.N., et al. (2011). Expression of the Zinc Transporters Genes and Metallothionein in Obese Women. Biological Trace Element Research, 143, 603-611.

79. Dozmorov, I., Bartke, A., \& Miller, R.A. (2001). Array-based expression analysis of mouse liver genes: Effect of age and of the longevity mutant Prop1df. Journals of Gerontology Series A: Biological Sciences and Medical Sciences, 56(2), B7280.

80. Eaton, D.L., \& Toal, B.F. (1982). Evaluation of the Cd/hemoglobin affinity assay for the rapid determination of metallothionein in biological tissues. Toxicology and Applied Pharmacology, 66, 134-142.

81. Eaton, D.L., \& Toal, B.F. (1983). A simplified method for quantitating metallothionein in biological tissues. The Science of the Total Environment, 28, 375-384.

82. Esposito, K., Pontillo, A., Giugliano, F., Giugliano, G., Marfella, R., \& Nicoletti, G. (2003). Association of low interleukin-10 levels with the metabolic syndrome in obese women. Journal of Clinical Endocrinology and Metabolism, 88, 1055-105.

83. Evans, J.L., \& Goldfine, I.D. (2013). Aging and insulin resistance: Just say iNOS. 
Diabetes, 62, 346-348.

84. Evans, J.L., Goldfine, I.D., Maddux, B.A., \& Grodsky, G.M. (2003). Are oxidative stress-Activated signaling pathways mediators of insulin resistance and $\beta$-cell dysfunction. Diabetes, 52, 1-8.

85. Evans, P. \& B. Halliwell. (2001). Micronutrients: oxidant/antioxidant status. British Journal of Nutrition, 85(2), S67-74.

86. Fain, J.N. (2006). Release of interleukins and other inflammatory cytokines by human adipose tissue is enhanced in obesity and primarily due to the nonfat cells. Vitamins \& Hormones, 74, 443-77.

87. Fairweather-Tait, S.J., Harvey, L.J., \& Ford, D. (2008). Does ageing affect zinc homeostasis and dietary requirements? Experimental Gerontology, 43,382-388.

88. Ferrara, A., Barrett-Connor, E., \& Shan, J. (1997). Total, LDL, and HDL cholesterol decrease with age in older men and women. The Rancho Bernardo Study 1984-1994. Circulation, 1, 37-43.

89. Figaro, M.K., Kritchevsky, S.B., Resnick, H.E., Shorr, R.I, Butler, J., Shintani, A., et al. (2006). Diabetes, inflammation, and functional decline in older adults: findings from the Health, Aging and Body Composition (ABC) study. Diabetes Care, 29(9), 2039-45.

90. Figueira, E., Branco, D., Antunes, S.C., Goncalves, F., \& Freitas, R. (2012). Are metallothioneins equally good biomarkers of metal and oxidative stress? Ecotoxicology and Environmental Safety, 84, 185-190.

91. Fontana, L., Eagon, J.C., Trujillo, M.E., Scherer, P.E., \& Klein, S. (2007). Visceral fat adipokine secretion is associated with systemic inflammation in obese humans. Diabetes, 56, 1010-1013.

92. Fotopoulos, V., Ziogas, V., Tanou, G., \& Molassiotis, A. (2010). Involvement of AsA/DHA and GSH/GSSG Ratios in Gene and Protein Expression and in the Activation of Defence Mechanisms Under Abiotic Stress Conditions. Ascorbate-Glutathione Pathway and Stress Tolerance in Plants. Springer Netherlands, 265-302.

93. Freund, A., Orjalo, A.V., Desprez, P.Y., \& Campisi J. (2010). Inflammatory 
networks Turing cellular senescence: causes and consequences. Trends in Molecular Medicine, 16, 238-246.

94. Fridovich, I. (2013). Oxygen: how do we stand it?. Medical Principles and Practice, 22(2),131-137.

95. Frohnert, B.I., \& Bernlohr, D.A. (2013). Protein carbonylation, mitocondrial dysfunction and insulin resistance. Advances in Nutrition, 4, 157-163.

96. Frohnert, B.I., Sinaiko, R.A., Serrot, J.F., Foncea, E.R., Moran, A., Ikramuddin, S., et al. (2011). Increased adipose protein carbonylation in human obesity. Obesity, 19(9), 1735-1741.

97. Furukawa, S., Fujita, T., Shimabukuro, M., Iwaki, M., Yamada, Y., \& Nakajima, Y. (2004). Increased oxidative stress in obesity and its impact on metabolic syndrome. Journal of Clinical Investigation, 114, 1752-1761.

98. Furuya, D.T., Poletto, A.C., Favaro, R.R., Martins, J.O., Zorn, T.M., \& Machado, U.F. (2010). Anti-inflammatory effect of atorvastatin ameliorates insulin resistance in monosodium glutamate-treated obese mice. Metabolism, 59, 395-399.

99. Fussenegger, D., Pietrobelli, A., Widhalm, K. (2008). Childhood obesity: political developments in Europe and related perspectives for future action on prevention. Obesity Reviews, 9, 76-82.

100. Galic, S., Oakhill, J.S., \& Steinberg, G.R. (2010). Adipose tissue as an endocrine organ. Molecular and Cellular Endocrinology, 316(2), 129-139.

101. Gallagher, E.J., LeRoith, D., \& Karnieli, E. (2010). Insulin Resistance in Obesity as the Underlaying Cause for the Metabolic Syndrome. Mount Sinai Journal of Medicine, 77, 511-523.

102. Garcia, C., Feve, B., Ferré, P., Halimi, S., Baizri, H., Bordier, L., et al. (2010). Diabetes and inflammation: Fundamental aspects and clinical implications. Diabetes \& Metabolism, 36, 327-338.

103. Garcia, S.J.J., Serrano, G.L.B.; Recio, V.R., \& Calderon, S.J.V. (2011). Tolerancia a la glucosa en personas mayores de 60 años. Revista de Educación Bioquímica, 30, 3-11.

104. Gendron, M.E., Thorin-Trescases, N., Villeneuve, L., \& Thorin, E. (2007). Aging 
associated with mild dyslipidemia reveals that COX-2 preserves dilation despite endothelial dysfunction. American Journal of Physiology - Heart and Circulatory Physiology, 61, 451-458.

105. Ghone, R.A., Suryakar, A.N., Kulhalli, P.M., Bhagat, S.S., Padalkar, R.K., Karnik, A.C., et al. (2013). A study of oxidative stress biomarkers and effect of oral antioxidant supplementation in severe acute malnutrition. Journal of clinical and diagnostic research, 7(10), 2146-2148.

106. Giannini, C., Giorgis, T., Scarinci, A., Cataldo, I., Marcovecchio, M.L., Chiarelli, F., et al. (2009). Increased carotid intima-media thickness in pre-puberal children with constitutional leanness and severe obesity; the speculative role of insulin sensitivity, oxidant status and chronic inflammation. European Journal of Endocrinology, 161, 73-80.

107. Glass, C.K., \& Ogawa, S. (2006). Combinatorial roles of nuclear receptors in inflammation and immunity. Nature Reviews Immunology, 6, 44-55.

108. Golay, A., \& Ybarra J. (2005). Link between obesity and Type 2 diabetes. Best Practice \& Research Clinical Endocrinology \& Metabolism, 19, 649-63.

109. Gong, Z., \& Muzumdar, R.H. (2012). Pancreatic function, type 2 diabetes and metabolism in aging. International Journal of Endocrinology, 2012, Article ID 320482, 13 pages, 2012. doi:10.1155/2012/320482.

110. Gonzalez, I.H., Alvarez, L., García, M., Petrash, C., Sanz-Medel, A., \& CocaPrados, M. (2014). Metallothioneins (MTs) in the human eye: a perspective article on the zinc-MT redox cycle. Metallomics, 6(2), 201-208.

111. González, N.H., Vinué, A., Sanz, M.J., Delgado, M., Pozo, M.A., Serrano, M., et al. (2013). Increased dosage of Ink4/Ard protects against glucose intolerance and insulin resistance associated with aging. Aging Cell, 12, 102-111.

112. Goodman, G.D., \& Barrett, C.E. (1996). Sex differences in measures of body fat and body fat distribution in the elderly. American Journal of Epidemiology, 143, 898-906.

113. Grimsrud P.A., Xie, H., Griffin, T.J., \& Bernlohr, D.A. (2008). Oxidative stress and covalent modification of protein with bioactive aldehydes. Journal of 
Biological Chemistry, 283(32), 21837-21841.

114. Grimsrud, P.A., Picklo, M.J., Griffin, T.J., \& Bernlohr, D.A. (2007) Carbonylation of adipose proteins in obesity and insulin resistance. Identification of adipocyte fatty acid-binding protein as a cellular target of 4-hidroxynonenal. Molecular and cellular proteomics, 6, 624-637.

115. Haigis, M.C., \& Yakner, B.A. (2010). The aging stress response. Molecular Cell, 40(2), 333-344.

116. Halliwell, B., \& Whiteman, M. (2004). Measuring reactive species and oxidative damage in vivo and in cell culture: How should you do it and what do the results mean? Brithis Journal Pharmacology, 142, 231-255.

117. Halliwell, B. (2012). Free Radicals and antioxidants; updating a personal view. Nutrition reviews, 70(5), 227-265.

118. Halliwell, B., Aeschbach, R., Löliger, J., \& Aruoma, O.I. (1995). The characterizaction of antioxidants. Food and Chemical Toxicology, 33(7), 601-17.

119. Halliwell, B., Gutteridge, J.M., \& Cross, C.E. (1992). Free radicals, antioxidants, and human disease: where are we now? Journal of Laboratory and Clinical Medicine, 119(6), p. 598-620.

120. Hanley, A.J., Bowden, D., Wagenknecht, L.E., Balasubramanyam, A., Langfeld, C., Saad, M.F., et al. (2008). Influence of sex hormones on adiponectin expression in human adipocytes. Hormone and Metabolic Research, 40, 779786.

121. Harman, D. (1956). Aging: a theory based on free radical and radiation chemestry. Journals of Gerontology Series A: Biological Sciences and Medical Sciences, 11(3), 298-300.

122. Hata, K., Kubota, M., Shimizu, M., Moriwaki, H., Kuno, T., Tanaka, T., et al. (2012). Monosodium glutamate-induced diabetic mice are susceptible to azoxymethane-induced colon tumorigenesis. Carcinogenesis, 33, 702-707.

123. Haynes, V., Connor, T., Tchernof, A., Vidal, H., \& Dubois, S. (2013). Metallothionein 2a Gene Expression is Increased in Subcutaneous Adipose Tissue of Type 2 Diabetic Patients. Molecular Genetics and Metabolism,108(1), 
90-94.

124. Hebert-Schuster, M., Fabre, E.E., \& Nivet-Antoine, V. (2012). Catalase polymorphisms and metabolic diseases. Current Opinion in Clinical Nutrition \& Metabolic Care, 15(4):397-402.

125. Hildrum, B., Mykletun, A., Hole, T., Midthjell, K., \& Dahl, A.A. (2007). Agespecific prevalence of the metabolic syndrome defined by the International Diabetes Federation and the National Cholesterol Education Program: the Norwegian HUNT 2 study. BioMed Central Public Health, 7, 220.

126. Hocking, S., Samocha-Bonet, D., Milner, K.L., Greenfield, J.R., \& Chisholm, D.J. (2013). Adiposity and insulin resistance in humans: The role of the different tissue and cellular lipid depots. Endocrine Reviews, 34, 463-500.

127. Hotamisligil, G.S. (2006). Inflammation and metabolic disorders. Nature, 444, 860-867.

128. Hotamisligil, G.S. (2010). Endoplasmic reticulum stress and the inflammatory basis of metabolic disease. Cell, 140, 900-917.

129. Hotamisligil, G.S., Arner, P., Caro, J.F., Atkinson, R.L., \& Spiegelman, B.M. (1995). Increased adipose tissue expression of tumor necrosis factor-alpha in human obesity and insulin resistance. Journal of Clinical Investigation, 95, 24092415.

130. Hotamisligil, G.S., Shargill, N.S., \& Spiegelman, B.M. (1993). Adipose expression of tumor necrosis factor-alpha: direct role in obesity-linked insulin resistance. Science, 259, 87-91.

131. Internacional Obesity Task Force. 2008. http//www.iotf.org/millennium.asp. Accessed July 2014.

132. Inuwa, H.M., Aina, V.O., Gabi, B., Ola, A., \& Jaáfaru, L. (2011). Determination of nephrotoxicity of monosodium glutamate (MSG) consumption. British Journal of Pharmacology and Toxicology, 2, 148-153.

133. Islam, M.S., \& Loots du, T. (2009). Experimental rodent models of type 2 diabetes: A review. Methods and Findings in Experimental and Clinical Pharmacology, 31(4), 249-261. 
134. Izadi, V., Farabad, E., \& Azadbakht, L. (2013). Epidemiologic evidence on serum adiponectin level and lipid profile. International Journal of Preventive Medicine, 4, 133-140.

135. Jia, J., \& Chen, J., (2008). Chronic nickel-induced DNA damage and cell death: the protection role of ascorbic acid. Environmental Toxicology, 23(3):401-406.

136. Jiang, Z., Jiang, C., Chen, B., Koh, C.S., Yong, J.H., Park, D.H., et al. (2013). Age-associated changes in pancreatic exocrine secretion of the isolated perfused rat pancreas. Laboratory Animal Research, 29, 19-26.

137. Jomova, K., \& Valko, M. (2011). Advances in metal-induced oxidative stress and human disease. Toxicology, 283(2-3):65-87.

138. Kadowaki, T., Yamauchi, T., Waki, H., Iwabu, M., Okada-Iwabu, M., \& Nakamura, M. (2011). Adiponectin, adiponectin receptors, and epigenetic regulation of adipogenesis. Cold Spring Harbor Symposia on Quantitative Biology, 76, 257-265.

139. Kaludercic, N., Deshwal, S., \& Di Lisa, F. (2014). Reactive oxygen species and redox compartmentalization. Frontiers in Physiology, 5, 285. doi: 10.3389/fphys.2014.00285.

140. Kang, Y.J. (2006). Metallothionein Redox Cycle and Function. Experimental Biology and Medicine (Maywood), 231(9), 1459-1467.

141. Kang, Y.S. (2013). Obesity associated hypertension: new insights into mechanism. Electrolyte Blood Press, 11(2), 46-52.

142. Karaouzene, N., Merzouk, H., Aribi, M., Merzouk, S.A., Berrouiguet, A.Y.; Tessier, C., et al. (2011). Effects of the association of aging and obesity on lipids, lipoproteins and oxidative stress biomarkers: A comparison of older with young men. Nutrition, Metabolism and Cardiovascular Diseases, 21, 792-799.

143. Kaur, J.A. (2014). comprehensive review on metabolic syndrome. Cardiology Research and Practice, 2014, 943162.

144. Kehayias, J.J., Fiatarone, M.A., Zhuang, H., \& Roubenoff, R. (1997). Total body potassium and body fat: Relevance to aging. American Journal of Clinical Nutrition, 66, 904-910. 
145. Kennedy, R.L., \& Khoo, E.Y.H. (2006). Health, functional and therapeutic implications of obesity in aging. In Conn, P.M., (ed.) Handbook of Models for Human Aging. Elsevier Academic Press, Amsterdam, The Netherlands, 829-839.

146. Kenyon, C. (2005). The plasticity of aging: insights from long- lived mutants. Cell, 120,449-460.

147. Klover, P.J., Clementi, A.H., \& Mooney, R.A (2005). Interleukin-6 depletion selectively improves he- patic insulin action in obesity. Endocrinology, 146, 34173427.

148. Kodydková, J., Vávrová, L., Kocík, M., \& Zák, A. (2014). A Human catalase, its polymorphisms, regulation and changes of its activity in different diseases. Folia Biologica (Prague), 60(4), 153-67.

149. Koga, H., Kaushik, S., \& Cuervo, A.M. (2011). Protein homeostasis and aging: The importance of exquisite quality control. Ageing Research Reviews, 10(2), 205-215.

150. Kotani, K., \& Yamada, T. (2012). Oxidative stress and metabolic syndrome in a Japanese female population. Australian Journal on Ageing, 31 (2), 124-127.

151. Kregel, K.C., \& Zhang, H.J. (2007). An integrated view of oxidative stress in aging: basic mechanisms, functional effects, and pathological considerations. American Journal of Physiology. Regulatory, Integrative and Comparative Physiology, 292(1), R18-36.

152. Kroemer, G., Marino, G., \& Levine, B. (2010). Autophagy and the integrated stress response. Molecular Cell, 40(2), 280-293.

153. Kronmal, R.A., Cain, K.C., Ye, Z., \& Omenn, G.S. (1993). Total serum cholesterol levels and mortality risk as a function of age. A report based on the Framingham data. Archives of Internal Medicine, 153, 1065-1073.

154. Kruth, H.S. (2011). Receptor-independent fluid-phase pinocytosis mechanisms for induction of foam cell formation with native low-density lipoprotein particles. Current Opinion in Lipidology, 22, 386-393.

155. Kuhla, A., Blei, T., Jaster, R., \& Vollmar, B. Aging is associated with a shift of fatty metabolism toward lipogenesis. Journals of Gerontology Series A: Biological 
Sciences and Medical Sciences, 66, 1192-1200.

156. Kumar, H., Lim, H.W., More, S.V., Kim, B.W., Koppula, S., Kim, I.S., \& Choi, D.K. (2012). The role of free radicals in the aging brain and Parkinson's disease: convergence and parallelism. International Journal of Molecular Sciences, 13(8), 10478-10504

157. Kunutsor, S.K., Apekey, T.A., \& Walley, J. (2013). Liver aminotransferases and risk of incident type 2 diabetes: A systematic review and meta-analysis. American Journal of Epidemiology, 178, 159-171.

158. Laemmli, U.K. (1970). Cleavage of structural proteins during the assembly of the head of bacteriophage T4. Nature, 227, 680-685.

159. Lazarevic, G., Antic, S., Cvetkovic. T., Vlahovic, P., Tasic, I., \& Stefanovic, V. (2006). A physical activity programme and its effects on insulin resistance and oxidative defense in obese male patients with type 2 diabetes mellitus. Diabetes and Metabolims, 32, 583-590.

160. Le Bourg, E. (2009). Mild stress and life extension in Drosophila melanogaster. In Life-Span Extension (pp. 75-88). Humana Press.

161. Le-Lay S., Simard G., Martinez, M.C.,\& Andriantsitohaina, R. (2014). Oxidative Stress and Metabolic Pathologies: From an Adipocentric Point of View. Oxidative Medicine and Cellular Longevity, 2014, Article ID 908539, 18 pages.

162. Li, A.C., Brown, K.K., Silvestre, M.J., Willson, T.M., Palinski, W., \& Glass, C.K. (2010). Peroxisome proliferator-activated receptor gamma ligands inhibit development of atherosclerosis in LDL receptor-deficient mice. Journal of Clinical Investigation, 106, 523-531.

163. Liochev, S.I., \& Fridovich, I. (2010). Mechanism of the peroxidase activity of $\mathrm{Cu}, \mathrm{Zn}$ superoxide dismutase. Free Radical Biology and Medicine, 48(12), 15651569.

164. Liu, J., Shen, W., Zhao, B., Wang, Y., Wertz, K., Weber, P., et al. (2009). Targeting mitocondrial biogénesis for preventing and treating insulina resistance in diabetes and obesity: Hope from natural mitocondrial nutrients. Advanced Drug Delivery Reviews, 61,1343-1352. 
165. López-Diazguerrero, N.E., Martínez-Garduño, C.M, \& Konigsberg, M. (2005). La Senescencia Replicativa como una respuesta Celular al Estrés. Revista de Educación Bioquímica, 24 (2), 47-53.

166. Main, P.A., Angley, M.T., O'Doherty, C.E., Thomas, P., \& Fenech, M. (2012). The potential role of the antioxidant and detoxification properties of glutathione in autism spectrum disorders: a systematic review and meta-analysis. Nutrition \& Metabolism (Lond), 9, 1-35.

167. Malik, V.B.T., \& Ahluwalia, P. (1994). Studies on effect of monosodium glutamate (MSG) on various fractions of lipids and certain carbohydrate metabolic enzymes in liver and blood of adult male mice. Toxicology Letters, 74, 69-77.

168. Manolagas, S.C. (2010). From estrogen-centric to aging and oxidative stress: A revised perspective of the pathogenesis of osteoporosis. Endocrine Reviews, 31, 266-300.

169. Maret, W. (2008). Metallothionein redox biology in the cytoprotective and cytotoxic functions of zinc. Experimental Gerontology, 43(5), 363-369.

170. Margoshes, M., \& Vallee, B.L. (1957). A cadmium protein from equine kidney cortex. Journal of the American Chemical Society, 79, 4813-4814.

171. Marí, M., Morales, A., Colell, A., García-Ruiz, C., \& Fernández-Checa, J.C. (2009). Mitochondrial glutathione, a key survival antioxidant. Antioxidants \& Redox Signaling, 11(11), 2685-2700.

172. Marí, M., Morales, A., Colell, A., García-Ruiz, C., Kaplowitz, N., \& FernándezCheca, J.C. (2013). Mitochondrial glutathione: features, regulation and role in disease. Biochimica et Biophysica Acta, 1830(5), 3317-3328.

173. Matsuda, M., \& Shimomura, I. (2013). Increased oxidative stress in obesity: implications for metabolic syndrome, diabetes, hypertension, dyslipidemia, atherosclerosis, and cancer. Obesity Research \& Clinical Practice, 7(5), 330-41.

174. Mehdi, S.H., \& Qamar, A. (2013). Paraquat-induced ultrastructural changes and DNA damage in the nervous system is mediated via oxidative-stress-induced cytotoxicity in Drosophila melanogaster. Toxicological Sciences, 134(2), 355-365.

175. Metha, S., \& Farmer, J.A. (2007). Obesity and inflammation: A new look at an 
old problem. Current Atherosclerosis Reports, 9, 134-138.

176. Meyer, M.R., Clegg, D.J., Prossnitz, E.R., \& Barton, M. (2011). Obesity, insulin resistance and diabetes: Sex differences and role of oestrogen receptors. Acta Physiologica, 203, 259-269.

177. Michaud, M., Balardy, L., Moulis, G., Gaudin, C., Peyrot, C., Vellas, B., et al. (2013). Proinflammatory cytokines, aging, and age-related diseases. Journal of the American Medical Directors Association, 14(12), 877-82.

178. Miller, A.F. (2012) Superoxide dismutases: ancient enzymes and new insights. FEBS Letters, 586(5), 585-595.

179. Minois, N. (2000). Longevity and aging: beneficial affects of exposure to mild stress. Biogerontology, 1,15-29.

180. Mocchegiani, E., Giacconi, R., Cipriano, C., Muzzioli, M., Fattoretti, P., BertoniFreddari, C., et al. (2001). Zinc-bound metallothioneins as potential biological markers of ageing. Brain Research Bulletin, 55(2), 147-153.

181. Mohanti, S., Saha, S., Md. S. Hossian, D., Adhikary, A., Mukherjee, S., Manna, A., et al. (2014). ROS-PIASY cross talk channelizes ATM signaling from resistance to apoptosis during chemosensitization of resistant tumors. Cell Death and Disease, 5(1), e1021.

182. Morgan, P.E., Pattison, D.I., Hawkins, C.L., \& Davies, M.J. Separation, detection, and quantification of hydroperoxides formed at side-chain and backbone sites on amino acids, peptides, and proteins. Free Radical Biology and Medicine, 45(9), 1279-1289.

183. Mori, R.C., Hirabara, S.M., Hirata, A.E., Okamoto, M.M., \& Machado, U.F. (2008). Glimepiride as insulin sensitizer: Increased liver and muscle responses to insulin. Diabetes, Obesity and Metabolism, 10(7), 596-600.

184. Muñoz, M.T, (2007). Pubertad normal y sus variants. Pediatría Integral, 11, 505-14.

185. Murakami, S. (2006), Stress resistance im long lived Mouse models. Experimental Gerontology, 41(10), 1014-19.

186. Murphy, K.G \& Bloom, S.R. (2006). Are all fat created equal? Nature Medicine, 
$12,32-3$

187. Nagata, M., Suzuki, W., lizuka, S., Tabuchi, M., Maruyama, H., Takeda, S., et al. (2006). Type 2 Diabetes mellitus in obese mouse model induced by monosodium glutamate. Experimental Animals, 55, 109-115.

188. Nakamura, T., Furuhashi, M.P., Li, H., Cao, G., Tuncman, N. Sonenberg, C.Z., et al., (2010). Double-stranded RNA-dependent protein kinase links pathogen sensing with stress and metabolic homeostasis. Cell, 140, 338-348.

189. Nakatsuji, H., Kishida, K., Sekimoto, R., Komura, N., Kihara, S., Funahashi, T., \& Shimomura, I. (2014). Accumulation of adiponectin in inflamed adipose tissues of obese mice. Metabolism, 63(4), 542-553.

190. Nazıroğlu, M. (2012). Molecular role of catalase on oxidative stress-induced $\mathrm{Ca}(2+)$ signaling and TRP cation channel activation in nervous system. Journal of Receptors and Signal Transduction Research, 32(3), 134-141.

191. Newairy, A.A., El-Sharaky, A.S., Badreldeen, M.M., Eweda, S.M., \& Sheweita, S.A. (2007). The hepatoprotective effects of selenium against cadmium toxicity in rats. Toxicology, 242(1-3), 23-30.

192. Nickelson, K.J., Stromsdorfer, K.L., Pickering, R.T., Tzu-Wen, L., Ortinau, L.C., Keating, A.F., et al. (2012). A comparison of inflammatory and oxidative stress markers in adipose tissue from weight-matched obese male and female mice. Experimental Diabetes Research, 1, 1-8.

193. Nishida, M., Moriyama, T., Sugita, Y., \& Yamauchi-Takihara, K. (2007). Interleukin-10 associates with adiponectin predominantly in subjects with metabolic syndrome. Circulation Journal, 71, 1234-1238.

194. Noeman, S.A., Hamooda, H.E., \& Baalash, A.A. (2011). Biochemical study of oxidative stress markers in the liver, kidney and heart of high fat diet induced obesity in rats. Diabetology and Metabolic Syndrome, 3, 17.

195. Norma Oficial Mexicana, NOM-062-ZOO-1999 revised 2001.

196. Nystrom, T. (2005). Role of oxidative carbonylation in protein quality control and senescence. European Molecular Biology Organization, 24, 1311-1317.

197. Oda, E. (2008). The metabolic syndrome as a concept of adipose tissue 
disease. Hypertension Research, 431, 1283-91.

198. Ogawa, D., Asanuma, M., Miyazaki, I., Tachibana, H., Wada, J., Sogawa, N., et al. (2011). High Glucose Increases Metallothionein Expression in Renal Proximal Tubular Epithelial Cells. Experimental Diabetes Research, 2011, Article ID 534872, 8 pages. Doi:10.1155/2011/534872.

199. Olney, J. W. (1969). Brain lesions, obesity and others disturbances in mice treated with monosodium glutamate. Science, 164, 719-721.

200. Owen, J.B., \& Butterfield, D.A. (2010). Measurement of oxidized/reduced glutathione ratio. Methods in Molecular Biology, 648, 269-277.

201. Parsons, A.P. (2007) Survival and longevity improvements at extreme ages: an interpretation assuming an ecological stress theory of aging. Biogerontology, 8, 225-231.

202. Peng, C., Wang, X., Chen, J., Jiao, R., Wang, L., Li, Y.M., et al. (2014). Biology of ageing and role of dietary antioxidants. BioMed Research International, 2014, Article ID 831841. doi: 10.1155/2014/831841.

203. Penninx, B.W., Kritchevsky, S.B., Yaffe, K., Newman, A.B., Simonsick, E.M., Rubin, S., et al. (2003). Inflammatory markers and depressed mood in older persons: results from the health, aging and body composition study. Biological Psychiatry, 54(5), 566-572.

204. Perluigi, M., Coccia, R., \& Butterfield, A. (2012). 4-Hydroxy-2-Nonenal, a Reactive Product of Lipid Peroxidation, and Neurodegenerative Diseases: A Toxic Combination Illuminated by Redox Proteomics Studies. Antioxidants \& Redox Signaling, 17(11), 1590-1609.

205. Pickering, A.M., \& Davies, K.J. (2012). Degradation of damaged proteins: the main function of the $20 \mathrm{~S}$ proteasome. Progress in Molecular Biology and Translational Science, 109, 227-248.

206. Poljšak, B., \& Fink, R. (2014). The Protective Role of Antioxidants in the Defence against ROS/RNS-Mediated Environmental Pollution. Oxidative Medicine and Cellular Longevity, 2014, Article ID 671539, 22 pages.

207. Pradeep, A.R., Ramchandraprasad, M.V., Bajaj, P., Rao, N.S., \& Agarwal, E. 
(2013). Protein carbonyl: An oxidative stress marker in gingival crevicular fluid in healthy, gingivitis, and chronic periodontitis subjects. Contemporary Clinical Dentistry, 4(1), 27-31.

208. Proctor, C.J., \& Lorimer, I.A.J. (2011). Modelling the role of the Hsp70/Hsp90 system in the maintenance of protein homeostasis. PLoS One, 6(7), e22038. Doi:10.1371/journal.pone.0022038

209. Qu, W., Pi, J., \& Waalkes, M.P. (2013). Metallothionein blocks oxidative DNA damage in vitro. Archives of Toxicology, 87, 311-321.

210. Qureshi, I.Z., Shabana, A., \& Fareeha, A. (2006). Effect of overweight and obesity on liver function in a sample from Pakistani population. Pakistan Journal of Zoology, 38, 49-54.

211. Rabe, K., Lehrke, M., Parhofer, K.G., \& Broedl, U.C. (2008). Adipokines and insulin resistance. Molecular Medicine, 14(11-12), 741-751.

212. Raguso, C.A., Kyle, U., Kossovsky, M.P., Roynette, C., Paoloni-Giacobino, A., Hans, D., et al. (2006). A 3-year longitudinal study on body composition changes in the elderly: Role of physical exercise. Clinical Nutrition, 25, 573-580.

213. Rezzani, R., Stacchiotti, A., \& Rodella, L.F. (2012). Morphological and biochemical studies on aging and autophagy. Ageing research reviews, 11(1), 1031.

214. Ribas, V., García-Ruiz, C., \& Fernández-Checa, J.C. (2014). Glutathione and mitochondria. Frontiers in Pharmacology, 5, 151. Doi: 10.3389/fphar.2014.00151.

215. Ríspoli, L.T., Tarragon, A.V., Prado, A.V., Tormo, G.S., Ismalil, A.M., \& Puchol, V.G. (2013). Estrés oxidante; estudio comparativo entre un grupo de población normal y un grupo de población obesidad mórbida. Nutrición Hospitalaria, 23(3), 671-675.

216. Ristow, M., \& Schmeisser, K. (2014). Mitohormesis: Promoting Health and lifespan by increased levels of Reactive Oxygen Species (ROS). Dose Response, 12(2), 288-341.

217. Rodier, F., \& Campisi, J. (2011). Four faces of cellular senescence. Journal of Cell Biology, 192,547-556. 
218. Rodríguez, H.H., Simental, M.L.E., Rodríguez, R.G., Reyes, R.M.A. (2013). Obesity and inflammation: Epidemiology, risk factors, and markers of inflammation. International Journal of Endocrinology, 2013. Doi:10.1155/2013/678159.

219. Rogge, M.M. (2009). The role of impaired mitochondrial lipid oxidation in obesity. Biological Research For Nursing, 10, 356-373.

220. Rubinsztein, D.C., Mariño, G., \& Kroemer, G. (2011). Autophagy and aging. Cell, 146(5), 682-95.

221. Rupérez, A.L., Olza, J., Gil-Campos, M., Leis, R., Mesa, M.D., Tojo, R., et al. (2013). Are catalese-844/G polymorphysm and activity associated with childhood obesity? Antioxidants \& Redox Signaling, 19(16), 1970-1975.

222. Sabolic', I., Breljak, D., \& Skarica, M. (2010). Role of metallothionein in cadmium traffic and toxicity in kidneys and other mammalian organs. Biometals, 23, 897-926.

223. Sato, M., Kawakami, T., Kondoh, M., Takiguchi, M., Kadota, Y., Himeno, S., et al. (2010). Development of high-fat-diet-induced obesity in female metallothionein-null mice. Journal of Federation of American Societies for Experimental Biology, 24(7), 2375- 2384.

224. Schenk, S., Saberi, M., \& Olefsky, J.M. (2008). Insulin sensivity: modulation by nutrients and inflammation. The Journal of Clinical Investigation, 118(9), 29923002.

225. Segura, B., \& Jurado, M.A. (2009). Síndrome metabólico y envejecimiento. Déficit cognitivo y alteraciones estructurales del sistema nervioso central. Revista de Neurología, 49(8), 417-424.

226. Sengupta, S., Peterson, T.R., \& Sabatini, D.M. (2010). Regulation of the mTor complex 1 by nutrients, growth factors and stress. Molecular Cell, 40(2), 310-322.

227. Sepe, A., Tchkonia, T., Thomou, T., Zamboni, M., \& Kirkland, J.L. (2011). Aging and regional differences in fat cell progenitors - a mini-review. Gerontology, 57, 66-75.

228. Serru, V., Baudin, B., Ziegler, F., David, J.P., Cals, M.J., Vaubourdolle, M., et al. (2001). Quantification of reduced and oxidiced glutathione in whole blood 
samples by capillary electrophoresis. Clinical Chemistry, 47(7), 1321-1324.

229. Sfar, S., Boussoffara, R., Sfar, M.T., \& Kerkeni, A. (2013). Antioxidant enzymes activities in obese Tunisian children. Nutrition Journal, 12, 18.

230. Shang, F., \& Taylor, A. (2011). Ubiquitin-proteasome pathway and cellular responses to oxidative stress. Free Radical Biology and Medicine, 51(1), 5-16.

231. Shore, S.A. (2010). Obesity, airway hyperresponsiveness, and inflammation. Journal of Applied Physiology, 108, 735-743.

232. Siddique, Y.H., Ara, G., \& Afzal, M. (2012). Estimation of lipid peroxidation induced by hydrogen peroxide in cultured human lymphocytes. Dose Response, 10(1), 1-10.

233. Singh, K., Kaur, P., Ahluwalia, P., \& Sharma, J. (2012). Effect of monosodium glutamate on various lipid fractions and certain antioxidant enzymes in arterial tissue of chronic alcoholic adult male mice. Toxicology International, 19, 9-14.

234. Sitte, N., Merker, K., von Zglinicki, T., \& Grune, T. (2000). Protein oxidation and degradation during proliferative senescence of human MRC-5 fibroblasts. Free Radical Biology and Medicine, 28(5), 701-8.

235. Slawik, M., \& Vidal-Puig, A.J. (2006). Lipotoxicity, overnutrition and energy metabolism in aging. Ageing Research Reviews, 5, 144-154.

236. Sood, A., Qualls, C., Arynchyn, A., Beckett, W., Gross, M., Steffes, M., et al. (2009). Obesity-Asthma Association; Is it Explained by Sistemic Oxidant Stress? Chest Journal, 136(4), 1055-1062.

237. Stadtman, E.R., Starke-Reed, P.E., Oliver, C.N., Carney, J.M., \& Floyd, R.A. (1992). Protein modification in aging. Experientia Supplementum, 62, 64-72.

238. Strange, R.W., Hough, M.A., Antonyuk, S.V., \& Hasnain, S.S. (2012). Structural evidence for a copper-bound carbonate intermediate in the peroxidase and dismutase activities of superoxide dismutase. PLoS One, 7(9), e44811.

239. Suganami, T., Tanimoto-Koyama, K., Nishida, J., Itoh, M., Yuan, X., Mizuarai, S., et al. (2007). Role of the Toll-like receptor 4/NF-kappaB pathway in saturated fatty acid-induced inflammatory changes in the interaction between adipocytes and macrophages. Arteriosclerosis, Thrombosis, and Vascular Biology, 27(1), 84- 
91.

240. Sweeting, H.N. (2007). Measurement and definitions of obesity in childhood and adolescence: a field guide for the uninitiated. Nutrition Journal, 26, 6, 32.

241. Szweda, P.A., Friguet, B., \& Szweda, L.I. (2002). Proteolysis, free radicals and aging. Free Radical Biology and Medicine, 33(1), 29-36.

242. Takasaki Y. (1978). Studies on brain lesion by administration of monosodium L-glutamate to mice. I. Brain lesions in infants caused by administration of monosodium L-glutamate. Toxicology, 9, 293-305.

243. Takashi, K., Toshimasa, Y., Naoto, K., Kazuo, H., Kohjiro, U., \& Kazuyuki, T. (2006). Adiponectin and adiponectin receptors in insuline resistance, diabetes and the metabolic syndrome. Journal of Clinical Investigation, 116, 1784-1792.

244. Tarantino, G., \& Caputi, A. (2011). Jnos, insulina resistance and inflammation: A posible link between NALFD and coronary artery disease. World Journal of Gastroenterology, 7 (33), 3785-3794.

245. Tchkonia, T., Zhu, Y., van Deursen, J., Campisi, J., Kirkland, J.L. (2013). Cellular senescence and the senescent secretory phenotype: therapeutic opportunities. Journal of Clinical Investigation, 123(3), 966-972.

246. Tchkonia, T., Morbeck, D.E., Zglinicki, T., Deursen, J., Lustgarten, J., Scrable, H., et al. (2010). Fat tissue, aging, and cellular senescence. Aging Cell, 9, 667684.

247. Tietze, F. (1969). Enzymatic method for quantitative determination of nanogram amounts of total and oxidised glutathione: applications to mammalian blood and other tissues. Analytical Biochemistry, 27, 502-522.

248. Tilg, H., \& Moschen, A.R. (2008). Inflammatory Mechanisms in the Regulation of Insulin Resistance. Molecular Medicine, 14 (3-4), 222-231.

249. Trayhurn, P. \& Wood, I.S. (2004). Horizons in Nutritional Science Adipokines: inflammation and the pleiotropic role of white adipose tissue. British Journal of Nutrition, 92, 347-55.

250. Tweedell, A., Mulligan, K.X., Martel, J.E., Chueh, F.Y., Santomango, T., \& McGuinness, O.P. (2011). Metabolic response to endotoxin in vivo in the 
conscious mouse: Role of interleukin-6. Metabolism, 60, 92-98.

251. Uchida, Y., Takeshita, K., Yamamoto, K., Kikuchi, R., Nakayama, T., Nomura, M., et al. Stress augments insulin resistance and prothrombotic state. Role of visceral Adipose-derived monocyte chemoattractant protein-1. Diabetes, 61, 1552-1561.

252. Uysal, K.T., Wiesbrock, S.M., Marino, M.W., Hotamisligil, G.S. (1997). Protection from obesity-induced insulin resistance in mice lacking TNF-alpha function. Nature, 389, 610-614.

253. Valdecantos, M.P., Pérez, M.P., \& Martínez, J.A. (2009). Obesidad y estrés oxidante: papel de la suplementación con antioxidantes en la dieta. Revista de Investigación Clínica, 61(2), 127-139.

254. Valko, M., Rhodes, C.J., Moncol, J., Izakovic, M., Mazur, M. (2006). Free radicals, metals and antioxidants in oxidative stress-induced cancer. ChemicoBiological Interactions, 160(1), 1-40.

255. Van-Beek, L., Lips, M.A., Visser, A., Pijl, H., loan-Facsinay, A., Toes, R., et al. (2014). Increased systemic and adipose tissue inflammation differentiates obese women with T2DM from obese women with normal glucose tolerance. Metabolism, 63(4), 492-501.

256. Vasto, S., Mocchegiani, E., Candore, G., Listi', F., Colonna-Romano, G., Lio, D., et al. (2006). List Inflammation, genes and zinc in ageing and age-related diseases. Biogerontology, 7, 315-327.

257. Verrotti, A., Scardapane, A., Franzoni, E., Manco, R., \& Chiarelli, F. (2008). Increased oxidative stress in epileptic children treated with valproic acid. Epilepsy Research, 78, 171-177.

258. Vincent, H.K., Innes, K.E, \& Vincent, K.R. (2007). Oxidative stress and potencial intervention toreduce oxidative stress in overweight and obesity. Diabetes, Obesity and Metabolism, 9, 813-839.

259. Vincent, H.K., \& Taylor, A.G. (2006). Biomarkers and potencial mechanisms of obesity-induced oxidant stress in humans. International Journal of Obesity. 30, 400-418.

260. Vlassara, H., Torreggiani, M., Post, J.B., Zheng, F., Uribarri, J., \& Striker, G.E. 
(2009). Role of oxidants/inflammation in declining renal function in chronic kidney disease and normal aging. Kidney International Supplements, 114, S3-11.

261. Wada, J. (2008). Vaspin: a novel serpin with insulin-sensitizing effects. Expert Opinion on Investigational Drugs, 17(3), 327-333.

262. Wallenius, V., Wallenius, K., Ahrén, B., Rudling, M., Caristen, H., Dickson, S.L. et al. (2002). Interleukin-6-deficient mice develop mature-onset obesity. Nature Medicine, 8, 75-79.

263. Waller-Evans, H., Hue, C., Fearnside, J., Rothwell, A.R., Lockstone, H.E., Caldérari, S., et al. (2013). Nutrigenomics of high fat diet induced obesity in mice suggests relationships between susceptibility to fatty liver disease and the proteasome. PLoS One, 8(12), e82825.

264. Wang, M., Monticone, R.E., \& Lakatta, E.G. (2010). Arterial aging: a journey into subclinical arterial disease. Current Opinion in Nephrology and Hypertension, 19(2), 201-7.

265. Wang, C. (2014a). Obesity, Inflammation and lung injury (OILI): The good. Mediators of Inflammation, 2014, Article ID 978463, 15 p.

266. Wang, Z., Lyons, B., Truscott, R.J., \& Schey, K.L. (2014b). Human protein aging: modification and crosslinking through dehydroalanine and dehydrobutyrine intermediates. Aging Cell, 13(2), 226-234.

267. Weijenberg, M.P., Feskens, E.J., \& Kromhout, D. (1996). Age-related changes in total and high density-lipoprotein cholesterol in elderly Dutch men. American Journal of Public Health, 86, 798-803.

268. Weisberg, S.P., McCann, D., Desai, M., Rosenbaum, M., Leibel, R.L \& A.W., Ferrante, Jr. (2003). Obesity is associated with macrophage accumulation in adipose tissue. Journal of Clinical Investigation, 112, 1796-808.

269. Wellen, K.E., \& Thompson, C.B. (2010). Cellular metabolic stress: Considering what happens when cells overeat. Molecular Cell, 40(2), 323- 332.

270. WHO (World Health Organization). Obesity and over Weight. Available online: http://www.who.int/octsheets/fs311/en/ (accessed on 10 January 2014).

271. Winterbourn, C., Hawkins, R., Brian, M., \& Carrell, R. (1975). The Estimation 
of Red Cell Superoxide Dismutase Activity. Journal of Laboratory and Clinical Medicine, 85, 337.

272. Wilson, P.W., Anderson, K.M., Harris, T., Kannel, W.B., \& Castelli, W.P. (1994). Determinants of change in total cholesterol and HDL-C with age: The Framingham Study. Journals of Gerontology Series A: Biological Sciences and Medical Sciences, 49, 252-257.

273. Winrow, V.R., Winyadr, P.G., Morris, C.J., \& Blake, D.R. (1993). Free radicals in inflammation: second messengers and mediators if tissue destruction. British Medical Bulletin, 49(3), 506-22.

274. Wong, C.P., \& Ho, E. (2012). Zinc and its role in age-related inflammation and immune dysfunction. Molecular Nutrition \& Food Research, 56, 77-87.

275. Wong, C.P., Magnusson, K.R., \& Ho, E. (2013). Increased inflammatory response in aged mice is associated with age-related zinc deficiency and zinc transporter dysregulation. Journal of Nutritional Biochemistry, 24(1), 353-359.

276. Wong, C.M., Marcocci, L., Liu, L., \& Suzuki, Y.J. (2010). Cell signaling by protein carbonylation and decarbonylation. Antioxidants \& Redox Signaling, 12(3), 393-404.

277. Xu, A., Chan, K.W., Hoo, R.L., Wang, Y., Tan, K.C., Zhang, J., et al. (2005). Testosterone selectively reduces the high molecular weight form of adiponectin by inhibiting its secretion from adipocytes. Journal of Biological Chemistry, 280, 18073-18080.

278. Xu, H., Barnes, G.T. Yang, Q., Tan, G., Yang, D., Chou, C.J., et al. (2003). Chronic inflammation in fat plays a crucial role in the development of obesityrelated insulin resistance. Journal of Clinical Investigation, 112, 1821-1830.

279. Xue, W., Zender, L., Miething, C., Dickins, R.A., Hernando, E., Krizhanovsky, V., et al. (2007). Senescence and tumour clearance is triggered by p53 restoration in murine liver carcinomas. Nature, 445, 656-660.

280. Yamamoto, T., Matsuo, S., Ueshima, Y., Inoue, F., Kinugasa, A., \& Sawada, T. (1993). Plasma levels of insulin-like growth factor-I are reduced at one week of age in monosodium L-glutamate-treated mice. Endocrine Journal, 40, 461-465. 
281. Ye, J., \& MacGuinness, O.P. (2012). Inflammation during obesity is not all bad: Evidence from animal and human studies. American Journal of Physiology Endocrinology and Metabolism, 304, 466-477.

282. Yki-Jarvinen, H. (1984). Sex and insulin sensitivity. Metabolism, 33, 10111015.

283. Yoneda, J., Chin, K., Torii, K., \& Sakai, R. (2011). Effects of oral monosodium glutamate in mouse models of asthma. Food and Chemical Toxicology, 49, 299304.

284. Zelezná, B., Maixnerová, J., Matysková, R., Haugvicová, R., Blokesová, D., \& Maletínská, L. (2009). Anorexigenic effect of cholecystokinin is lost but that of CART (Cocaine and Amphetamine Regulated Transcript) peptide is preserved in monosodium glutamate obese mice. Physiological Research, 58, 717-723.

285. Zhang, N., Huan, Y., Huang, H., Song, G.M., Sun, S.J., \& Shen, Z.F. (2010). Atorvastatin improves insulin sensitivity in mice with obesity induced by monosodium glutamate. Acta Pharmacologica Sinica, 31, 35-42.

286. Zierath, J.R., Houseknecht, K.L., Gnudi, L., \& Kahn, B.B. (1997). High fat feeding impairs insulin-stimulated GLUT4 recruitment via an early insulin-signaling defect. Diabetes, 46, 215-223.

287. Zitka, O., Skalickova, S., Gumulec, J., Masarik, M., Adam, V., Hubalek, J., et al. (2012). Redox status expressed as GSH:GSSG ratio as a marker of oxidative stress in paedriatic tumour patients. Oncology Letters, 4(6), 1247-1253.

288. Zitnanova, I., Korytar, P., Sobotová, H., Horáková, L., Pueschel, S., \& Duracková, Z. (2006). Markers of oxidative stress in children with Down syndrome. Clinical Chemistry and Laboratory Medicine, 44(3), 306-310. 